\title{
A Transcription for the Viola of Three Violin Works by Amy Beach: A Historical, Theoretical, and Pedagogical Analysis
}

\author{
Courtney Erin Grant
}

Follow this and additional works at: https://researchrepository.wvu.edu/etd

\section{Recommended Citation}

Grant, Courtney Erin, "A Transcription for the Viola of Three Violin Works by Amy Beach: A Historical, Theoretical, and Pedagogical Analysis" (2017). Graduate Theses, Dissertations, and Problem Reports. 5704.

https://researchrepository.wvu.edu/etd/5704

This Dissertation is protected by copyright and/or related rights. It has been brought to you by the The Research Repository @ WVU with permission from the rights-holder(s). You are free to use this Dissertation in any way that is permitted by the copyright and related rights legislation that applies to your use. For other uses you must obtain permission from the rights-holder(s) directly, unless additional rights are indicated by a Creative Commons license in the record and/ or on the work itself. This Dissertation has been accepted for inclusion in WVU Graduate Theses, Dissertations, and Problem Reports collection by an authorized administrator of The Research Repository @ WVU.

For more information, please contact researchrepository@mail.wvu.edu. 
A Transcription for the Viola of Three Violin Works by Amy Beach:

A Historical, Theoretical, and Pedagogical Analysis

\author{
Courtney Erin Grant
}

in partial fulfillment of the requirements for the degree of

\author{
Doctor of Musical Arts in \\ Viola Performance
}

Mikylah McTeer, DMA, Chair, Co-Research Advisor

David Taddie, PhD, Co-Research Advisor

Andrea Houde, MM

William Haller, DMA

Pablo Garcia Loaeza, PhD

School of Music

Morgantown, West Virginia

2017

Keywords: Amy Beach, Romance, Opus 23, Invocation, Opus 55, Three Pieces for Violin and Piano, Opus 40, Viola Transcription

Copyright 2017 Courtney Erin Grant 


\begin{abstract}
A Transcription for the Viola of Three Violin Works by Amy Beach: A Historical, Theoretical, and Pedagogical Analysis

Courtney Erin Grant
\end{abstract}

The primary purpose of this project was to transcribe and create publisher-ready scores for viola and piano of three works originally written for violin and piano by Amy Beach. These scores are being made available through Spartan Press Music. The pieces transcribed are the Romance, opus 23, Three Pieces for Violin, opus 40, and Invocation, opus 55. A detailed analysis of each of these pieces is also included, as no other scholar has yet published such an analysis. The harmonic, thematic, and melodic components are broken down into as much detail as possible.

Each piece also adds significantly to the viola repertoire. There is a noticeable lack of pieces composed by early American women composers currently available for viola. Besides helping to fill that void, many of these pieces could also serve a specific pedagogical purpose within a viola studio. For example, La Captive, one of the pieces from opus 40, is to be played entirely on the $\mathrm{C}$ string when transcribed (originally entirely on the violin $\mathrm{G}$ string), necessitating many shifts into high positions. Berceuse, another piece from opus 40, is to be played muted. The inclusion of these works into the viola repertoire provides both performers and teachers with new programming and study options. 


\section{Acknowledgements}

They say it takes a village to raise a child, I would also argue it takes a village of support to finish a doctorate. First, I would like to thank Prof. Andrea Houde, my primary teacher, for all her help and encouragement during both my masters and doctorate degrees. My co-research advisors, Dr. Mikylah McTeer and Dr. David Taddie, have provided support and guidance throughout the writing of this document and the course of my degree. Dr. McTeer deserves another round of acknowledgement for also serving as the chair of my committee. Many thanks to the rest of my committee, Dr. Pablo García Loaeza and Dr. William Haller, for their time and support.

My family and friends are one of the major reasons I have been able to finish this document and degree. There have been countless people over the years that have prayed for and supported me throughout the process. I wish there was room to thank each one individually.

To my best friend in the whole world, Meghan Adams. Thank you for your countless hours of revisions along with being a superb listener.

To my sister, Michelle Charlier, who has always shown me unconditional love.

My parents...I am not sure any of us had a clue where this journey would lead when I started playing the violin in $3^{\text {rd }}$ grade. But you have been there every step of the way with your unending support and tireless enthusiasm. I could not have asked for two more loving and supportive parents.

Last, but most certainly not least, my wonderful husband, Kristopher Grant. You have always been my rock throughout this process. Thank you for keeping me as sane as possible and reminding me that taking time to breathe is always a good thing. 


\section{Table of Contents}

List of Musical Examples $\quad$ V

$\begin{array}{ll}\text { Chapter } 1 \text { - Introduction } & 1\end{array}$

Chapter 2 - A Brief Biography of Amy Beach 5

Chapter 3 - Analysis of Romance for Violin and Piano, op. $23 \quad 25$

Chapter 4 - Analysis of Three Works for Violin and Piano, op. $40 \quad 69$

$\begin{array}{ll}\text { La Captive } & 70\end{array}$

$\begin{array}{lr}\text { Berceuse } & 80\end{array}$

$\begin{array}{ll}\text { Mazurka } & 92\end{array}$

Chapter 5 - Analysis of Invocation for Violin and Piano, op. 55

Chapter 6 - Pedagogical and Performance Uses of the Viola Transcriptions 137

$\begin{array}{ll}\text { Chapter } 7 \text { - Conclusion } & 147\end{array}$

$\begin{array}{ll}\text { Bibliography } & 149\end{array}$ 


\section{List of Musical Examples}

Example 3.1: Sweetheart, Sigh No More! mm. 1-4 26

Example 3.2: Romance, mm. 1-2 27

Example 3.3: Romance, mm. 1-12, violin only 27

Example 3.4: Romance, mm. 13-23, violin only 29

Example 3.5: Romance, mm. 15-22 29

Example 3.6: Romance, mm. 25-26 31

Example 3.7: Romance, mm. 13-14 32

Example 3.8: Romance, mm. 17-19 32

Example 3.9: Romance, mm. 13-15 33

Example 3.10: Romance, mm. 8-9 33

Example 3.11: Romance, mm. 22-24 34

Example 3.12: Romance, mm. 4-13 35

Example 3.13: Romance, mm. 15-21 36

Example 3.14: Romance, mm. 21-29 38

Example 3.15: Romance, mm. 29-43 40

Example 3.16: Romance, mm. 43-52 43

Example 3.17: Romance, mm. 55-58 45

Example 3.18: Romance, mm. 59-63 46

Example 3.19: Romance, mm. 64-73 47

Example 3.20: Frédéric Chopin's Prelude in E Minor, mm. 1-12 49

Example 3.21: Romance, mm. 57-63 50

Example 3.22: Romance, mm. 67-75 52

Example 3.23: Romance, mm. 75-78 53

Example 3.24: Romance, mm. 103-105 54

Example 3.25: Romance, mm. 87-91 54

Example 3.26: Romance, mm. 78-81 55

Example 3.27: J.S. Bach's Praeludium VI, mm. 1-2 57

Example 3.28: Romance, mm. 79-93

Example 3.29: Romance, mm. 91-96 59

Example 3.30: Romance, mm. 99-105 61

Example 3.31: Romance, mm. 108-109 62

Example 3.32: Franz Schubert's Der Doppelgänger, mm. 31-34 63

Example 3.33: Romance, mm. 113-117 64

Example 3.34: Romance, mm. 105-106 65

Example 3.35: Romance, mm. 112-113 65

Example 3.36: Romance, mm. 118-119 66

Example 3.37: Romance, mm. 107-110 66

Example 4.1: La Captive, mm. 4-5 71

Example 4.2: La Captive, mm. 13-16 71

Example 4.3: La Captive, mm. 22-30 71

Example 4.4: La Captive, mm. 6-8 73 
Example 4.5: La Captive, mm. 25-30

Example 4.6: La Captive, mm. 1-3

Example 4.7: La Captive, mm. 22-25

Example 4.8: La Captive, mm. 4-5

Example 4.9: La Captive, mm. 10-12

Example 4.10: La Captive, mm. 7-11

Example 4.11: La Captive, mm. 13-16

Example 4.12: La Captive, mm. 17-18

Example 4.13: La Captive, mm. 22-26

Example 4.14: Berceuse, mm. 1-20

Example 4.15: Berceuse, mm. 27-31

Example 4.16: Berceuse, mm. 41-44

Example 4.17: Berceuse, mm. 48-49

Example 4.18: Berceuse, mm. 59-61

Example 4.19: Berceuse, mm. 16-20

Example 4.20: Berceuse, mm. 5-10

Example 4.21: Berceuse, mm. 18-20 86

Example 4.22: Berceuse, mm. 21-27

Example 4.23: Berceuse, mm. 27-36

Example 4.24: Berceuse, mm. 42-45

Example 4.25: Berceuse, mm. 47-53

Example 4.26: Berceuse, mm. 64-69

Example 4.27: Mazurka, mm. 1-12

Example 4.28: Mazurka, mm. 13-18

Example 4.29: Mazurka, mm. 21-28

Example 4.30: Mazurka, mm. 29-39

Example 4.31: Mazurka, mm. 45-48

Example 4.32: Mazurka, mm. 48-52

Example 4.33: Mazurka, mm. 53-69

100

Example 4.34: Mazurka, mm. 70-74

101

Example 4.35: Mazurka, mm. 78-85

102

Example 4.36: Mazurka, mm. 94-100

103

Example 4.37: Mazurka, mm. 1-5

104

Example 4.38: Mazurka, mm. 9-10

105

Example 4.39: Mazurka, mm. 17-20

105

Example 4.40: Mazurka, mm. 25-29

Example 4.41: Mazurka, mm. 29-34

107

Example 4.42: Mazurka, mm. 38-44 108

Example 4.43: Mazurka, mm. 45-48 109

Example 4.44: Mazurka, mm. 59-60 110

Example 4.45: Mazurka, mm. 64-68 110

Example 4.46: Mazurka, m. $80 \quad 111$

Example 4.47: Mazurka, mm. 86-95 111 
Example 5.1: Invocation, mm. 4-5

Example 5.2: Invocation, $\mathrm{mm}$. 26-28

Example 5.3: Invocation, mm. 20-21

Example 5.4: Invocation, mm. 43-48

Example 5.5: Invocation, mm. 12-13

Example 5.6: Invocation, mm. 35-36

Example 5.7: Invocation, $\mathrm{mm} .7-9$

Example 5.8: Invocation, mm. 30-32

Example 5.9: Invocation, mm. 18-19

Example 5.10: Invocation, mm. 41-42

Example 5.11: Invocation, mm. 4-5

Example 5.12: Invocation, mm. 26-28

Example 5.13: Invocation, mm. 48-49

Example 5.14: Invocation, mm. 1-5

Example 5.15: Invocation, mm. 10-15

Example 5.16: Invocation, mm. 27-29

Example 5.17: Invocation, mm. 49-50

Example 5.18: Invocation, mm. 55-57

Example 5.19: Invocation, mm. 1-5

Example 5.20: Invocation, mm. 5-10

Example 5.21: Invocation, mm. 13-15

Example 5.22: Invocation, mm. 21-22

Example 5.23: Invocation, mm. 22-28

Example 5.24: Invocation, mm. 43-49

Example 5.25: Invocation, mm. 49-52

Example 5.29: Invocation, mm. 43-44, viola transcription 136

Example 6.1: Romance, m. 39, viola transcription 139

Example 6.2: Romance, mm. 46-47, viola transcription 


\section{Chapter 1: Introduction}

For the first few hundred years of its existence, many composers did not view the viola as a soloistic equal to the violin and cello. Similarly it was not until the $20^{\text {th }}$ century that women composers gained their due respect. Although women have been writing music for as long as men, their pursuits were never considered a career option. Likewise, the viola was considered an integral part of orchestra and chamber ensembles, but was not fully accepted as a solo instrument until the $20^{\text {th }}$ century. As these two separate groups came into their own at the same time, it is hardly surprising that their convergence did not occur until the middle of the century. Of course this makes logical sense - why would a woman, who has to fight to have her compositions performed and respected, bother to compose for an instrument which was not a popular member of the string family? Naturally some outliers exist; for example, Beatrice Mattei composed a Sonata for Viola and Harpsichord in $1740 .{ }^{1}$ This is the first documented instance of a woman writing for solo viola. ${ }^{2}$ The next occurrence does not happen for another 140 years, when in 1881 Luise Adolpa Le Beau composed her Three Pieces for Viola and Piano. ${ }^{3}$ In America, the first composition of this type occurred in 1906, when Blanche Blood wrote her Barcarolle. ${ }^{4}$ Some may point to Rebecca Clarke's compositions as the first example of an American woman writing

1Carolyn Waters Broe, "Viola Music by Women Composers," American String Teacher 57, no. 3 (2007): 68.

2 For the purposes of this paper solo viola music will be defined as any piece for either unaccompanied viola, solo viola with orchestra, or viola with a keyboard instrument.

3 Hillary Herndon, La Viola, Performed by Hillary Herndon and Wei-Chun Bernadette Lo (2012; Newtown, CT: MSR Music), CD.

4 Blood, Blanche, "Barcarolle for Viola and Piano," ed. David M. Bynog, American Viola Society, http:// www.americanviolasociety.org/PDFs/Resources/American-Viola-Project/Blood-Barcarolle.pdf. 
for solo viola. However, although Clarke spent a large portion of her life in the United States, she was born in England and was living there when she composed many of her works for the viola. The simultaneous evolution of women composers and the viola means the viola repertoire is left with significant gaps.

This topic has been explored by many scholars, and a number of people have made contributions in order to help fill the gaps in the viola literature. Thanks to the work of many individuals, violists can now enjoy transcriptions of a variety of works spanning a wide range of composers and time periods. This effort began in the 20th century and has continued into the $21^{\text {st }}$ century. Viola masters such as Lionel Tertis and William Primrose both transcribed many works for the viola, especially pieces that add to the advanced viola literature. Lillian Fuchs contributed by making the first recording of the Bach Cello Suites on viola. ${ }^{5}$ It was her violin teacher, Louis Svečenski, who had the first viola edition of these suites published in the United States. ${ }^{6}$ Viola World Publications is a firm dedicated entirely to publishing works for the viola. While they publish many works originally composed for the viola, a glance through their repertoire list shows that the bulk of their products are transcriptions. In fact, transcriptions have become so common for the viola that scholars have devoted large portions of their dissertations to the topic. An example of this is Hsiaopei Lee's doctoral dissertation, "The History of Viola Transcription and A Comprehensive Analysis of the Transcription for Viola and Piano of Beethoven's Violin Sonata Op. 30, No.1" (2005). Transcriptions have become such a staple in the viola repertoire that it is difficult to program a solo viola recital without including at least one transcription on

\footnotetext{
5 Amédée Daryl Williams, Lillian Fuchs: First Lady of the Viola (Lincoln, NE: iUniverse, 2004), 86. 6 Ibid, 91.
} 
the program, especially if one wants to venture outside of the $20^{\text {th }}$ century. Despite these important additions one noticeable void still remains: compositions by early American women composers.Very few compositions by this formidable group of women, which includes Amy Beach, Margaret Lang, Lily Strickland, and Clara Rogers, have been transcribed for the viola. Of the list above the most notable name is perhaps Amy Beach. She was a trailblazer for American women composers in a variety of ways. Although she was a prolific composer, Beach's output for solo strings was very limited. For the violin her only compositions were the Violin Sonata, Romance, Invocation, and Three Pieces for Violin and Piano. The latter is a collection of character pieces. It is worth noting that upon her death there were five additional manuscripts for a combination of strings and keyboard which were never submitted for publication. ${ }^{7}$ A discussion of why these pieces, not all of which were incomplete, were never published could fill an additional research document. For the purposes of this paper only her published works will be considered. The Violin Sonata has already been transcribed, recorded, and written about in detail by other scholars. Yu-Hsien Judy Hung in her doctoral dissertation titled "The Violin Sonata of Amy Beach" (2005) provides a detailed analysis. Roger Hannay transcribed the Sonata for viola and it has been published by both Peters and Henmar Press. Finally, the Klugherz-Timmons Duo produced a recording of this Sonata in 1997 on the Centaur Records label. However, Beach's remaining pieces - the Romance, Invocation, and Three Pieces for Violin and Piano - have never been transcribed for viola. Their transcription is a central element of this document.

7 Jeanell Wise Brown, Amy Beach and Her Chamber Music (New Jersey, U.S.A.: Scarecrow Press, 1994), 317. 
The purpose of this paper is twofold. While the primary goal is to educate the viola community about the accessible transcriptions of these wonderful pieces, the secondary goal is to provide a detailed historical and theoretical analysis. Previously these pieces have received minimal individual attention. In her book Amy Beach and Her Chamber Music, Jeanell Wise Brown provides some basic analysis. Yu-Hsien Judy Hung wrote a few pages of analysis on each piece in her doctoral dissertation titled "The Violin Sonata of Amy Beach" (2005). An in-depth analysis of these pieces will be a valuable contribution to the scholarly literature. All examples in this document will be shown in the original key, which will make this analysis accessible to any violinist or violist wishing to have a deeper understanding of the music. Each analysis chapter will end with a brief discussion of any changes that were made in the transcription process.

The sixth chapter will detail what purposes these pieces can serve in the viola repertoire, besides merely filling a void. Each piece offers unique technical challenges which make them ideal for both studio teaching and performance.

For performers or scholars who may not be familiar with the life of Amy Beach, a brief biography chapter is included. It is the author's goal that this document will serve as a valuable resource to a variety of musicians in the years to come. 


\section{Chapter 2: A Brief Biography of Amy Beach}

Amy Beach is one of the most fascinating American women of the late 19th and early 20th centuries. Although most books about Amy Beach have only been published in the last 30 years, during her lifetime she was the subject of numerous articles which have been preserved and are accessible today. This chapter gives a synopsis of her life, geared towards any reader who may be unfamiliar with Amy Beach. If further reading is desired the following texts may be consulted, Amy Beach, Passionate Victorian: The Life and Work of an American Composer, 1867-1944 by Adrienne Fried Block or The Remarkable Mrs. Beach, American Composer by Walter S. Jenkins. Ms. Block, who lived until 2009, was considered the preeminent Amy Beach scholar of her time. Mr. Jenkins was a personal friend of Beach whose book is a "biographical account based on her diaries, letters, newspaper clippings, and personal reminiscences." 8 Both of these books offer fascinating, yet different, perspectives on Amy Beach.

Before beginning the brief biography of Amy Beach, some attention must first be given to her name. In this document, all references prior to her marriage will use her maiden name, Amy Cheney. In all references following her marriage she will be referred to as "Amy Beach" or “Mrs. H. H. A. Beach” interchangeably. In Amy Beach, Passionate Victorian, Adrienne Block points out, "a number of people have raised objections to the name 'Amy Beach' on the grounds that she was known after her marriage as Mrs. H. H. A. Beach. That is the truth, but not the

8 Walter S. Jenkins, The Remarkable Mrs. Beach, American Composer, ed., John H. Baron (Michigan: Harmonie Park Press, 1994) iii. 
whole truth. ${ }^{\prime 9}$ Despite her revolutionary life, at heart she was a conservative woman:

professionally, she was almost always referred to as Mrs. H. H. A. Beach. Following her husband's death in 1910 she attempted to use the name Amy Beach. She published an article in an American magazine and performed a few concerts in Europe billed under Amy Beach. However, when the public began to think that Amy Beach and Mrs. H. H. A. Beach were two separate people (presumably mother and daughter), she realized that her identity was tied to the more formal title. This did not stop her from using Amy Beach on her bookplates and stationary. Additionally, in her will she established the Amy Beach Fund, the proceeds of which would benefit the MacDowell Colony. ${ }^{10}$ Therefore, both names are fitting and appropriate for this special pioneering woman.

Amy Cheney was born on September $5^{\text {th }}, 1867$ in West Hanniker, New Hampshire, to parents who were multi-generational Americans. Both sides of her family could be traced back to settlers who arrived in America in the 1630s. At the time of her birth, her father was in the paper mill business. ${ }^{11}$ The place she called home as a young child was a modest farm house, yet it did contain a piano, which was an important symbol of the middle class. ${ }^{12}$ Amy Cheney was surrounded by music from birth as her mother and many relatives were musicians of varying caliber. She showed a musical proclivity from a young age and by her first birthday could hum

\footnotetext{
${ }^{9}$ Adrienne Fried Block, Amy Beach: Passionate Victorian (New York: Oxford University Press), 1998, x. ${ }^{10}$ Block, Amy Beach, x.

${ }^{11}$ Ibid, 16.

${ }^{12}$ Ibid, 4.
} 
forty tunes, always in the key she first heard them. ${ }^{13}$ This was a clear sign that Amy Cheney had absolute pitch. Besides having perfect pitch, Amy Cheney had chromesthesia, the association of colors to keys of music. Initially when Amy would ask for music by color, her mother thought she was referring to the color on the cover of the music. Mrs. Cheney eventually discovered that instead, Amy was naming the color she associated with the key of the piece. ${ }^{14}$ Amy was a very sensitive child, not only to music but sounds in general. Things such as loud laughter, rain, and thunder would all move the young child to tears. ${ }^{15}$ Consistent with the time period and social expectations, Amy Cheney's mother put a strict ban on piano playing during Amy's early years. This did not stop Amy from participating in music making. "Before Amy was two, when her mother rocked her to sleep, she exhibited a new skill, that of improvising a 'perfectly correct alto to any soprano' that her mother might sing." ${ }^{16}$ Amy's musical accomplishments during her first few years of life were nothing short of prodigious.

When Amy was two the paper mill burned down. A year later her father found a job in Boston. ${ }^{17}$ This move proved to be most advantageous for the budding musician. Boston was a musical city, known for being a supportive environment for young musical talents. Thanks to a visit from her aunt, Amy Cheney was finally allowed to play the piano at the age of four. Beach later recalled this vivid memory during an interview, "At last, I was allowed to touch the piano.

\footnotetext{
${ }^{13}$ Amy Beach, "Why I Chose My Profession: The Autobiography of a Woman Composer." Interview by Edna Aiken. Mother's Magazine 11 (1914): 7-8.

${ }^{14}$ Block, Amy Beach, 10.

${ }^{15}$ Ibid, 4.

16 Ibid, 5.

${ }^{17}$ Ibid, 7.
} 
My mother was still opposed, but I can remember my aunt coming to the house, and putting me at the piano. I played at once the melodies I had been collecting, playing in my head, adding full harmonies to the simple, treble melodies. Then my aunt played a new air for me, and I reached up and picked out a harmonized bass accompaniment, as I had heard my mother do."18 Amy was known for being a strong willed child and quite frequently her mother withheld the privilege of playing the piano as punishment. Using the piano, Amy was able to expand her compositions beyond the voice. Her first piano pieces were composed while spending the summer at her grandfather's house. "[W]hen I reached home I told my mother that I had 'made' three waltzes. She did not believe it at first, as there was no piano within miles of the farm. I explained that I had written them in my head, and proved it by playing them on her piano."19 This compositional technique continued throughout her life. Very rarely did she compose at the piano, preferring instead to compose at her desk.

Amy Cheney began performing on the piano when she was seven. These performances were given mostly in the private homes of family friends. After one such performance, at least two concert managers offered contracts to start Amy Cheney on a career as a traveling pianist. ${ }^{20}$ Her parents saw no benefit in this lifestyle and promptly turned down all such offers. Later in life, Amy Beach realized the wisdom in this decision. When Amy was eight, the Cheneys began looking for an outside piano tutor. Amy's mother, Clara Cheney, previously taught her. After playing for many leading Boston pianists, they recommended that Amy travel to Germany for

\footnotetext{
${ }^{18}$ Beach, "Why I Chose My Profession", 7.

19 Ibid, 7.

${ }^{20}$ Block, Amy Beach, 13.
} 
conservatory training. ${ }^{21}$ This was standard practice at the time for talented American musicians, as it was believed that one needed European training to succeed. For a variety of reasons, including the necessary separation of the family, the Cheneys denied Amy the chance to study in Europe. This decision made Amy “the first American concert pianist to succeed with local training. Thus she helped demolish the notion that only those trained in a German conservatory could make a go of it." 22 Instead she began piano lessons with Ernst Perabo. Amy studied with Perabo from 1876 to 1882 and flourished under his teaching.

At age 11, Amy Cheney spent a year in San Francisco with her aunt, uncle, and younger cousin. She greatly enjoyed that year, especially spending time with her aunt and cousin. For Christmas of 1880, she composed a setting of Longfellow's poem, "Rainy Day" as a present for her aunt. Three years later, "Rainy Day" was the first piece ever published by Amy Cheney. ${ }^{23}$ Upon returning from California, Amy began attending Professor William L. Whittemore's preparatory school. Prior to formal schooling, her early education was entirely at home under the tutelage of her mother. She spent two years studying full time at the school and excelled in every subject. $^{24}$

While at Whittemore's school Amy Cheney changed piano teachers and began studying with Carl Baermann. A year later, at age 16, she gave her professional debut as a solo pianist. The event was immensely successful and the critics showered her with praise. It was considered

${ }^{21}$ Gertrude F. Cowen, “Mrs. H. H. A. Beach, the Celebrated Composer,” Musical Courier 60 (1910): 14.

22 Block, Amy Beach, vii - viii.

${ }^{23}$ Ibid, 28.

${ }^{24}$ Hazel Gertrude Kinscella, “ 'Play No Piece in Public When First Learned,'Says Mrs. Beach.” Musical America 28 (1918): 9-10. 
a victory that the reviewers did not mention her gender as a potential limitation. ${ }^{25}$ Following her debut, she continued to play public recitals regularly for the next two years. The climax of these years was Amy Cheney's performances with two of America's leading orchestras. She played Chopin's Concerto in F minor, op. 21 with the Boston Symphony Orchestra and Mendelssohn's Concerto No. 2 in D minor with Theodore Thomas's orchestra.

As Amy Cheney was now clearly an established pianist in the Boston area, she wished to turn her attention back to composition. Though she was a naturally gifted composer ${ }^{26}$, women of her time were becoming accepted as performers, but not as composers. After seeking advice on Amy's desire to compose, her parents were told she should teach herself by studying the works of the masters. Amy undertook this task with great enthusiasm. The question has been raised, however, that if she were a boy, would her parents have received different advice? ${ }^{27}$ Equally important to her compositional studies was her relationship with Arthur Schmidt. Schmidt was a music publisher who strongly believed in supporting American composers regardless of gender. In fact, he paid the same royalties to female as to male composers. ${ }^{28}$ For 25 years, all of Amy Cheney's compositions were published by his firm shortly after their completion.

Amy's talents did not escape the attention of eligible bachelors, in particular, Dr. Henry Harris Aubrey Beach. Dr. Beach, a widower, was a few years older than Amy's own father, yet he found himself attracted to Miss Cheney. He was an amateur musician and was fully able to appreciate her musical talents. On December 2, 1885, Amy Marcy Cheney married Dr. Henry

\footnotetext{
${ }^{25}$ Block, Amy Beach, 31.

${ }^{26}$ Ibid, 34.

${ }^{27}$ Ibid, 40.

${ }^{28}$ Ibid, 41.
} 
Beach. Given the time period, this match may have been one of the best outcomes for Amy Beach. She became mistress of a prominent home, including multiple servants, allowing her to focus on her music. One concession made upon her marriage, at her husband's request, was turning the focus of her musical life to composition instead of performance. This was following the custom of the day, which stipulated that it was not proper for married women to perform in public. She still played the occasional concert with major orchestras, such as her February 1886 performance of the Mozart D minor concerto with the Boston Symphony Orchestra. Dr. Beach strongly encouraged her to expand her compositional output to include large scale works, such as masses, concertos and symphonies. ${ }^{29}$ One aspect of their marriage which helped Amy Beach's career was their lack of children. Although later in life she expressed a wish that she had borne children, it was probably Dr. Beach who made that decision concerning their marriage. He was incredibly supportive of her professional life, and was likely concerned that childbirth might endanger her physical well being, besides taking time away from her music. Although one can look at her marriage to Dr. Beach in a variety of ways, Amy Beach scholar Adrienne Fried Block remarks, "If, for her [Amy Beach], marriage was bought at the cost of a professional performing career, it may also have been a mixed blessing; for those who enjoy and value her music now are indebted not only to her but also to Henry Beach for his support and encouragement of her work as a composer, which then took a stellar path." 30

Amy Beach knew that further compositional study was required, especially if she was to tackle the large forms encouraged by her husband. Again formal training was denied, so instead

\footnotetext{
${ }^{29}$ Ibid, 48.

${ }^{30}$ Ibid, 53.
} 
she amassed a collection of books on composition, counterpoint, and orchestration, as well as musical scores. This collection would eventually, in her own opinion ${ }^{31}$, become one of the greatest in America. Boston Symphony concerts, which she regularly attended, provided Amy an opportunity to study a score during a live performance. Through this highly motivated course of self study, Amy Beach was able to increase her compositional knowledge and expand the genres in which she composed. Her first foray into larger genres was her Mass. Its premiere occurred in 1892 with Carl Zerrahn conducting the Handel and Haydn Society. Following the premiere, Julia Ward Howe, a writer for the Women's Journal wrote, "[The Mass] made evident the capacity of a woman's brain to plan and execute a work combining great seriousness with unquestionable beauty....Mrs. Beach is, so far as we know, the first of her sex who has given to the world a musical composition of the first order as to scope and conception." 32

Though the Mass was a success, Amy Beach was still largely unknown outside of Boston. This changed as she began receiving professional commissions. The second of these proved to be vital to her career. The board of lady managers for Chicago's Columbian Exposition of 1893 asked her to compose a festive piece for the dedication of the women's building at the fair. ${ }^{33}$ Besides the premiere of Festival Jubliate, her compositions were featured on all three concerts held during the Women's Musical Congress, which was part of the Columbian Exposition. One of the pieces composed for these concerts, the Romance for Violin and Piano, marks the first

\footnotetext{
${ }^{31}$ Ibid, 54.

32 Julia Ward Howe, Women's Journal (February 13, 1892).

${ }^{33}$ Jenkins, The Remarkable Mrs. Beach, 30.
} 
piece she ever composed for a solo string instrument with piano accompaniment. Details concerning this piece, including its premiere, will be discussed in Chapter 3.

Between 1893 and 1895 Mrs. H. H. A. Beach worked on a number of compositions and had a moderately active performing life, including an appearance as the soloist in Saint-Saens's Piano Concerto No. 2 with the Boston Symphony. Sadly, 1895 also contained some of her first personal losses, the deaths of both her father and grandmother. As a result, her mother came to live with Mr. and Mrs. Beach. Scholars have written about this change as both a blessing and a curse for Amy Beach. Since her mother was quite capable of running the household, this granted Mrs. Beach more time to devote to her music. Along with this freedom however came the constant presence of her mother, as Mrs. Cheney was known for sitting in the room while Amy was working.

Despite all this, the most important product of the next year was her Gaelic Symphony. She spent two years writing her four movement symphony. This symphony was written partially in reaction to Antonín Dvořák's comments after his stay in America. Dvořák urged American composers to create authentic American music, which in his opinion should include African and Native American folk tunes. By contrast, Amy Beach believed "that composers should look to their own heritage, that ' $[\mathrm{w}] \mathrm{e}$ of the North should be far more likely to be influenced by the old English, Scotch, or Irish songs, inherited with our literature from our ancestors." ${ }^{34}$ For this reason she titled her symphony the Gaelic symphony, using multiple Irish and Celtic themes throughout. Additionally, any theme that she composed was in a style consistent with traditional

\footnotetext{
${ }^{34}$ Block, Amy Beach, 87.
} 
Irish music. The symphony was premiered by the Boston Symphony in October of $1896 .{ }^{35}$ The critics found the piece very enjoyable and it received many positive reviews. Unfortunately, the critics seemed to focus on this symphony as a measurement of Amy Beach's ability as a female composer, rather than recognize the importance of the Irish elements she included. It was years after its premiere before a critic noticed and commented on the Irish content of the symphony. In 1896, an unnamed writer for the Boston Home Journal called Beach "an epoch maker who has broken through old boundaries and presented an enrichment and extension of women's sphere in art such as has not been surpassed or even equalled by any contemporary of her sex." 36 Walter Jenkins, a personal friend of Amy Beach wrote, "It was the premiere of the Gaelic Symphony by the Boston Symphony Orchestra under Emil Paur on 30-31 October 1896 that established her as a major American composer. This work enjoyed the greatest success of any American symphony by any composer of Mrs. Beach's generation." ${ }^{37}$ In the end though, as Adrienne Block wrote, “The big news was that a women had written a symphony and one of this country's leading orchestras had given its premiere."38

Following the Gaelic Symphony, one of her next major pieces was the Sonata for Violin and Piano, which premiered in January 1897. Almost immediately it enjoyed great success leading to many performances both then and now. The second European performance was given on April 4, 1900 by violinist Eugène Ysaÿe and pianist Raoul Pugno. They found the work in a

\footnotetext{
35 Jenkins, The Remarkable Mrs. Beach, 37.

${ }^{36}$ Unnamed author, attributed by Beach to C. L. Capen, Boston Home Journal, S2 (1896): 26.

37 Jenkins, The Remarkable Mrs. Beach, 37.

${ }^{38}$ Block, Amy Beach, 102-103.
} 
stack of music, happened to read it, and decided to program the Sonata. They claim to not have realized that the composer was either a female or American. Although the composer's name should have appeared as "Mrs. H. H. A. Beach," there is always a chance it was obscured somehow, because on the printed programs they listed the composer as "H. A. Beach". 39

Around the turn of the century, her compositional output included many piano works. In 1900 she composed the Piano Concerto in C\# minor, Op. 45 which she premiered with the Boston Symphony and in 1904 wrote Variations on Balkan Themes. Significant to this document is her Three Pieces for Violin and Piano, a collection of three character pieces, published in 1898. Of the three pieces, titled La Captive, Berceuse and the Mazurka, only the Berceuse and La Captive received their premiere in 1897 by Rudolph Berliner in Chicago. The Mazurka was not premiered until 1901 by Maud Powell.

Amy Beach's compositions for choral ensembles constitute an important genre within her repertoire. The early 1900s saw participation in women's choruses grow exponentially, which created a need for music written specifically for women's voices. Beach was more than happy to help fill the void. Her music became so central in the repertoire that multiple Choral Societies were renamed to include Beach's name in their title.

Despite her considerable aptitude in other genres, Amy Beach was primarily known as a composer of vocal songs. Throughout her lifetime she created over 150 songs. When she was frustrated or needed a break from a larger work, she would write a song, a process that normally took only a few hours. She set poems in English, German, and French from a variety of poets:

${ }^{39}$ Ibid, 122. 
including Shakespeare, Tennyson, Browning, Longfellow, Perronet, Thomas Moore, and her own husband, Henry Beach. Over the course of their marriage, which lasted 25 years, she set seven of his poems. The last one she set was in 1910, the year he died at age 66 .

Amy Beach's life began to drastically change with the unexpected passing of her husband. He suffered a fall and was immobilized for a time to let the muscles and tendons heal. Unfortunately during the immobilization period he developed an abscess which proved fatal. While he did leave Amy Beach with some money, it was not enough to ensure a secure future moving forward. Additionally, Clara Cheney, Amy's mother, was very ill. For the first time in her life Beach had to take control and make important decisions. She did so with decisive quickness. Amy moved herself and her mother into the Hotel Brunswick so Beach could devote herself to her mother's care ${ }^{40}$ Early in 1911, Clara Cheney passed away, leaving Beach entirely on her own. She mourned for over a year before she felt capable of returning to performing. During that year of mourning she planned for the future, relishing her new found freedom. She hired a concert manager and planned an extended European trip, the first in her life.

Amy Beach left for Europe on her $44^{\text {th }}$ birthday, September 5, 1911. Her traveling companion was Marcella Craft, the prima donna of the Munich Royal Opera and a close personal friend. ${ }^{41}$ Amy observed a difference in how music was appreciated by European audiences. Years later in an interview, she stated that music in Europe was "universally recognized and respected

\footnotetext{
${ }^{40}$ Ibid, 177.

${ }^{41}$ Agnes Lockhart Hughes, “Mrs. H. H. A. Beach, America’s Foremost Woman Composer,” Boston Times (March 1915), S3.
} 
by all classes and conditions as the great art that it is." 42 Initially she had planned to stay in Europe for just a year to re-launch her performing career. Yet in the spring of 1912 she decided to extend her trip another year, as she needed more time to mourn her recent losses. Beach used the time to travel, and visited the Alps, Berlin, Rome, and Venice. During this time, she hired an European concert manager; it was this manager who suggested that she use the name "Amy Beach" instead of "Mrs. H. H. A. Beach.” Due to her well-received performances, demand had greatly increased in Europe for her compositions. Unfortunately her American publisher, Schmidt, was unwilling to send over the necessary pieces to fill the orders. Due to this rapidly souring relationship between Beach and Schmidt, in 1914 the publishing firm of Schirmer took over the publication of her pieces. ${ }^{43}$

Amy Beach's next significant opportunity came when Theodore Spiering, an American conductor working with the Berlin Symphony, agreed to program Beach's works in the 1913-1914 season. The works included the Gaelic Symphony and the Piano Concerto, with Beach appearing as the soloist. After finishing a successful concert season in 1914, she continued her travels and spent the summer in Munich. While in Europe Beach took advantage of the easy traveling options; however, she did not entirely neglect her compositions. During her three years in Europe her compositional output consisted of eleven songs, six sacred choruses and two large scale piano works. The most interesting of these was her Prelude and Fugue op. 81 for solo piano. In this work she created a theme from the letters of her name A-B-E-A-C-H, using a Bb

\footnotetext{
42 Edwin Hughes, "The Outlook for the Young American Composer: An Interview with the Distinguished American Composer, Mrs. H. H. A. Beach,” Etude 33 (January 1915): 13.

${ }^{43}$ Block, Amy Beach, 186.
} 
for the $\mathrm{B}$ and a $\mathrm{B}$ f for the $\mathrm{H}$. This composition is also unique because she composed it at the piano instead of at a desk, as was her custom..$^{44}$ Beach finally left Germany in September of 1914, months after World War I had already been declared. She made it back to America safely and received a warm welcome in Boston following her three year absence.

Upon returning home, Beach realized that Boston was no longer the musical hub it was in her younger days. New York City had now assumed this role. Although her permanent address would eventually be in New Hampshire, she spent significant time in New York throughout the rest of her life. Re-energized from her time in Europe, Beach traveled quite extensively. In March of 1915 she left the east coast and traveled to California ${ }^{45}$ While she had a number of professional engagements on the west coast, she also wished to reconnect with her closest living family members, her aunt, uncle, and cousin. A musical highlight of this time included attending a performance of her Panama Hymn, op. 74, at the Panama-Pacific International Exposition in San Francisco. Additionally, she attended "Mrs. H. H. A. Beach Day" which was held on June 28, 1915 in San Diego at California's second fair. The following winter she appeared with the Chicago Symphony in a performance of her Piano Concerto. "For Beach, no performance, perhaps not even of the 'Gaelic' Symphony, offered her the satisfaction of playing her concerto with a first-rate ensemble like the Chicago Symphony Orchestra." 46

While living in San Francisco she completed a major work, her Theme and Variations for Flute and String Quartet. This piece is based on a part song for women's voices that she

\footnotetext{
44 Ibid, 189.

45 Jenkins, The Remarkable Mrs. Beach, 79.

${ }^{46}$ Block, Amy Beach, 206.
} 
composed in 1904. Unfortunately, Beach was not at its premiere in September 1916. Around August $6^{\text {th }}, 1916$ she, her aunt, and cousin suddenly left California. The exact reason is unknown, but the 50 year marriage between her aunt and uncle ended after they left. The three women traveled back east and made their home in Hillsborough, New Hampshire. During the winters and springs of 1916 and 1917, Beach traveled quite extensively for various performances. However, in January of 1918, Beach fired her concert manager, began personally handling all bookings, and made a drastic announcement:

Mrs. H. H. A. Beach... has decided to devote her energies exclusively to Red Cross and other war relief work until the end of the war. She is available for concerts for these purposes and will present not only her own music, but programs of the music of Allied countries....Those wishing to present Mrs. Beach in concerto or recital for patriotic purposes may make arrangements with her directly at her home, Hillsborough, N. H. For the remainder of this season Mrs. Beach wishes to confine her activities to the New England States. ${ }^{47}$

One reason for the sudden changes was the failing health of her cousin, Ethel Clement, who had a terminal illness. Ethel's mother, who was 75 years old, was unable to solely provide the care her daughter needed. Following Ethel's death in April 1920, Beach continued to turn down most professional engagements as she provided care for her now ailing aunt.

In 1907 Marian MacDowell, a friend of Amy Beach, established the MacDowell Colony as an artists retreat, which became a central element for the rest of Beach's life. "The mission of The MacDowell Colony is to nurture the arts by offering creative individuals of the highest talent an inspiring environment in which they can produce enduring works of the imagination." 48

\footnotetext{
47 “Mrs. Beach Will Devote Energies to War Work," Musical America, 27 (1918): 27.

48 “Our Mission,” The MacDowell Colony, accessed September 23, 2015, http:// www.macdowellcolony.org/about-Mission.html.
} 
Beach first attended in 1921, albeit with some hesitation. While she applauded the mission of the Colony, she did not feel a strong need in her own life for such a retreat. However, during her first visit, Beach found the colony provided the stimulation she was missing. In fact, over the next five years, she composed twice as many pieces as she did in the previous ten. From 1921 forward, every piece she wrote was either sketched or written at the Colony. As the Colony is set within the natural woodlands of New Hampshire, it should come as no surprise that many of Beach's compositions dealt with some aspect of nature. For example, she was a known collector of bird songs. On her first stay at the Colony, she heard a thrush singing outside her cottage. The thrush's song inspired $A$ Hermit Thrush at Eve, and A Hermit Thrush at Morn.$^{49}$ For the publication of these works Beach turned back to Schmidt Publishing, as her contract with Schirmer had expired in 1920. Arthur P. Schmidt passed away in 1921 and afterwards Beach felt comfortable returning to Schmidt as her primary publisher. Upon returning from her first sojourn at the MacDowell Colony, Amy Beach felt her presence was needed more at home due to the health of elderly Aunt. Over the next four years she stayed close to home, making only a few short performing tours out west.

Since Beach was spending less time traveling, she began to expand her charitable efforts. This included taking a strong interest in the musical education of children, and helping to found a "Beach Club" for children in the Hillsborough area. The children assembled at the local library where their gatherings included a chance to perform for one another. On a regular basis Beach would arrive and play for them, as well as share stories from her life. She formed a strong bond with the children. "The children responded to her kindness and warmth and bragged about her

${ }^{49}$ Dorothea Lawson, “Mrs. H. H. A. Beach,” The Colby Voice (October 1921), 8-10. 
importance as a composer... Sixty years later, surviving club members remembered with pleasure their trip with Beach to the MacDowell Colony where they visited Edward MacDowell's grave and met his widow." ${ }^{50}$ Amy Beach stayed active in supporting her colleagues by joining a variety of organizations founded to promote and encourage women composers. She also assisted in fundraising efforts for the MacDowell Colony.

Beach's next European trip occurred in 1926, following the death of her aunt. In a letter to the Schmidt Publishing Company, she explained that this trip was for "complete rest from musical work and comparative freedom from responsibility." ${ }^{11}$ While she was in Europe she participated in some small performances, but primarily attended as many concerts as possible. Upon her return in 1927, she settled into a new routine which included winters in Hillsborough, the months of June or September (or both) at the MacDowell Colony, and summers in Centerville. Her home in Centerville remained from her years of marriage to Dr. Beach. They bought the home in 1895 and the property remained with Beach until she passed away. During this time she also made many winter tours, especially to the South. In June of 1928 she was recognized by the University of New Hampshire, and was awarded an honorary Master's degree. A few days following the ceremony, she received a phone call from the President of the University expressing his regret that they had not awarded her an honorary doctorate instead. ${ }^{52}$ Another trip to Europe occurred in the winter of 1928-1929. This time she played more public recitals than during her previous visit, including a significant fundraiser for the American

\footnotetext{
${ }^{50}$ Block, Amy Beach, 244.

51 “The Arthur P. Schmidt Collection," (Library of Congress, Washington, D.C.) April 27, 1927.

52 Block, Amy Beach, 250.
} 
Hospital in Rome. She also visited her friend, Marcella Craft in Munich, reliving a portion of her first trip to Europe. ${ }^{53}$ Beach sailed back to America in May of 1929.

A big change occurred in 1930, when Beach finally decided to include New York City in her annual rotation of residences. New York became her winter residence, with her arrival occurring in November. While there, she rented a studio apartment in the American Women's Association Club House where she was a motherly figure for many of the girls. Due to her age, 63 , she was allowed to bypass some of the club rules and was permitted to have mixed company in her studio. She found life in New York invigorating. Her schedule was quite full, as she enjoyed not only performing and mentoring, but also attending a variety of concerts, especially ones involving her music. Saint Bartholomew's became her church home in New York City. She became close friends with the organist and served as an unofficial composer in residence.

Interestingly, the stock market crash of 1929 helped her regain popularity. Following the crash, a desire for American music based upon folk tunes resurfaced, a wish which Beach was easily able to fulfill. During this time she continued her other endeavors, such as raising money for the MacDowell Colony, and supporting organizations dedicated to the spread of music by women composers. This led to an appearance at the White House, ${ }^{54}$ among other venues.

Her final extended concert tour occurred in 1934, which centered around the Century of Progress Exposition in Chicago. She performed many times during the exposition and also received awards for her work. After the exposition, due to exhaustion, she cancelled many

\footnotetext{
53 Jenkins, The Remarkable Mrs. Beach, 97.

54 “Mrs. Beach Appears in Own Works at White House," Musical Leader 68 (May 1936): 10.
} 
scheduled performances. Following the tour she would play only single concerts, most of them located near to one of her home bases.

The last half of the 1930s saw a gradual slowing down in the life of Mrs. H. H. A. Beach. In 1936 she traveled, for the final time, to Europe with her dear friend Ruth Shaffner. Shaffner had been a vocal soloist at St. Bartholomew's Church in New York for many years. Amid controversy she was released from her duties in May of 1936. As a thank you for the years of service to the church, Beach provided her with an all expense paid trip to England. ${ }^{55}$ Once overseas they toured many cathedrals and attended various performances. At this time Beach was experiencing significant foot issues which limited her ability to tour some of the buildings. Overall though both women thoroughly enjoyed their trip to England.

A destructive storm rolled through the New England states in 1938 and caused significant damage to the MacDowell Colony. ${ }^{56}$ Of course Beach responded at once, donating some of her own money to the clean up effort and encouraging others to do the same. In 1940 she gave a performance of her Piano Trio. Although she did not know it at the time, this was to be her last performance. Shortly after, she became gravely ill with bronchitis and developed a heart condition which would plague her the rest of her life. During this time she was forced to skip her annual pilgrimage to the MacDowell Colony. Thereafter she was able to attend very few events due to her health.

The last year that Beach would be strong enough to spend time at her Hillsborough home or the MacDowell Colony was 1941. As her strength began to decrease, her life rotated between

\footnotetext{
55 Jenkins, The Remarkable Mrs. Beach, 133.

56 “50 Years Ago...Hurricane of '38 and Winds of War!” MacDowell Colony News 15 (1987-1988).
} 
New York and Centerville. ${ }^{57}$ Due to her copious number of friends she was very rarely left alone. It is remarkable that while she was forced to end her performing career, she continued composing. In the last few years of her life she wrote and revised a number of pieces, such as Prelude on an Old Folk Tune, and Though I Take the Wings of Morning, op. 152. She also revised her two-hand piano version of the Balkan Variations, among others.

Amy Beach died on December 27, 1944 of heart disease. ${ }^{58}$ Her estate continued her charitable contributions and legacy. She left pieces of jewelry given to her by Dr. Beach initially to the Emmanuel Church in Boston. Her intent was that they be inserted into a chalice or other vessel for decoration. She included a monetary donation with which to make the piece. Emmanuel Church turned down this offer, and instead it was given to St. Bartholomew's. ${ }^{59}$ She also set up the "Dr. H. H. A. Beach Fund" at Massachusetts General Hospital. Naturally she did not forget about the MacDowell Colony who, to this day, receives any money generated by the music of Amy Beach. Although interest in Beach's music has waxed and waned over the years, she still continues to contribute significantly to the colony that meant so much to her life. The contributions that Amy Beach made to American music cannot be overstated. This pioneering woman deserves to be studied and to have her music performed for years to come.

\footnotetext{
${ }^{57}$ Block, Amy Beach, 291.

58 “Mrs Beach, Leading Composer Dies at 77," Musical America 65 (January 1945): 24.

${ }^{59}$ Block, Amy Beach, 297.
} 


\section{Chapter 3 - Analysis of Romance for Violin and Piano, Op. 32}

Amy Beach's first composition for solo violin was the Romance for Violin and Piano, op. 23. It was written and published in 1893. Beach and Maud Powell premiered the Romance at Chicago's Columbian Exposition as part of the Women's Musical Congress. Powell was the first female American violinist to gain international fame. During her lifetime she was one of the first champions of Sibelius' Violin Concerto in America and recorded extensively for RCA Victor. The Romance was popular in Beach's lifetime, especially with violinist Franz Kneisel. Jeanell Brown, author of Amy Beach and her Chamber Music, notes that "due to its popularity during Beach's life, it may be her most frequently performed chamber work." ${ }^{\prime 60}$ Kneisel was originally from Romania, though he spent most of his life in the United States. He was the first head of the violin department at Juilliard, and performed frequently with his own well-known Kneisel Quartet. Beach occasionally joined them to perform piano quartets, which is how Kneisel came to know her music. The Romance is the longest and most complex work for solo violin that Beach composed, most likely due to Powell's virtuosity. The analysis below will detail the form, melodies, textures, and harmonies used throughout the piece.

The melodic origin of this work comes from a previously written song by Beach titled,

“Sweetheart, Sigh No More," op. 14, no. 3. Her Opus 14 was published in 1890, three years before she wrote the Romance. Beach and singer Jeanette Dutton performed "Sweetheart, Sigh No More," during the final day of the Women's Musical Congress in Chicago, a day after the

\footnotetext{
${ }^{60}$ Brown, Amy Beach and her Chamber Music, 166.
} 
premiere of the Romance. Adrienne Block observes, "In offering these two compositions, Beach demonstrated to her colleagues how she developed and expanded a musical idea. The relationship between the two works, however, was nowhere recognized." ${ }^{11}$ Later on in her book Block also points out, "Its origin in the song...is made clear by the identity of the opening phrase, which Beach then uses sequentially and developmentally. The appoggiatura-laden violin melody, together with the pulsating accompaniment, conveys the longing appropriate to a piece entitled 'Romance." " 62 In the original song the vocal line is only given the melodic fragment once, yet the piano plays it multiple times. To see the clear connection compare example 3.1 below from beginning of the song against examples 3.2 and 3.3, which shows the piano and violin's first entrances from the Romance.

Example 3.1: Sweetheart, Sigh No More! mm. 1-4

To H.

\section{Sweetheart, Sigh No More!}

(T.B. Aldrich.)

Mrs. H. H. A. Beach

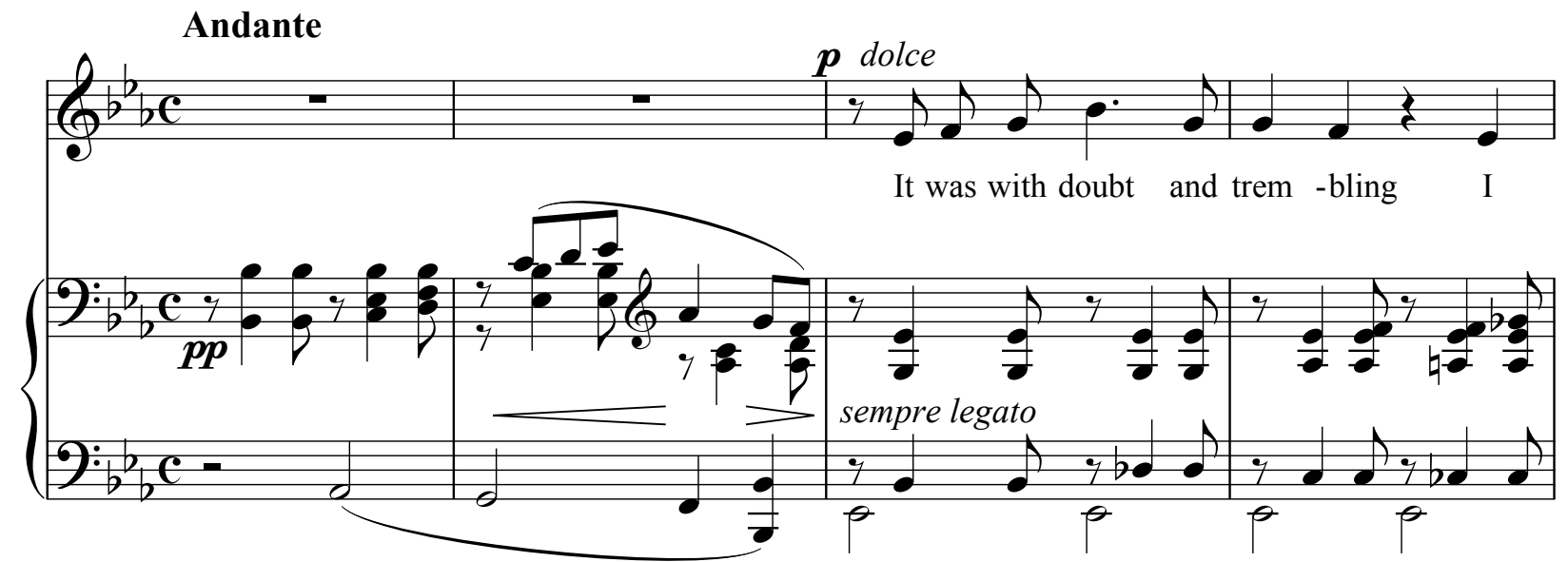

${ }^{61}$ Block, Amy Beach, 83.

62 Ibid, 113. 
Example 3.2: Romance, mm. 1-2

\section{Romance}

Mrs. H. H. A. Beach

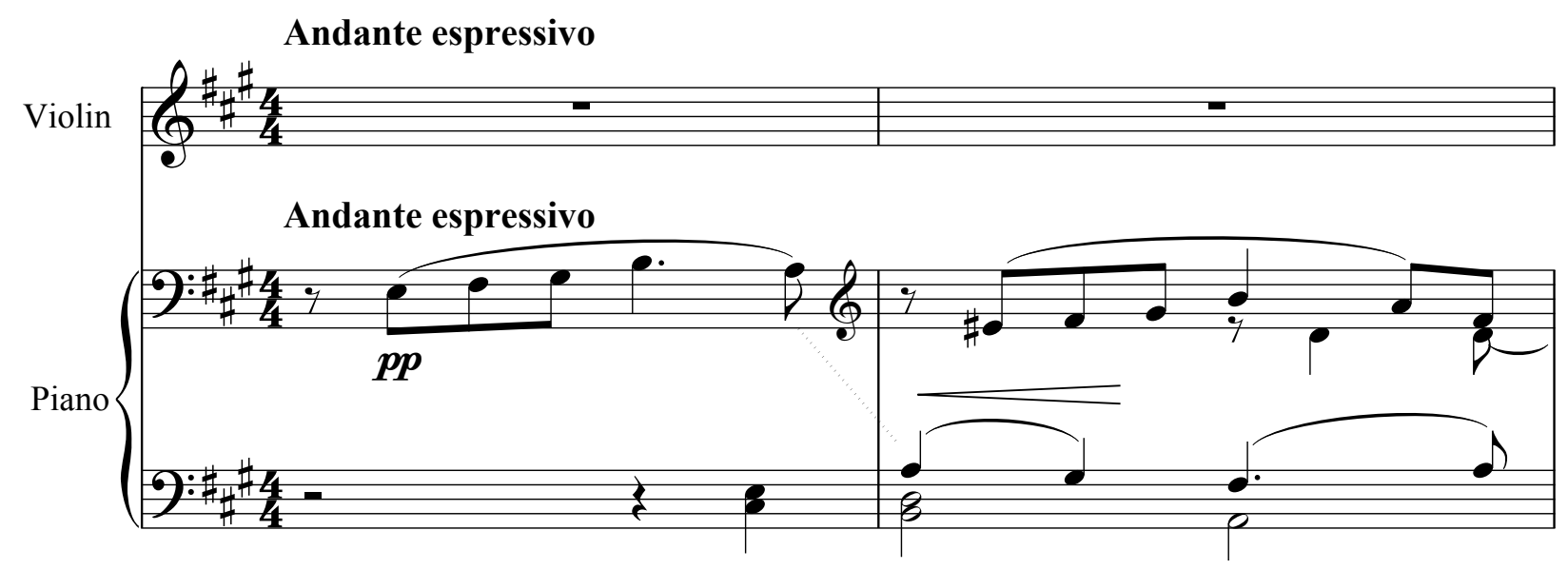

Example 3.3: Romance, mm. 1-12, violin only

Violin

\section{Romance}

Mrs. H. H. A. Beach

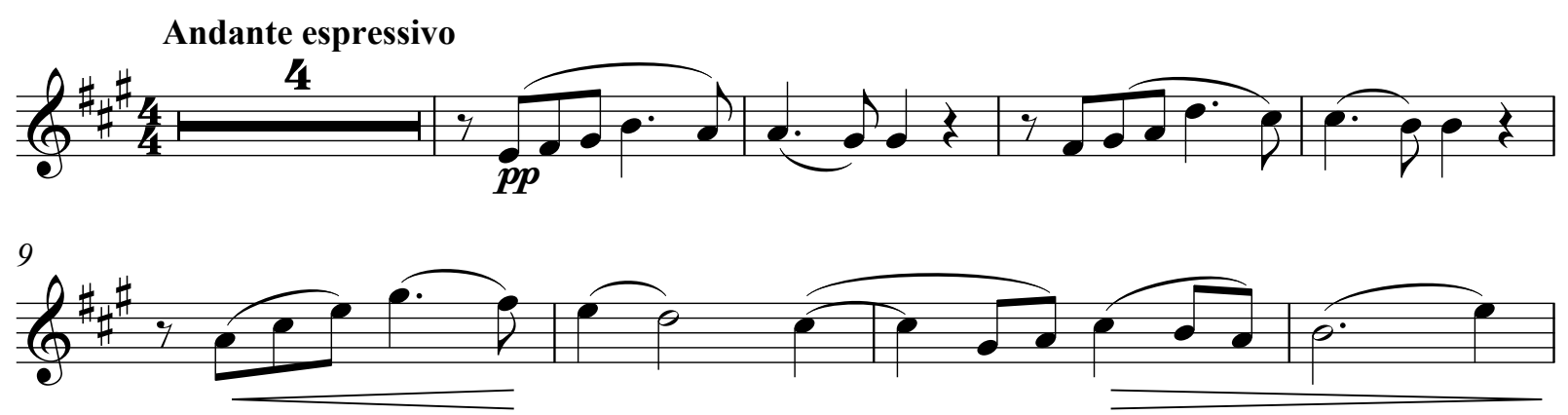

Before moving forward, a few points about the beginning of the song compared to the

beginning of the Romance. First, the very first note heard in both is sol $^{63}$. Also, while the voice

63 In this paper the solfege system used will be based upon moveable do and la based minor. 
starts on $d o$, the violin starts on sol, which means that while the pitches in the melodic line are similar their function within the key is not. For example, in the original song the fourth note of the vocal line is sol, clearly not a dissonant note within the key. However the violin's fourth note is $r e$, which is a dissonant note within an A major tonic harmony. Beach appropriately resolves the re down to $d o$, treating it as an appoggiatura. In the following measure she turns the $d o$ into a suspension which ultimately resolves to $t i$ (example 3.12).

The Romance is in ternary form, which Beach seemed to favor in compositions for the solo violin. She used this form in her Berceuse and Mazurka, which will be discussed in the following chapter. Each major section of the Romance contains a four measure piano interlude, a characteristic which helps to clarify the form. The A section runs from mm. 1-29, the B section from mm. 29-75 and A' from mm. 75-end.

There are multiple ways to analyze the phrasing of the A section. If more weight is given to melodic considerations than harmonic then the melody could be divided into three phrases. In that instance the first phrase runs from mm. 5-12, the second phrase from mm. 13-22, beat 2, and the third phrase from 22, beat 3-29. Beach uses the borrowed melodic fragment in a modified sequence throughout the first phrase. The use of the term modified refers to the continuous intervallic expansion between the bottom and top pitches of each iteration. Observe the violin in example 3.3. In the first instance the interval is a fifth (E-B), the next repetition is a sixth $(F \sharp-D)$ and the final statement is a seventh (A-G\#). The second phrase is an octave higher than the first phrase. However, starting with the $B \#$ in $\mathrm{m} .16$, she catapults the violin into the 
upper register. The third phrase starts with the same notes as the second phrase, although it is rhythmically displaced by two beats (end of example 3.4).

Example 3.4: Romance, mm. 13-23, violin only
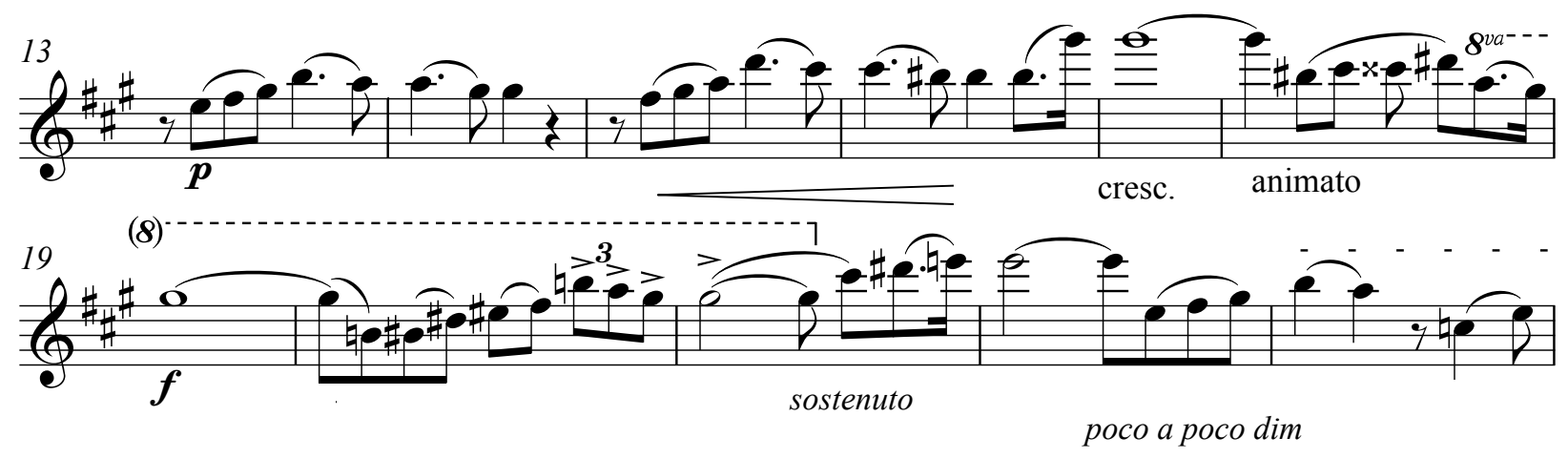

Of course melody is not the only factor when deciding phrase divisions. Looking from a purely harmonic standpoint while the division between the first and second phrases remains clear, the third phrase could be seen as starting in $\mathrm{m}$. 21. In this particular section her key center is $\mathrm{C} \#$ minor and $\mathrm{m} .21$ is the resolution of a very prolonged dominant/cadential ${ }_{4}^{6} \mathrm{starting}$ in $\mathrm{m}$. 16.

Example 3.5: Romance, mm. 15-22

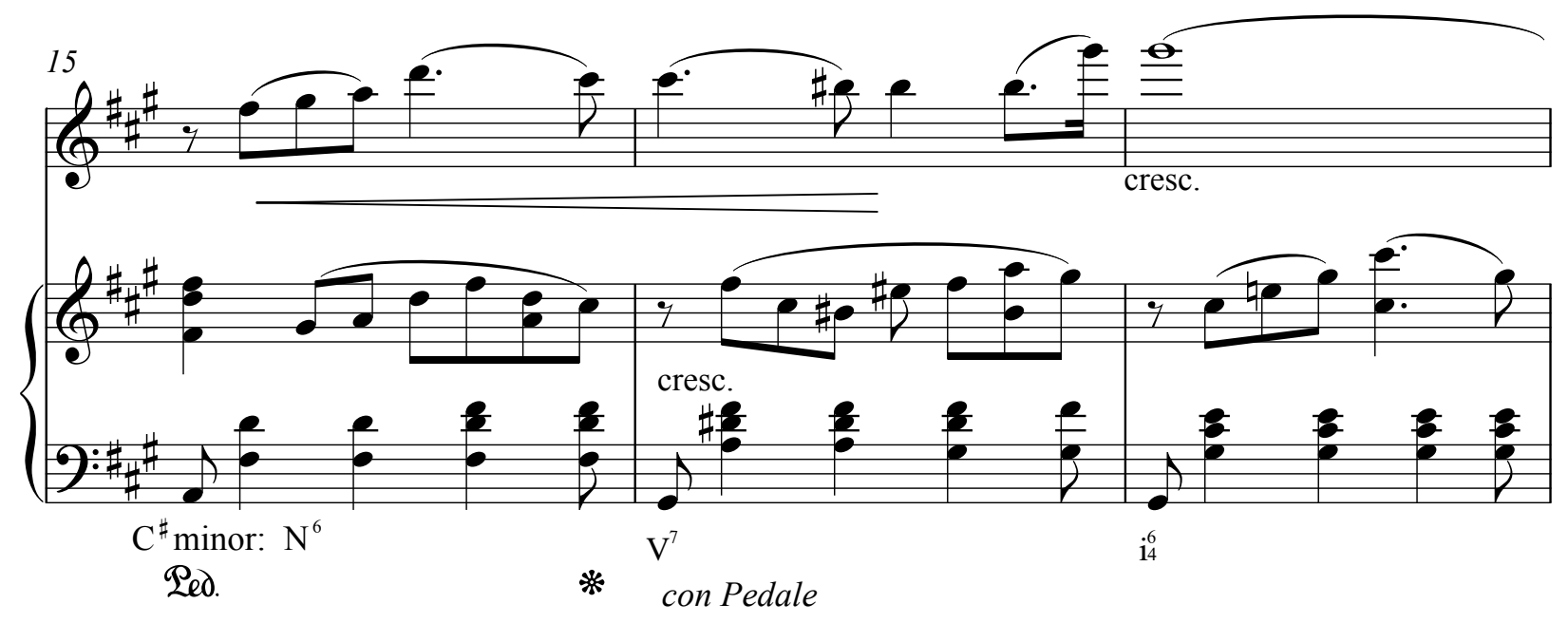


Example 3.5: Cont.
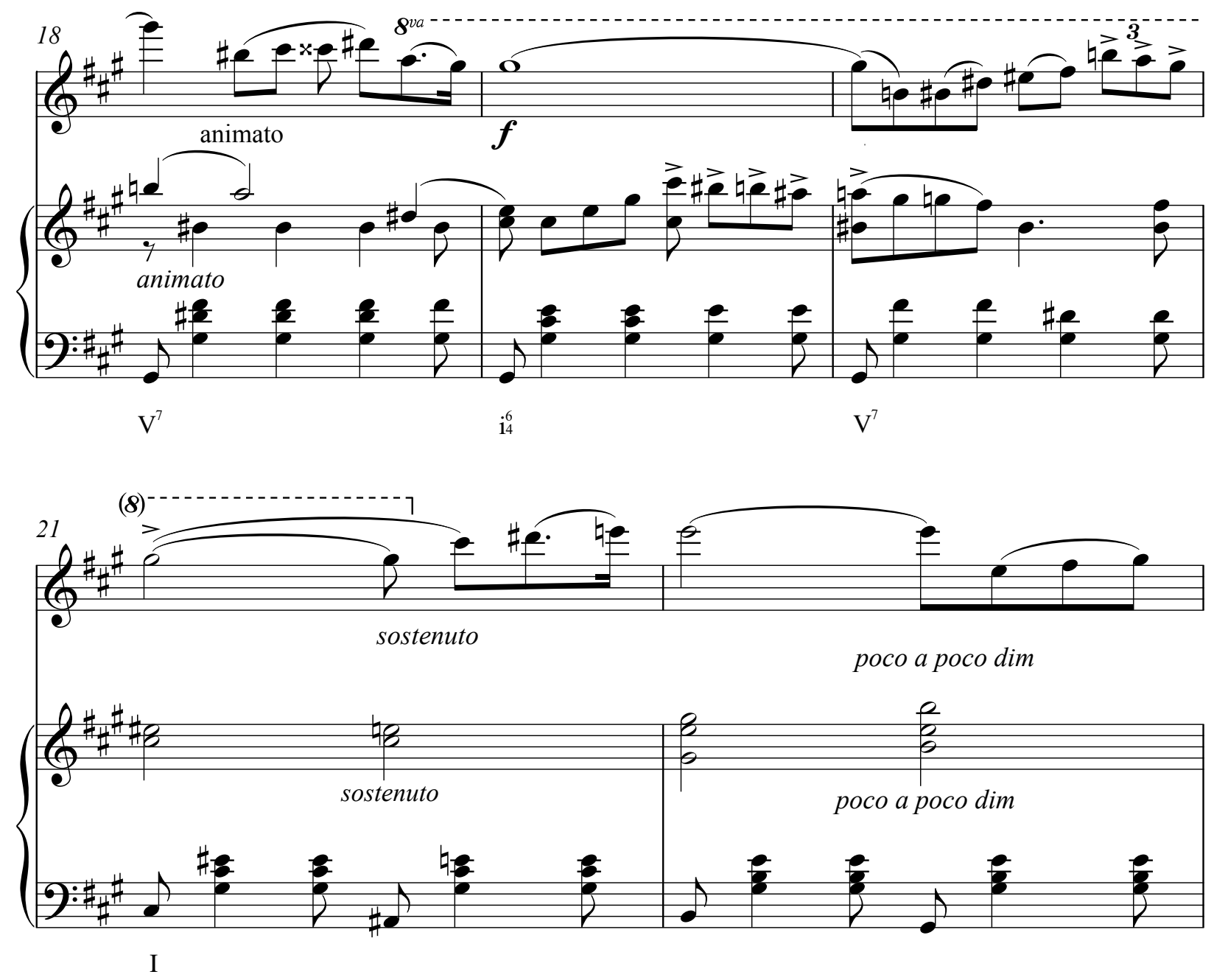

Evidence for $\mathrm{m} .21$ as the start of the third phrase also includes the overall melodic motion. From the start of the second phrase Beach is continually ascending in the violin's register until the $\mathrm{G} \#$ in $\mathrm{m} .21$, and then she gently descends until the end of the A section. Naturally a third possibility would be to consider all the points above, and interpret mm. 13-29 as one long second phrase with a midway point around m. 21 . 
Throughout the A section the melodic fragment is used not only at the beginnings of the major phrases. She frequently incorporates the pattern of three scalar notes, whether ascending or descending, such as in mm. 20 and 21 (example 3.4). As this section is unwinding Beach includes the figure in mm. 25 and 26 .

Example 3.6: Romance, mm. 25-26

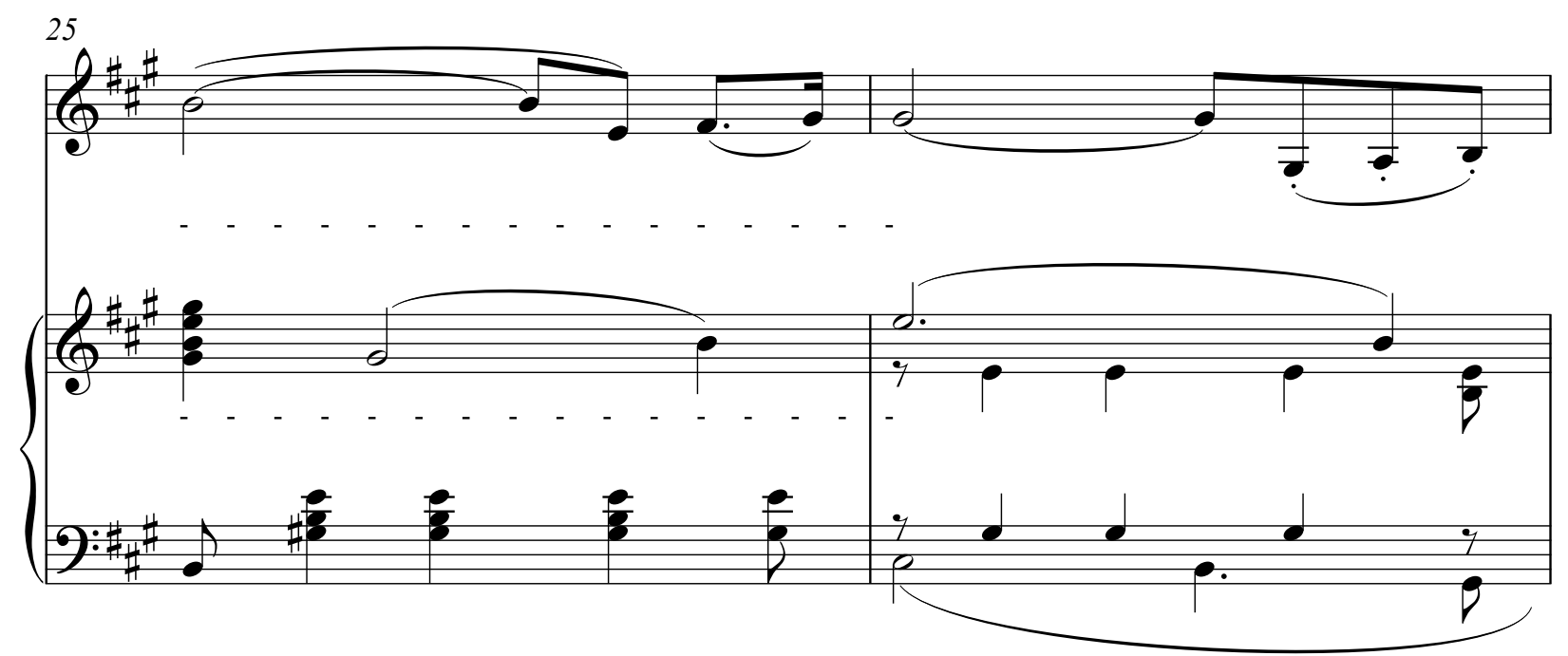

Other than the very beginning, the piano is never again prominently featured playing the main melodic fragment in the A section; however, that does not mean the piano part is devoid of it all together. The first instance is in mm. 13-14 when the piano is doubling the violin at an octave lower (example 3.7). The second and third times happen in mm. 17 and 19 (example 3.8). Both times the piano is playing the expanded version first seen in m. 9 (example 3.3) of the violin. 
Example 3.7: Romance, mm. 13-14

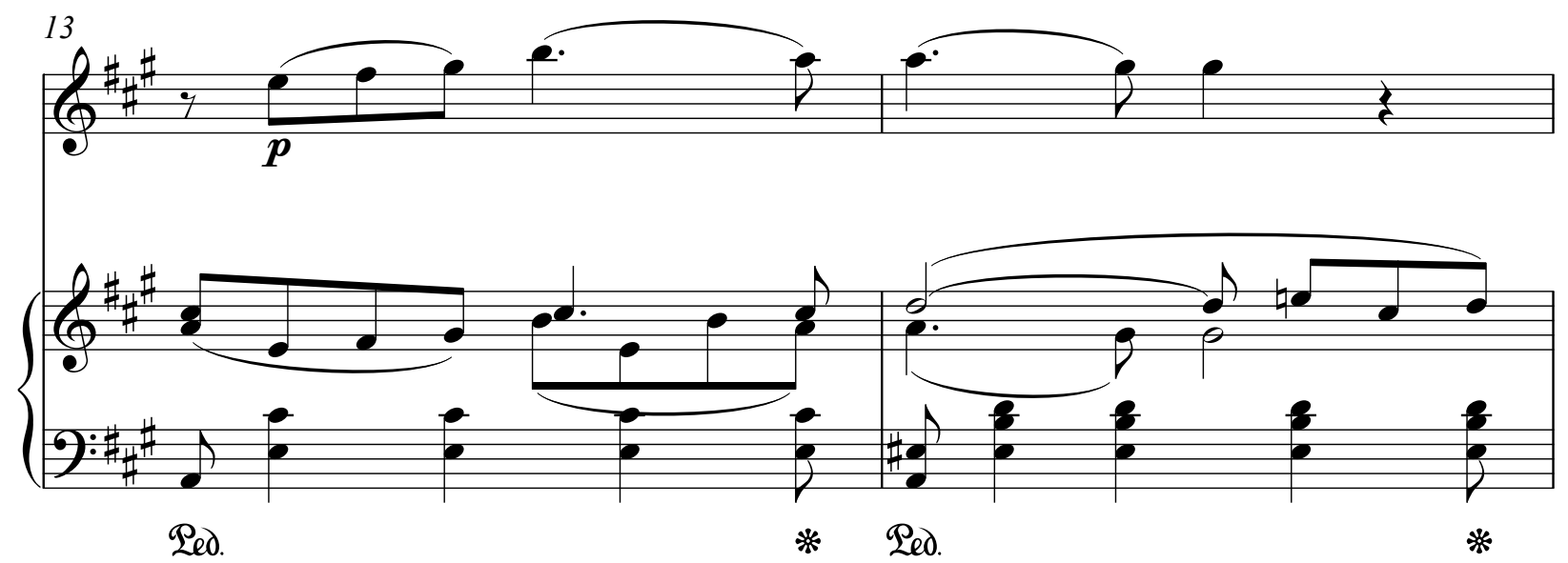

Example 3.8: Romance, mm. 17-19

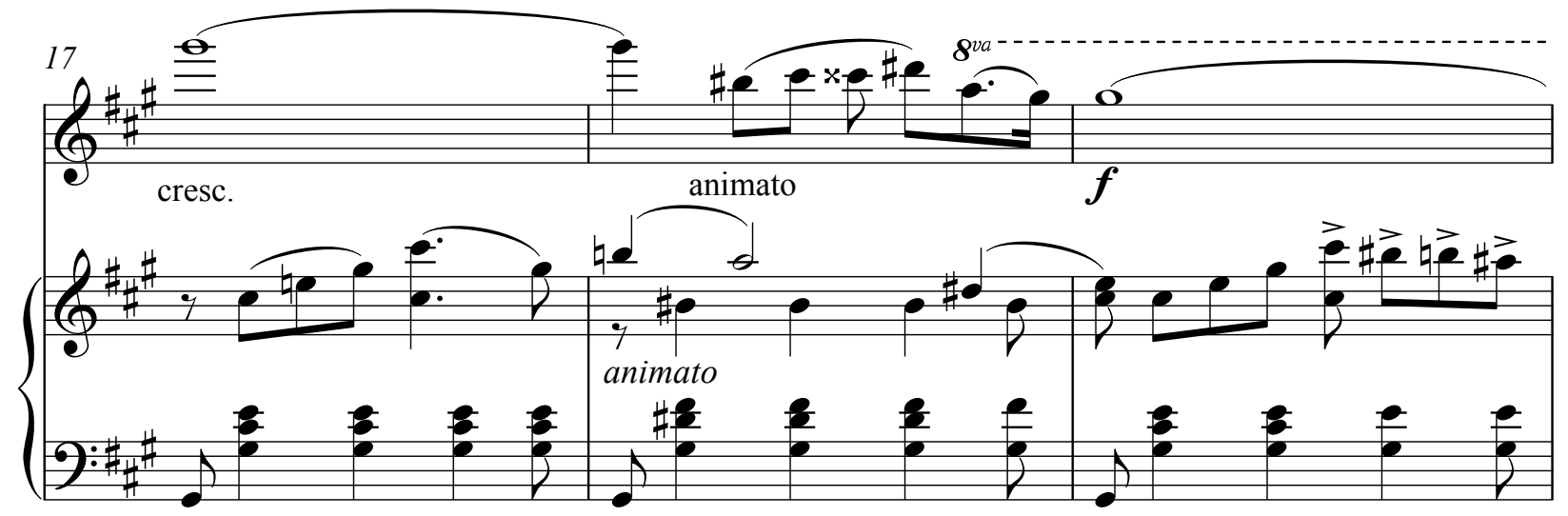

Once the violin enters in $\mathrm{m} .5$, the piano introduces a new texture that lasts the entire A section. This texture consists of the bass voice, which supplies the downbeat, followed immediately by syncopated quarter notes in the chordal accompaniment. The right hand of the piano varies throughout. Sometimes it plays a complementary line to the violin (example 3.9), assists in the syncopated quarter notes (example 3.10) or provides half note chords (example 3.11). 
Example 3.9: Romance, mm. 13-15

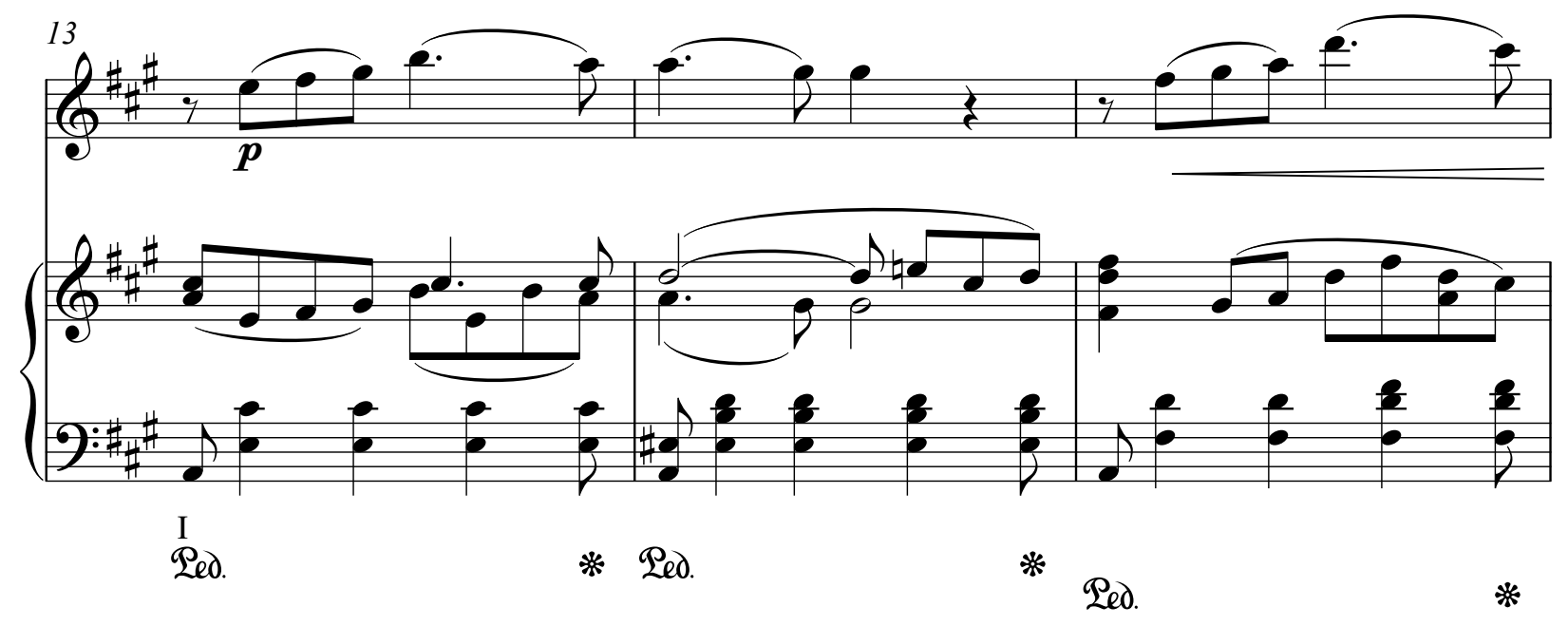

Example 3.10: Romance, mm. 8-9

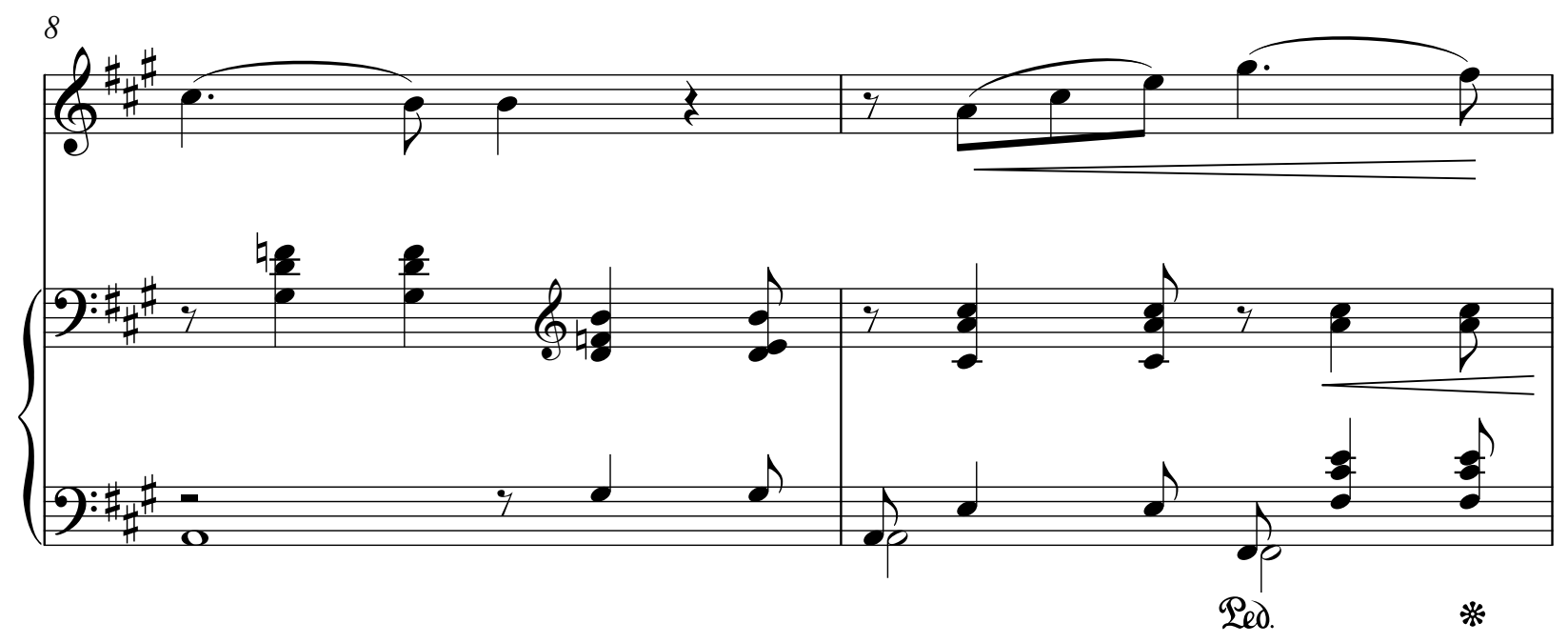


Example 3.11: Romance, mm. 22-24

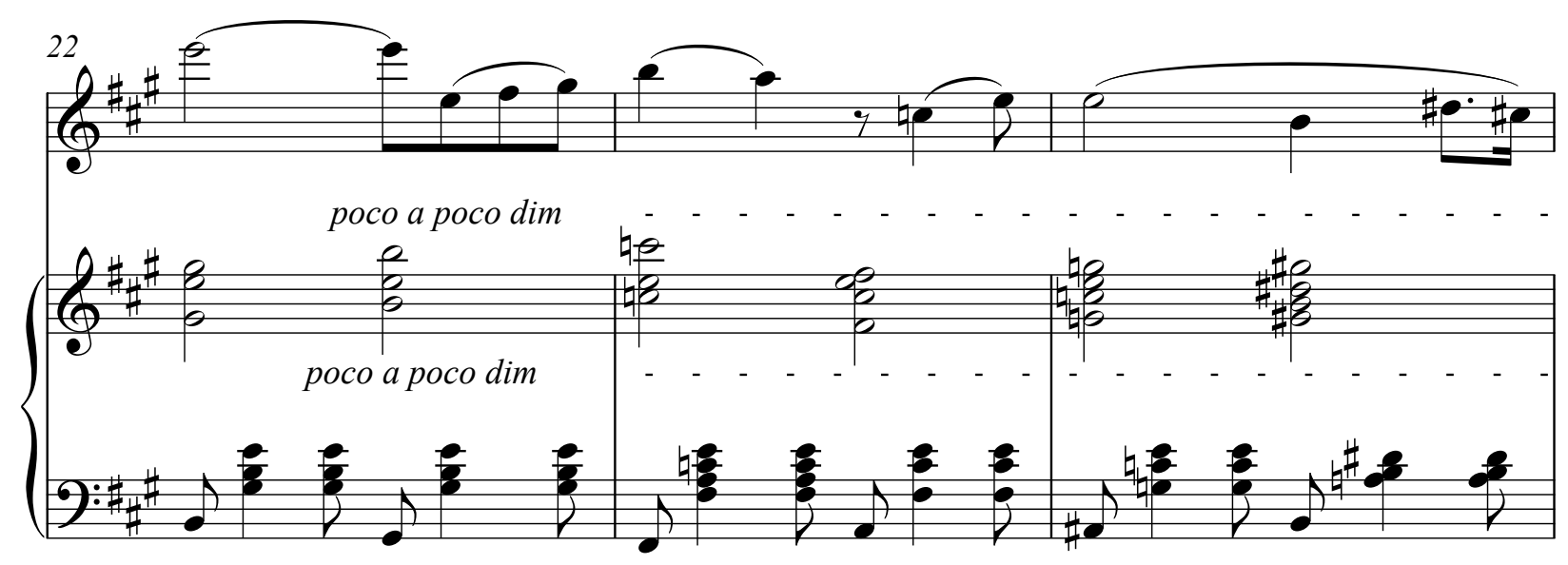

The Romance is in A major when viewed as a whole. However, the first four measures are somewhat ambiguous. A major is not firmly established until the violin enters in $\mathrm{m}$. 5, just after an authentic cadence set up in $\mathrm{m} .4$. This first section begins with a tonic pedal. The use of pedal tones is a feature Beach seems to favor in her compositions. She also prominently used a tonic pedal in her Invocation, Berceuse, and the Mazurka. The first phrase (from mm. 5-12) is diatonic and its important harmonies are I (m. 5); IV (m. 9) ii $^{7}$ (m. 10) and $\mathrm{V}^{7}-\mathrm{I}$ (mm. 12-13). A final feature to point out is the voice exchange in $\mathrm{mm} .11-12$ between the bass and alto of the piano. 
35

Example 3.12: Romance, mm. 4-13
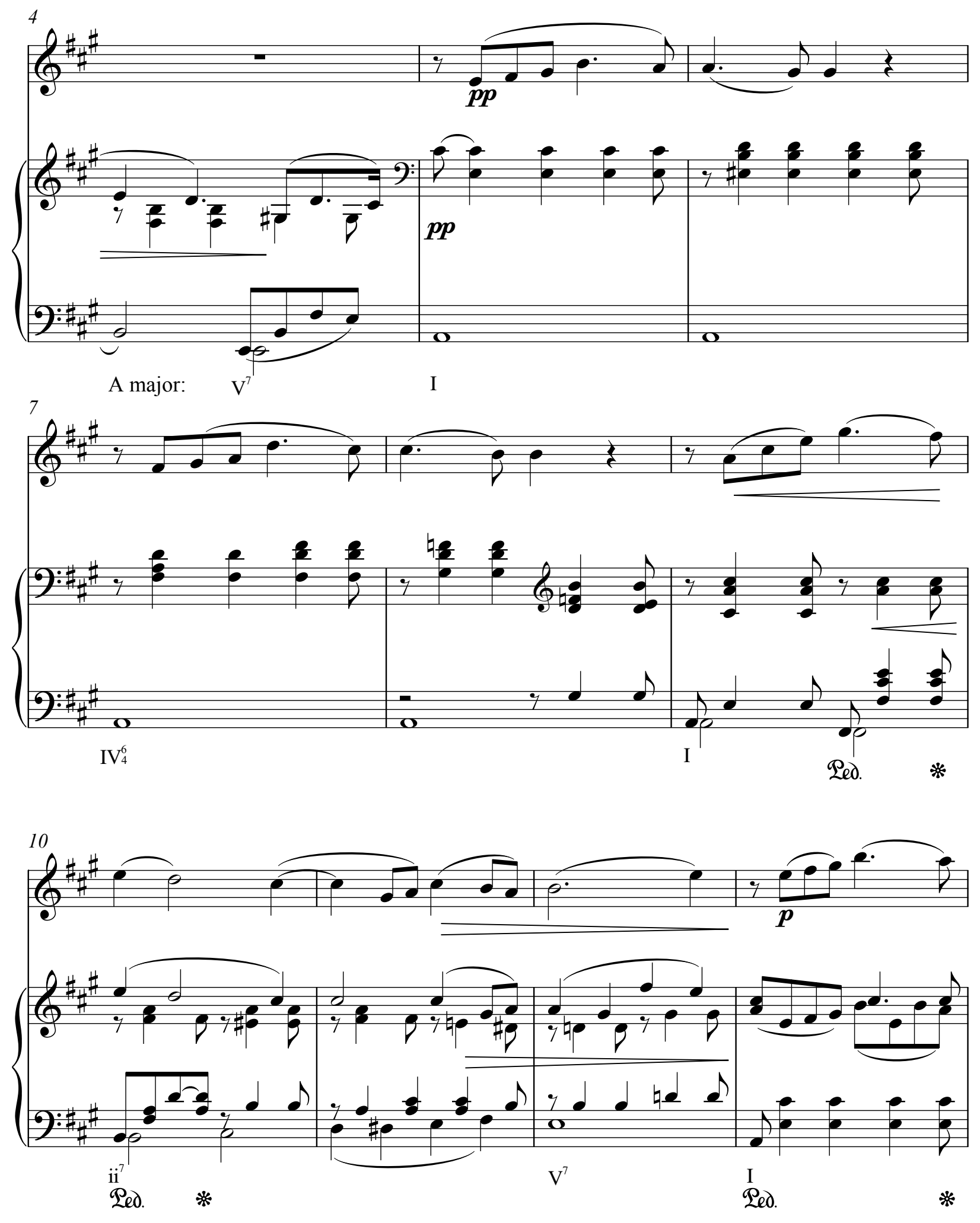
The first half of the second phrase (mm. 13-23) begins in A major with a tonic pedal.

After three measures the pedal descends a half-step to a $G \sharp$ before eventually ascending to $C \sharp$ in m. 21. The $\mathrm{G} \#$ pedal in $\mathrm{mm}$. 16-20 functions as the dominant of $\mathrm{C} \sharp$ minor. The motion to $\mathrm{C} \#$ minor (from A major) illustrates Beach's use of mediant key relationships, a common feature in her music. She sets up the key change via a pivot chord in m. 15, a IV in A major which is the Neapolitan of $\mathrm{C} \sharp$ minor. An unusual feature in $\mathrm{m} .15$ is that the Neapolitan chord occurs in second inversion. Throughout the section in $\mathrm{C} \#$ minor she uses a long dominant pedal over which alternate $\mathrm{V}^{7}$ and $\mathrm{i}_{4}^{6}$. The $\mathrm{i}_{4}^{6}$ provides tension during these measures of dominant prolongation. In m. 21 there is finally a resolution; however, she resolves to a $\mathrm{C} \#$ major chord instead of the expected $\mathrm{C} \sharp$ minor.

Example 3.13: Romance, mm. 15-21

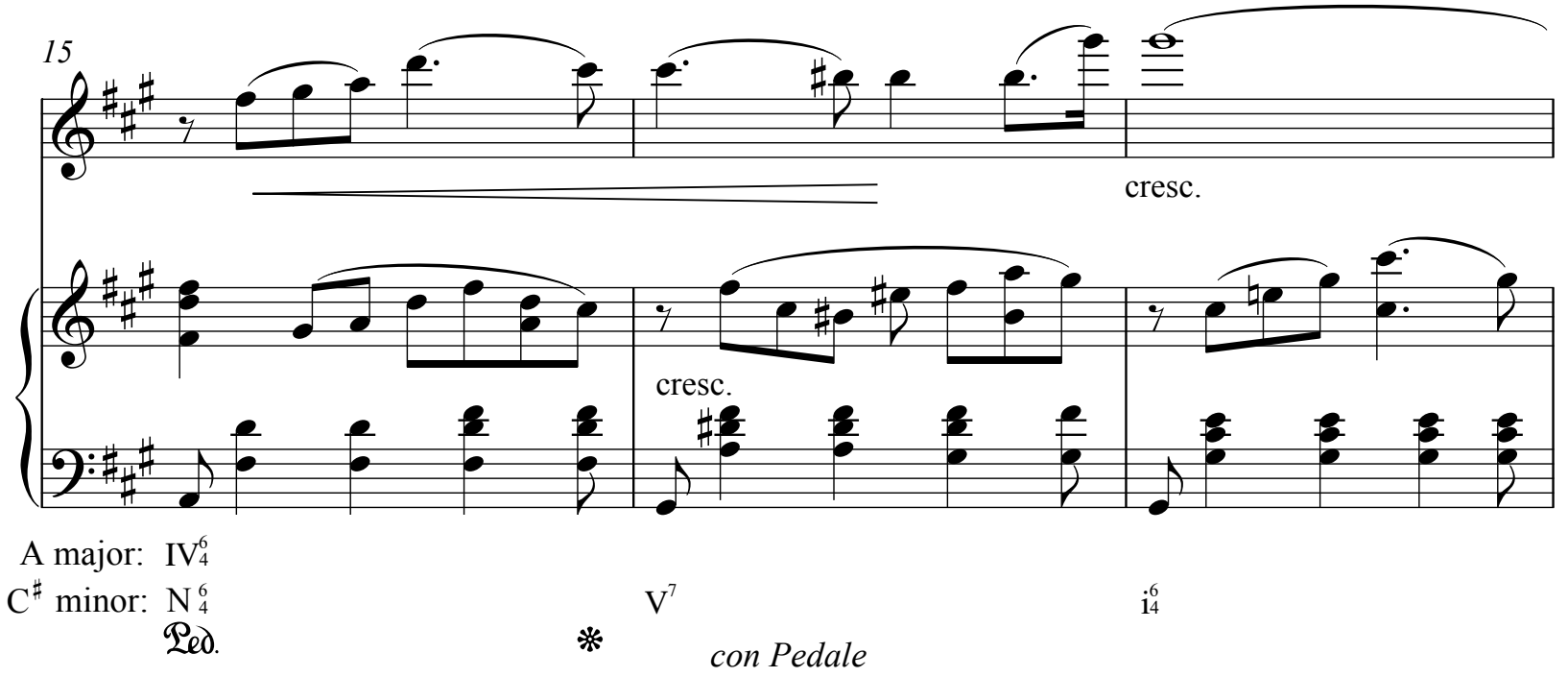


Example 3.13 Cont.
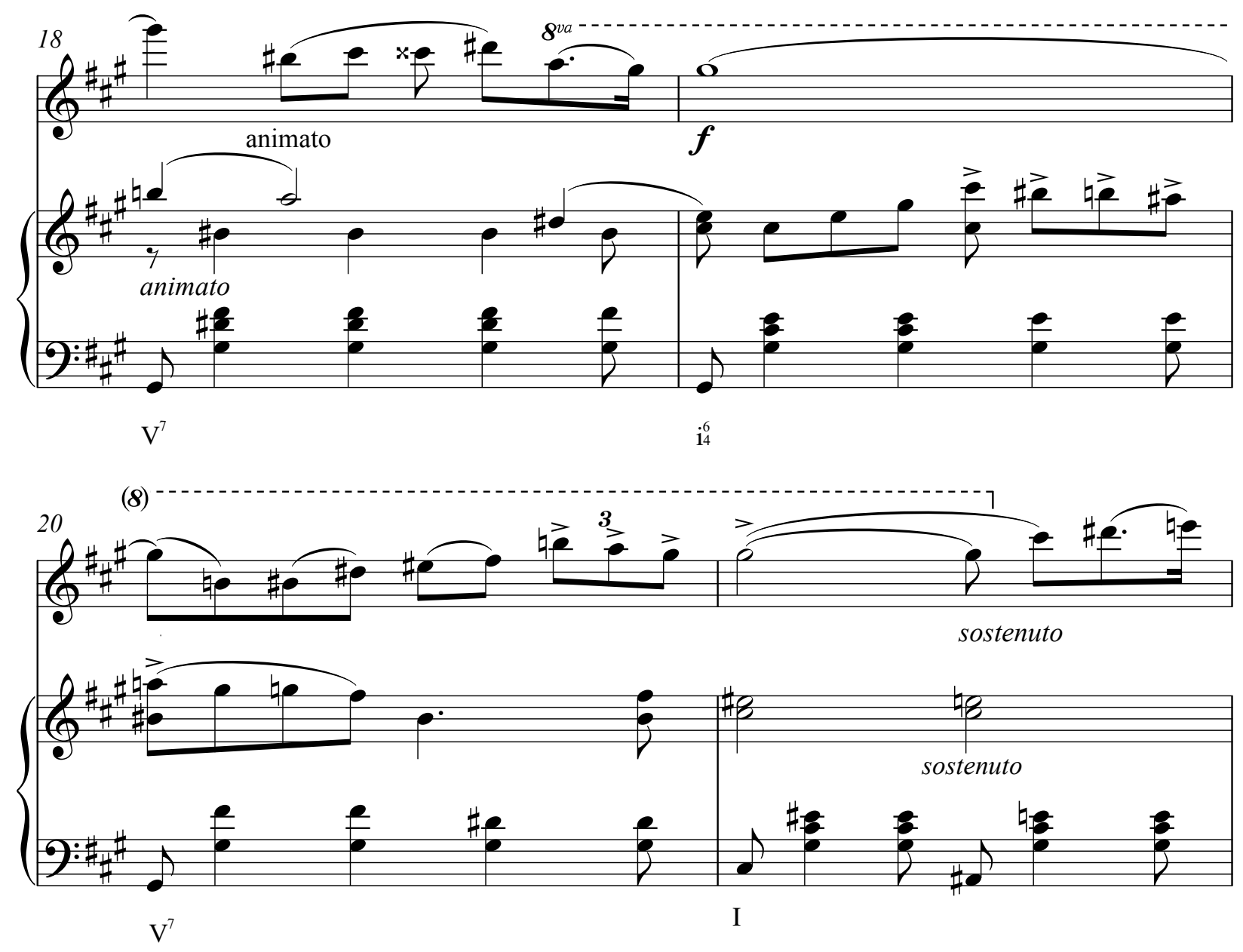

The rest of the second phrase (mm. 21-29) contains a repeating bass line of $\mathrm{C} \#-B-\mathrm{G}-$ $\mathrm{F} \#-\mathrm{A}-\mathrm{A} \#-\mathrm{B}$. The $\mathrm{A} \#$ in $\mathrm{m} .21$ is a chromatic neighbor note. Above the bass line she uses the same chords with each repetition. Although the chords throughout this section are highly chromatic they do function within a diatonic framework. For example, the $\mathrm{C} \#$ major chord on the downbeat of $\mathrm{m} .21$ is a modally borrowed tonic chord. Starting in $\mathrm{m} .21$ she also begins the transition from the key area of $\mathrm{C} \sharp$ minor to $\mathrm{E}$ major. The chord on beat three of $\mathrm{m} .21$ is a pivot chord functioning as $\mathrm{vi}^{87}$ in $\mathrm{C} \#$ and $\mathrm{vii}^{67} / \mathrm{V}$ in $\mathrm{E}$ major. This moves to $\mathrm{i}_{4}^{6}$ in $\mathrm{E}$, which functions as a cadential ${ }_{4}^{6}$, although its resolution to $\mathrm{V}$ is delayed until the second half of $\mathrm{m}$. 24 . Also in mm. 
$23-25$ there is an interesting chord progression consisting of a modally borrow ii ${ }^{67}$ (m. 23 beats 3-4), to an inverted ${ }^{64} \mathrm{Gr}^{+6}$ (m. 24 beats 1-2), to a B13 (m. 24 beats 3-4) and ultimately an E major chord in $\mathrm{m}$. 24. In this progression both the $\mathrm{ii}^{67}$ and the $\mathrm{Gr}^{+6}$ are functioning as predominants, while the $\mathrm{B} 13$ is the dominant chord to E. As noted above while these chords are all very chromatic in nature they also have a clear function within the diatonic framework.

Example 3.14: Romance, mm. 21-29
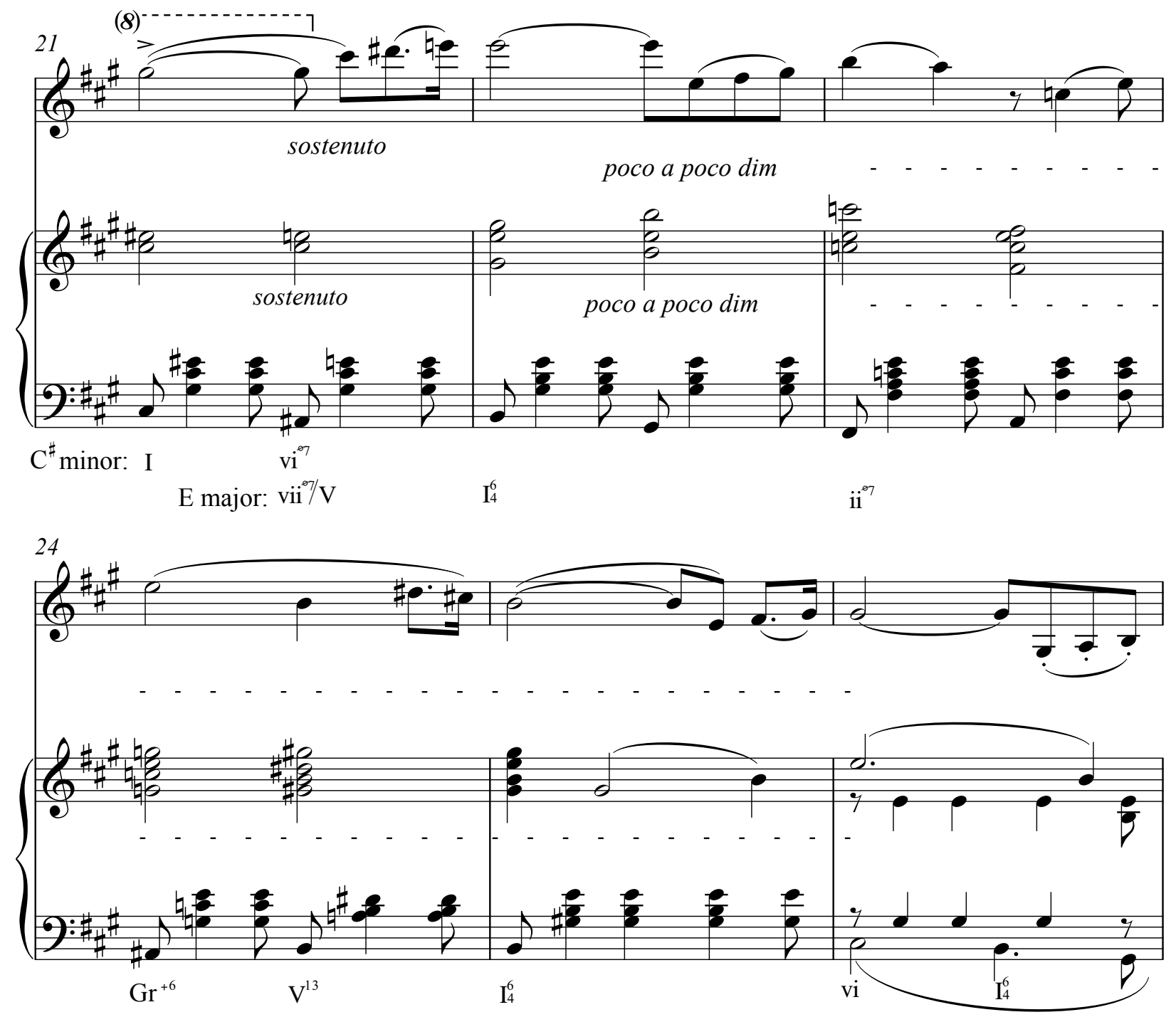

${ }^{64}$ The use of the term inverted, when applied to an augmented sixth chord, refers to when the raised $\hat{4}$ is in the bass instead of the lowered $\hat{b}$. This causes the interval between the two notes to be spelled as a diminished $3^{\text {rd }}$ instead of an augmented $6^{\text {th }}$. 
Example 3.14: Cont.

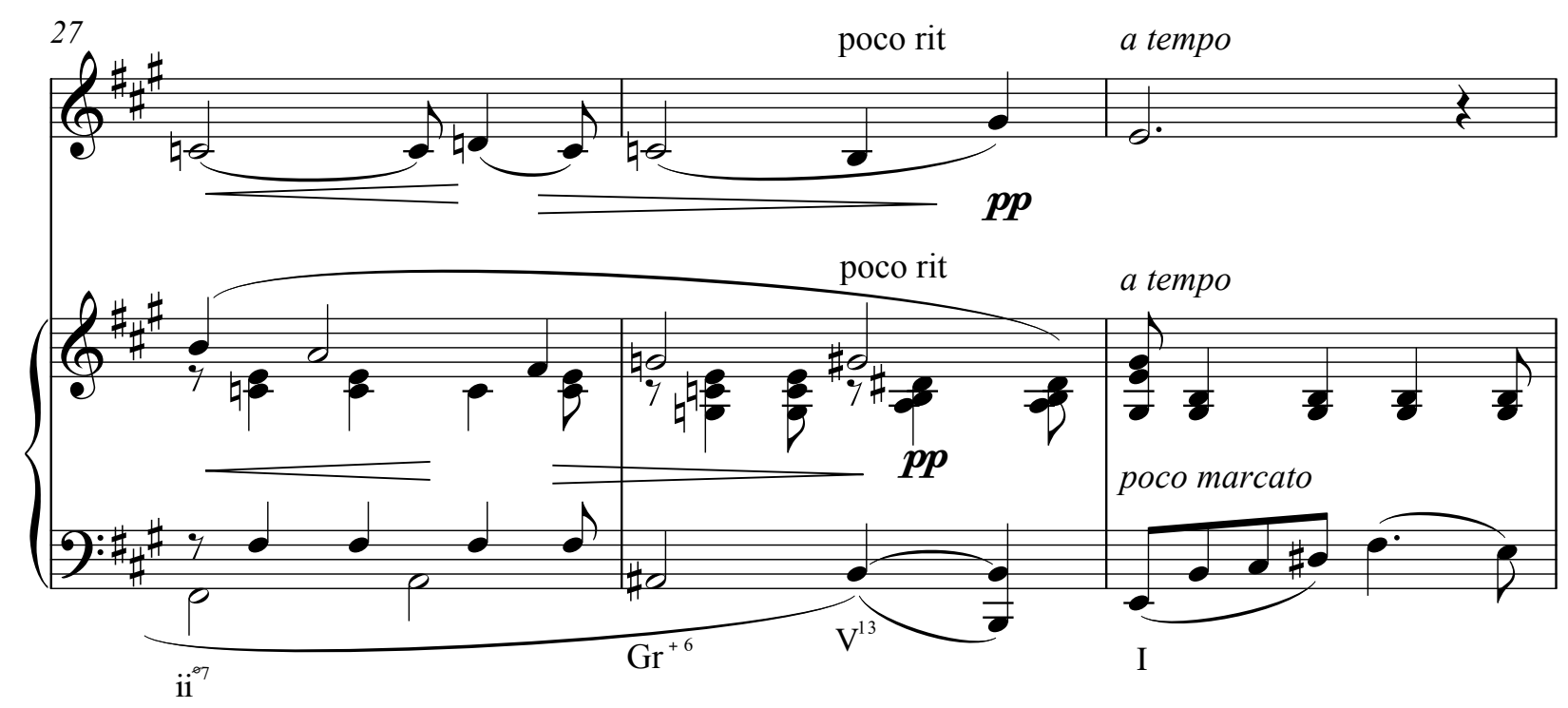

The B section is organized into three distinct parts based upon differences of melodic content, textures and harmonic progressions. These three sections are from mm. 29-43, mm. 4355, and mm. 55-73. Note the use of the opening melodic fragment in the piano interlude in mm. 29 and 31 (example 3.15). Throughout the first part of the B section, Beach alternates between virtuosic writing and long, lyrical melodic lines. Her virtuosic writing is characterized by faster rhythmic values and rapid changes in register. During the lyrical sections the primary melodic motive features prominently in both the violin and piano lines. The piano texture in the lyrical sections is one of the key differences between the A and B sections. Constant eighth note motion serves as the foundation for much of the B section. This can clearly be seen in example 3.15. In m. 39 there is another virtuosic figure in the violin, very similar to what was heard in m. 33. Both of the virtuosic figures occur over fully diminished seventh chords which serve as pivot chords to the new key areas, a feature that will be discussed at length later in the chapter. 
Example 3.15: Romance, mm. 29-43 65

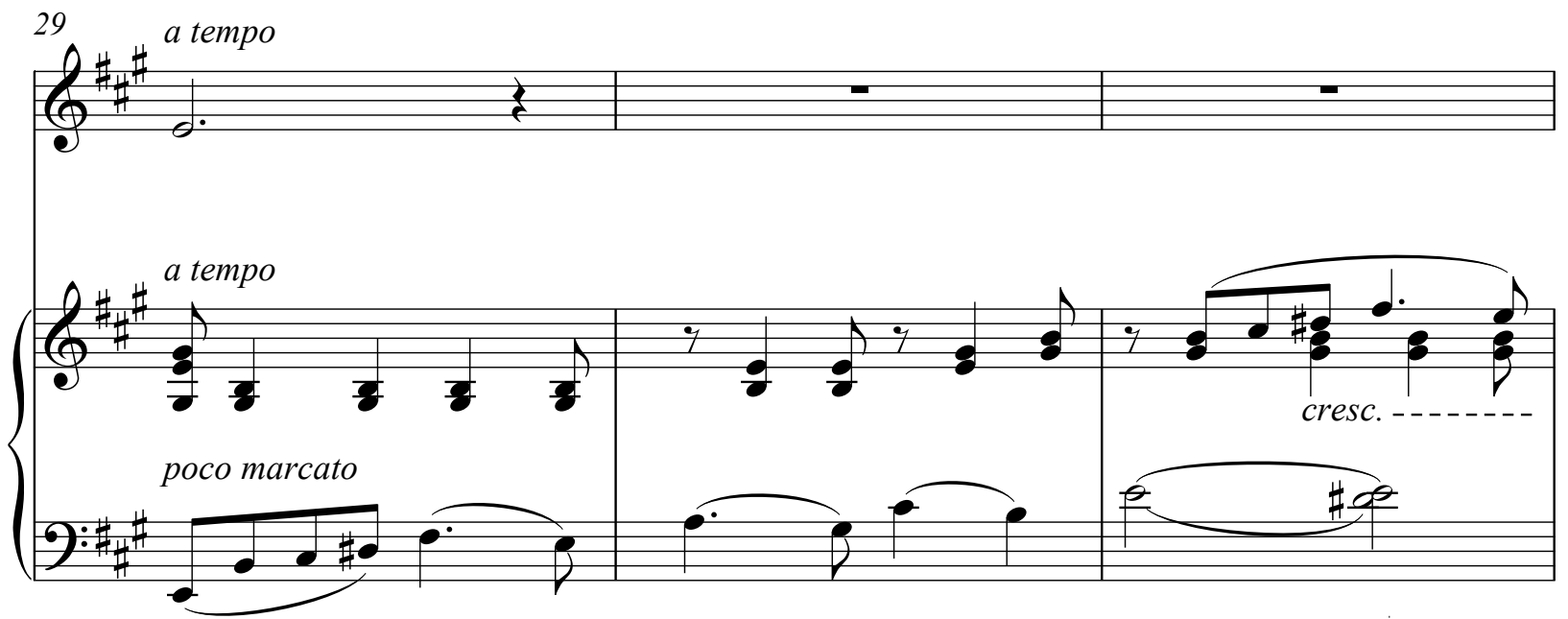

E major: I

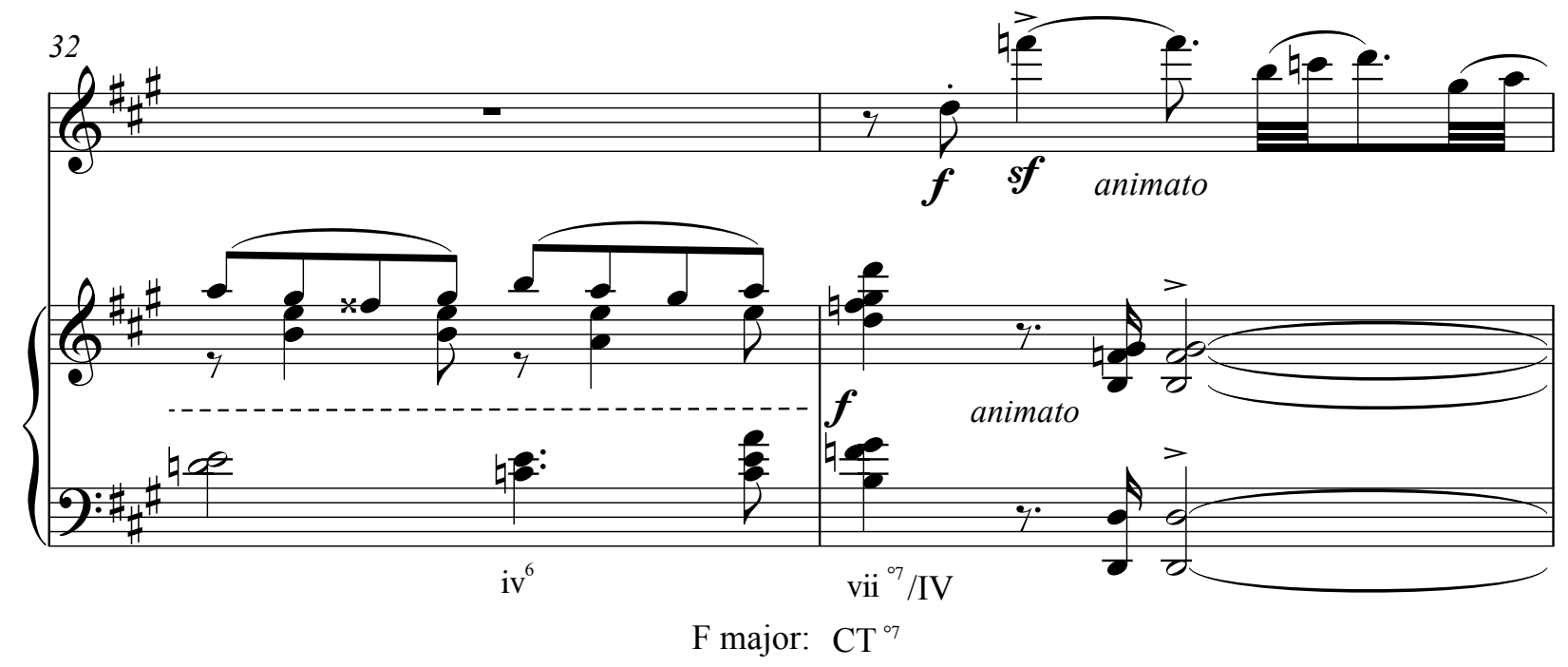

${ }^{65} \mathrm{CT}^{\circ 7}$ in the examples above stands for a common tone diminished seventh chord. This is a reinterpreted diminished seventh chord which while spelled correctly in one key area, is misspelled in the alternate key. In $\mathrm{m}$. 39 above the $\mathrm{D} \#$ and $\mathrm{F} \#$ are correct for the new key area of $\mathrm{F} \#$ major, but are misspelled for $\mathrm{F}$ major. 
Example 3.15 Cont.
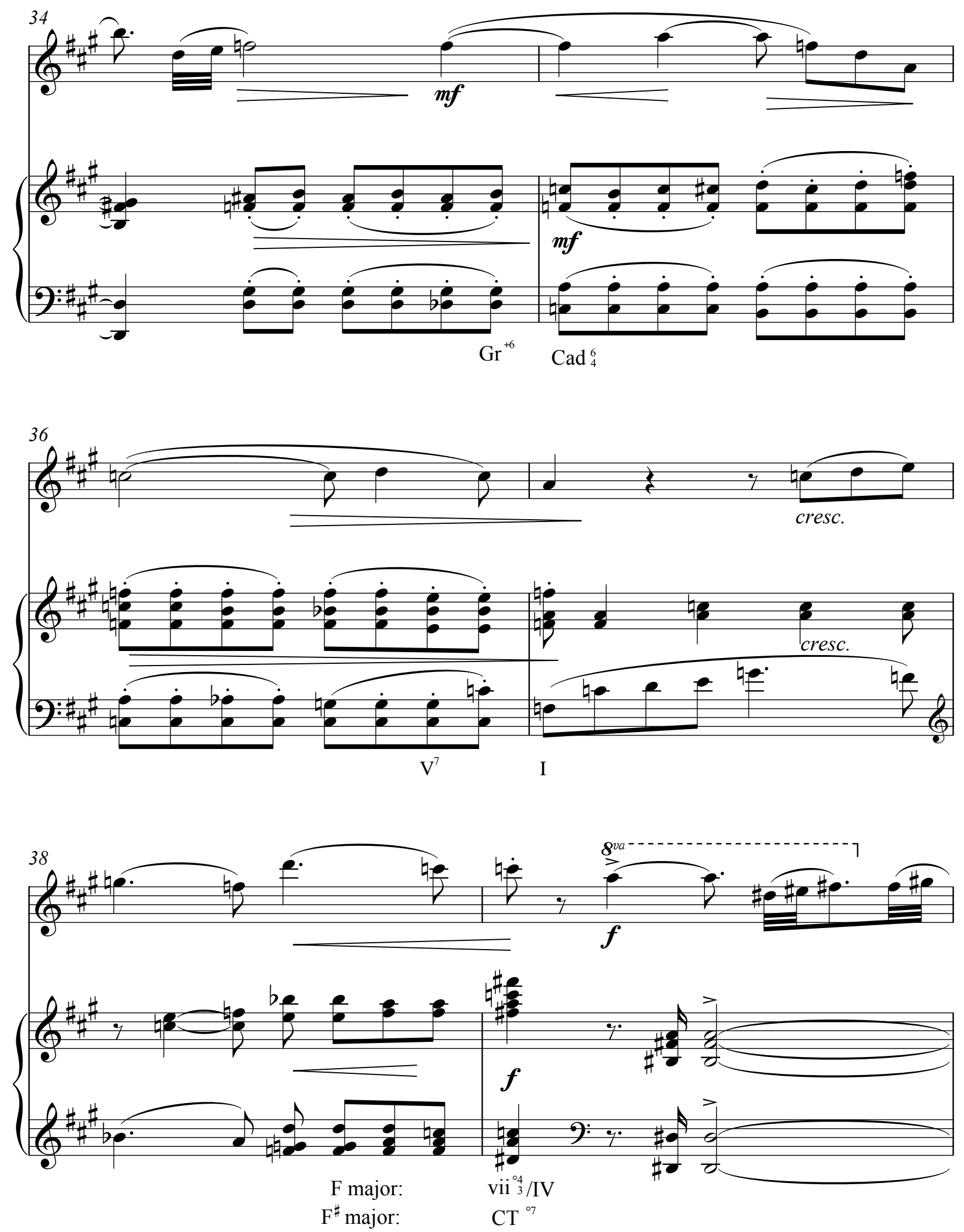
Example 3.15 Cont.
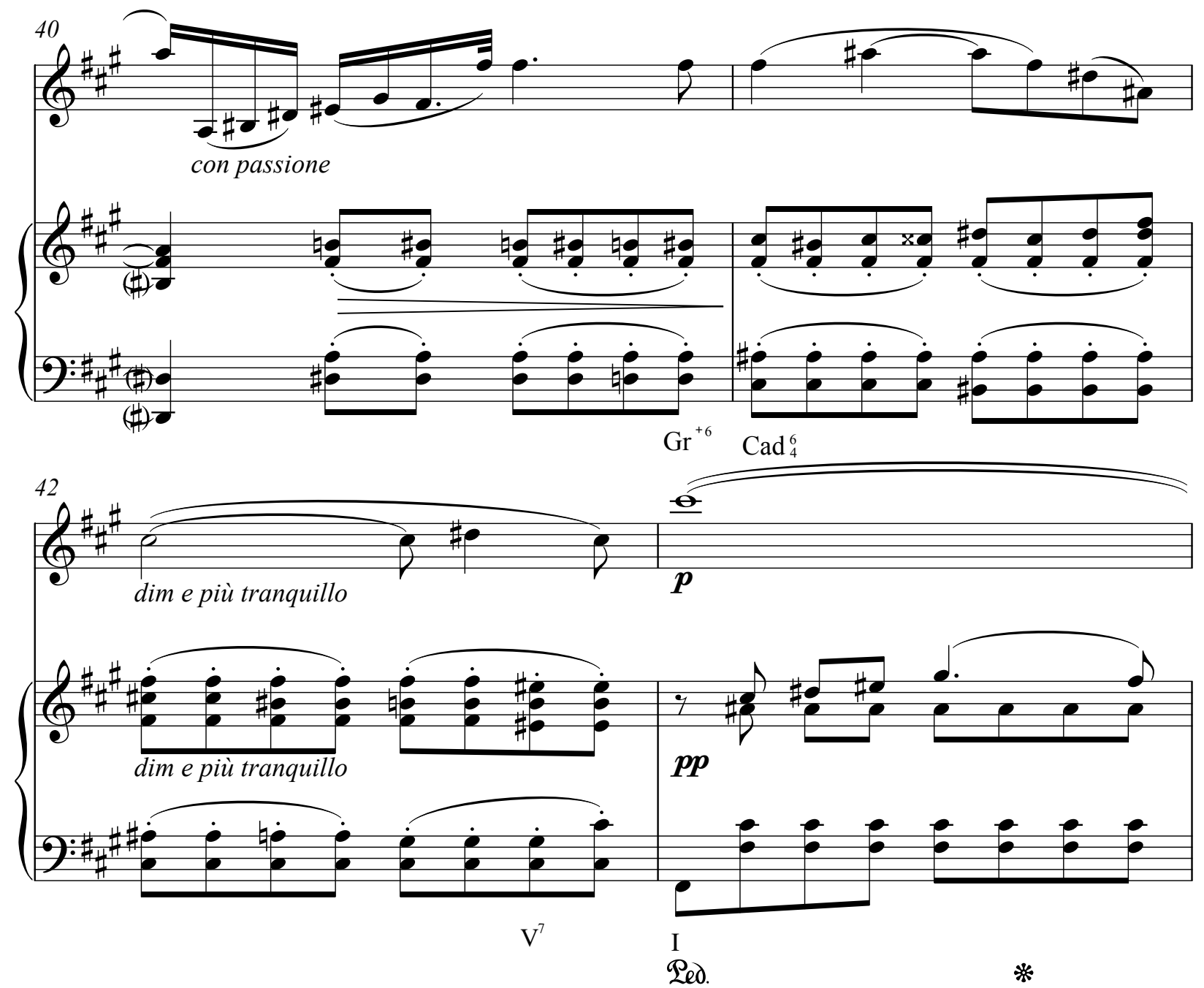

The second section within B starts on the downbeat of $\mathrm{m} .43$ at the perfect authentic cadence in

F\# major. For the first eight measures of this section, the piano has its longest melodic statement of the piece. The bass voice of the piano also contains the same rhythmic and melodic figure that the violin played in $\mathrm{mm} .33$ and 39 . In example 3.17 below, notice the primary melody in the upper voice of the piano with the contrasting figure in the bottom voice. From mm. 43-52 both the piano and the violin have important melodic content, which contrasts with the first section of 
B. Starting in $\mathrm{m} .51$ the violin begins to descends in register for the start of the third section in B, which begins at m. 55 .

Example 3.16: Romance, mm. 43-52
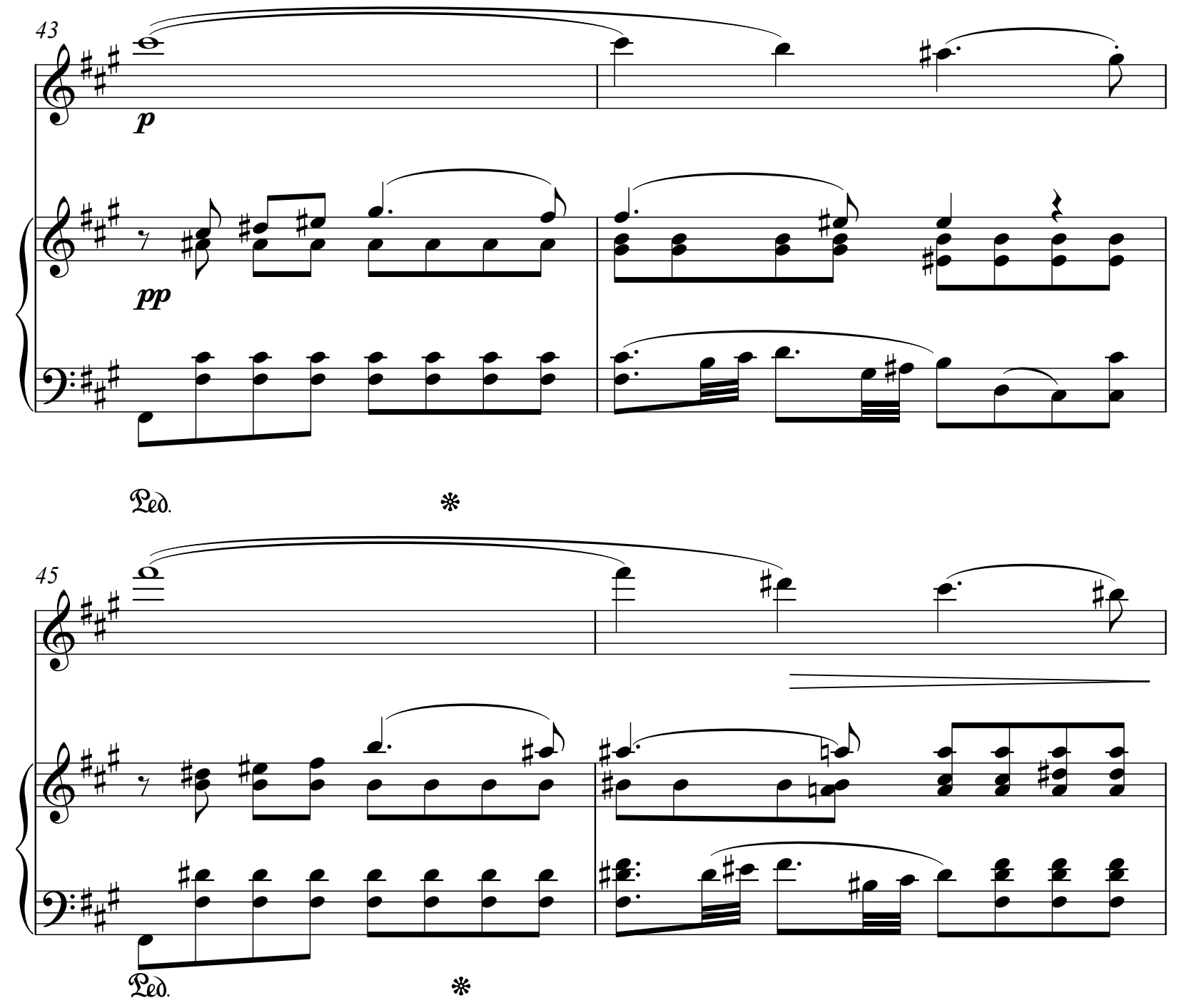
Example 3.16: Cont.
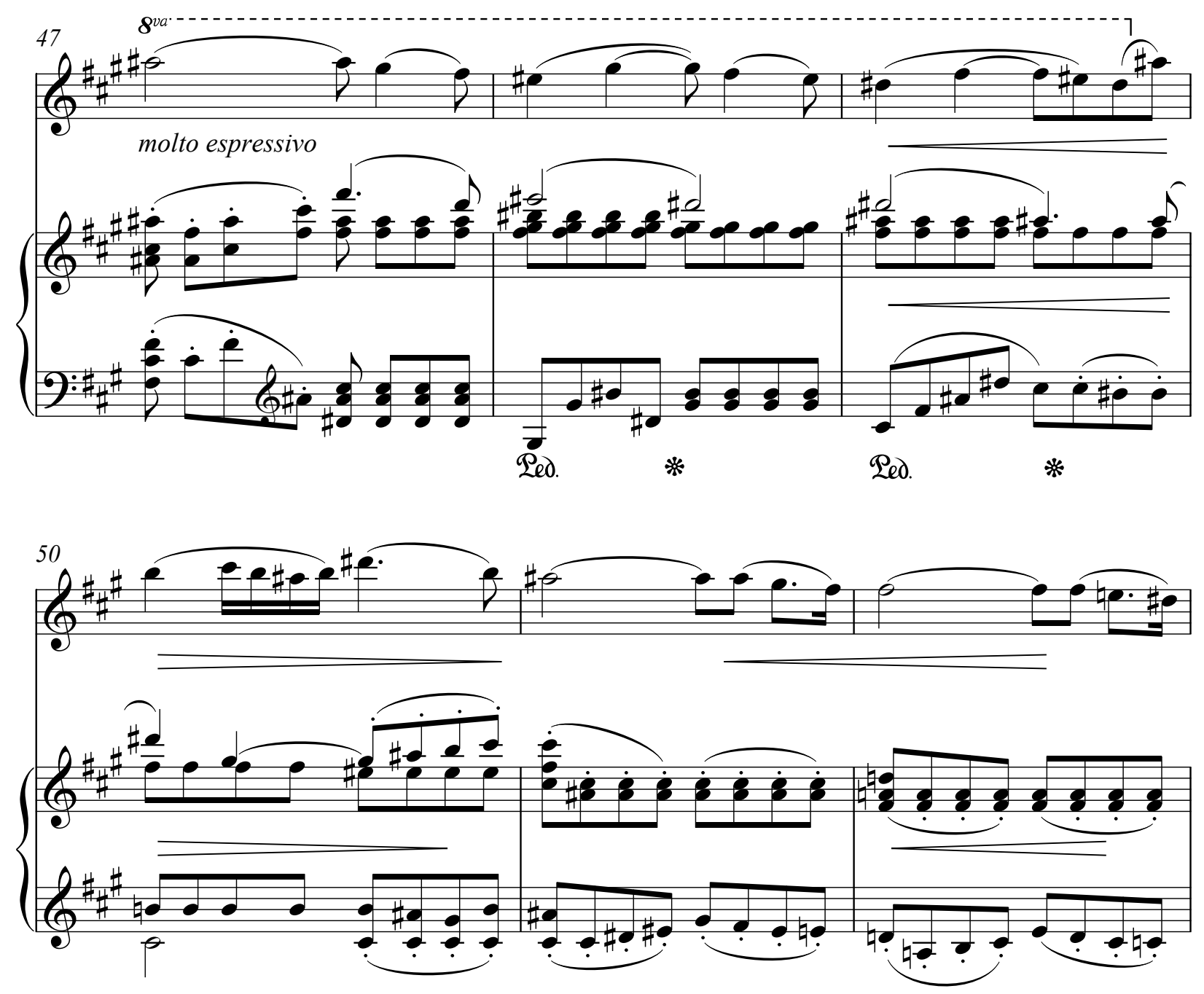

The third major section within B is distinguished by a sudden change in the piano texture.

In $\mathrm{m} .55$ the piano has a single line consisting of an arpeggiated fully diminished seventh chord.

The legato triplets are a drastic change from the staccato eighth notes of the previous section.

This continuous stream of triplets, which shows an increase in rhythmic activity, continues until m. 63. Then the piano switches to a dotted eighth/sixteenth note pattern (example 3.18), which is a development of the piano rhythm found in mm. 33 and 39 (example 3.15). 
Example 3.17: Romance, mm. 55-58

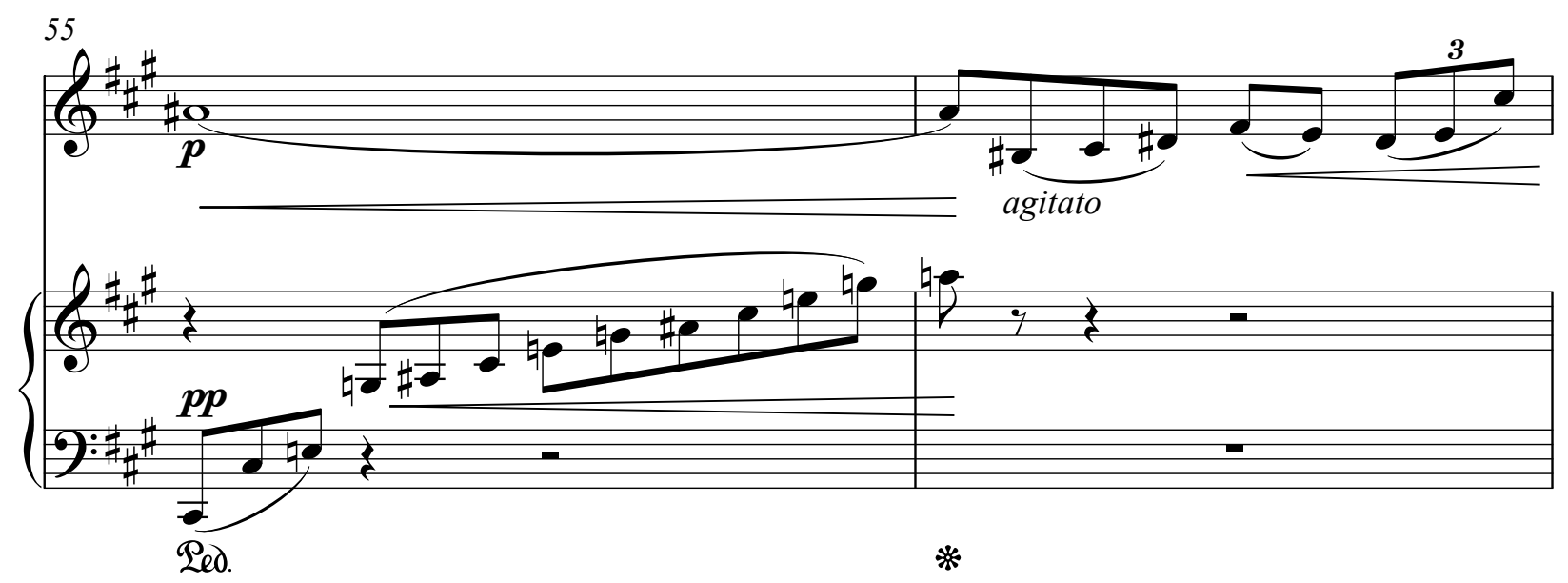

Example 3.17 Cont.

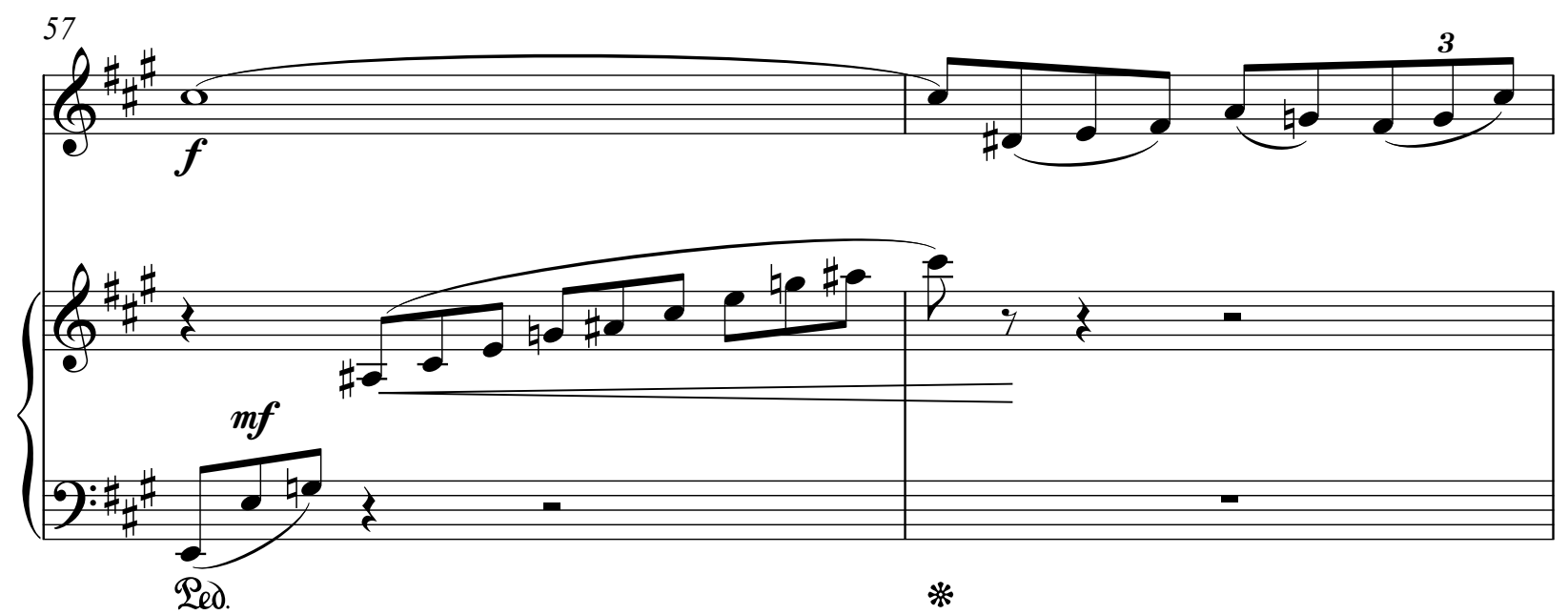

In this section Beach uses the primary melodic motive to create a sense of urgency. She begins by using it at the end of each measure (mm. 59-60) and then switches to every other beat (m. 61). This creates a sense of building that is completed at the $C \sharp 766 \mathrm{in} \mathrm{m} .62$. Not only is this the highest violin note of this section, but it is also marked with the loudest dynamic of the piece thus far. Additionally, she increases the density of the texture in the piano by splitting the activity

${ }^{66}$ In this document the numerical octave designation will follow the standard of the Acoustical Society of America which classifies middle $\mathrm{C}$ as $\mathrm{C} 4$. 
between the hands (mm. 59-60) then combining them (m. 61) to swell the music to fortissimo.

The overall increase in rhythmic activity, textural density, dynamics, and use of the melodic high point all make the climax of the B section very clear.

Example 3.18: Romance, mm. 59-63

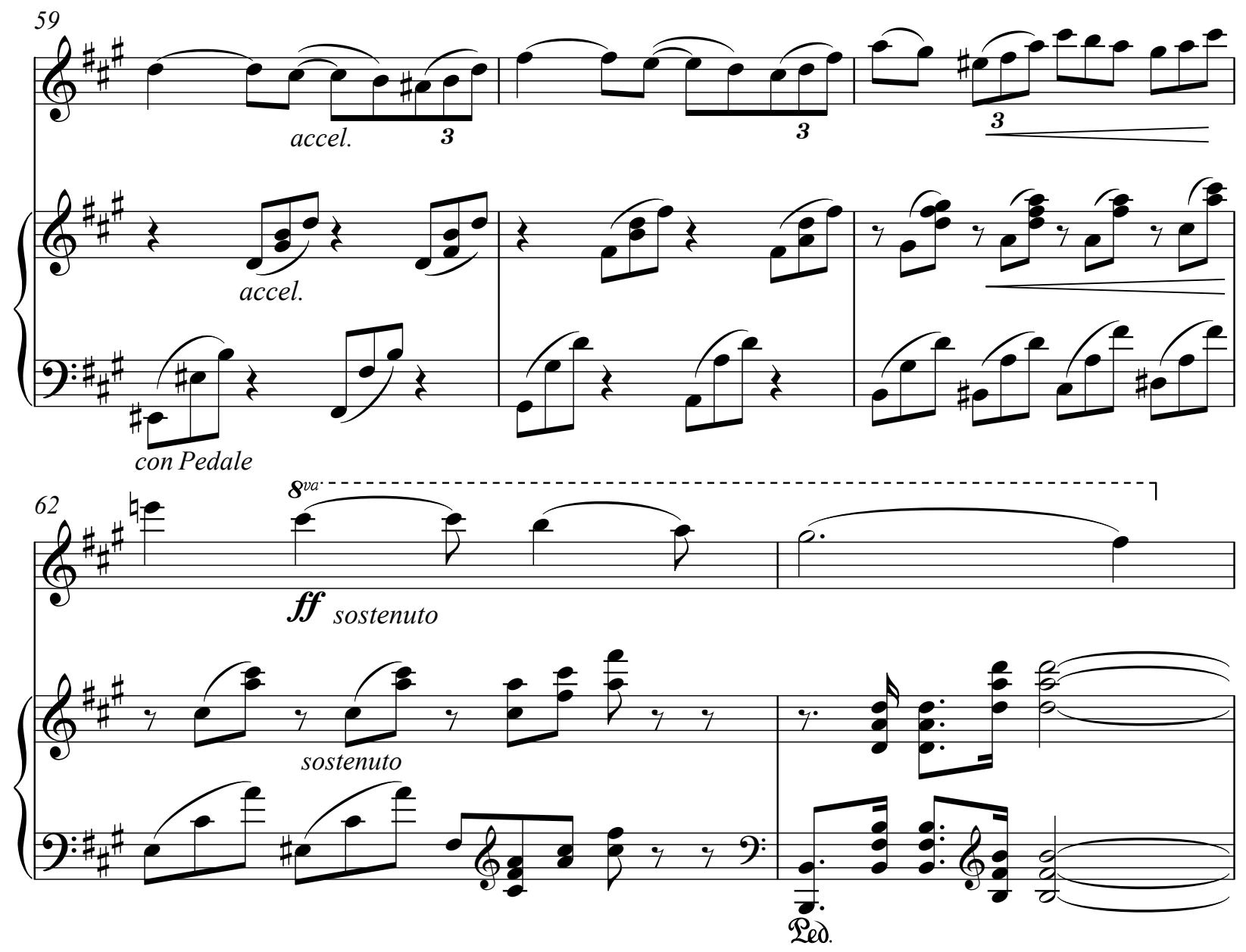

Following the climax of the $\mathrm{B}$ section (the $\mathrm{C} \sharp 7$ ), Beach uses the primary melodic motive to relax the register and character through a descending sequence starting in $\mathrm{m}$. 64 . The final repetition of the sequence occurs in m. 69 where Beach writes for the lowest register of the violin. She also marks for m. 69-71 to be played sul G. This technique leads to a darker, deeper sound than if the violinist had been permitted to switch between the G and D strings. To 
conclude the B section, the piano part is at its simplest rhythmically and texturally with primarily half notes and occasional moving eighth notes.

Example 3.19: Romance, mm. 64-73
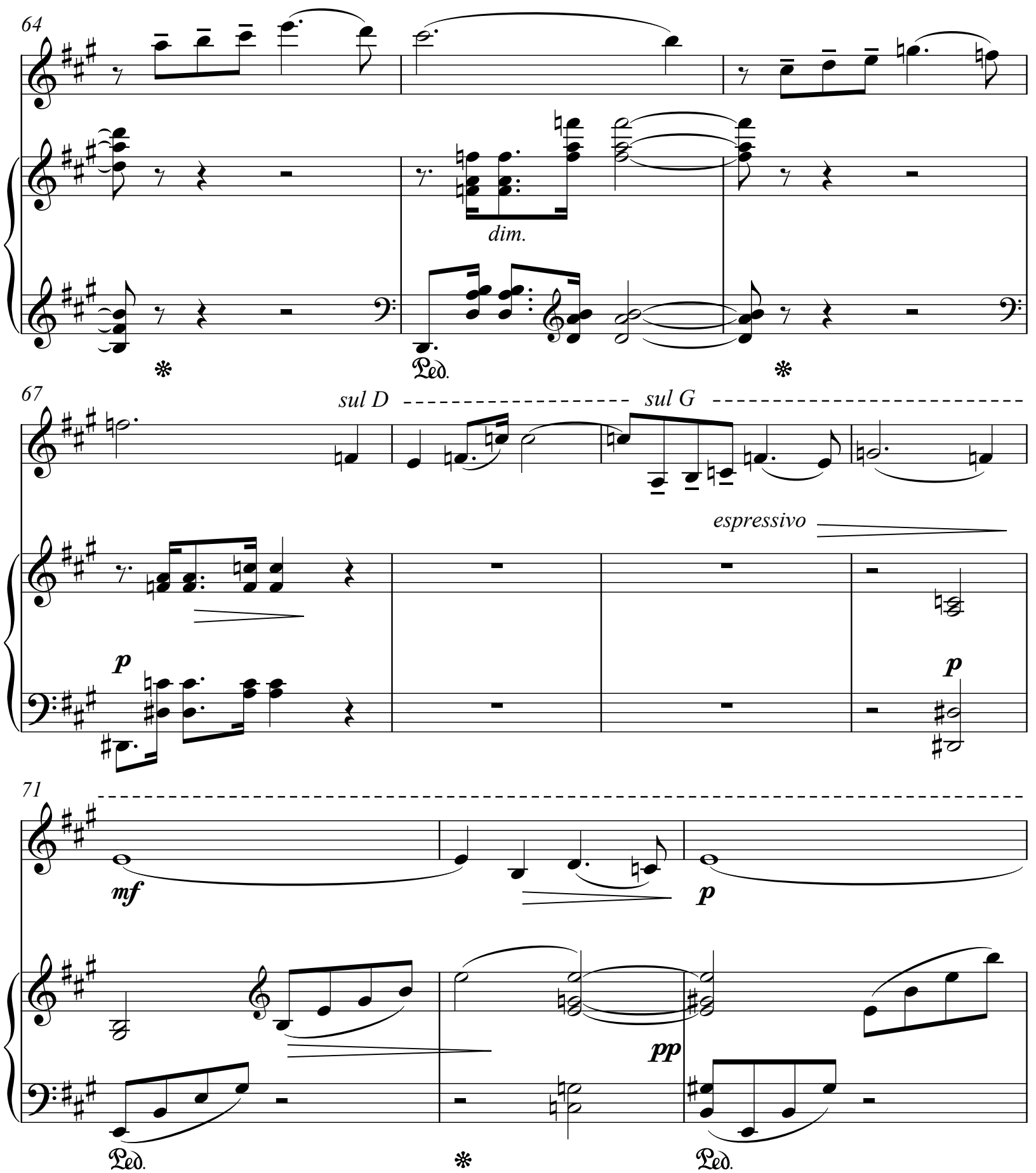
Harmonically, the B section begins in E major. In $\mathrm{m} .32$ she uses a modally borrowed A minor chord (iv) to precede a G\# fully diminished seventh chord, through which she will modulate to F major. The important tonal centers in $\mathrm{mm}$. 35-45 are F major (mm. 35-38) and F\# major (mm. 39-45). These tonal centers are established by the same progression, a $\mathrm{CT}^{\circ 7}-\mathrm{Gr}^{+6}$ Cadential ${ }_{4}^{6}-\mathrm{V}^{7}-\mathrm{I}$. The first progression appears in $\mathrm{mm} .32-37$ and the second in $\mathrm{mm} .39-43$. The final parallel is the violin melody in mm. 34-36 and mm. 40-42. All of the measures for this paragraph are covered in example 3.15.

Example 3.15 is a good illustration of Beach's use of chromaticism. Many chromatic notes occur, especially in mm. 34-36 and 40-42, yet these notes almost always have a diatonic function. For example, in $\mathrm{m} .34$, the B in the top voice of the piano functions as a neighbor note for most of the measure until the end where it becomes a passing tone. The same thing occurs in m. 35 as the top voice in the piano contains a variety of non chord tones which all have a clear function. The $\mathrm{B}$ is a neighbor note, the $\mathrm{C} \#$ a chromatic passing tone and $\mathrm{F}$ a at the end of the measure is an appoggiatura that resolves on beat four of m. 36. Although Beach uses chromaticism extensively within this passage it is important to note the underlying harmonic progression, which the chromatic notes only decorate. This is a contrast to the linear chromaticism seen in composers such as Wagner and Chopin. In those cases the notes are moving chromatically, in a similar fashion to the example above, however without a clear underlying diatonic progression. One of the clearest examples of this is from Chopin's Prelude in E minor. It begins on $\mathrm{i}^{6}$ chord, however the next chord serving a clear diatonic function within the progression does not occur until $\mathrm{m}$. 9. This is followed in $\mathrm{m} .12$ by a half cadence. While some of the chords in-between could be assigned a roman numeral, they do not function within a 
conventional tonal progression. This is the difference between Chopin's linear chromaticism and the chromaticism that Beach chose to use when writing the Romance.

Example 3.20: Frédéric Chopin's Prelude in E Minor, mm. 1-12

\section{Prelude 4 in E Minor}

Largo

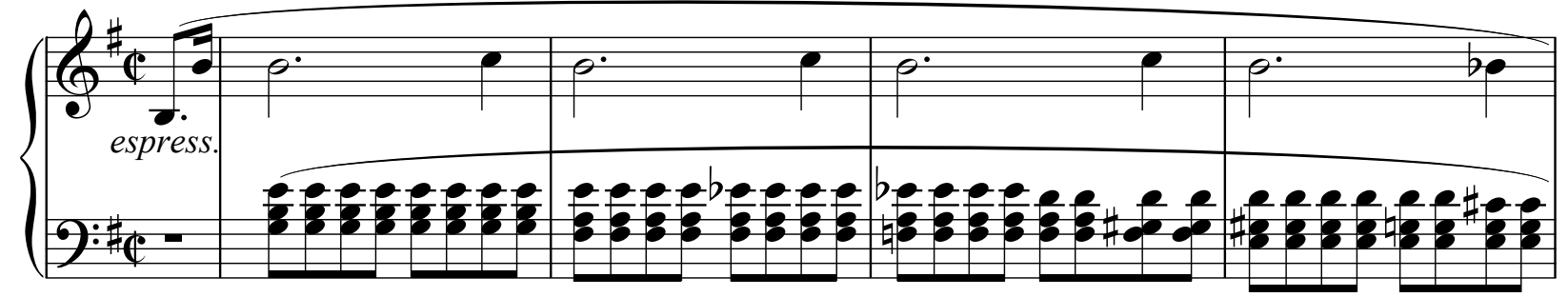

E minor: $\quad i^{6}$
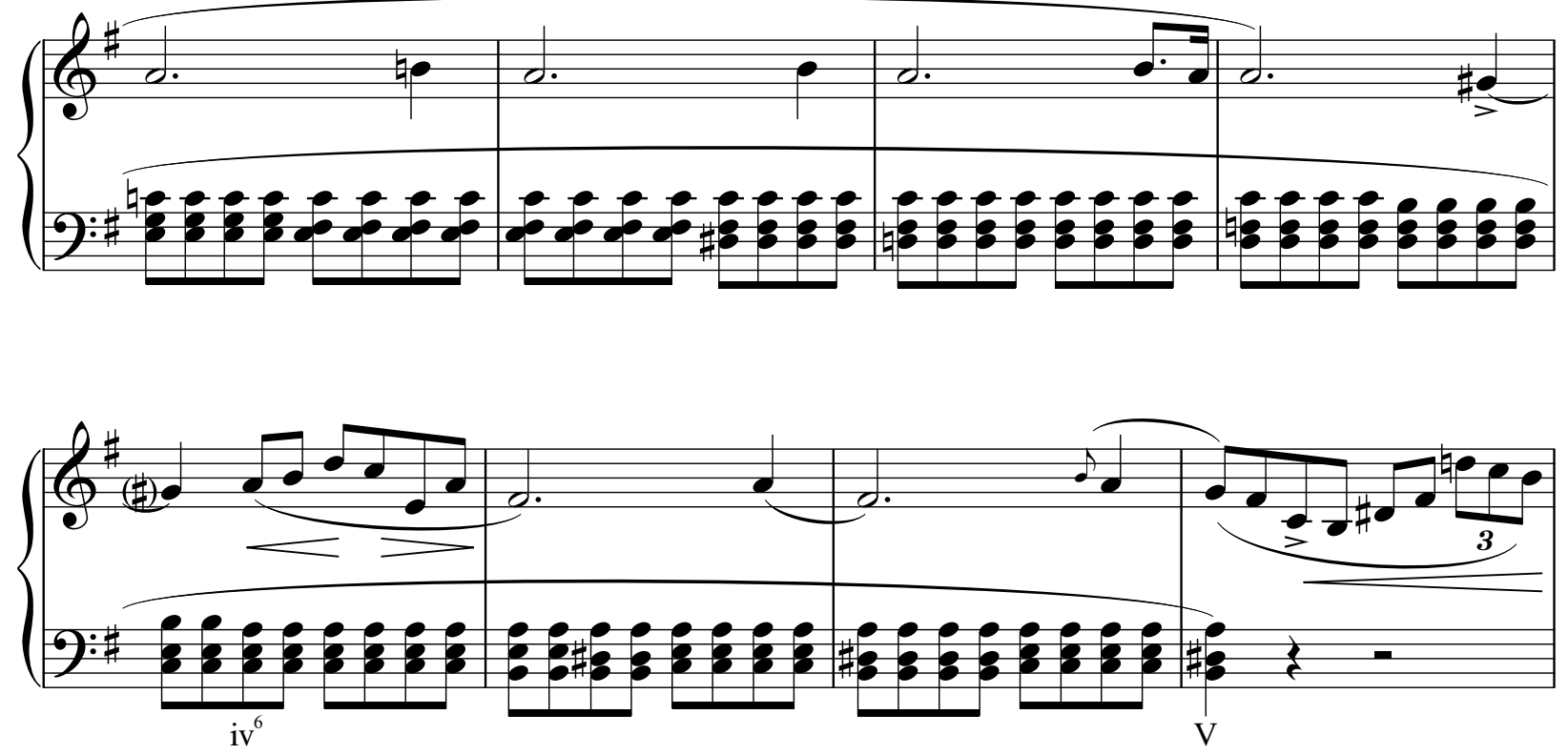
In mm. $55-58$ there is an arpeggiation of an $A \sharp^{\circ 7}$ chord (example 3.17). This is an expansion of the use of the fully diminished seventh chords seen throughout this piece, most recently in $\mathrm{m} .39$ (example 3.15). In the next section the music very temporarily tonicizes B minor. The $A \sharp^{\circ 7}$ functions as vii ${ }^{\circ 7}$ of the new key area. In mm. 57-62 the bass notes move chromatically from the $\mathrm{E}$ of the $\mathrm{A} \sharp^{07}$ up a 9 th to $\mathrm{F} \#$, the dominant of $\mathrm{B}$. The rhythm of this ascent speeds up gradually throughout these measures. At first the bass note movement is two measures apart in $\mathrm{mm}$. 57-59. Then it is two beats apart in $\mathrm{mm}$. 59-60 and finally it moves on every beat in mm. 61-62. This all resolves in $\mathrm{m} .63$, where there is a B minor chord with an added seventh. The added seventh indicates that while this is a point of arrival, it is also a point of departure. This arrival in m. 63 also coincides with the change in rhythm as noted earlier.

Example 3.21: Romance, mm. 57-63

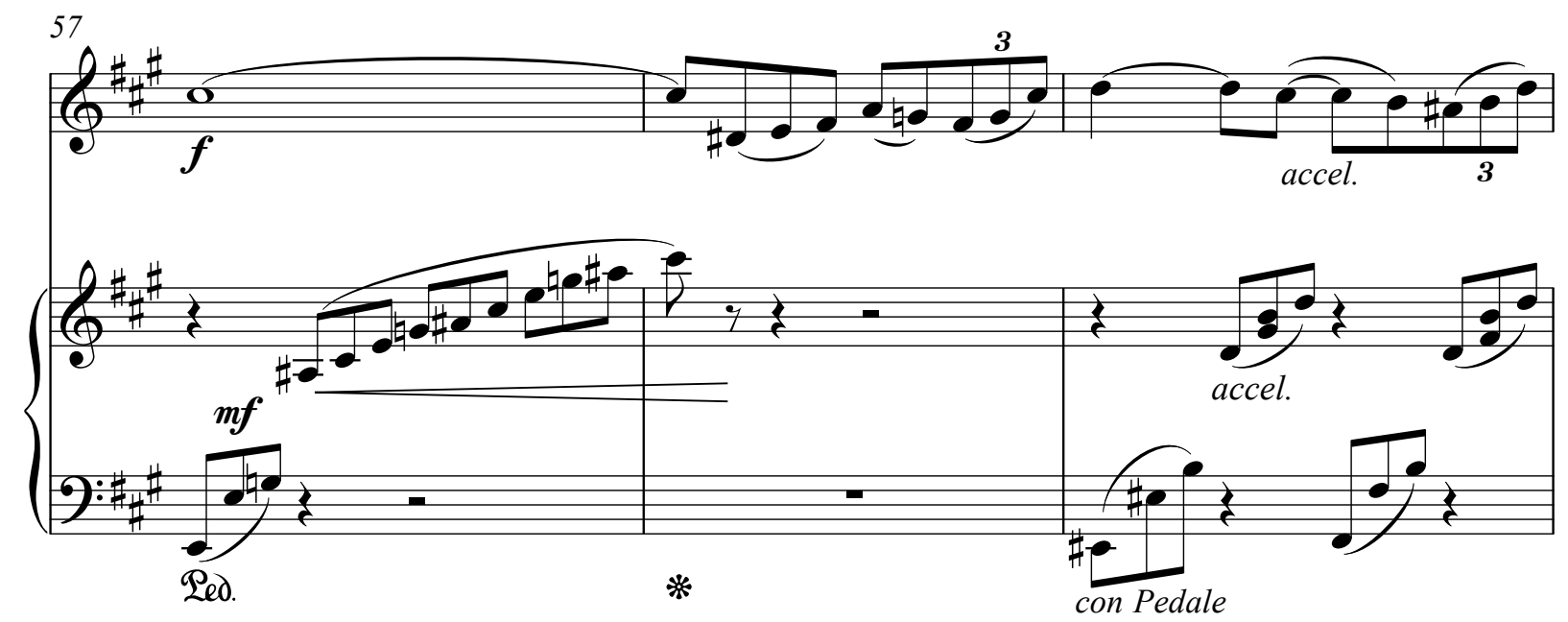

B minor: $\quad$ vii $^{\circ 7}$ 
Example 3.21: Cont.
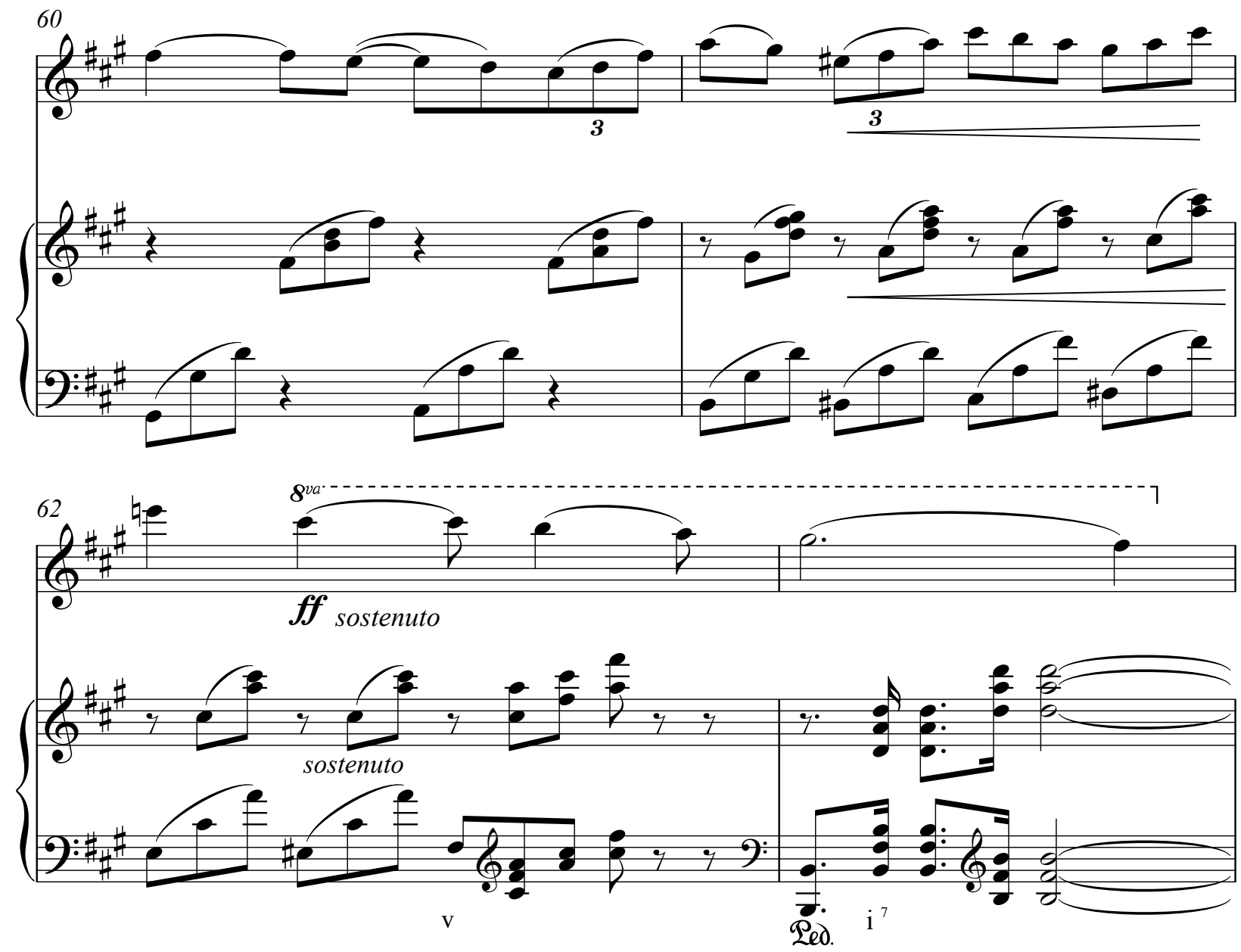

Throughout mm. $67-75$ there is a prolonged dominant preparation for the eventual return to A major. Beach mostly alternates between chromatic chords (which still have a diatonic function) and $\mathrm{E}$ major. This passage contains an unusual resolution of a $\mathrm{Gr}^{+6}$. In $\mathrm{m} .74$ there is a traditionally spelled $\mathrm{Gr}^{+6}$, with $\mathrm{E}$ as the tonic pitch. However, instead of resolving to the dominant B major, or a $\mathrm{I}_{4}^{6}$, it resolves directly to a root position E major triad. 
Example 3.22: Romance, mm. 67-75
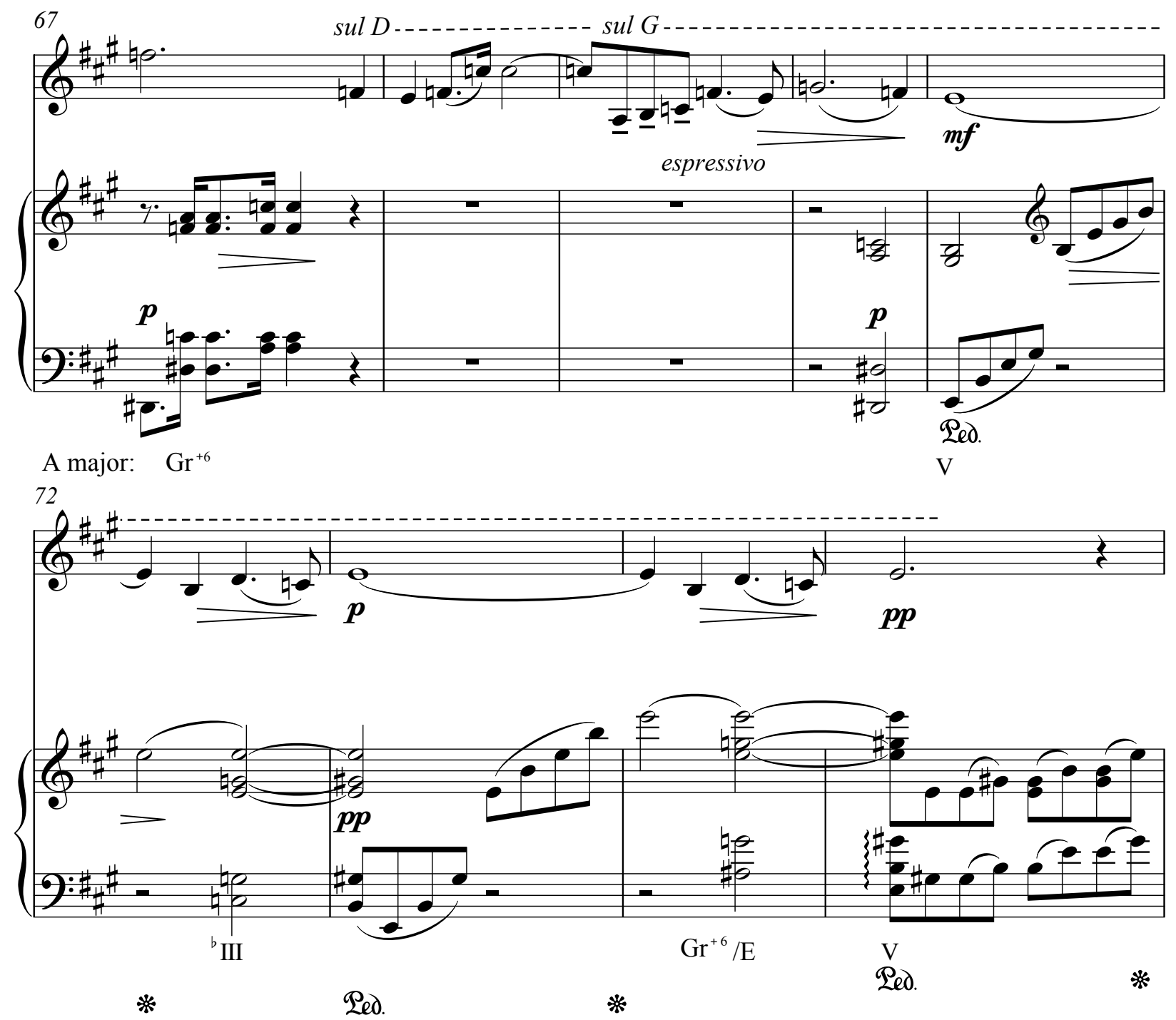

A unique aspect of the final interlude, which begins in $\mathrm{m} .75$, is the addition of the violin's pedal tone. The interlude, from $\mathrm{mm}$. $75-78$, is a continued dominant preparation for the return to A major. There is one measure of $\mathrm{C} \sharp$ minor (m. 77), showing Beach’s preference for third relationships. 
Example 3.23: Romance, mm. 75-78

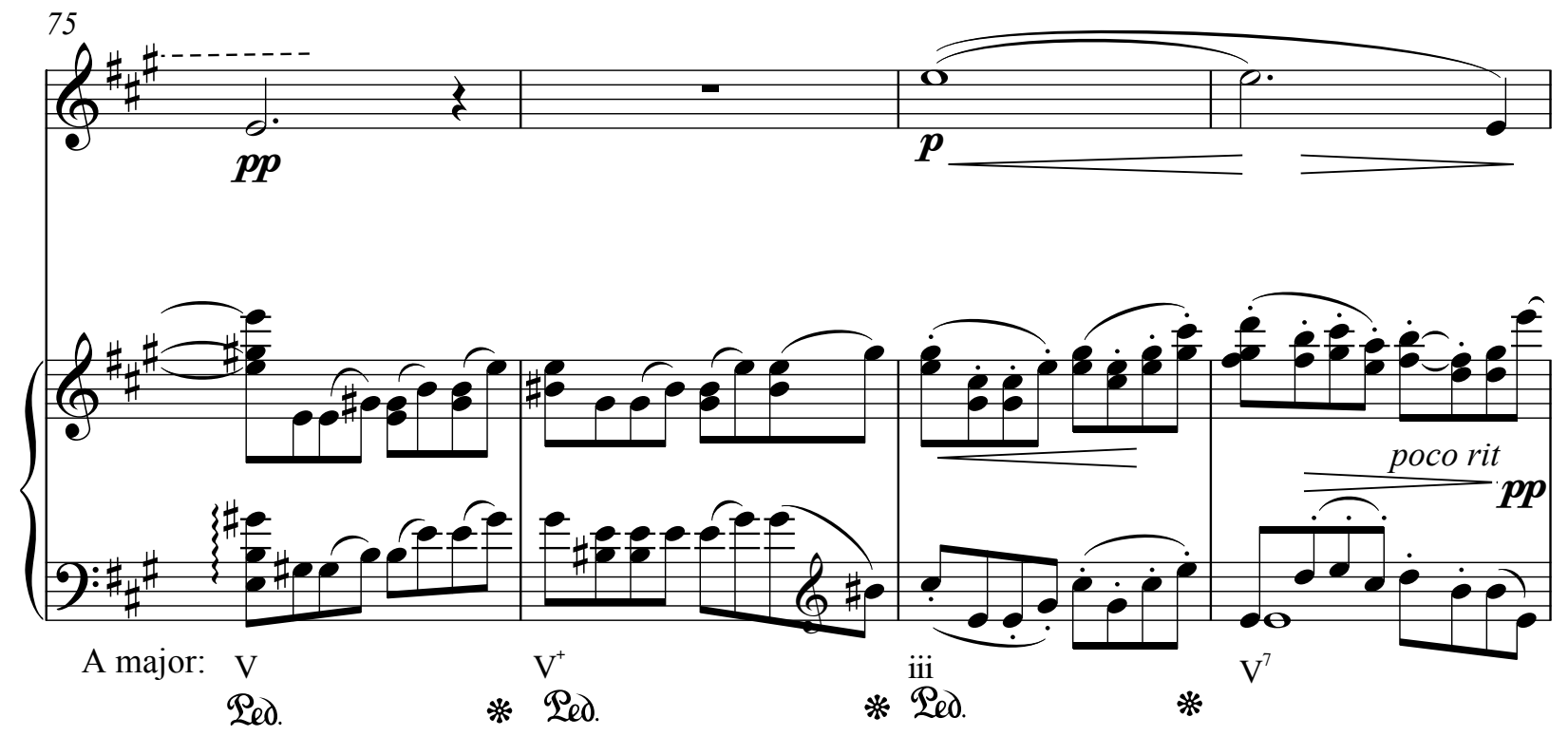

The A' section can be divided into two major sections. Mm. 75-105 make up the first section and then 105-end constitute the second section. This division is made clear by a variety of factors. First, there is a very clear perfect authentic cadence in A major. Secondly, there is a ritenuto molto leading into $\mathrm{m} .105$ and an a tempo at m. 105. Thirdly, the melody passes to the piano with the violin merely playing a long held note, which is a change from the previous phrase. Finally, there is also a diminuendo at $\mathrm{m} .105$ which marks the beginning of the end. Throughout the entire final section there is not a single dynamic marking above piano. 
Example 3.24: Romance, mm. 103-105

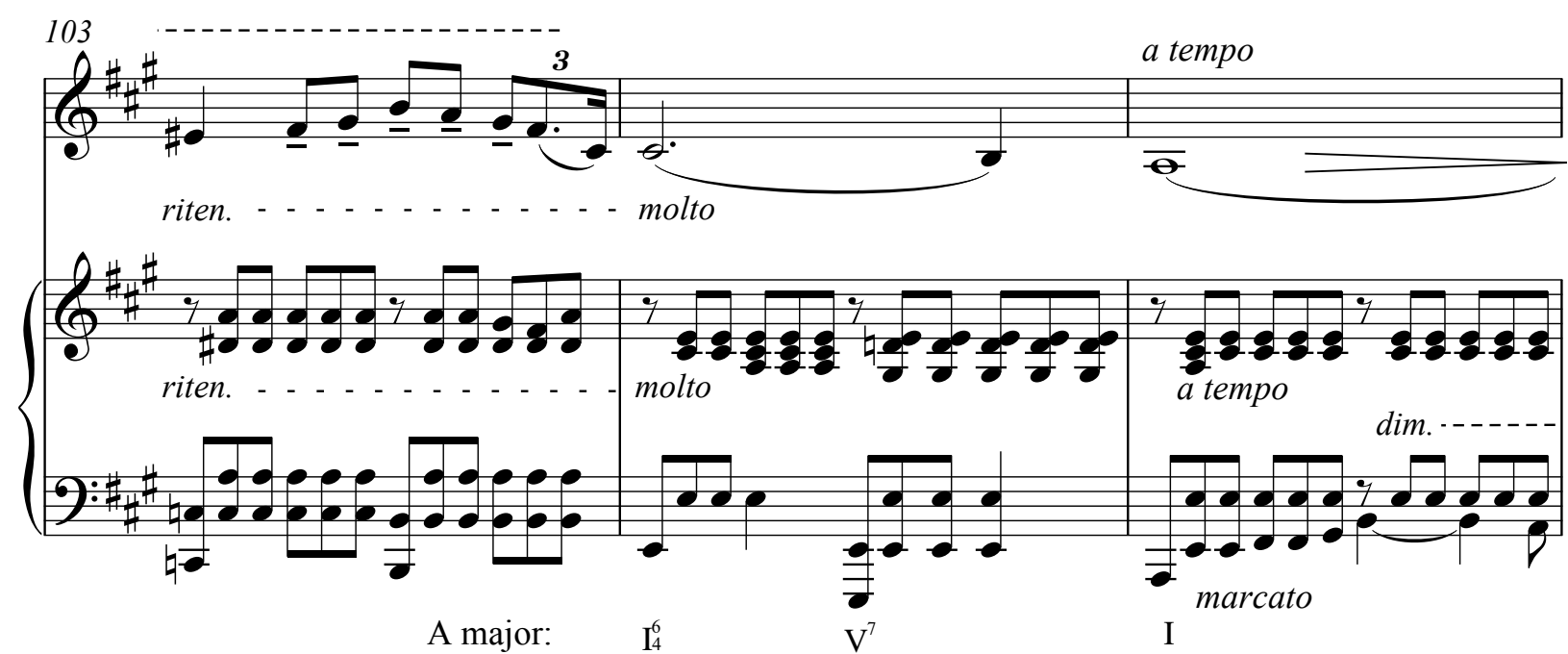

Melodically the first part of A' begins with an eight measure phrase in the violin line

followed by the piano having the melody in the top voice. It can be hard to see the melody in the piano so the note heads below have been altered to draw attention to the melodic notes.

Example 3.25: Romance, mm. 87-91

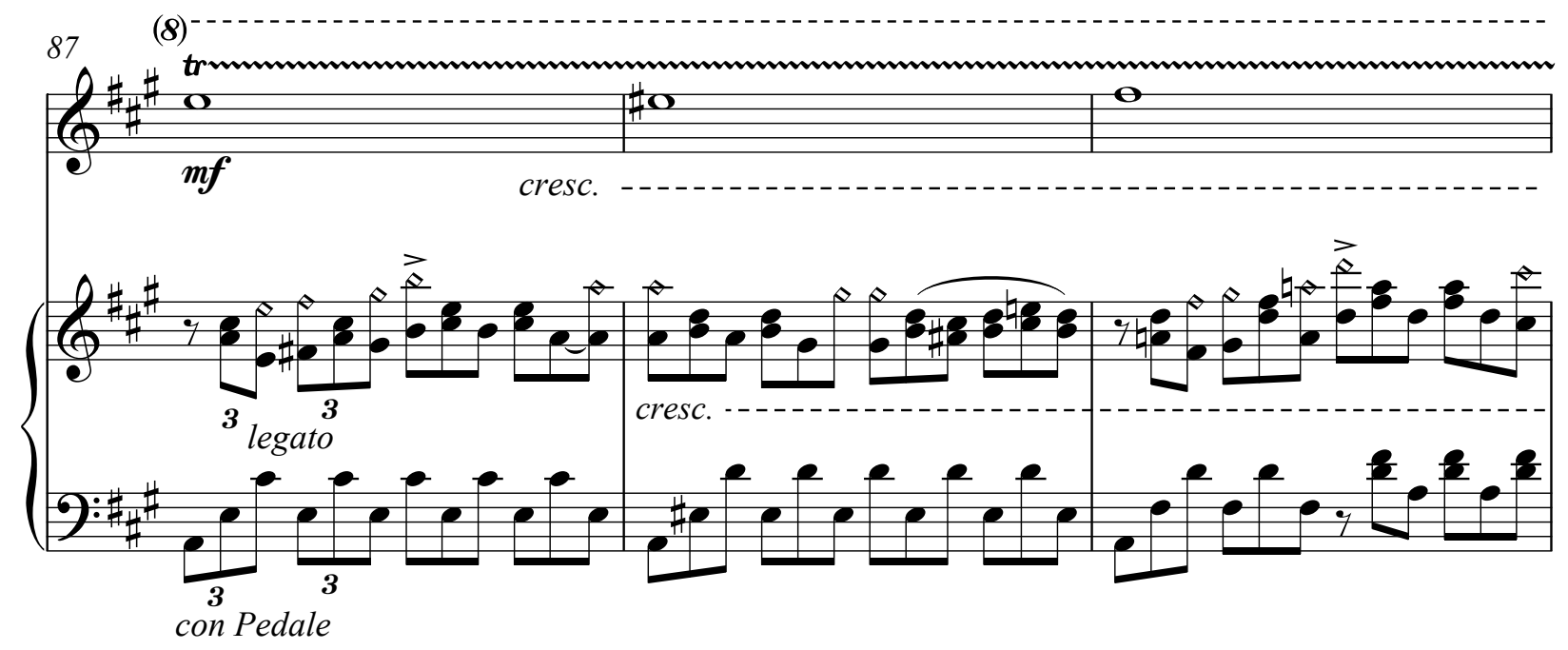


Example 3.25: Cont.

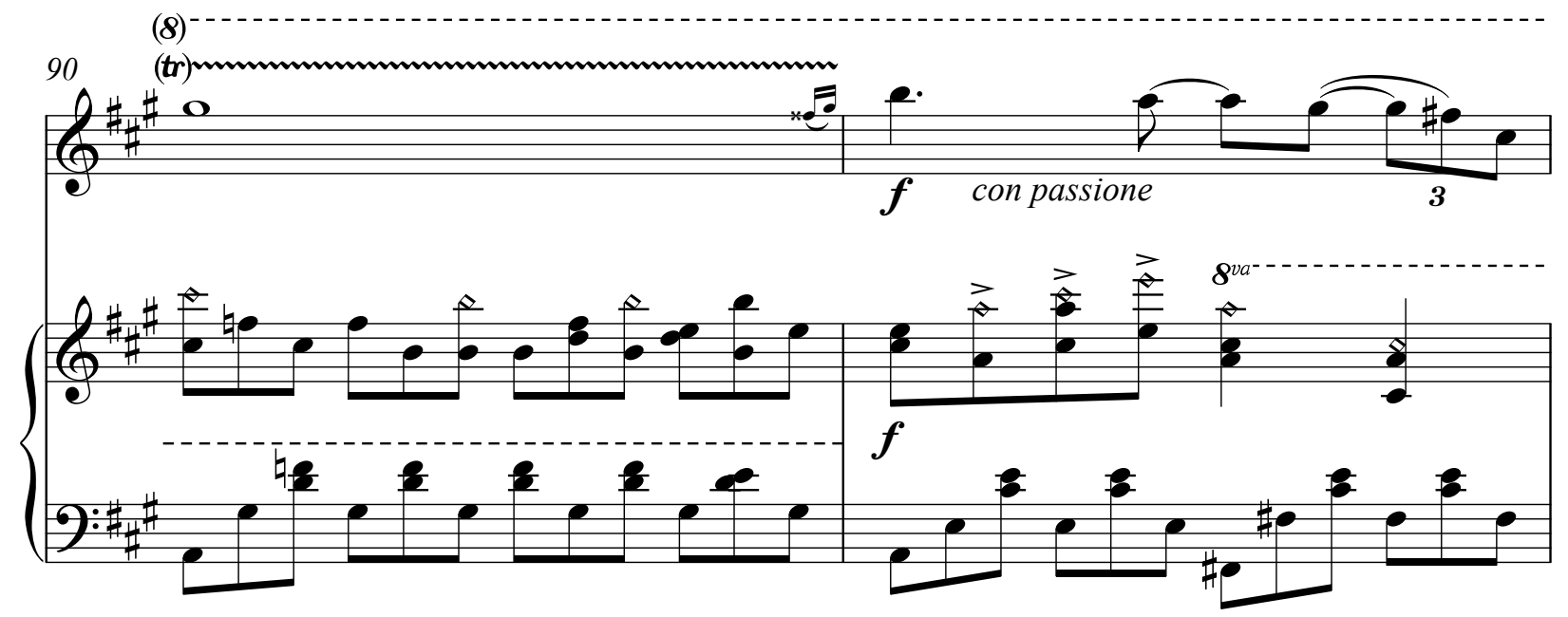

The A' section begins with the primary texture of B (constant staccato eighth notes), but

using a register in the piano accompaniment yet unexplored in the piece. This section is beautiful in the contrast between the violin and piano's registers. It allows the violin melody to be fully heard beneath the delicate sounding chords in the piano's upper register.

Example 3.26: Romance, mm. 79-81

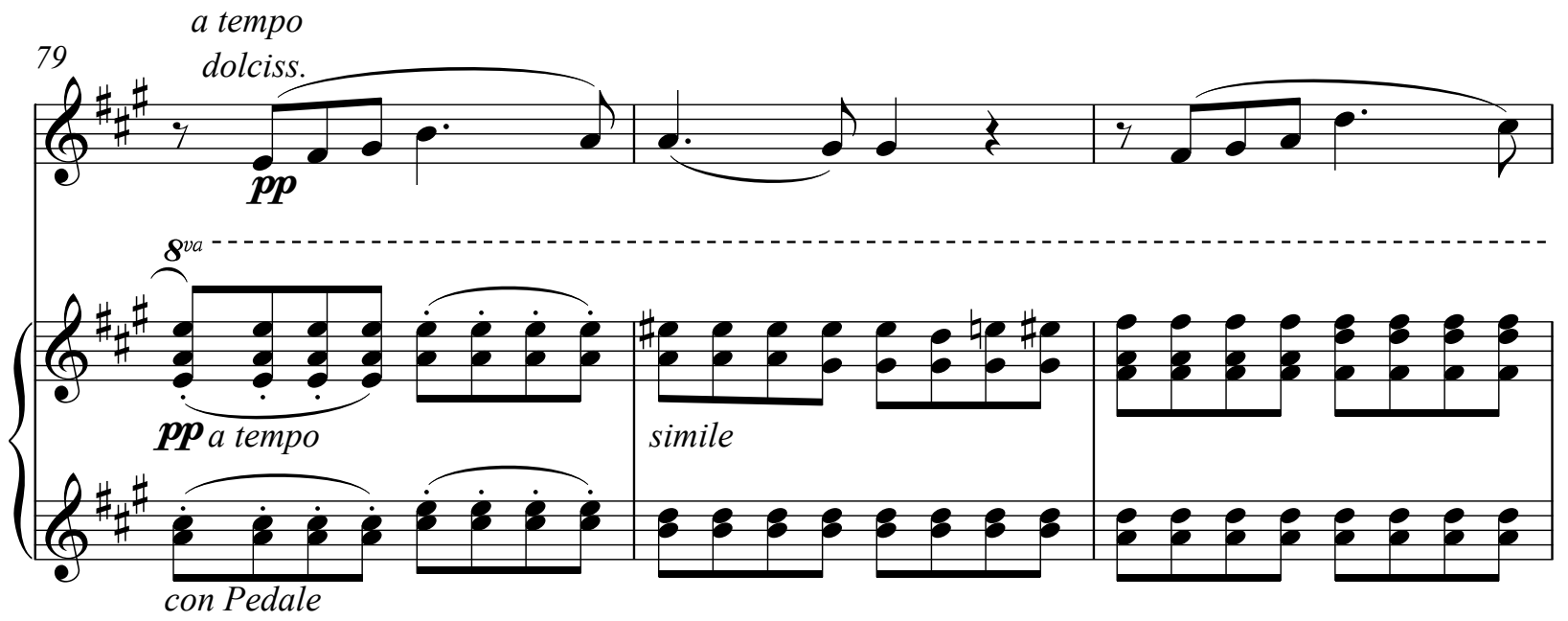


The start of the A' section employs more chromatic chords. Even with the chromaticism, there are still plenty of reminders of the home key of A major. For example, there is an A major chord every few measures, including a V-I progression in $\mathrm{mm}$. 86-87. Also, there is an A in every chord in mm. 79-87, through a variety of voices. In effect, this creates a pedal tone, though it is somewhat obscured because of the movement between voices. Starting in $\mathrm{m} .87$ the tonic pedal is in the bass voice, helping to clear up any doubts about the key. An interesting feature is that $\mathrm{mm} .79-85$ and $\mathrm{mm} .87-93$ have very similar chord progressions. These two phrases are suggestive of Amy Beach's self-education in composition. As noted in Chapter 2 she was denied formal composition lessons throughout her life and instead had to embark upon a course of selfstudy. She took that charge very seriously and amassed a considerable library of scores and books. Below, in mm. $79-83$, there is a progression of I $-\mathrm{CT}^{07}$-IV-vii $-\mathrm{I}$ all during a tonic pedal. This is a progression which can be traced back to Bach. When comparing example 3.30, from Bach's Well-Tempered Clavier I, to the beginning of example 3.31 it is easy to see the similarities. Example 3.27, like example 3.28 contains a tonic pedal over which there is a progression consisting of I, IV or iv, and vii chords. As chord function is more important than inversion, all labels below do not account for any inversions (example 3.27). 
Example 3.27: J.S. Bach's Praeludium VI, mm. 1-2

\section{Praeludium VI}

J.S. Bach

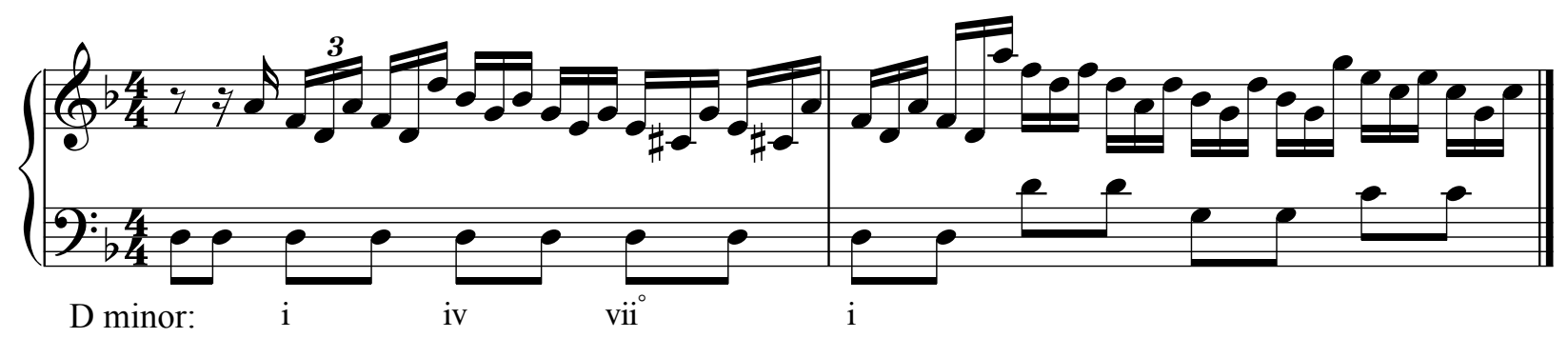

Example 3.28: Romance, mm. 79-93

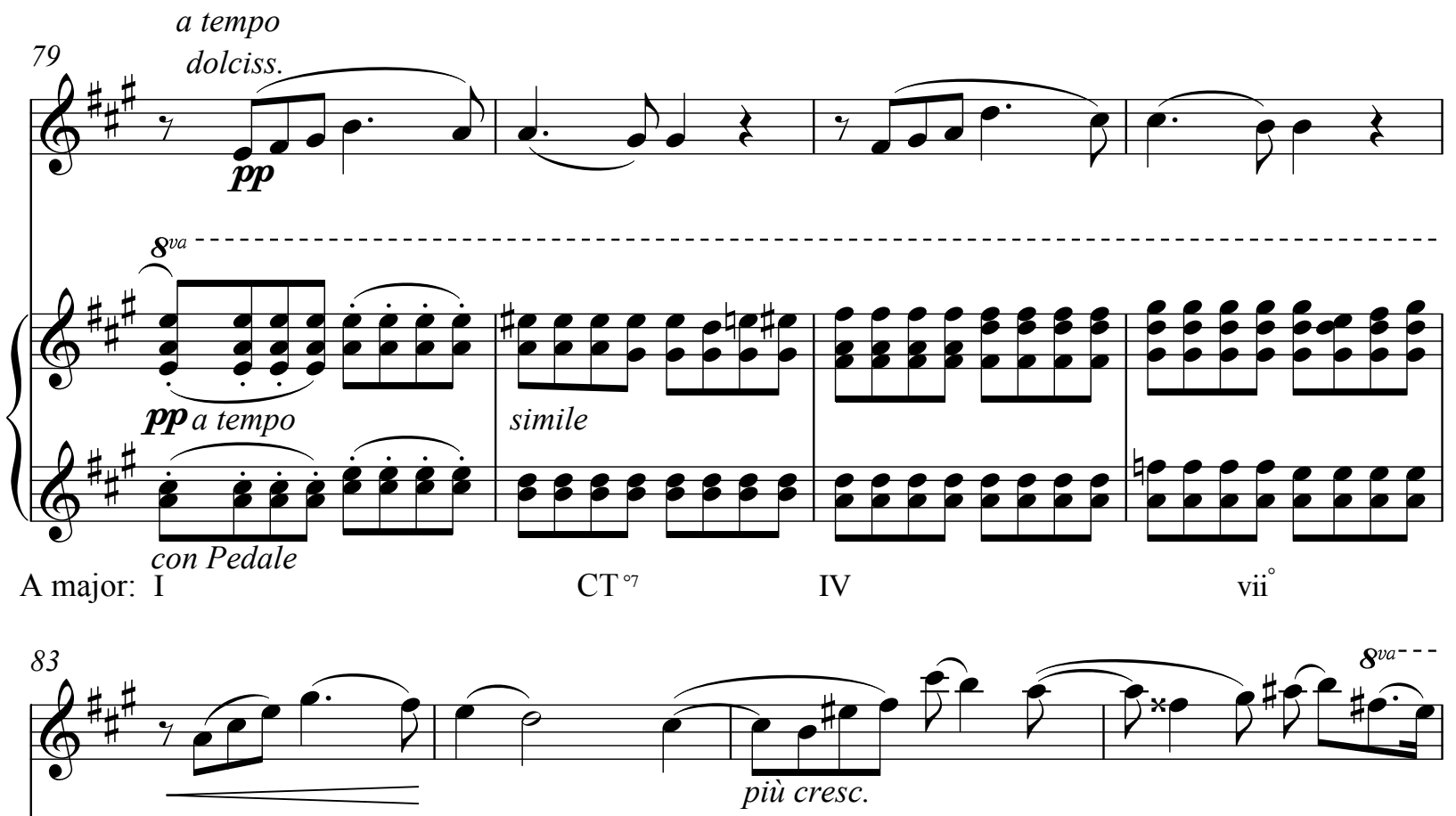

(8)

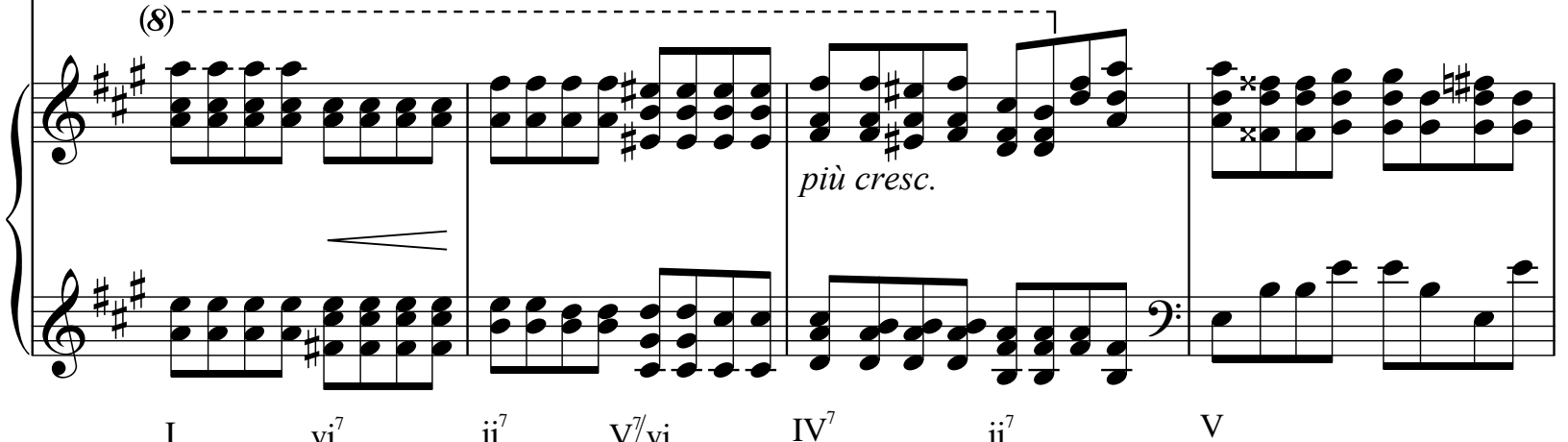


Example 3.28: Cont.

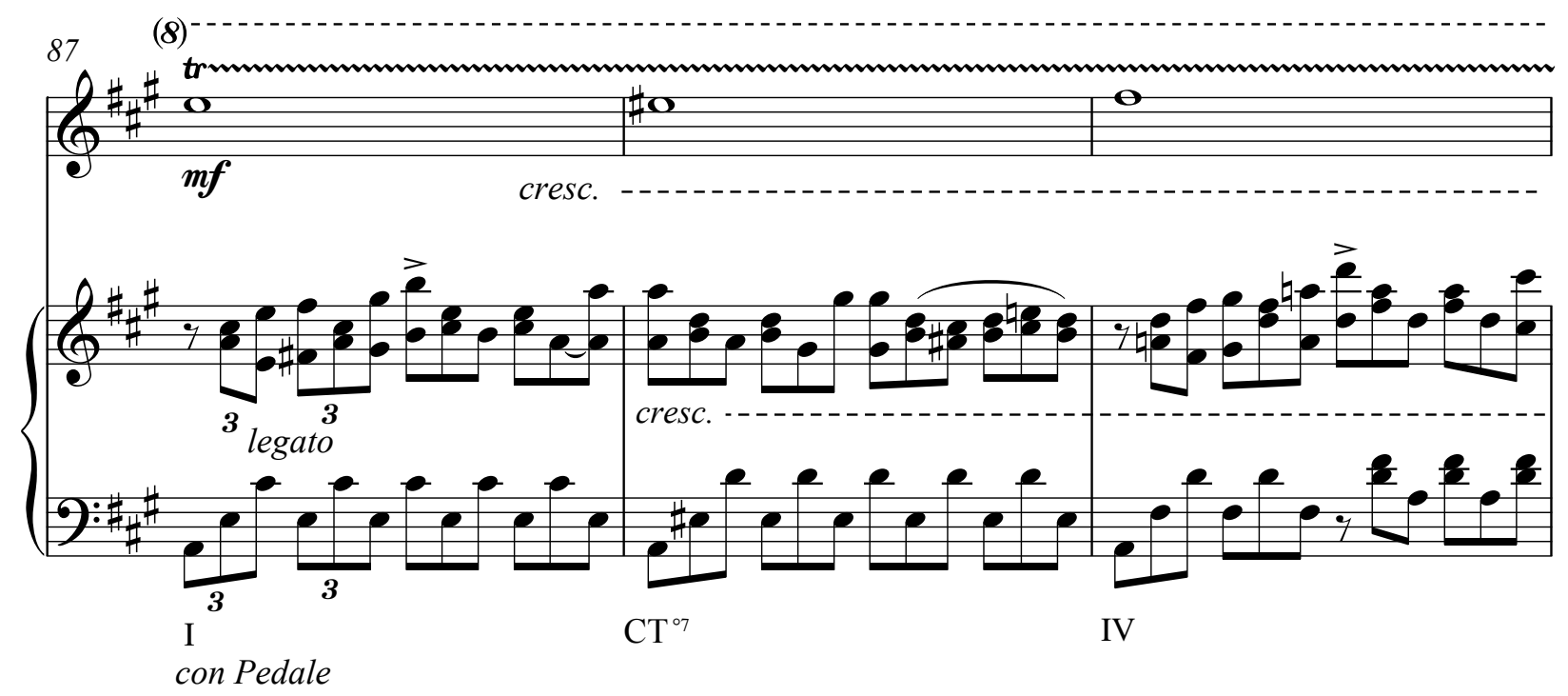

(8)
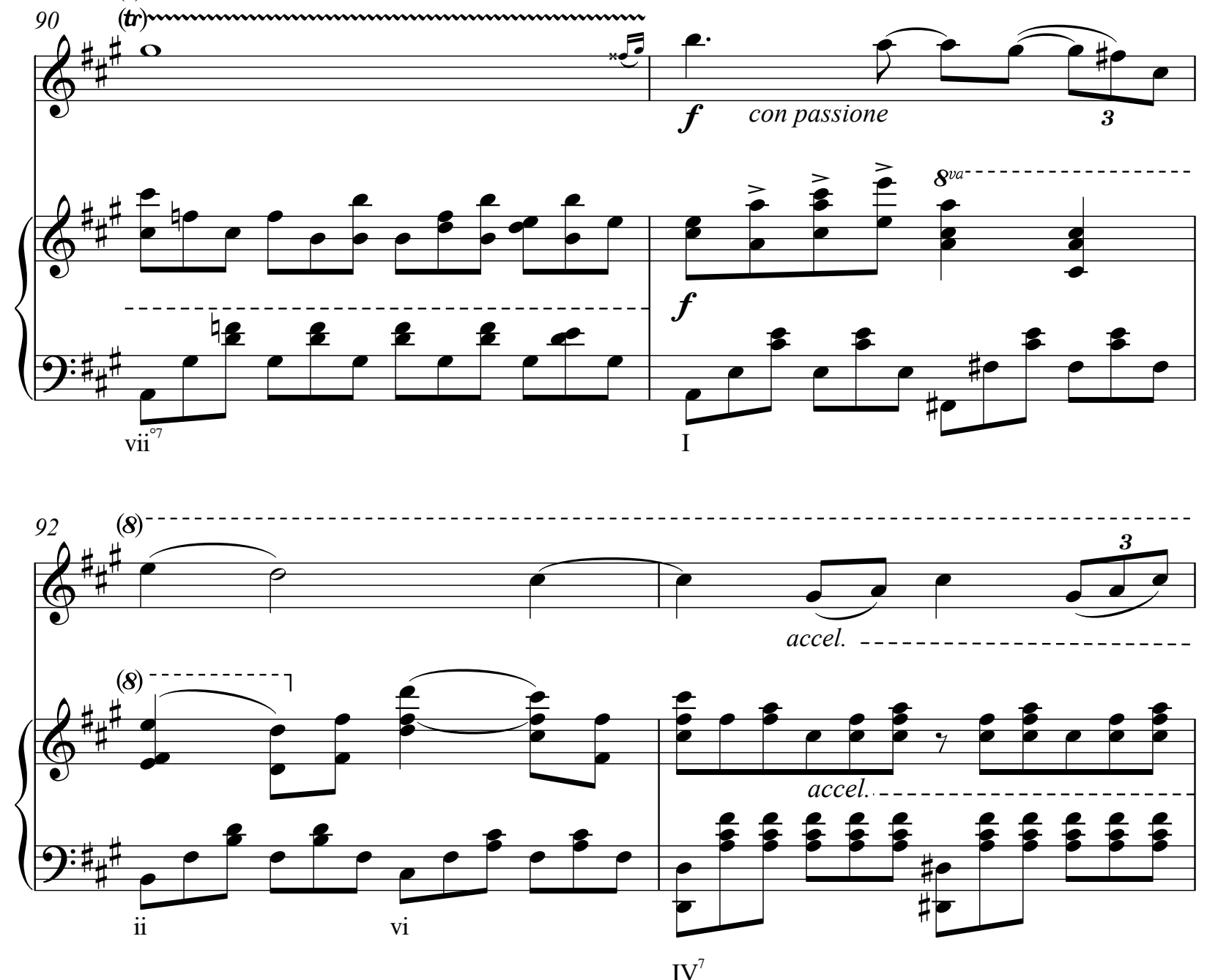
An 8va, which encompasses mm. 86-98, intensifies the music as it heads towards the climax. The piano also assists with the intensification by changing from straight eighth notes to triplets, which continues for the remainder of the piece. Beach begins a rising line in the bass in m. 91 with the note A. This ascending bass line, and accelerando marked in m. 93, coincides with the overall build to the climax in $\mathrm{m} .96$. The climax occurs on the single highest violin note of the piece, D7, marked fortissimo, only the second time that dynamic is used. Harmonically, the climax occurs with an E\# fully diminished seventh chord. The combination of dynamics, density, range, and tempo make the climax abundantly clear.

Example 3.29: Romance, mm. 91-96

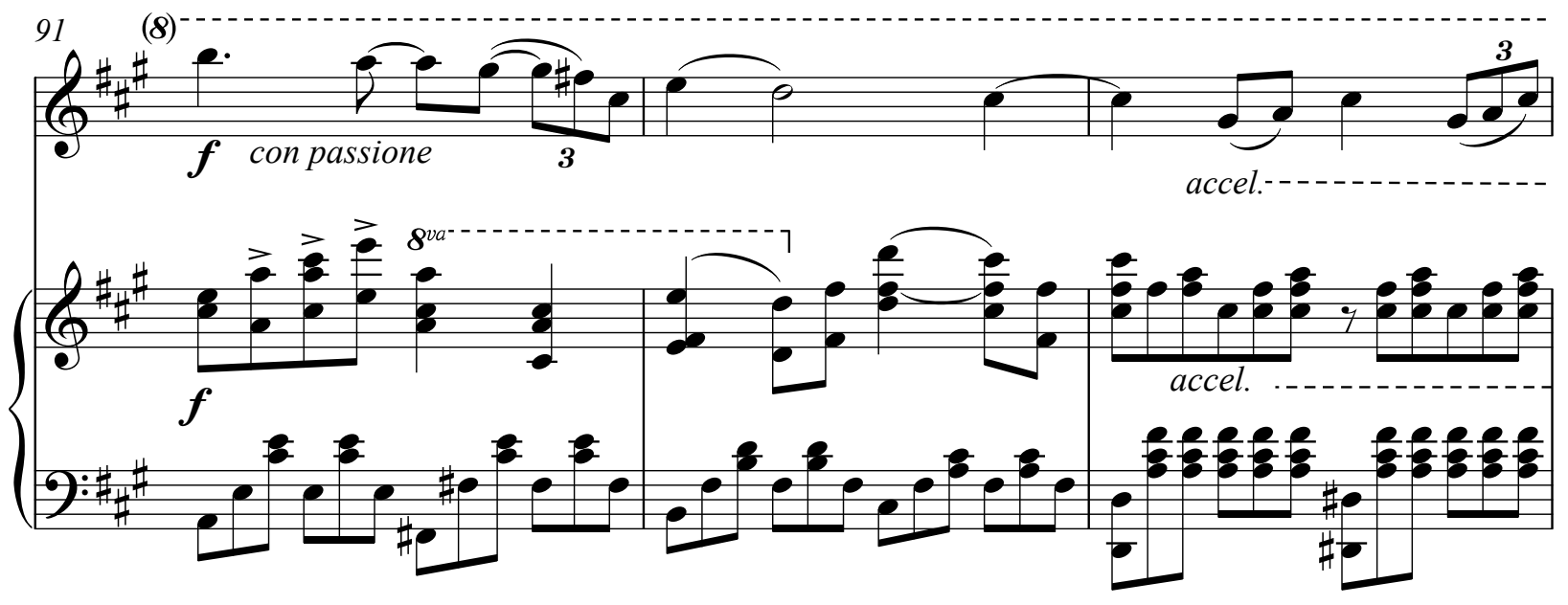


Example 3.29: Cont.

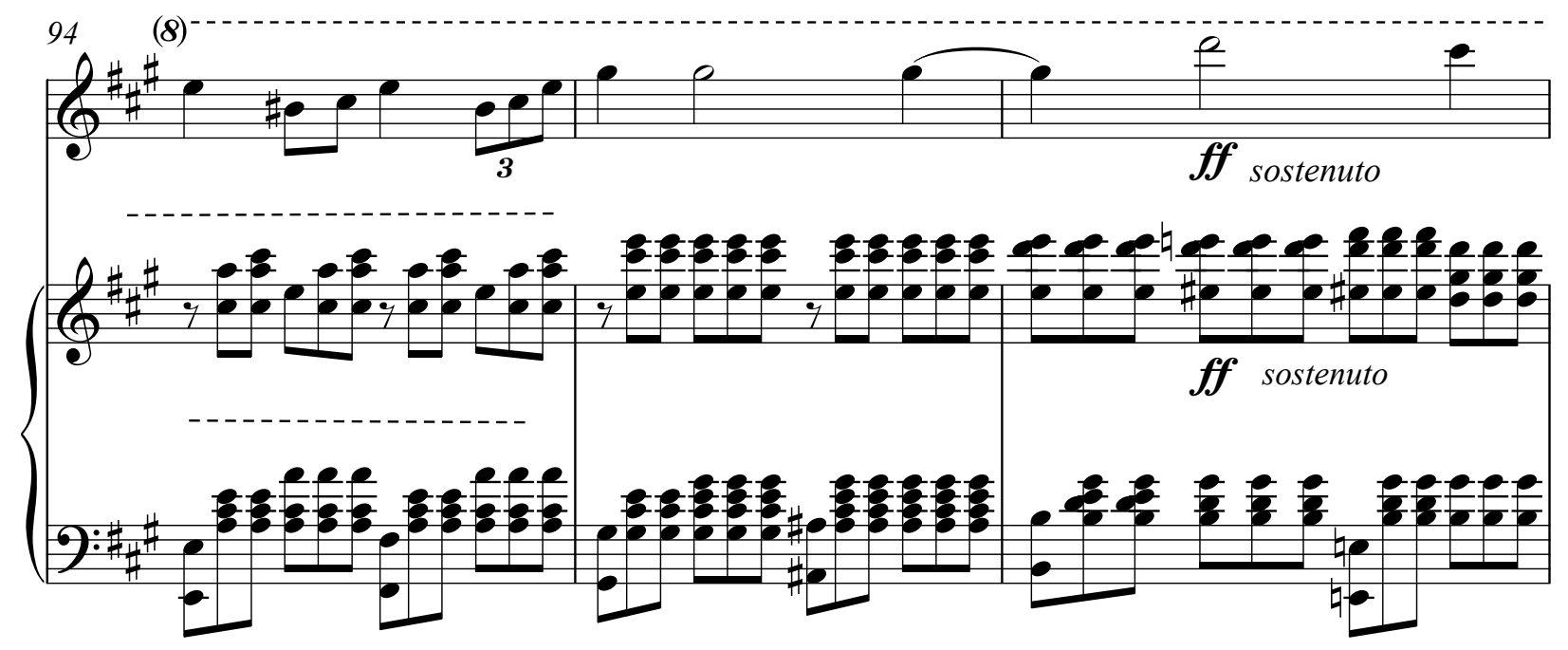

After the climax, the violin line begins to descend, yet the intensity level is maintained. In m. 99 Beach marks sempre fortissimo, and a measure later she adds a small crescendo. The violin continues to descend in pitch however the fortissimo dynamic is expected to be maintained for the next five measures, including a passage that is to be played high on the G string $(\mathrm{mm} .102-$ 103). Throughout this section she drops continual hints that we will, eventually, be returning to A major. The frequent appearance of $\mathrm{E}$ in the bass is one clue (mm. 99-102 and 104). She also uses a second inversion A major chord twice in mm. 102-104. Of course, the most traditional use of a $\mathrm{I}_{4}^{6}$ is in a cadential ${ }_{4}^{6}$ progression. The second time, in m. 104, she finally resolves the $\mathrm{I}_{4}^{6}-\mathrm{V}^{7}$ then leads to a root position A major chord in m. 105. 
Example 3.30: Romance, mm. 99-105
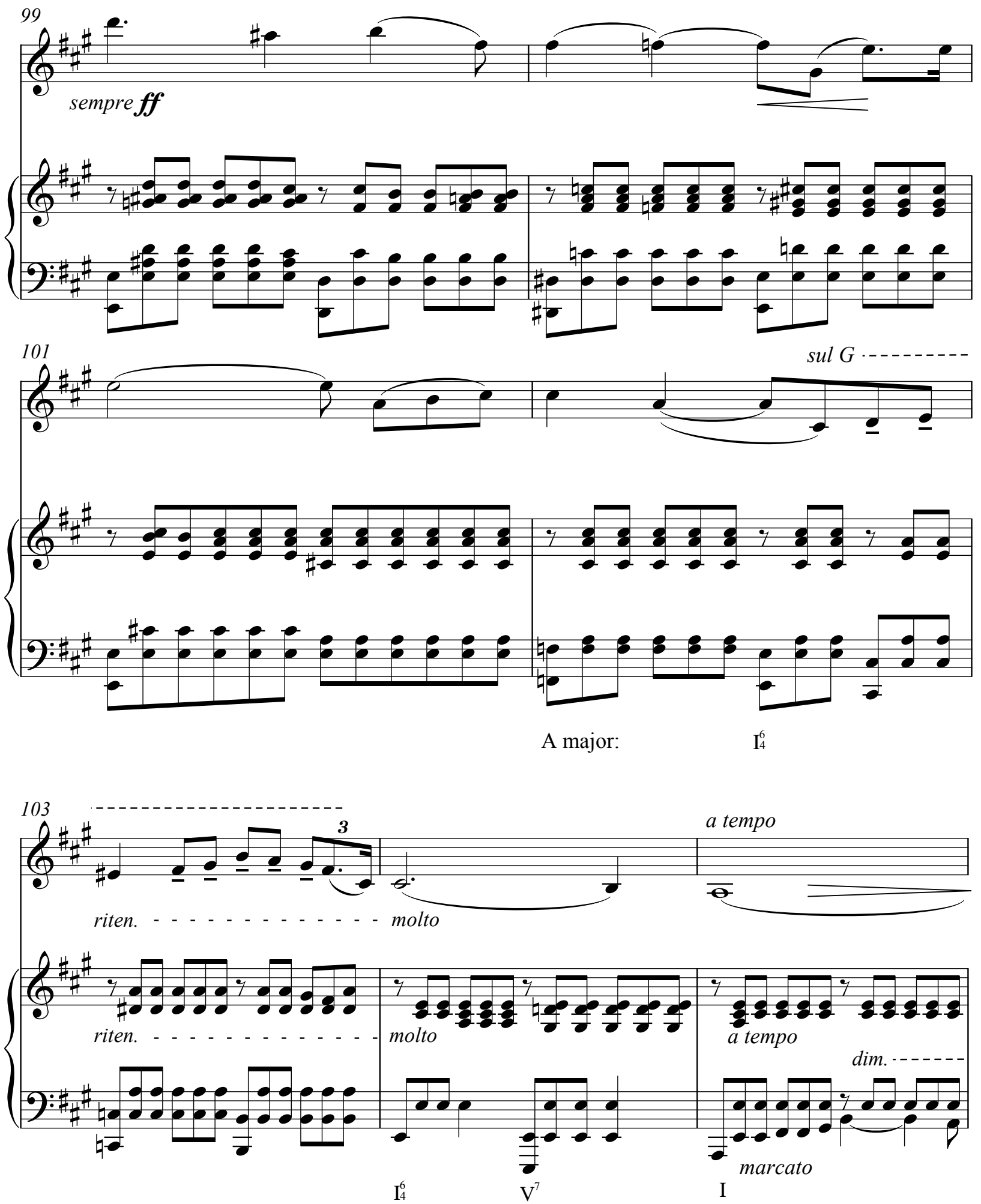
In $\mathrm{m} .108$ there is a $\mathrm{Fr}^{+6}$ that is worth noting. What makes this augmented sixth chord different is the way she builds the augmented sixth. Instead of the augmented sixth occurring between $a b \hat{b}$ and $\sharp \hat{4}$, she creates an augmented sixth between $a b \hat{2}$ and the leading tone. This spelling means the chord wants to resolve to tonic, which it does in m. 109, instead of the dominant. Although this is an unexpected spelling it is not without precedent. Other composers, such as Schubert and Brahms, also created augmented sixth chords between scale degrees other than the traditional bô and $\sharp \hat{4}$. An example is shown below from Schubert's Der Doppelgänger (example 3.32). Beach uses a similar, but more elaborate progression in the Berceuse which will be discussed in detail in the next chapter.

Example 3.31: Romance, mm. 108-109

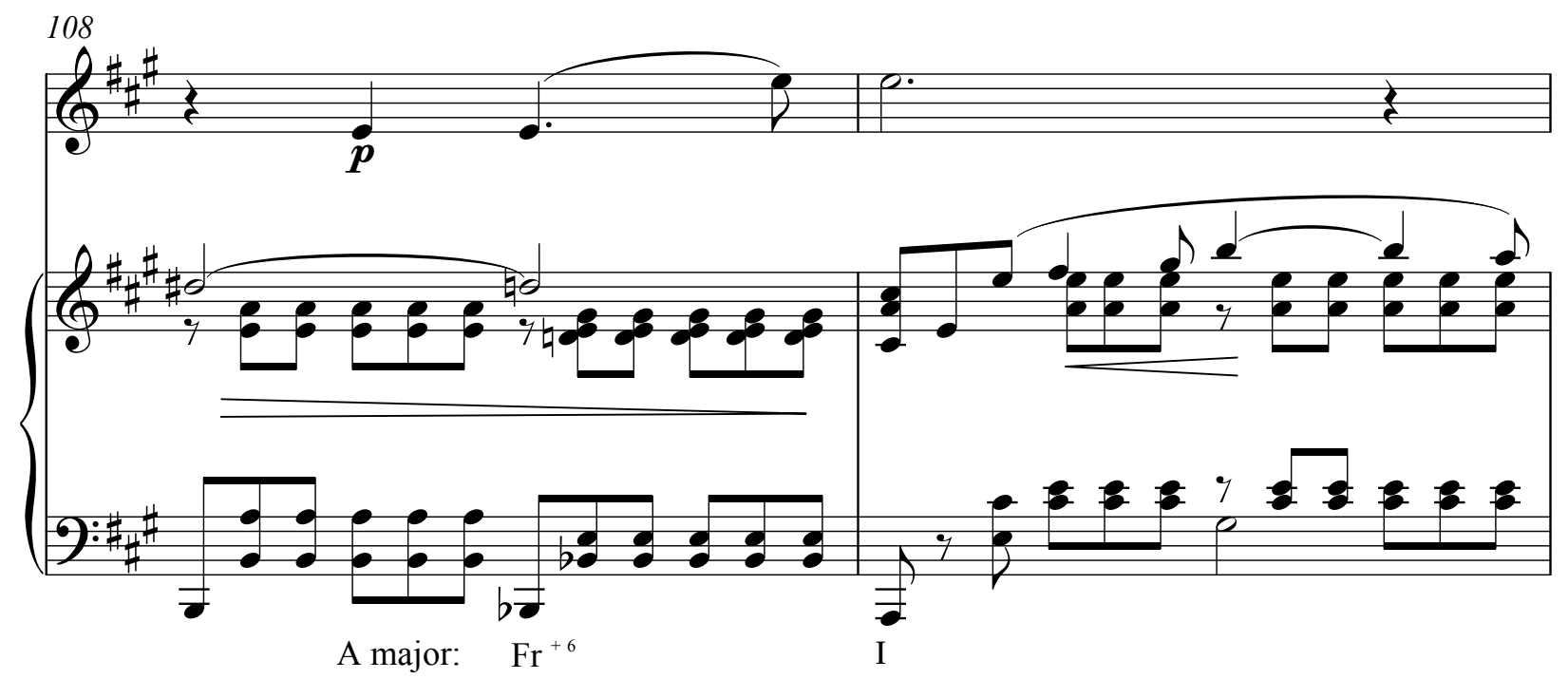


Example 3.32: Franz Schubert's Der Doppelgänger, mm. 31-34

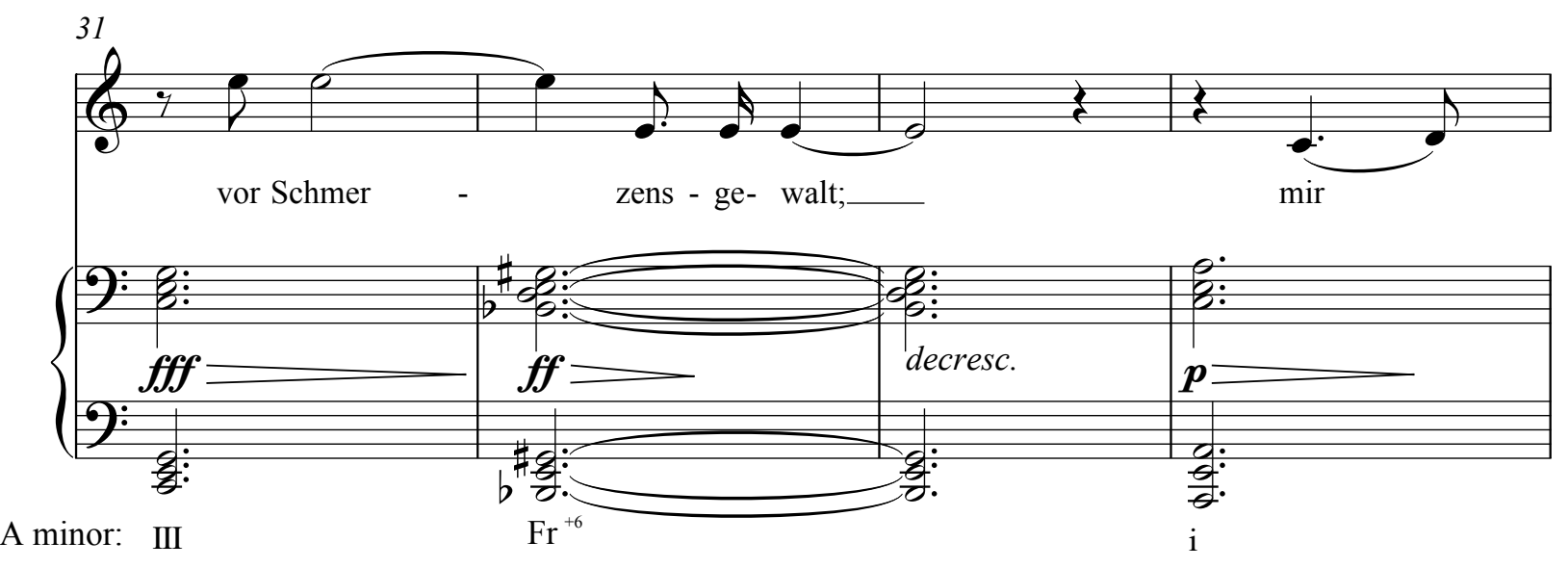

The harmonic motion from m. 105 to the end slows down. This section serves to reinforce A major as the tonic key, as well highlight other chords that have been important throughout the piece. Those chords are $\mathrm{F} \#$ minor, $\mathrm{C} \#$ minor, and D major. Beach's use of these particular chords shows her fondness for third relationships. An obvious exclusion from this list is $\mathrm{E}$ major, the dominant of $\mathrm{A}$. In fact, during this entire ending section, there is not a single dominant chord. The prominence of A (I), F\# (vi), $\mathrm{C \#} \mathrm{(iii)} \mathrm{and} \mathrm{D} \mathrm{(IV)} \mathrm{can} \mathrm{be} \mathrm{seen} \mathrm{in} \mathrm{example}$ 3.33 .

Example 3.33: Romance, mm. 113-117 


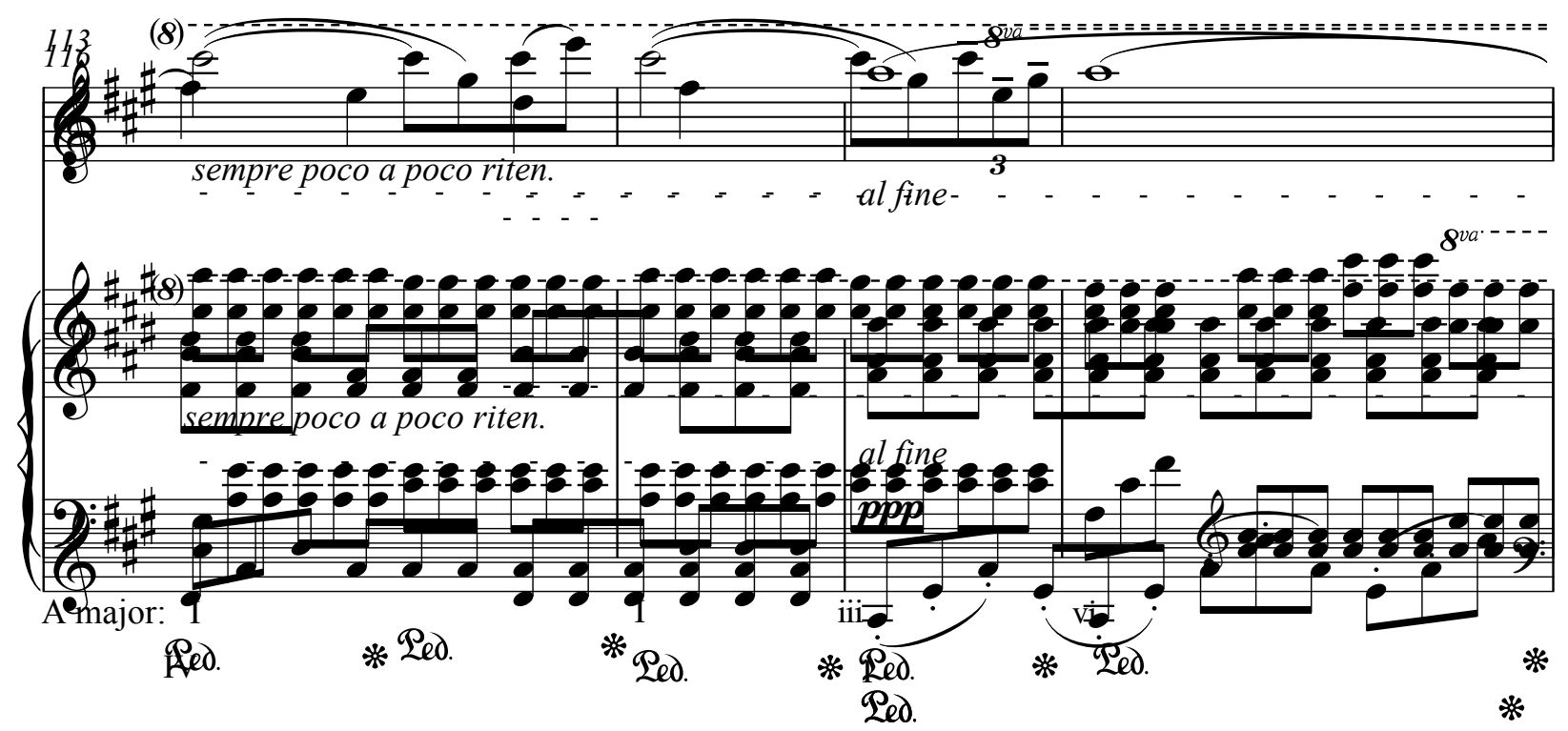

From mm. 107-113, the piano has the primary melodic material, and the violin is clearly in an accompaniment role. The piano foreshadows this change in $\mathrm{m}$. 105. As can been seen in example 3.34, the bass voice has a slight variation on the primary melodic fragment.

Example 3.34: Romance, mm. 105-106

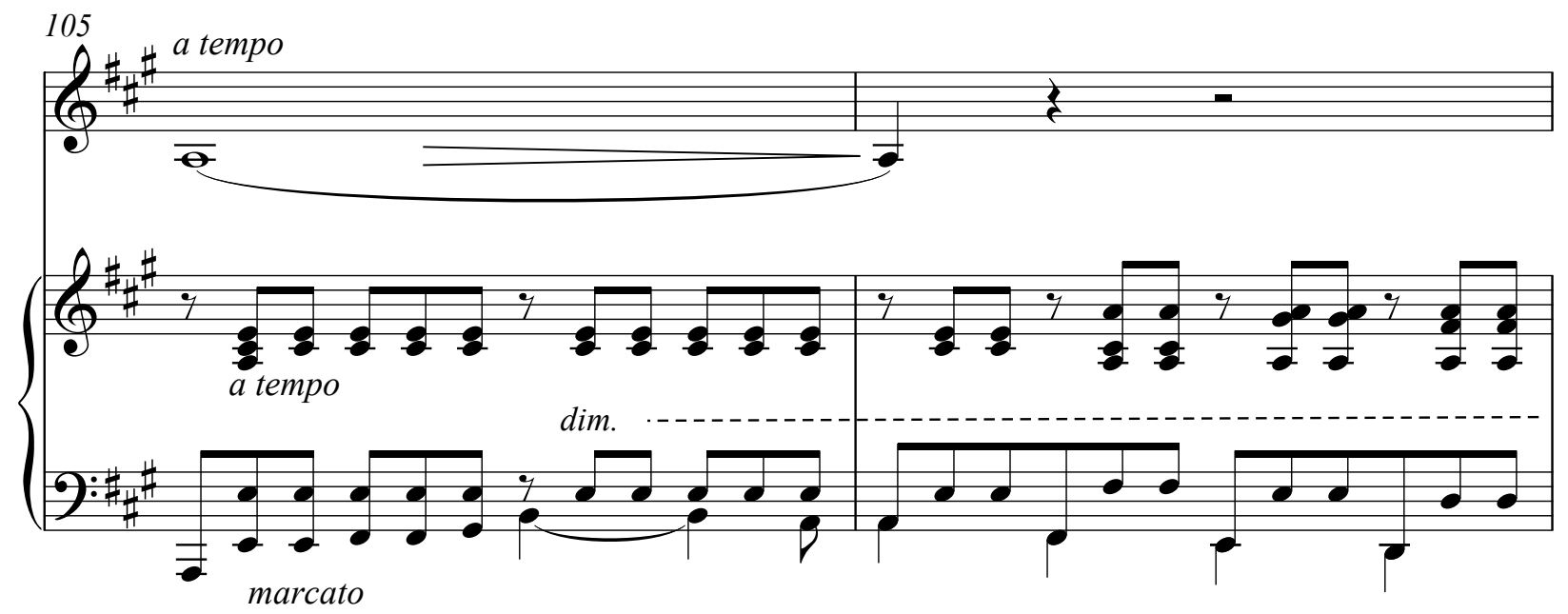


The violin reclaims the melody in mm. 112-113 (example 3.35), and from there Beach begins a final ascent into the upper range of the violin, where the piece will draw to a close. The final figure in the piano consists of an ascending arpeggiated tonic chord (example 3.36), a concluding figure she also utilizes in the Mazurka, and to a lesser extent the Invocation.

Example 3.35: Romance, mm. 112-113

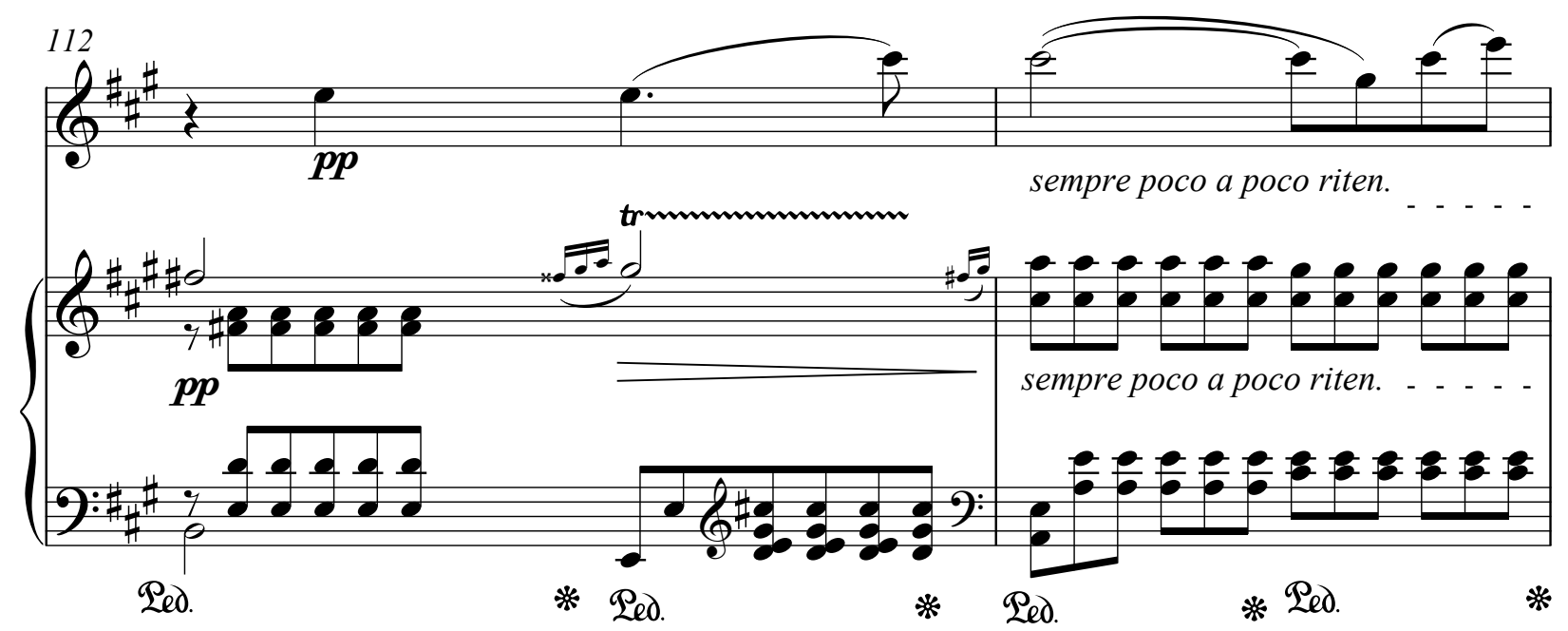

Example 3.36: Romance, mm. 118-119

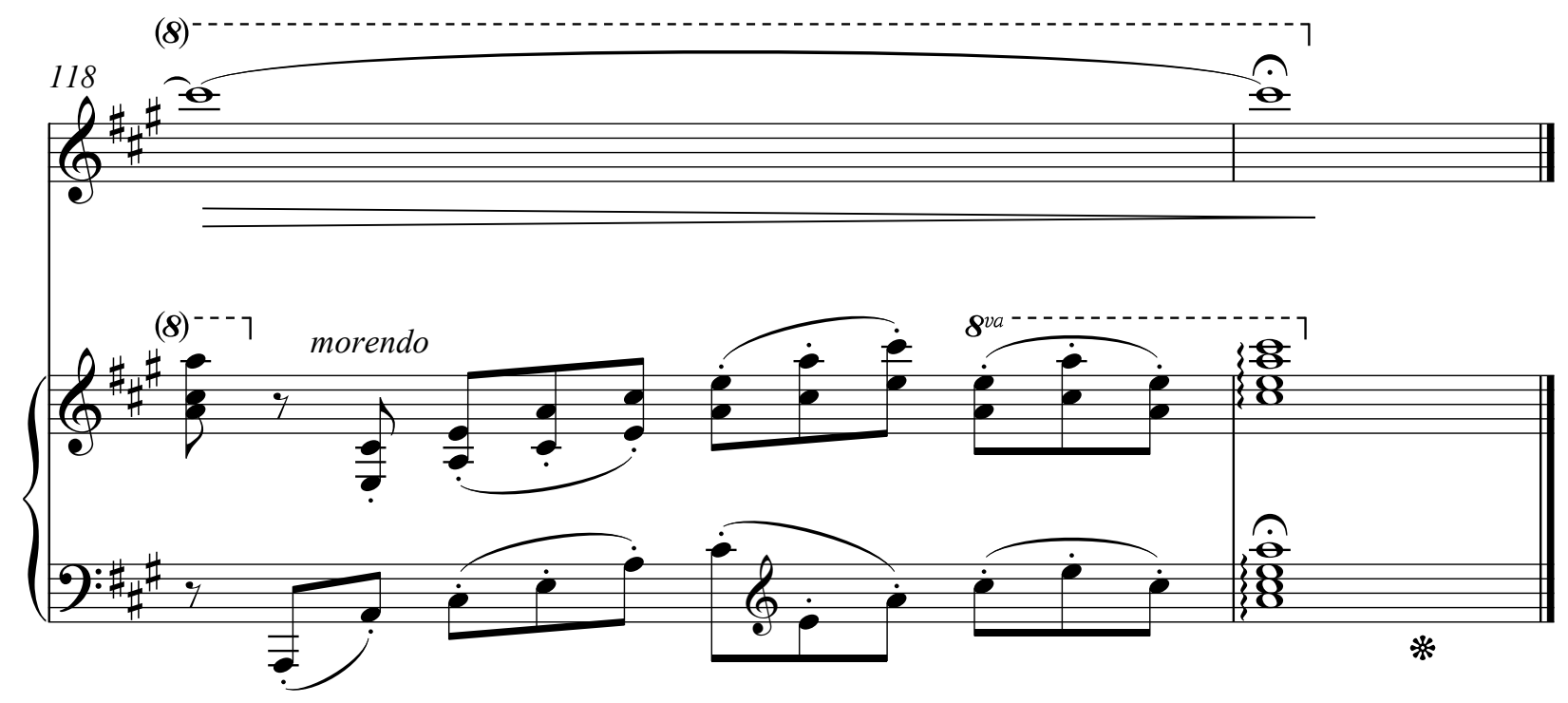


With a thorough discussion of the piece complete, there is another interesting feature about Beach's use of the main melodic fragment. As noted on page 28 she expands the interval between the bottom and top pitches of the primary melodic fragment. Here at the end, in the piano part, she does the opposite. This first statement in the piano at $\mathrm{m} .107$ has an interval of a sixth. Two measures later, when the figure is restated, then the interval will be a fifth.

Example 3.37: Romance, mm. 107-110

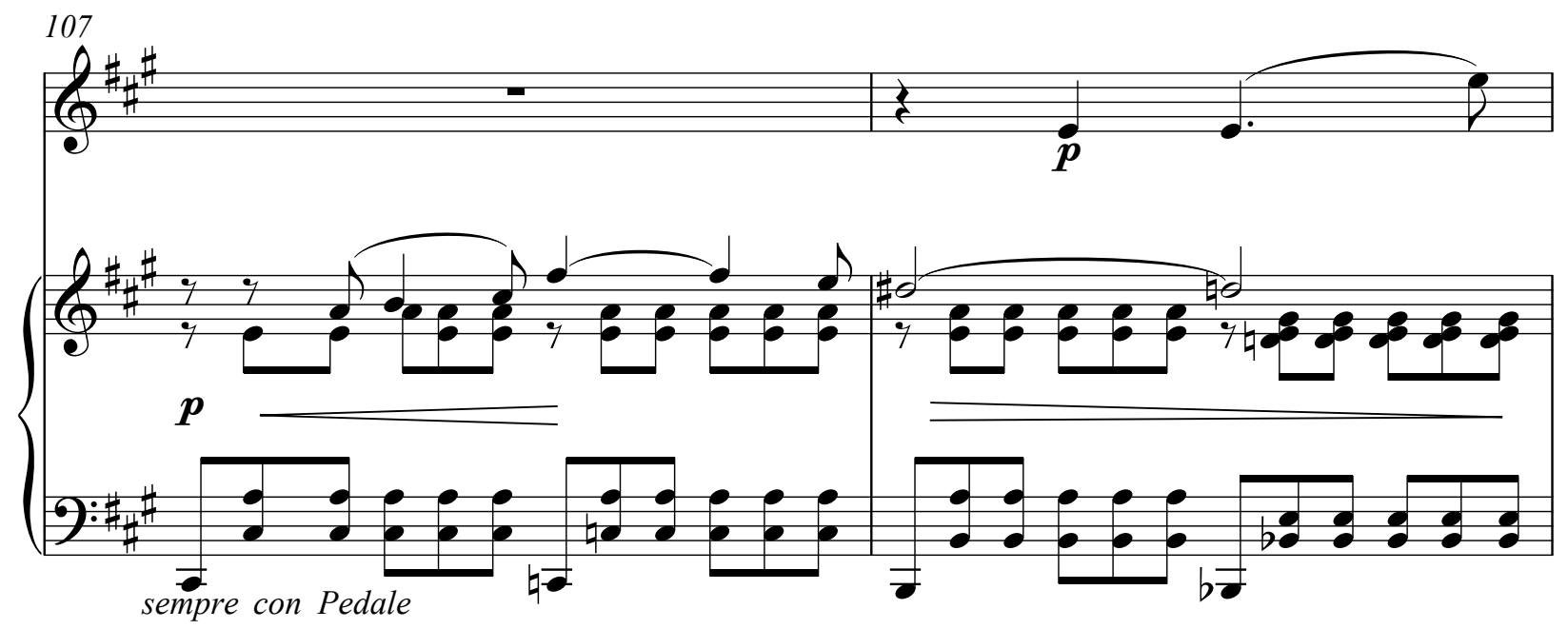

Example 3.39: Cont.

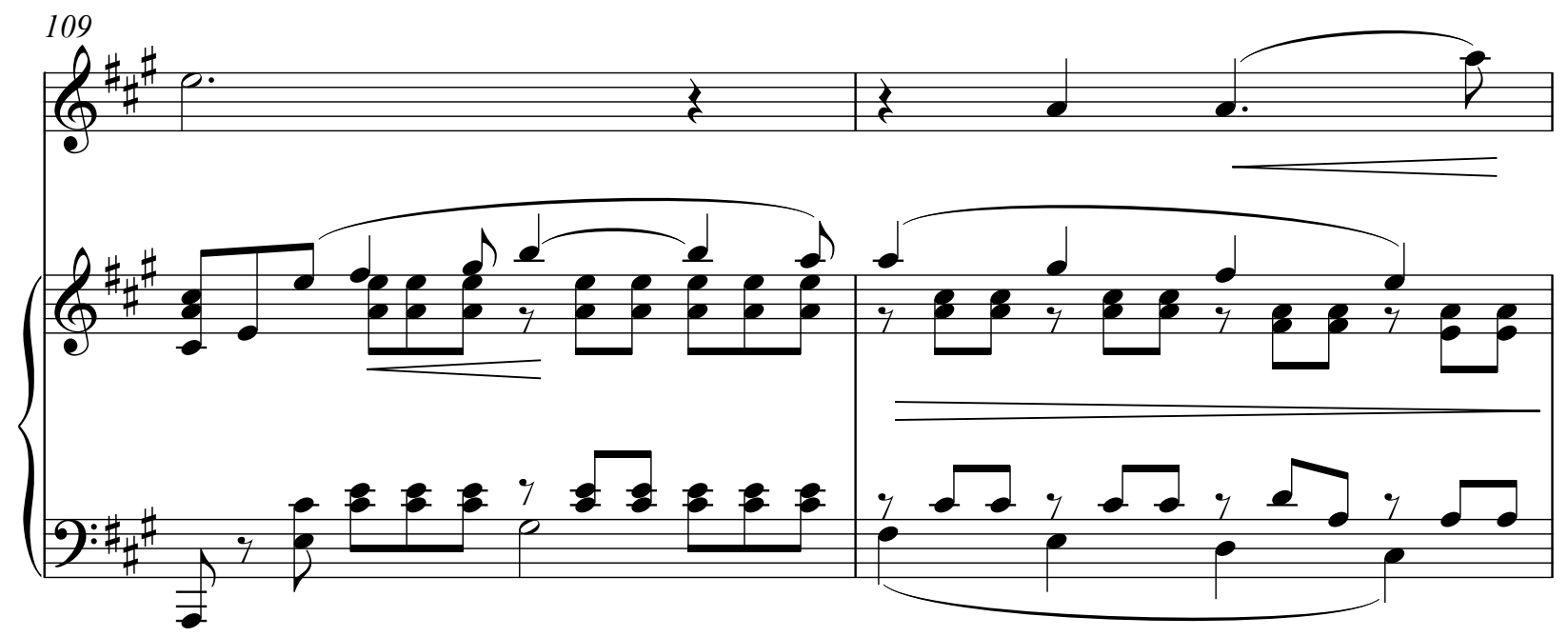


When making an appropriate version for the viola, this piece presented some of the most substantial challenges compared to the other works transcribed for this project. Due to the virtuosic nature, especially the use of the extreme upper register, this piece needed to be edited so it would fall within the viola's range. Since the violin's open strings (E5, A4, D4, and G3) sound a fifth higher than the open strings of the viola (A4, D4, G3, C3) the first inclination was to transpose the entire piece down a fifth. However, upon initial hearing, the lower key caused sections of this piece to lose the light-hearted character of the romance. Many attempts were made to keep the piece in the original key and to modify the viola line as needed. Ultimately, these attempts failed as the upper register is frequently used for the most intense, climactic moments. By allowing the viola to play an octave lower, those moments lost their effectiveness. In the end it was decided that a slightly darker character, with powerful moments, was preferable to a lighter character with a noticeable lack of intensity. While the viola part could be transposed down a fifth with no other changes, there were some necessary revisions to the piano part. The first is that the opening four measures were raised an octave. As the viola does not enter in those measures, there is no possibility of balance issues. Moving up the octave assists in setting up a lighter, romantic character. Both hands of the piano accompaniment were also raised an octave in m. 104-106. These measures are the end of the A' section when the viola is finishing one phrase and the piano is taking over the melodic material. The change in octave helps to lighten the overall character and allows the melody lines in the piano to be better heard. Those were the only changes to the music that were used for this transcription. Some changes of clefs were made to facilitate ease of reading the music but involved no change of pitch. 
The Romance is a wonderful by-product of the 1893 Columbian Exposition. This exposition was a great step forward for women in America. It presented an important opportunity for two of America's best musicians, Maud Powell and Amy Beach, to collaborate on an international stage. This Romance can assist in filling the void in the viola repertoire of compositions by American Women composers at the end of the $19^{\text {th }}$ century. It is hoped that this chapter and transcription help to provide both a detailed analysis for performers and a beautiful addition to the viola repertoire. 


\section{Chapter 4: Analysis of Three Works for Violin and Piano, op. 40}

Amy Beach's Opus 40 is a collection of three short character pieces for violin and piano, which were published by Schmidt in 1898. Their titles, in publication order, are La Captive, Berceuse, and Mazurka. Although they were published as a set, each piece is an independent work. As noted in Chapter 2, while the Berceuse and La Captive were premiered in 1897, it took until three years after publication for the Mazurka to receive its premiere. For a variety of reasons, these pieces are very atypical of Beach's writing. In her book, Amy Beach and Her

Chamber Music, Jeanell Brown makes an extensive list of the ways in which this particular collection could be considered out of the ordinary for Beach.

These three short works are not characteristic of Beach's usual style for several reasons. First, the themes are not as chromatic as many others from this same period. Second, the harmonic rhythms are slower. Third, the extensive use of remote harmonies and altered chords serving as functional harmony is not as frequent. For example, there is more emphasis on the traditional chordal harmonies $\left(\mathrm{I}-\mathrm{IV}-\mathrm{V}^{7}\right)$, with well-defined authentic cadences. There are no lengthy and involved sections of transition and modulation.... These three pieces are precise and compact, with Schubertian, song-like textures. The piano writing is simple and chordal, devoid of the usual figuration or bravura playing."67

Brown goes on to theorize, "although there is no indication that this set was written for pedagogical purposes, they could well serve that function."68

${ }^{67}$ Brown, Amy Beach and her Chamber Music, 188.

68 Ibid, 188. 


\section{La Captive, Op. 40 No. 1}

The title of the first piece, La Captive, means "The Captive" in French. This is a fitting title as Beach indicates that the whole work is to be played sul $G$, meaning the violinist is to be held captive by the G string. La Captive is in binary form. ${ }^{69}$ There are two measures of introduction followed by eight measures of A, eight measures of B, and nine measures of the coda. The form is defined by the use of repeats as each major section (A and B) is repeated once. Beach clearly strove for symmetrical division within the form, a feature that will occur in other Op. 40 works.

Each section of this piece is also defined by the piano texture. Between the A and $\mathrm{B}$ sections these textures can be differentiated by the right hand of the piano, as the textural accompaniment in the left hand stays consistent. Throughout the A section the treble staff mostly functions as an extension of the quarter note chords found on beats two and four of each measure in the bass staff (example 4.1), whereas in the B section the treble staff functions more contrapuntally with the violin line ${ }^{70}$ (example 4.2). In the coda, the piano has the melody for the first time since the introduction, while the violin accompanies with either pedal tones or a $\mathrm{G}$ major arpeggio (example 4.3). Texturally, a surprise occurs at the very end when the violin plays natural harmonics (example 4.3). This allows the final pitches to be higher than otherwise possible without leaving the $\mathrm{G}$ string.

69 Yu-Hsien Judy Hung, "The Violin Sonata of Amy Beach” (Doctoral dissertation, Louisiana State University, 2005), 17.

70 Ibid, 17. 
Example 4.1: La Captive, mm. 4-5

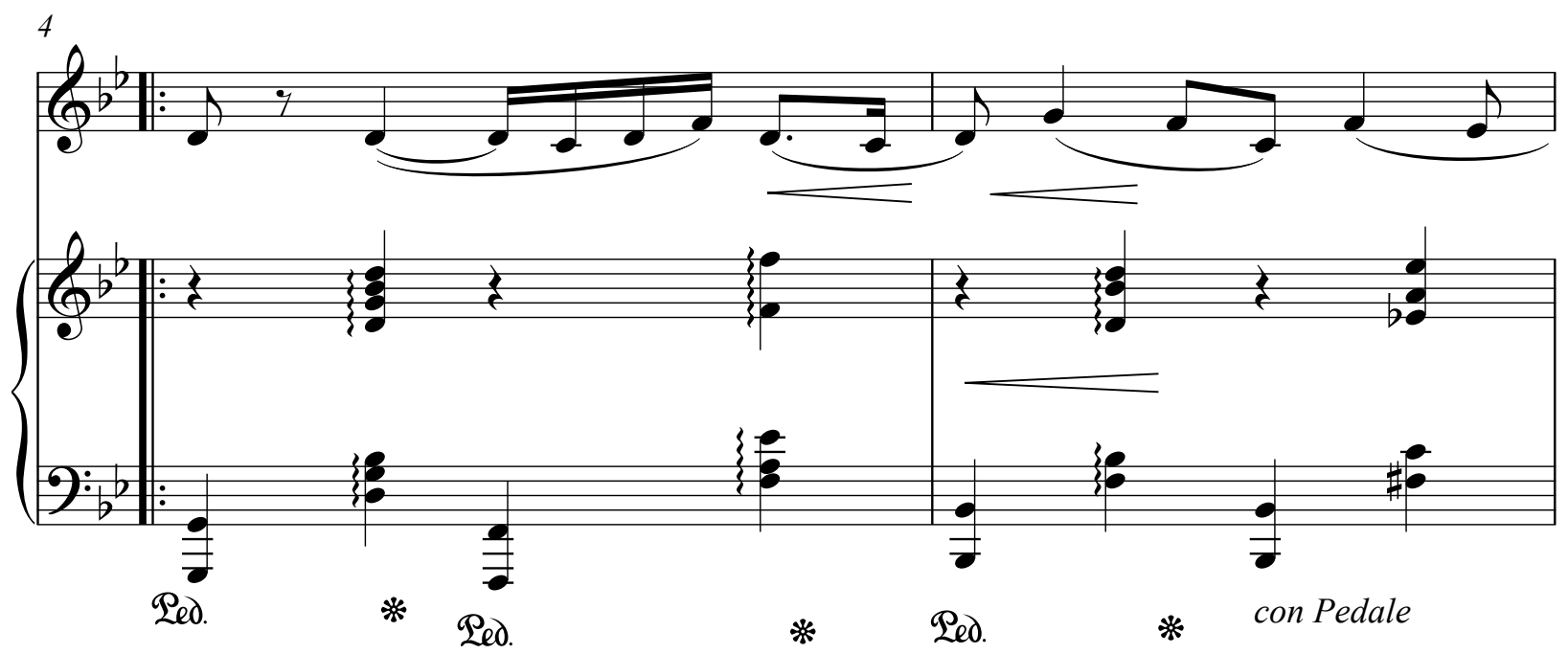

Example 4.2: La Captive, mm. 13-16

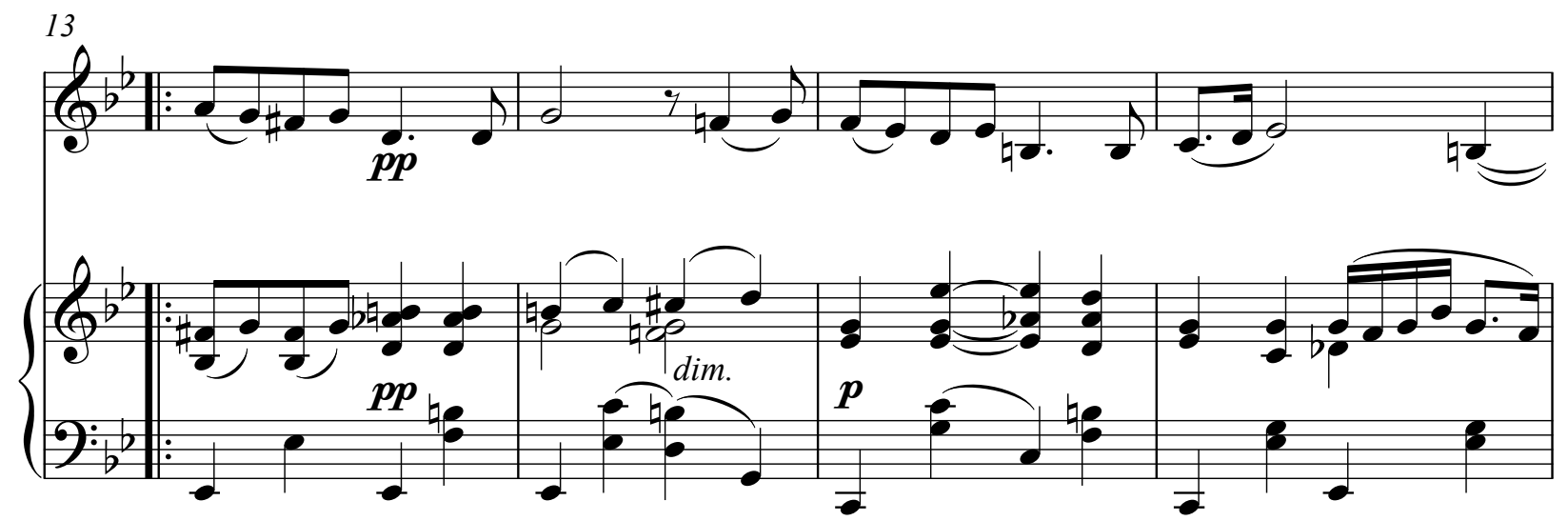

Example 4.3: La Captive, mm. 22-30

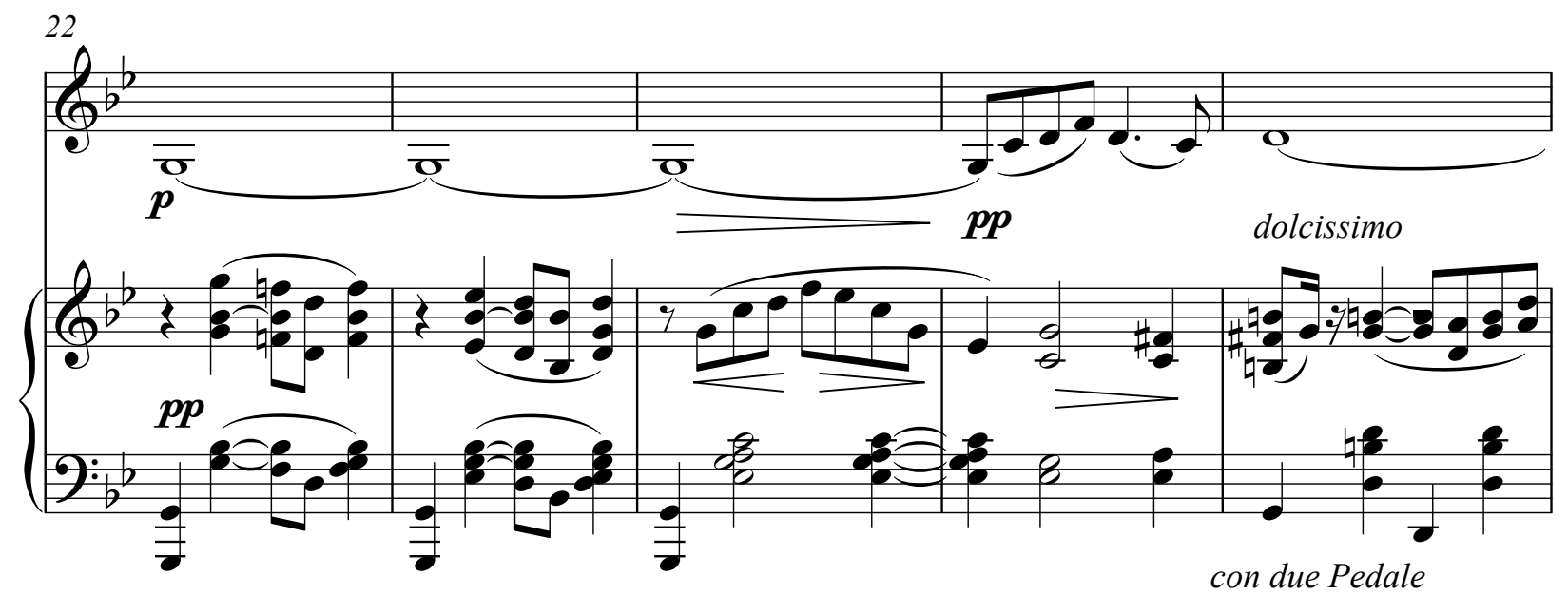


Example 4.3: Cont.

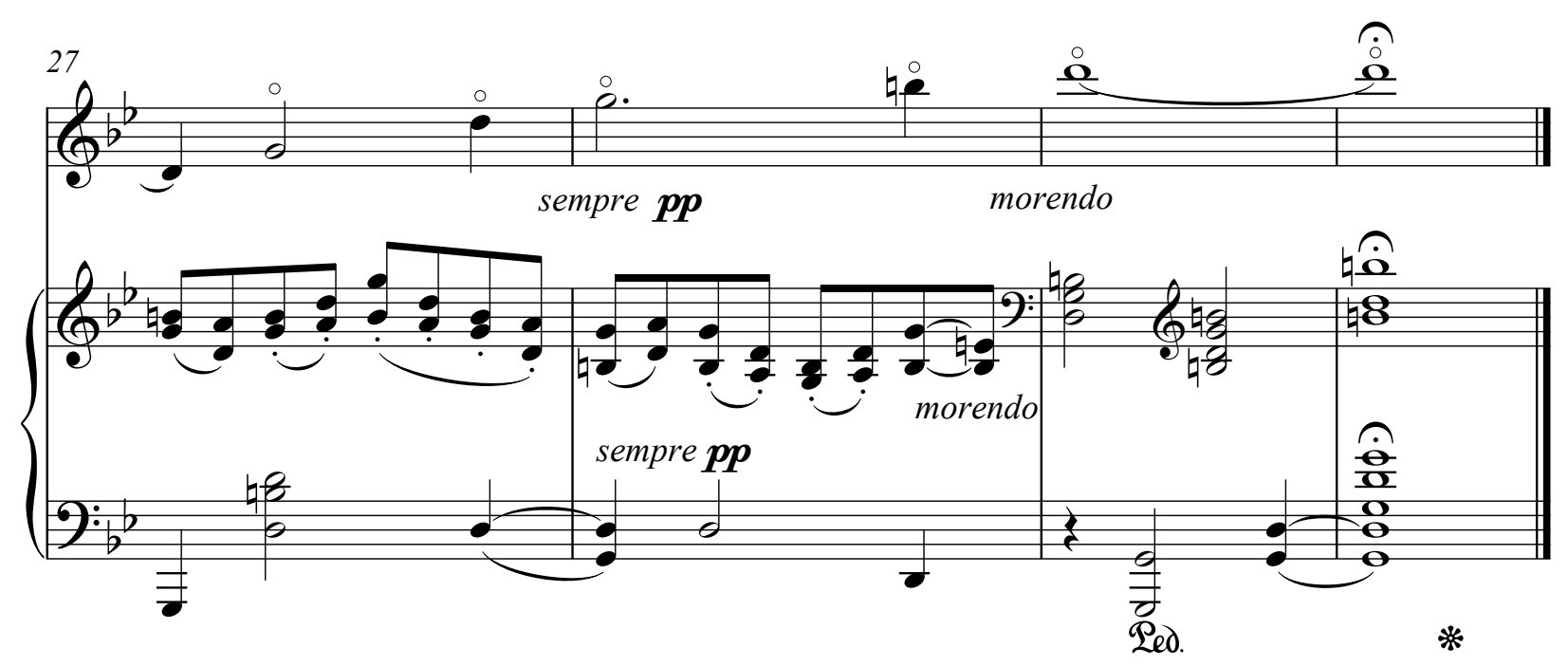

Melodically the phrases are not as evenly divided as the form. The A section consists of

two phrases, from m. 2, beat 3-m. 8 and m. 8, beat 2-mm. 11/12 (accounting for first and second endings). This division is clear due to the half cadence and the eighth rest after the downbeat of m. 8 which creates a slight breath (example 4.4). By contrast, the B section, which starts in m. 13, consists of one long eight measure phrase. The climax occurs in $\mathrm{m} .18$ which, much like the Romance, contains the loudest dynamic of the piece: forte.

The final major section, the coda, consists of a four measure phrase followed by a five measure phrase. Similar to the A section, the phrase break in the coda is evident partially because of a cadence. In m. 26 the cadence is expected to occur in $\mathrm{G}$ minor, with a iv-vii ${ }^{\circ 7}$-i. Instead Beach makes the final chord major, and spends the last five measures emphasizing G major (example 4.5). Although the downbeat of m. 26 is a G major chord with a major seventh, the 
major seventh is a 7-8 suspension ${ }^{71}$. Once the resolution happens (within beat 1 of $\mathrm{m} .26$ ), $\mathrm{F} \#$ is not seen again for the remainder of the piece. Additionally, the violin also switches pedal tones in mm. 25-26 from G to D, creating a sense of separation between the two phrases.

Example 4.4: La Captive, mm. 6-8

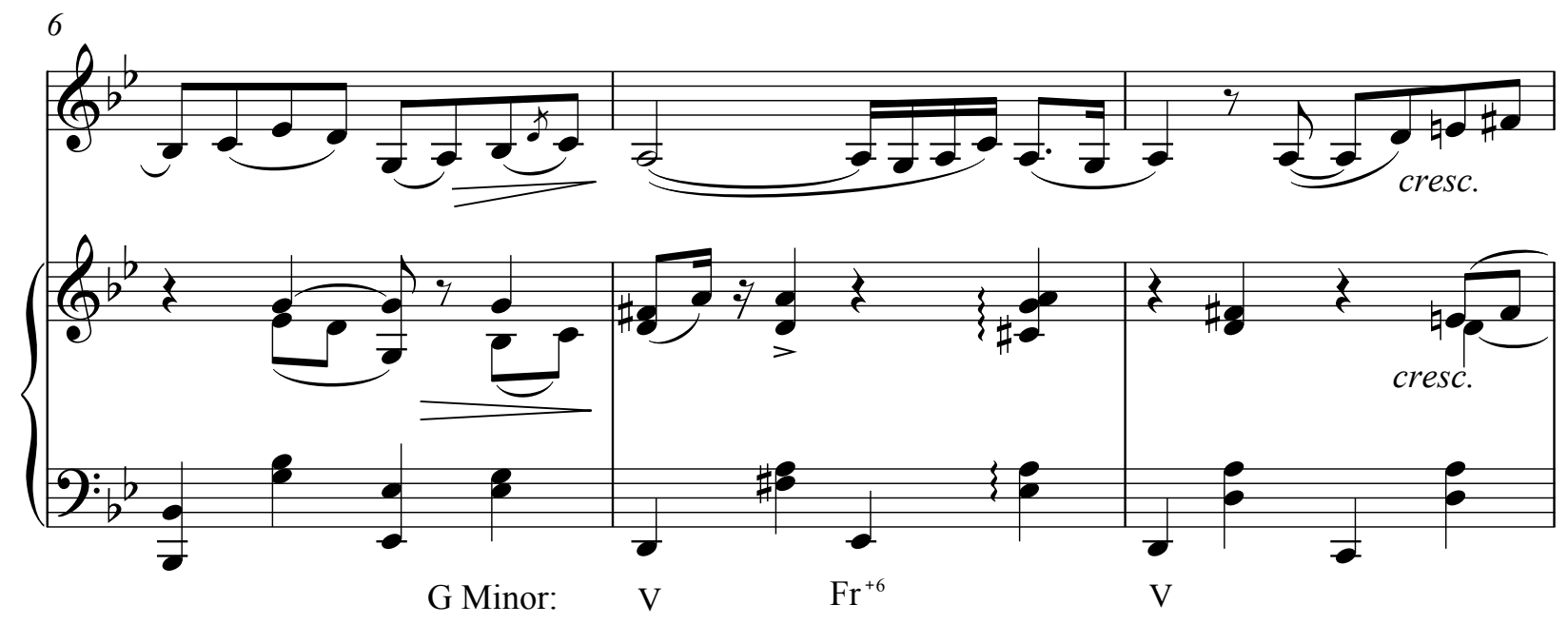

Example 4.5: La Captive, mm. 25-30

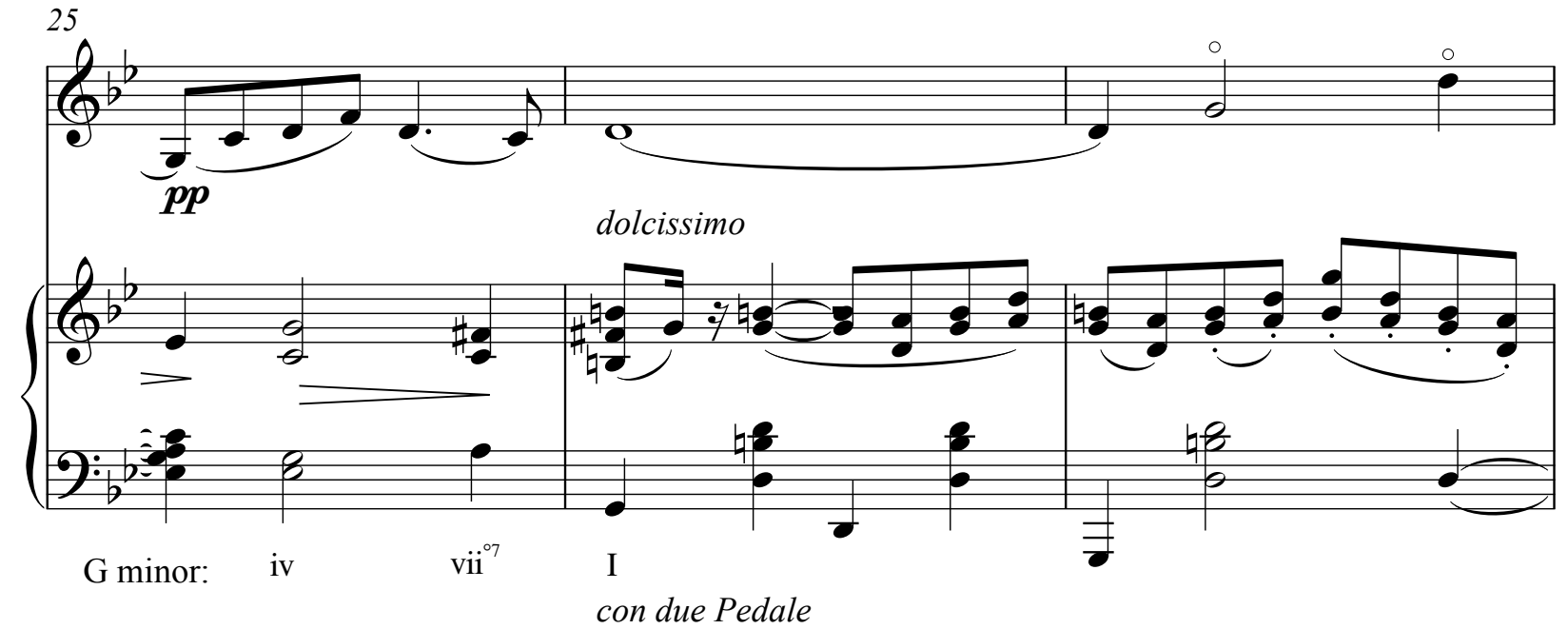

71 This type of upward resolving suspension, especially since it is a leading tone to tonic, is also commonly called a retardation by theorists. 
Example 4.5: Cont.

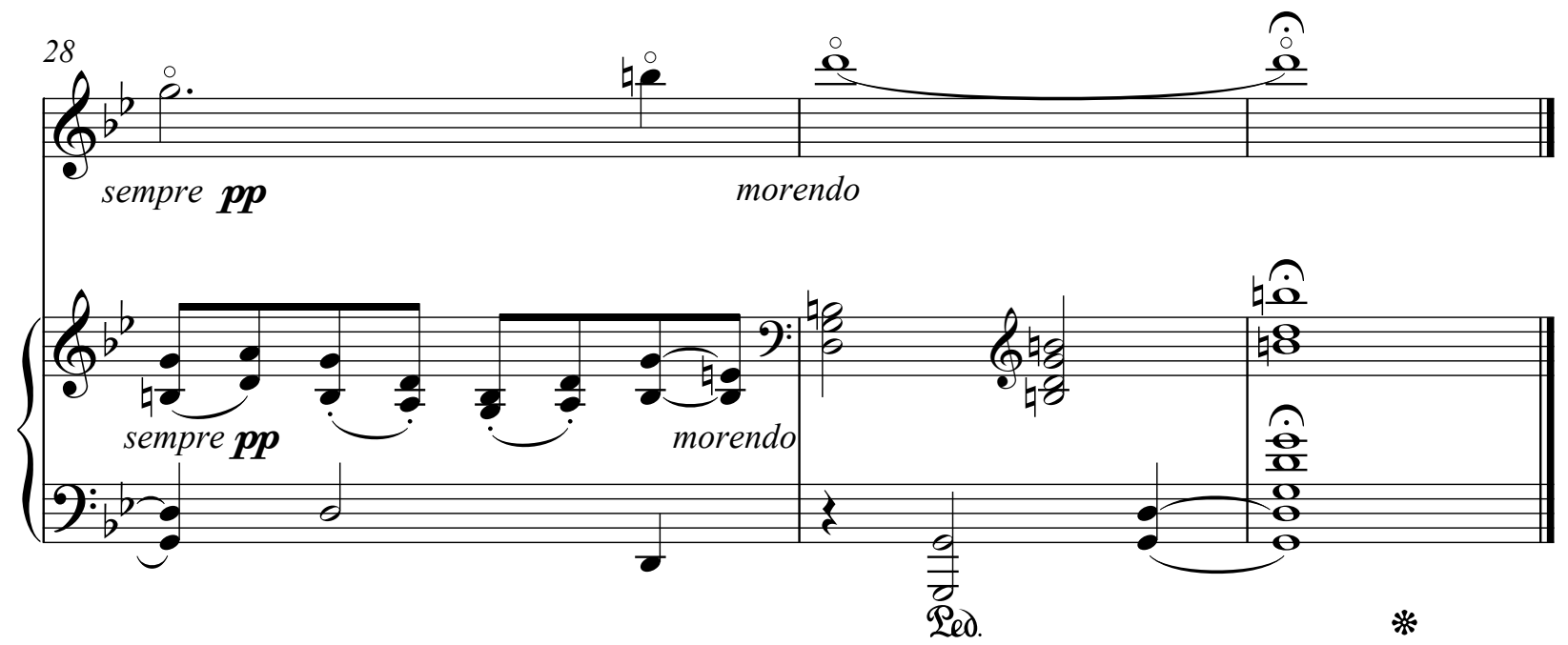

Melodic material from earlier in the piece is reused in the coda. The sequence in the

piano in $\mathrm{mm} .22-23$ has its origin in $\mathrm{m}$. 2. Also there is an augmentation of the violin's melodic line, specifically m.3, from the introduction.

Example 4.6: La Captive, mm. 1-3

\section{La Captive}

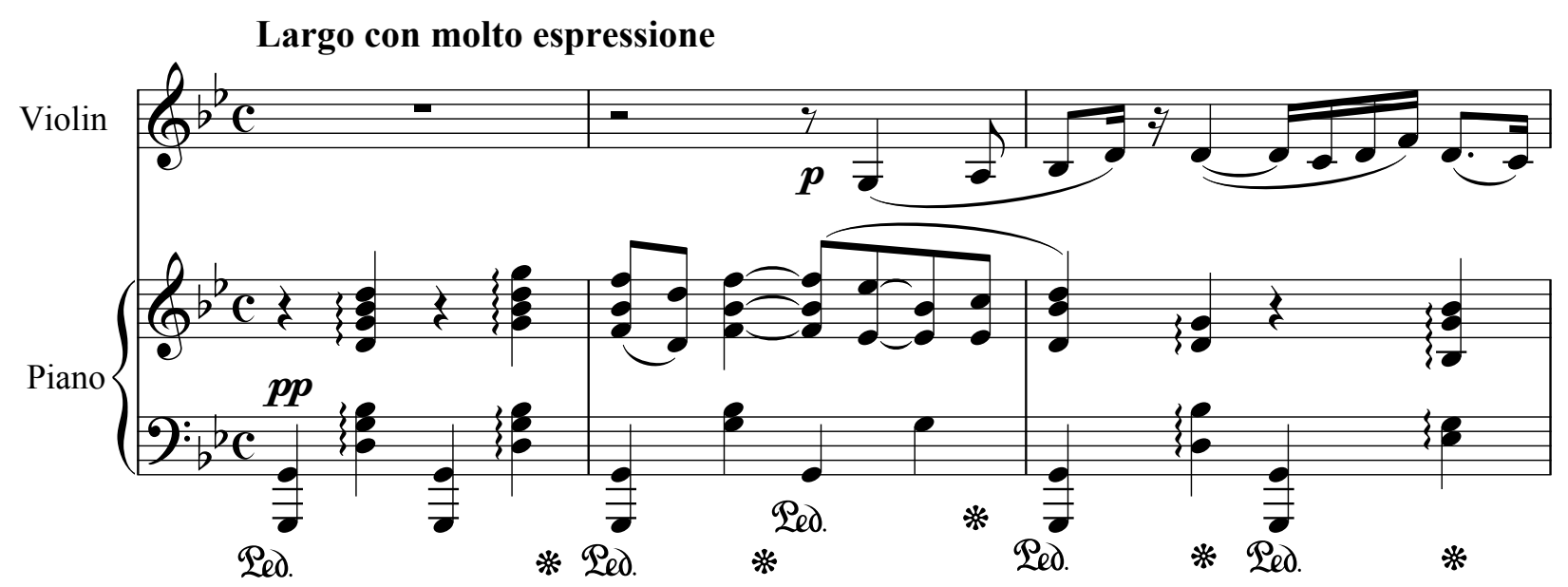


Example 4.7: La Captive, mm. 22-25

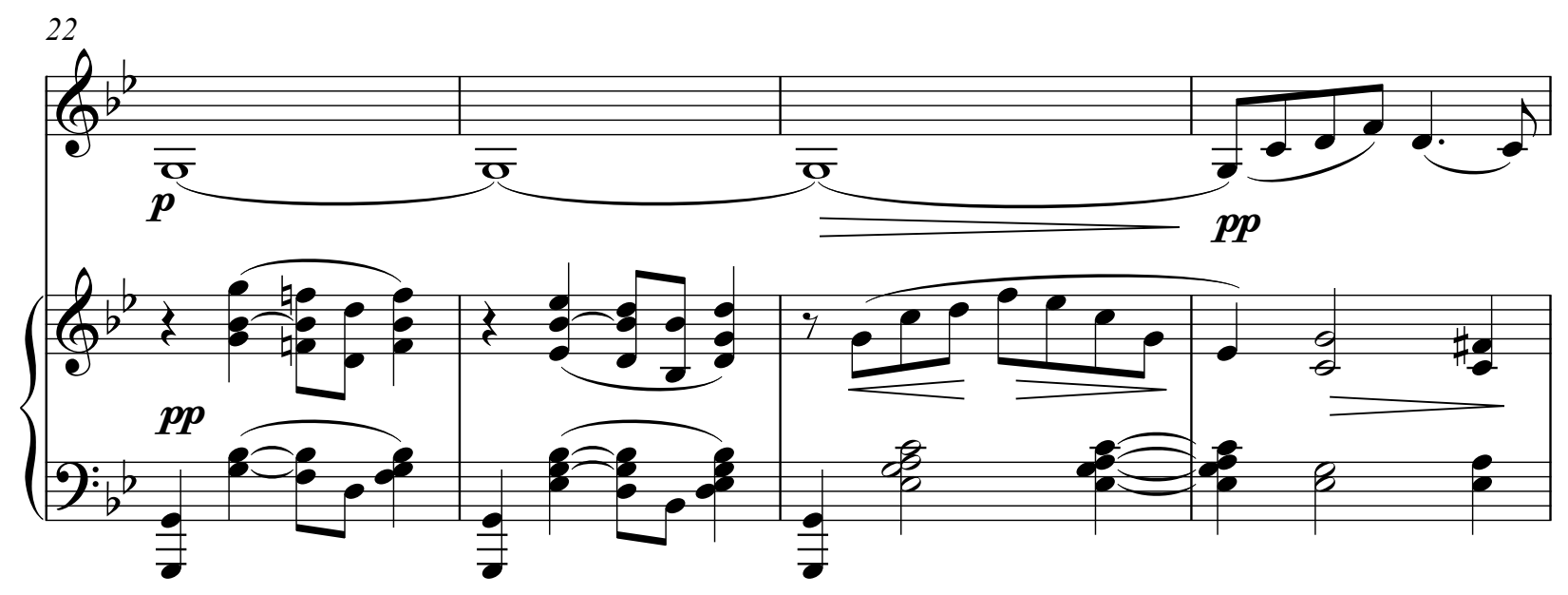

The opening key of G minor is firmly established in the introduction. While the A section generally serves to reinforce $\mathrm{G}$ minor with the frequent use of $\mathrm{V}$ and $\mathrm{i}$, there is a brief tonicization of III between the fourth and fifth measures.

Example 4.8: La Captive, mm. 4-5

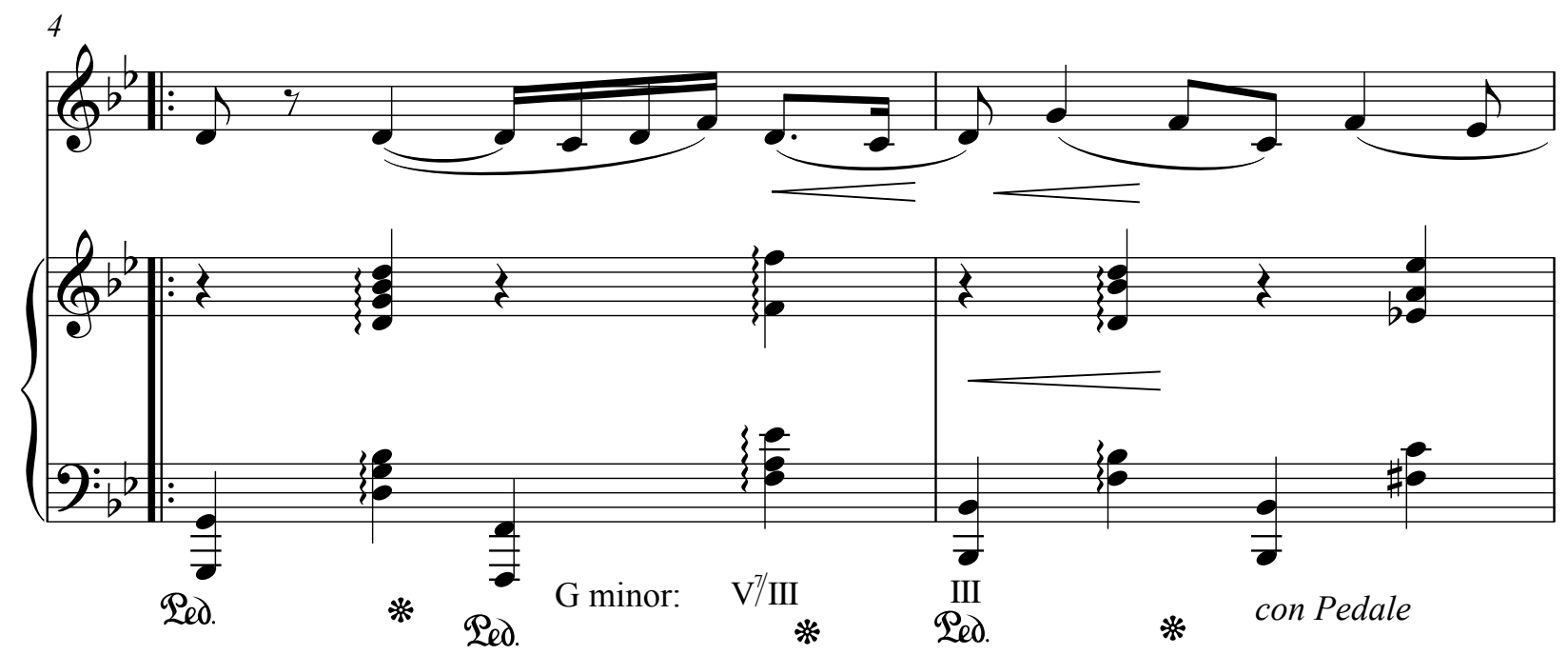


In the A section Beach chose to end all phrases on a half cadence. The first instance occurs in $\mathrm{m} .7$ at the end of the first phrase (example 4.4). In $\mathrm{m} .10$ there is another half cadence to end the second phrase. Lastly, a half cadence occurs in the second ending as the transition to the B section.

Example 4.9: La Captive, mm. 10-12

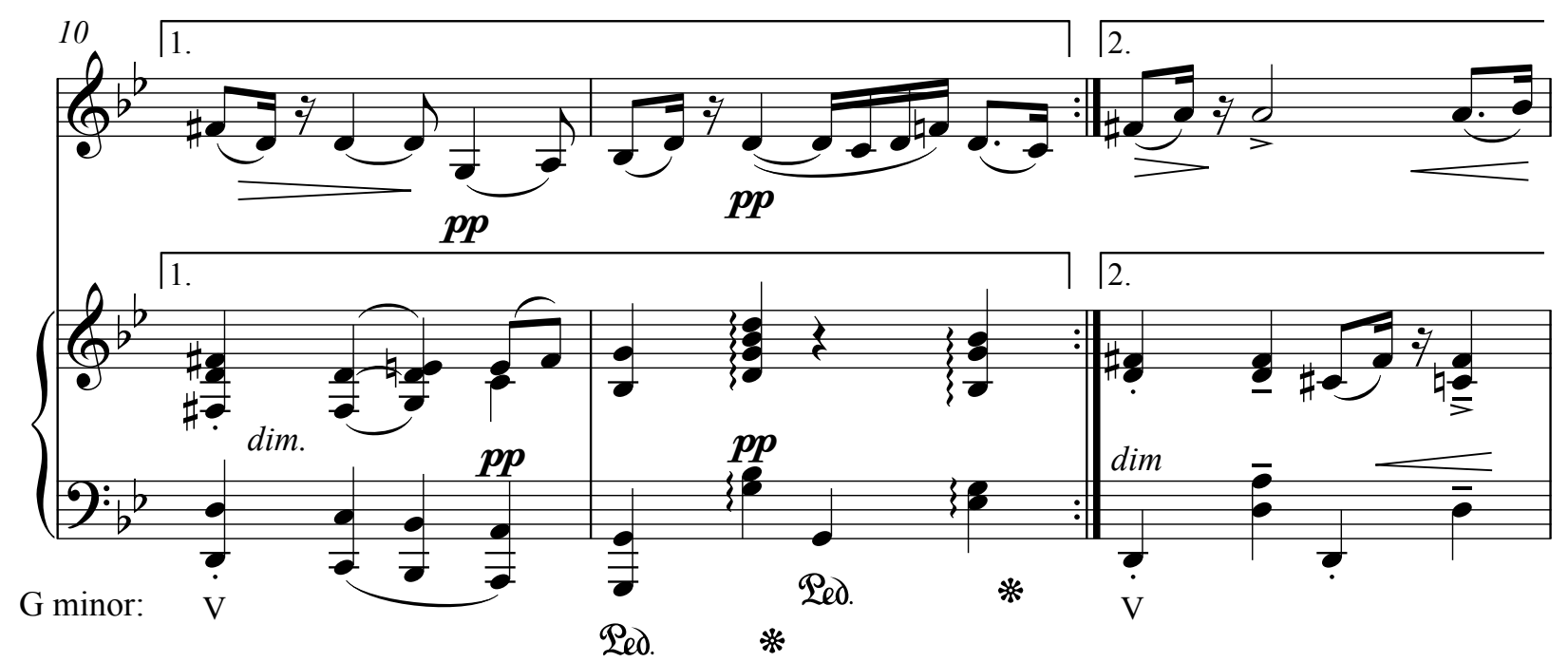

Another feature of the A section is the descending bass line between mm. 7-11. Beach begins with an $\mathrm{Eb}$ in $\mathrm{m} .7$ and descends by stepwise motion to an $\mathrm{A}$ in $\mathrm{m} .9$ before jumping back up to D. Then she uses the D as the start of a new descent which reaches the tonic pitch of G. 
Example 4.10: La Captive, mm. 7-11
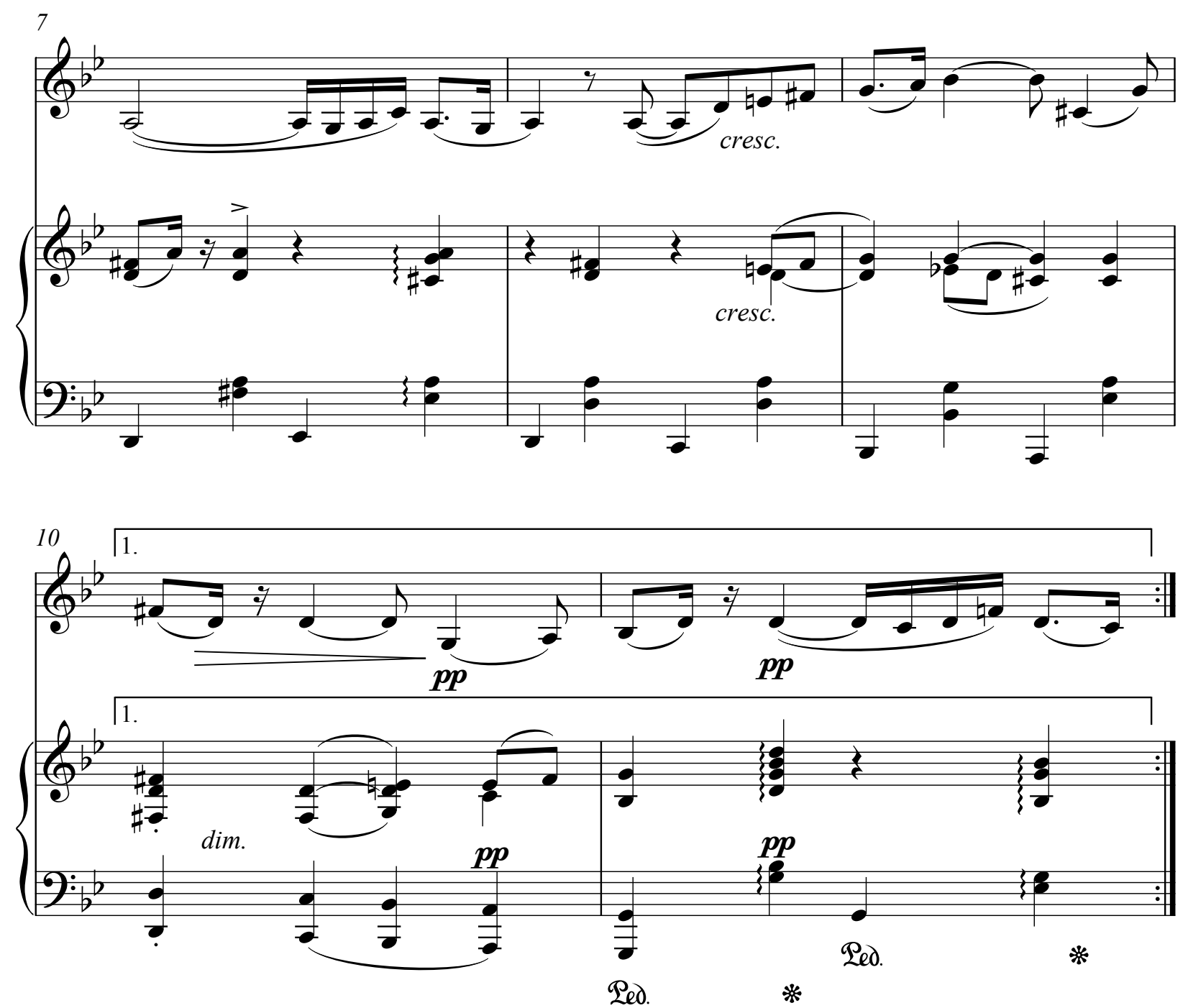

The B section is harmonically more complex. It begins with an Eb major chord, a VI in $\mathrm{g}$ minor. She uses the VI as a pivot chord to move to $\mathrm{C}$ minor. Throughout mm. 13-16 there are multiple progressions which tonicize $\mathrm{C}$ minor. Note the instances of either vii ${ }^{\circ 7}$ or $\mathrm{V}$ which always resolve to $\mathrm{i}$. 
Example 4.11: La Captive, mm. 13-16

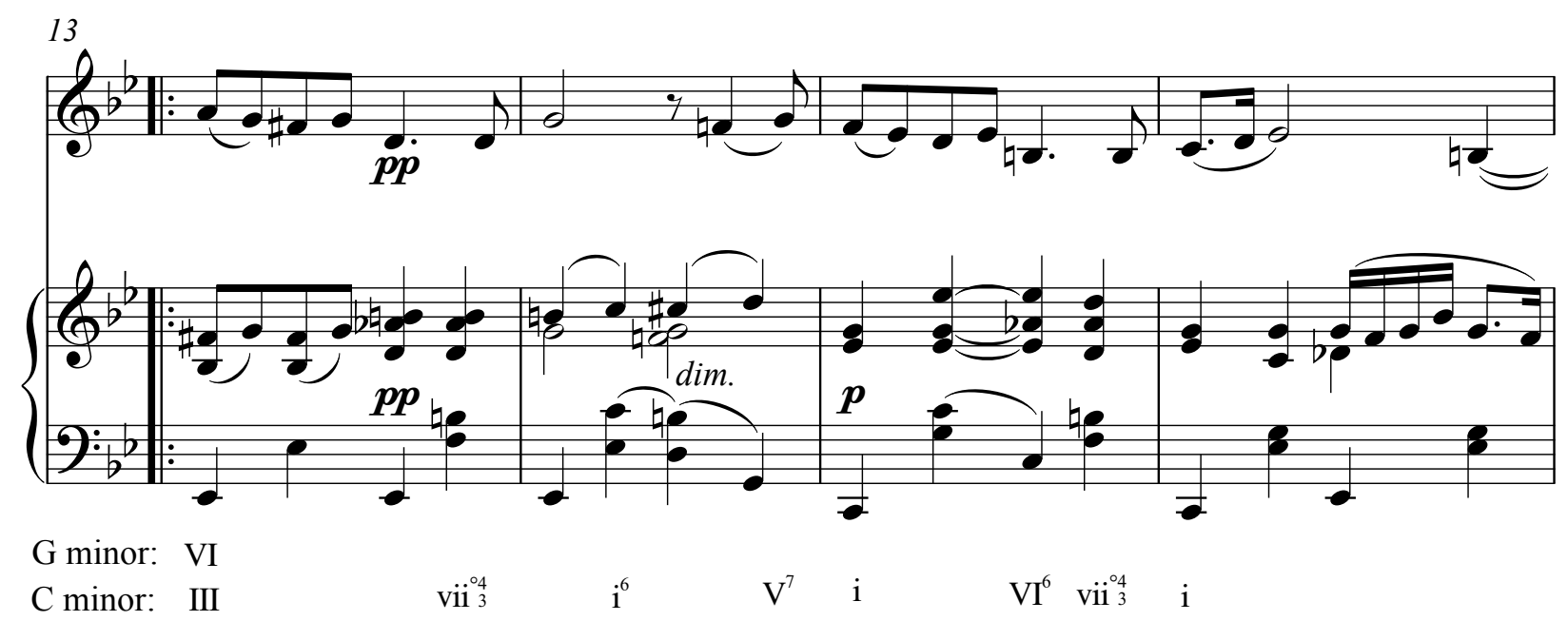

Following $\mathrm{C}$ minor the key moves back to $\mathrm{G}$ minor in $\mathrm{mm} .17-18$. The same type of chord, a vii ${ }^{07}$, tonicizes both the move to $\mathrm{C}$ minor and the return to $\mathrm{G}$ minor. $\mathrm{A} \mathrm{B}^{\circ 7}$ tonicizes the first instance of $\mathrm{C}$ minor (example 4.11) and an $\mathrm{F}^{\mathrm{O}^{\circ 7}}$ tonicizes the return to $\mathrm{G}$ minor (example 4.12).

Example 4.12: La Captive, mm. 17- 18

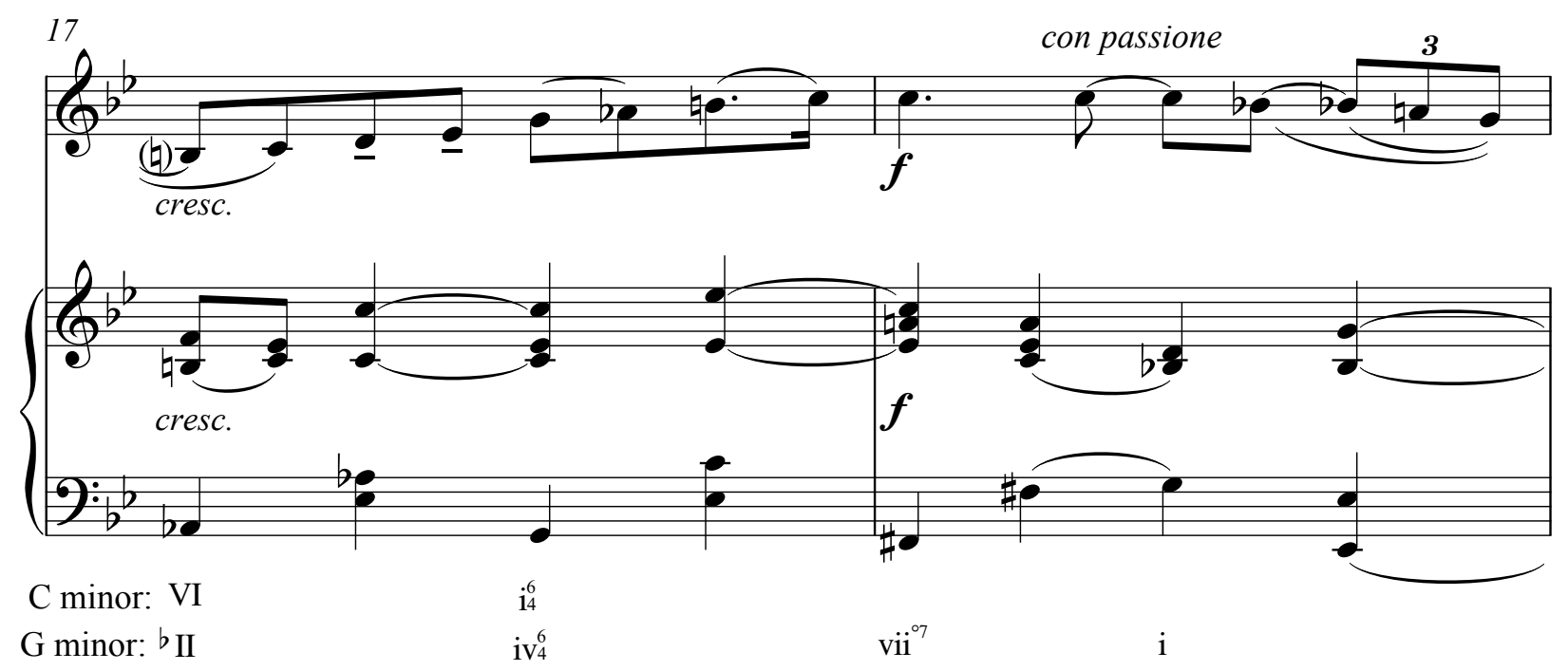


While the coda primarily emphasizes $\mathrm{G}$ (both major and minor), Beach does include other chords that served important roles earlier in the piece. In m. 23 there is an Eb major chord (VI), the same chord that started the B section. There is also a C minor chord (iv) in $\mathrm{m}$. 25, which was a prominent key area in the B section. Lastly, the final five measures reinforce $\mathrm{G}$ major. In fact, the progression leading to the G major chord in $\mathrm{m} .26$ (example 4.13) is preceded by the exact same chords as the return to $\mathrm{G}$ minor in the B section (example 4.12).

Example 4.13: La Captive, mm. 22-26

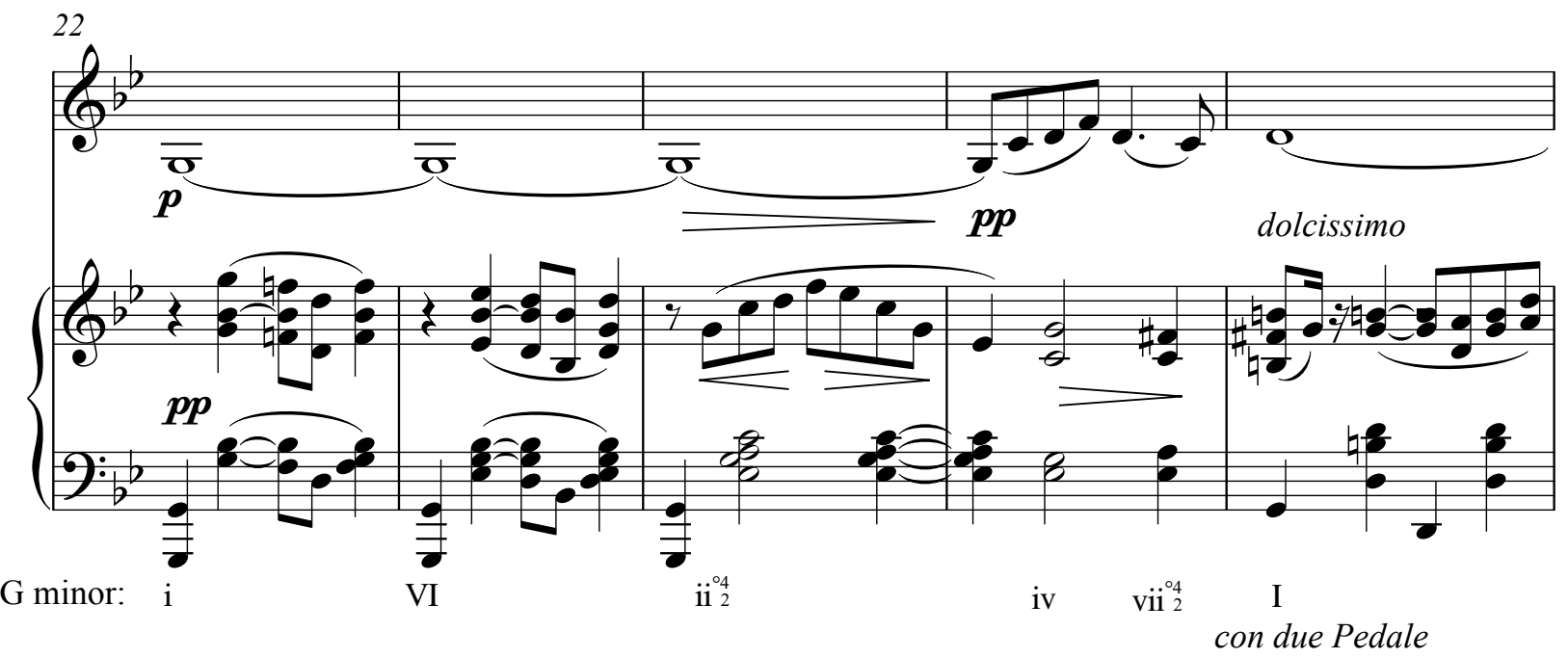

Beach possibly chose to end in major to show hope, as the captive's time of confinement is almost complete. 


\section{Berceuse, Op. 40 No. 2}

Op. 40, No. 2 is titled Berceuse. According to Grove Music Online,

A berceuse is a gentle song intended for lulling young children to sleep. In instrumental music the term usually refers to a character piece for piano. The defining work of the genre is Chopin's Berceuse in Db major Op. 57 (1843-4), a model imitated by several other composers. Its most notable characteristics are compound time, a quiet dynamic level, a tonic pedal bass and a 'rocking' accompaniment oscillating between I and V, over which Chopin places a simple melody later varied with a profusion of filigree passagework. ${ }^{72}$

Keeping in line with the soft dynamics and hushed feel, Beach calls for the solo violin to be muted throughout.

The Berceuse is in ternary form (ABA' with a coda) ${ }^{73}$, and like La Captive, the form is incredibly balanced. After a four measure introduction, each major section is 16 measures long. The only exception is the coda, which is 17 measures. Each major section can be further subdivided into two eight measure phrases, each with its own unique characteristics. In the first section (A), the two eight measure phrases (labeled a and b) begin similarly, as the second phrase is an ornamented echo of the first. Throughout $b$, Beach extends the range and dynamics used in the violin. In a the highest note in the violin is D5, whereas in $\mathrm{b}$ the violin goes a fifth higher to A5. Dynamically a has a crescendo, presumably rather minimal since there is no marked ending dynamic, whereas in $\mathrm{b}$ the marked crescendo goes to a mezzo-forte. Frequently throughout the A section the piano plays the opening melodic fragment, usually as an echo of the violin. This can be seen in mm. 1, 6, 8, 14, 17, and 18 .

\footnotetext{
${ }^{72}$ Kenneth L.Hamilton, "Berceuse." Grove Music Online. Oxford Music Online. Oxford University Press, accessed April 7, 2015, http:/www.oxfordmusiconline/com/subscriber/article/grove/music/02749.

73 Hung, "The Violin Sonata of Amy Beach" 18.
} 
Example 4.14: Berceuse, mm. 1-20

\section{BERCEUSE.}

Mrs. H. H. A. BE ACH.

Op. 40 , No. 2

Andantino con molto tenerezza. con sordino

$\mathrm{A} \mathrm{a}$

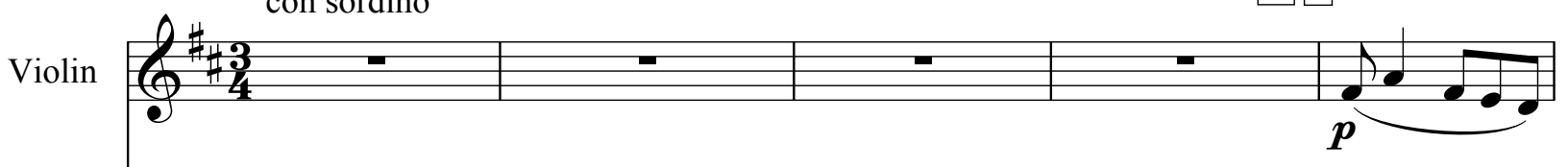

Andantino con molto tenerezza.

dolce

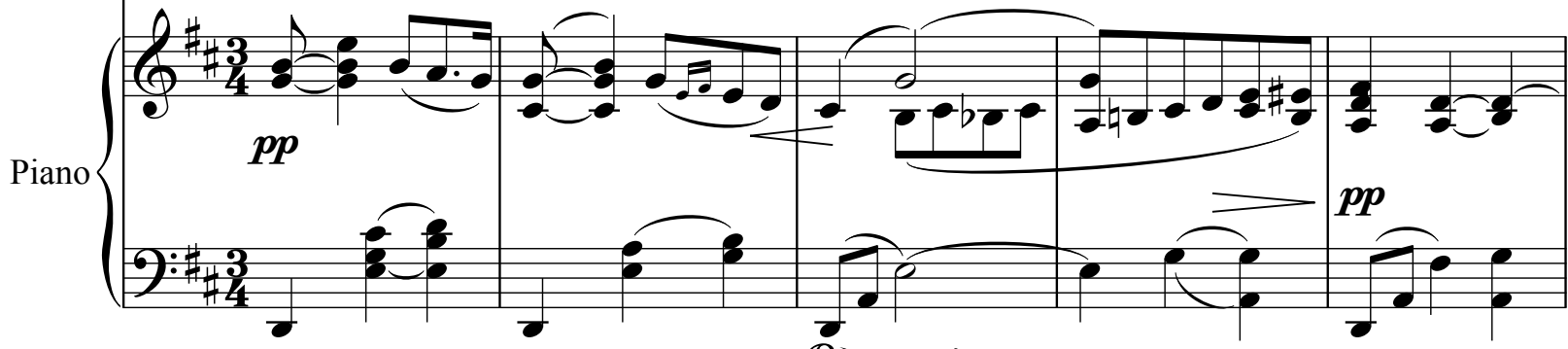

Ted. $*$ Ted.

* Ted. *
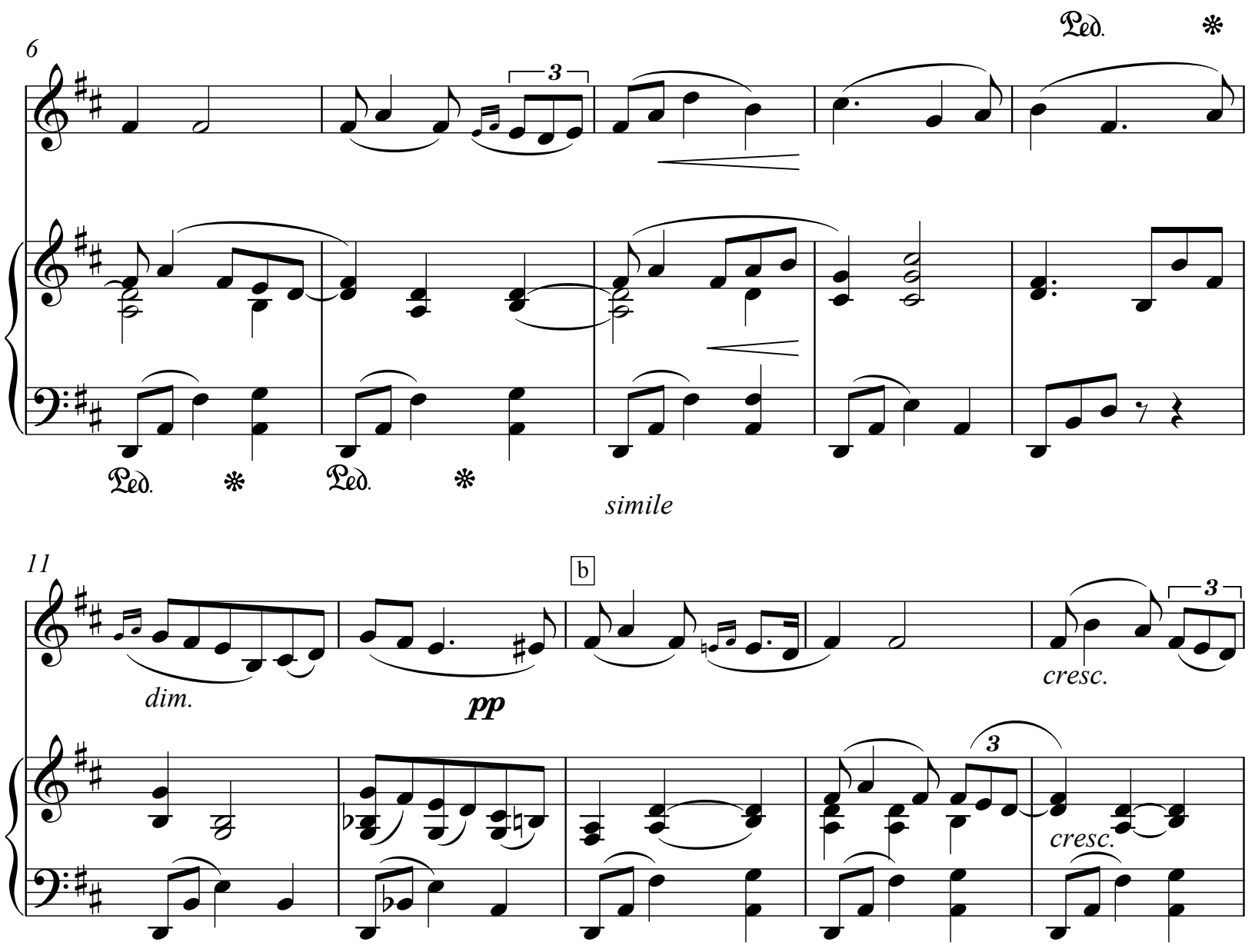
Example 4.14 Cont.

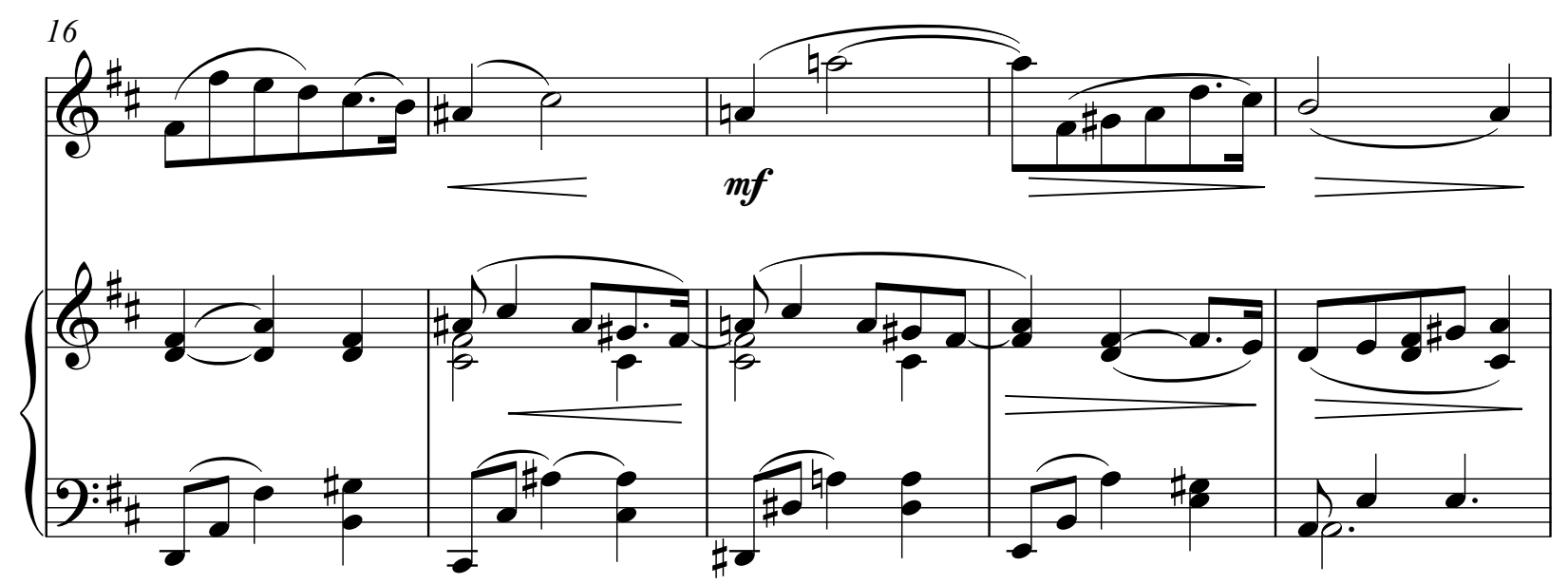

Moving into the B section, the first clear difference is a lack of the primary melodic

motive in the piano during the first eight measures. Also, while there are two clear eight measure phrases in the B section (mm. 21-28 and mm. 29-37), they are not melodically related like the A section. Instead, their division is evident by a register change in the violin and the return of the opening melodic material in the piano (m. 29, example 4.15).

Example 4.15: Berceuse, mm. 27-31

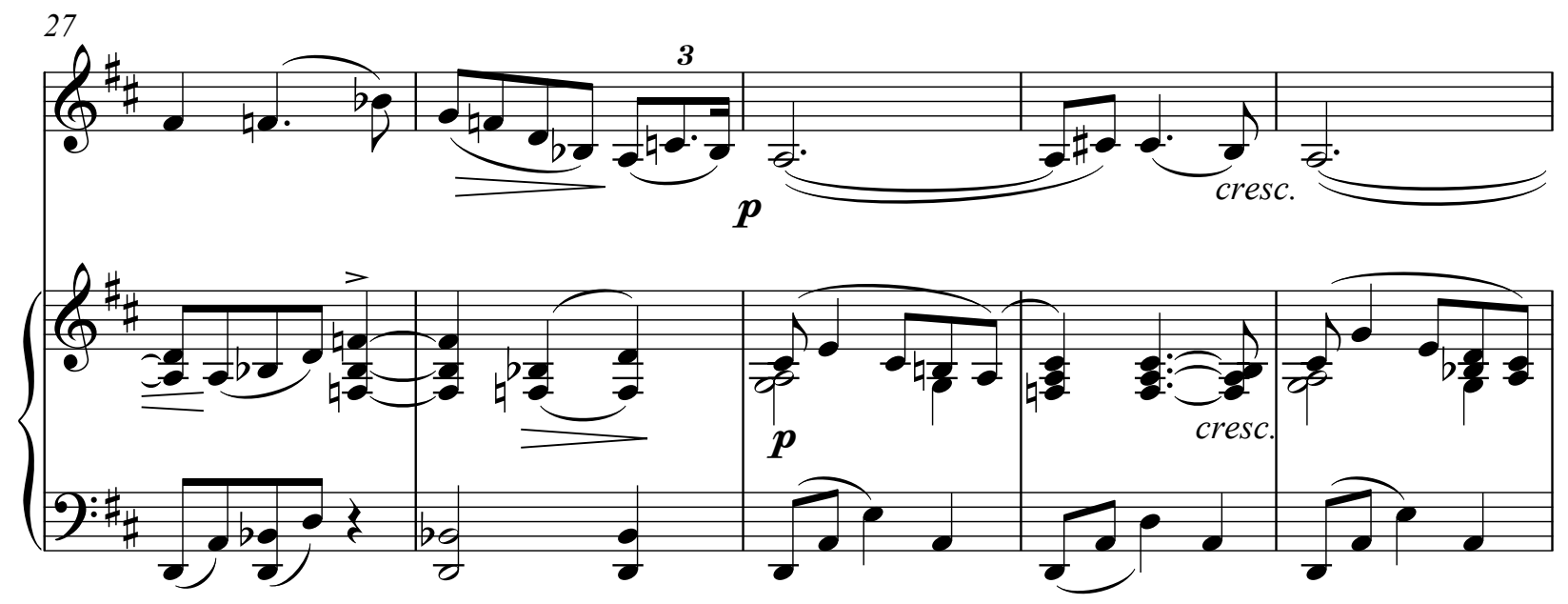


The next major section is A', which is not an exact duplicate of A. Although the general melodic contour remains and certain measures are preserved, Beach does expand the original melody. A good example of this is seen when comparing mm. 9-12 in example 4.14 with mm. 41-44 in example 4.16. Despite these changes to the melody and rhythm there is enough similarity that the listener would likely hear it as a return of the A section. The biggest change in the first eight measures of $\mathrm{A}^{\prime}$ is the lack of dynamics. Up until now, throughout both A and B, there had been dynamic changes occurring at least every few measures. However, from mm. 3546, there are no dynamic markings. An important moment in the A' section is the climax in m.

49. Much like in the Romance, the climax occurs on the highest violin note thus far, a $\mathrm{C} \sharp 6$, and is marked with the loudest dynamic marking used in this piece, forte (example 4.17).

Example 4.16: Berceuse, mm. 41-44

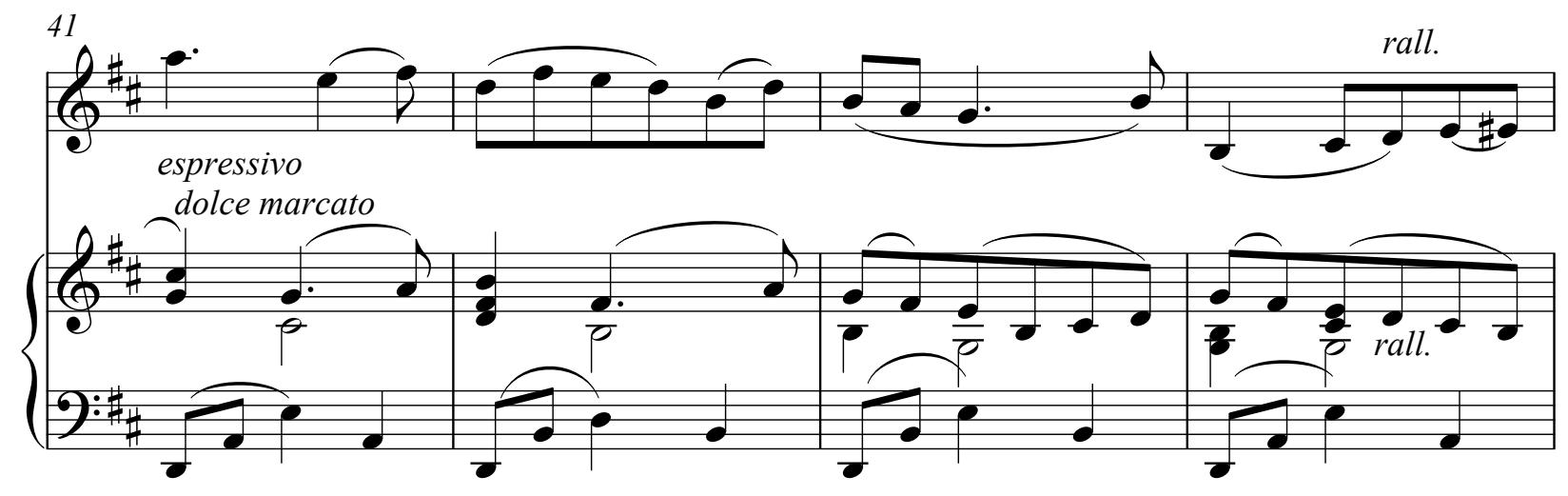


Example 4.17: Berceuse, mm. 48-49

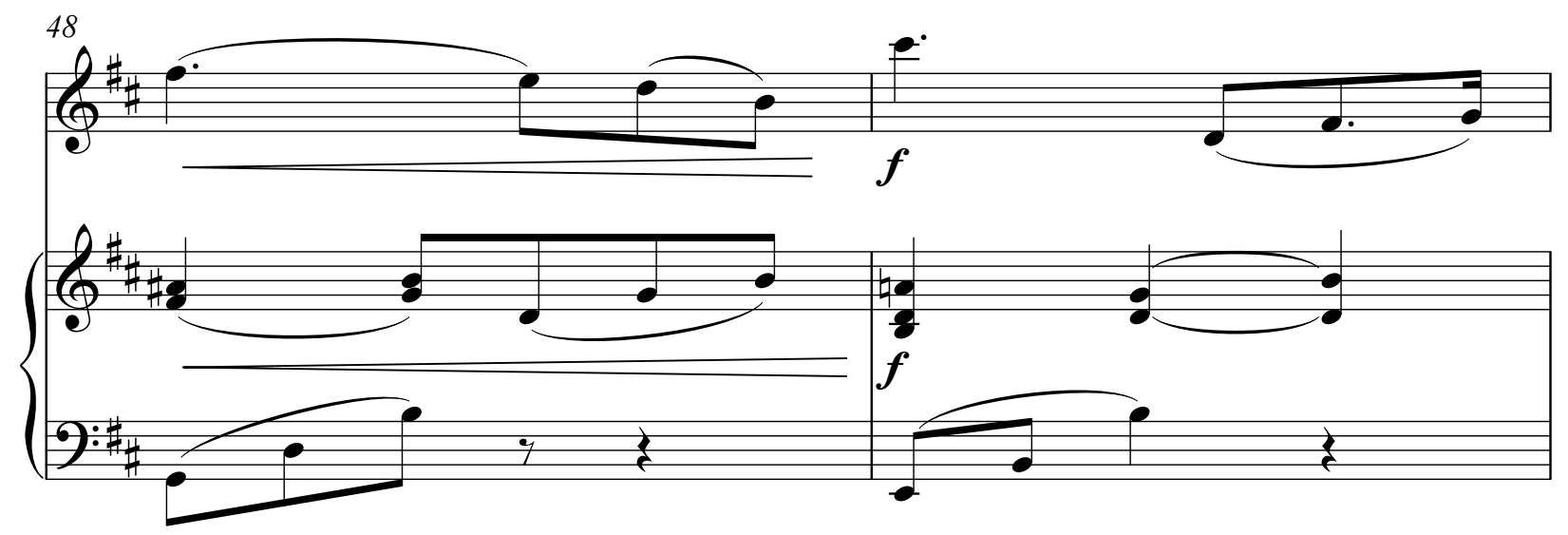

As is commonly the case, the coda is mostly made up of elements from earlier sections.

However, there is some new material presented in $\mathrm{mm}$. 59-61, a scale which climbs to the highest note of the piece for the violin, a F\#6 (example 4.18). Dynamically, the entire coda is marked pianissimo. Five measures after the initial pianissimo marking Beach reiterates the dynamic with a sempre pianissimo. Seven measures before the end there is also a poco a poco ritardando al fine and a morendo at the end. Through the dynamics and tempo markings, there is a clear sense of unwinding.

Example 4.18: Berceuse, mm. 59-61

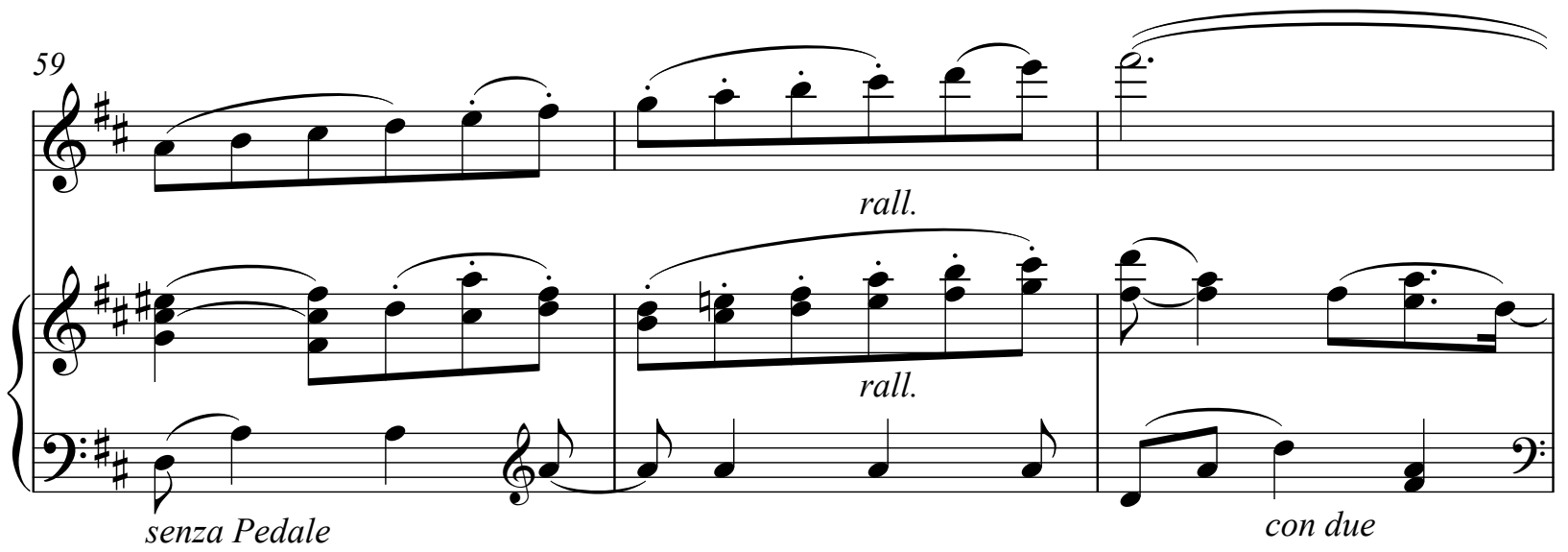


Beach incorporates many of the harmonic tendencies found in Chopin's Berceuses. This piece is primarily in $\mathrm{D}$ major. In the first section there is a tonic pedal from mm. 1-17 where it moves, over the course of four measures, to the dominant (example 4.19).

Example 4.19: Berceuse, mm. 16-20

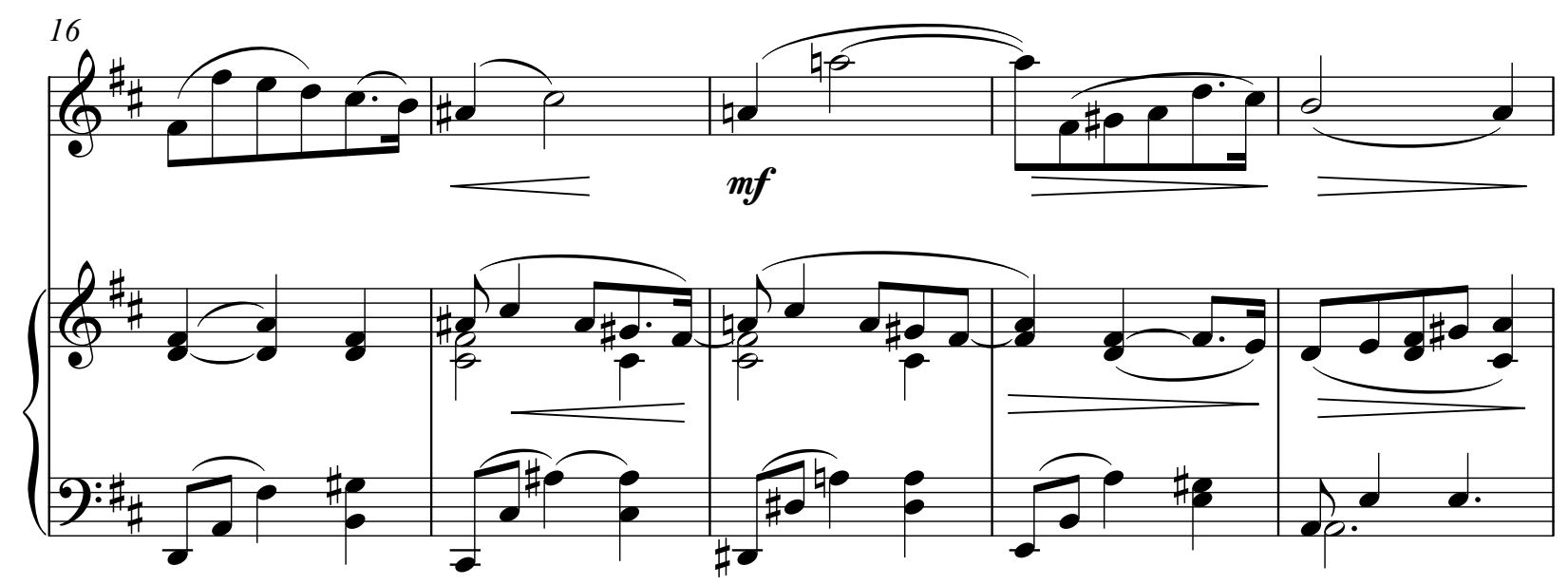

An analysis based only on the bass clef pitches of the piano in mm. 5-10 (example 4.20), would imply the "rocking" accompaniment oscillating between I and $\mathrm{V}^{74}$. However, when the treble clef is taken into account, the apparent IV chord over the dominant in the bass produces a $\mathrm{V}^{11}$. Measure 9 contains a fully realized dominant seventh chord on beats two and three to set up the authentic cadence in $\mathrm{m} .10$ (example 4.20). The other harmonic moment of note in the A section is the brief tonicization of the dominant in mm. 18-20 (example 4.21).

74 Hamilton, “Berceuse.” 
Example 4.20: Berceuse, mm. 5-10
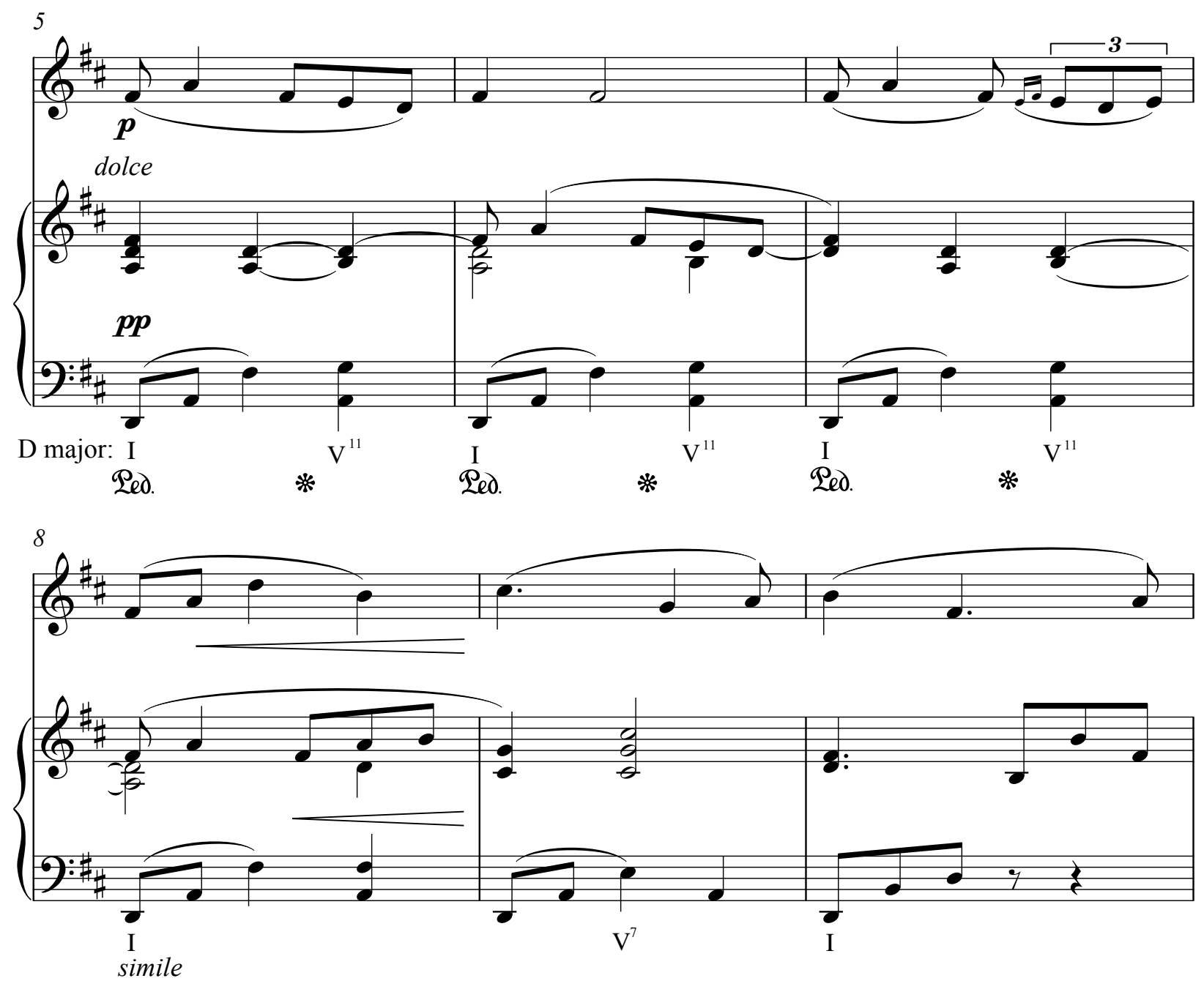

Example 4.21: Berceuse, mm. 18-20

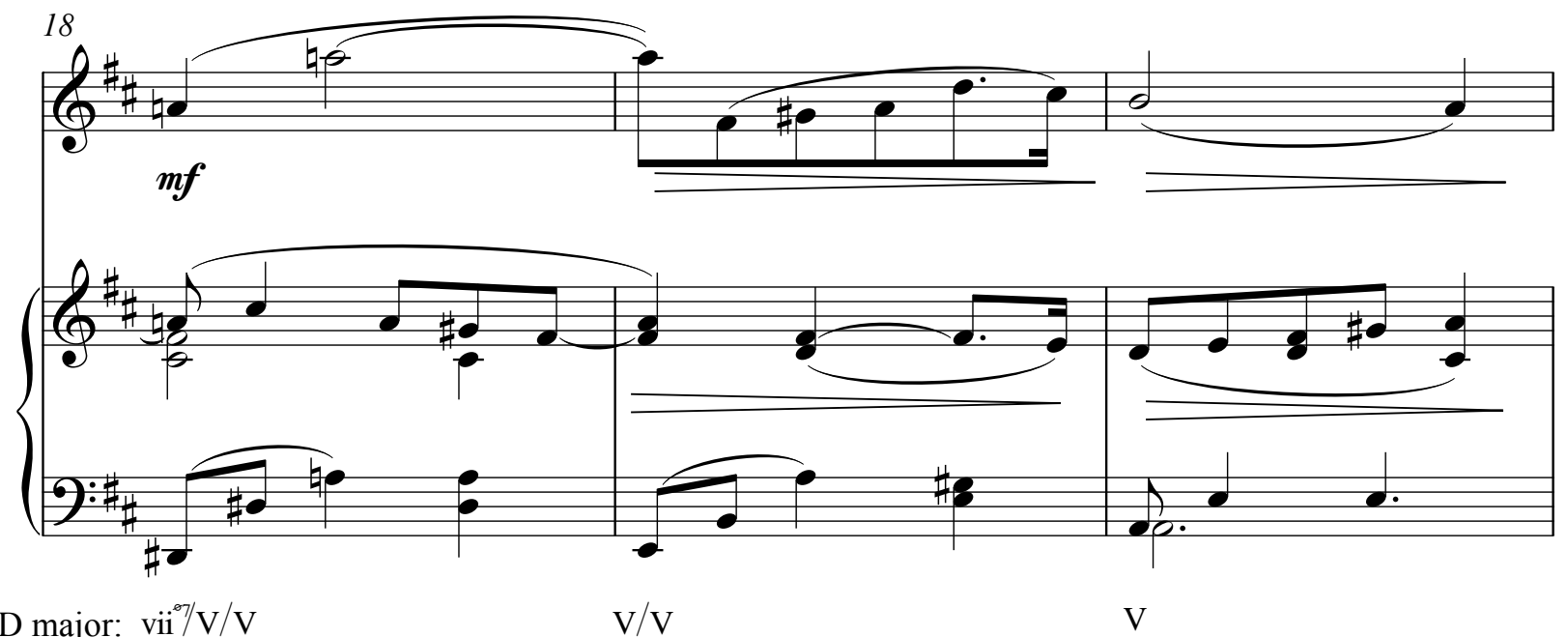


As a contrast to A, the B section quickly moves away from dominant and tonic harmonies. Beach starts off on a iv, beginning a descending circle progression in mm. 21-25. This progression is best analyzed within the key area of $\mathrm{D}$ minor. $\mathrm{A} \mathrm{Fr}^{+6}$ breaks the circle progression in $\mathrm{m} .26$, and then resolves to a $\mathrm{D}$ major chord. $\mathrm{The}^{\mathrm{F}}{ }^{+6}$ serves as a substitute for the expected dominant chord, which then resolves to the major tonic. This type of progression, $\mathrm{ii}^{67}$ $\mathrm{Fr}^{+6}-\mathrm{I}$, which came to be know as a tritone substitution, is a common jazz progression that developed in the mid to late 1930s, over 30 years after this piece was written. As mentioned in the previous chapter there is precedent for resolving an augmented sixth chord to tonic. What makes Beach's progression unique is the $\mathrm{Fr}^{+6}$ serving as the dominant substitute and then resolving to the tonic. To the author's knowledge there is no precedent in the classical repertoire for this progression. This is a fascinating topic that is worthy of future scholarly research.

Example 4.22: Berceuse, mm. 21-27

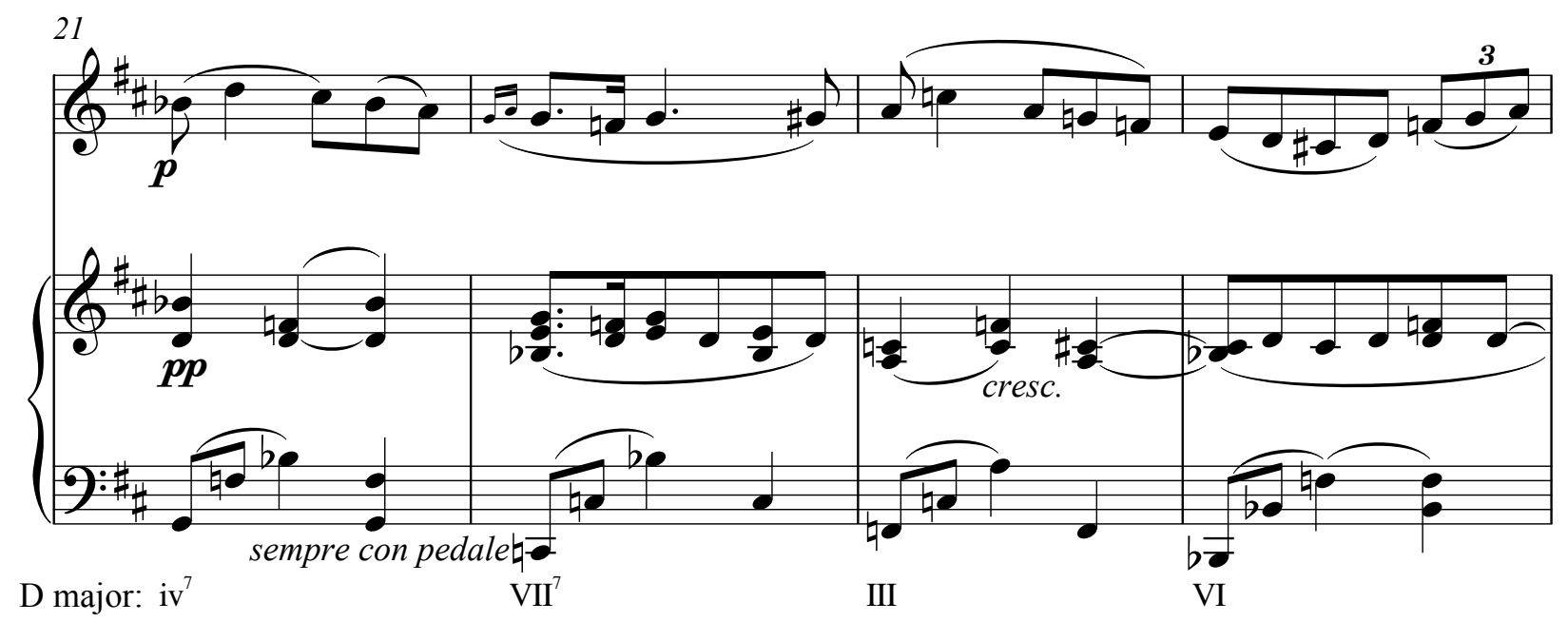


Example 4.22: Cont.

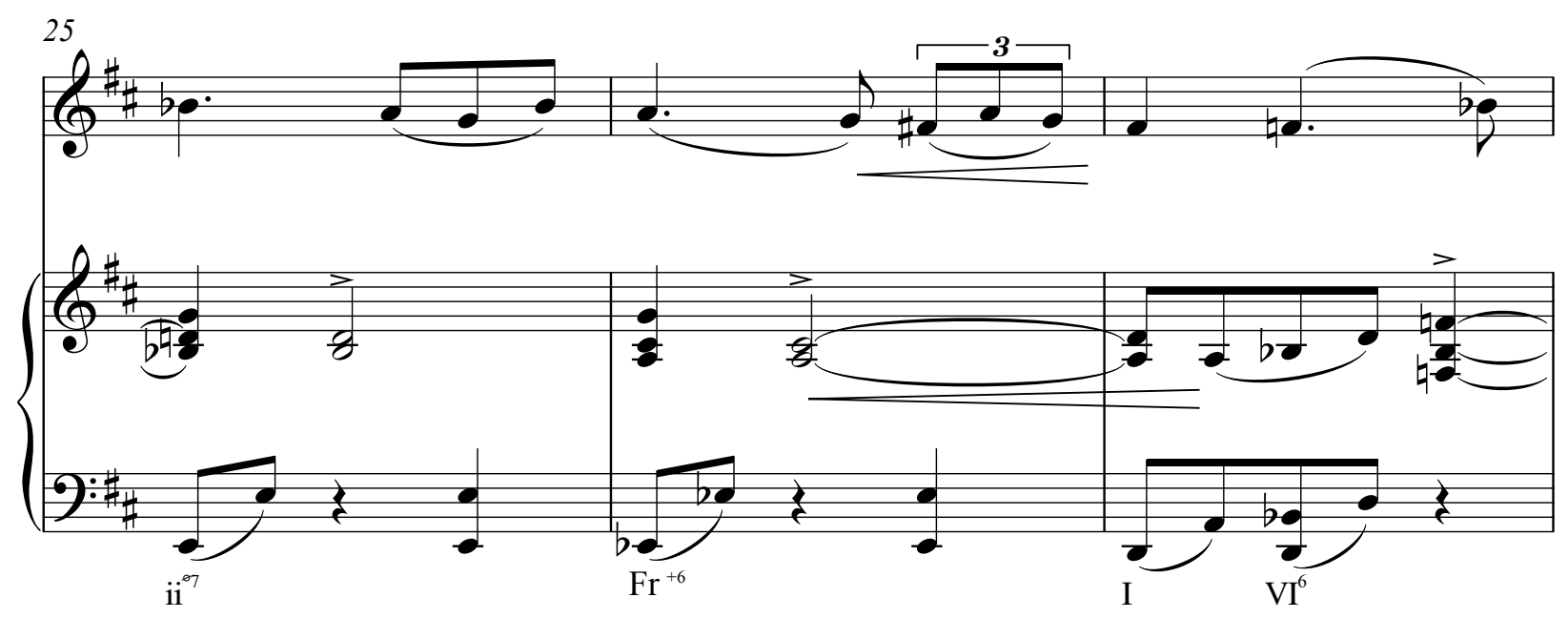

Although the tonic pedal returns in $\mathrm{m} .27$, other than the downbeat of $\mathrm{m} .27$ there is no major tonic harmony in the entire B section. Instead, the tonic pedal functions in a variety of ways. These include as a non-chord tone (m. 29), within various non-tonic harmonies (m. 27), or within a modally borrowed i harmony (m. 30).

Example 4.23: Berceuse, mm. 27-36

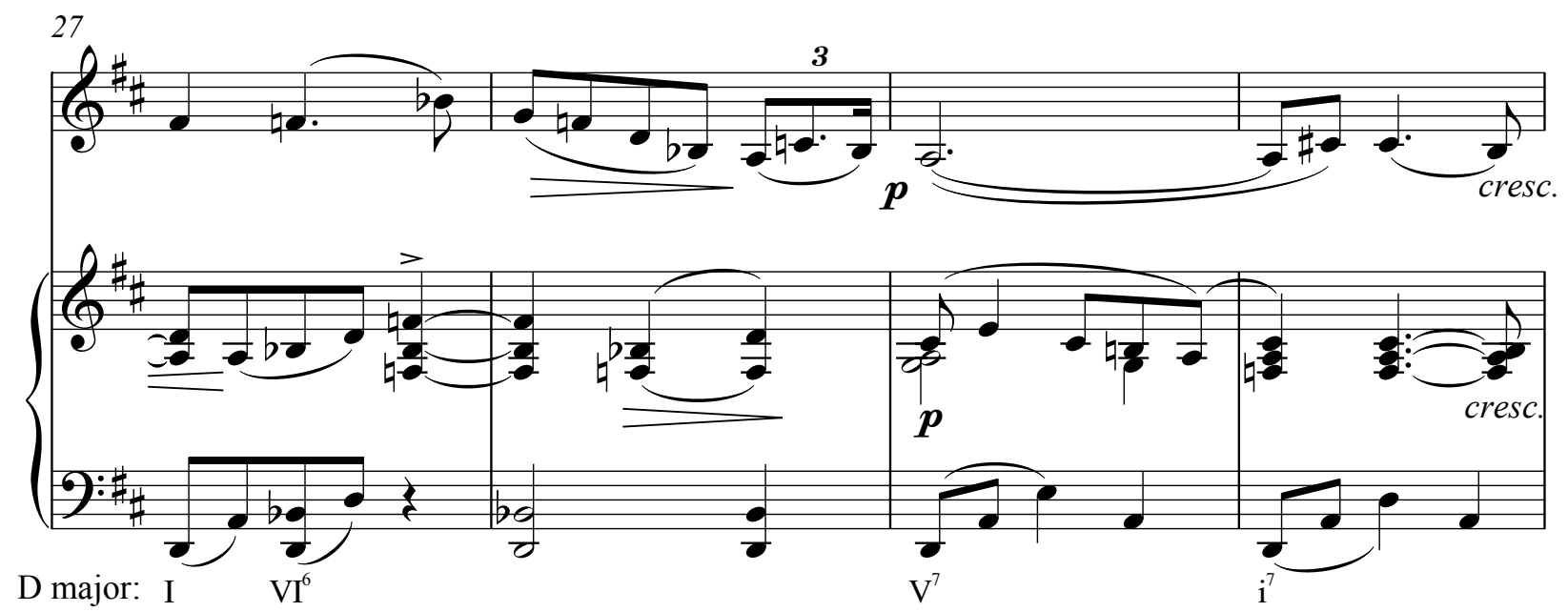


Example 4.23: Cont.

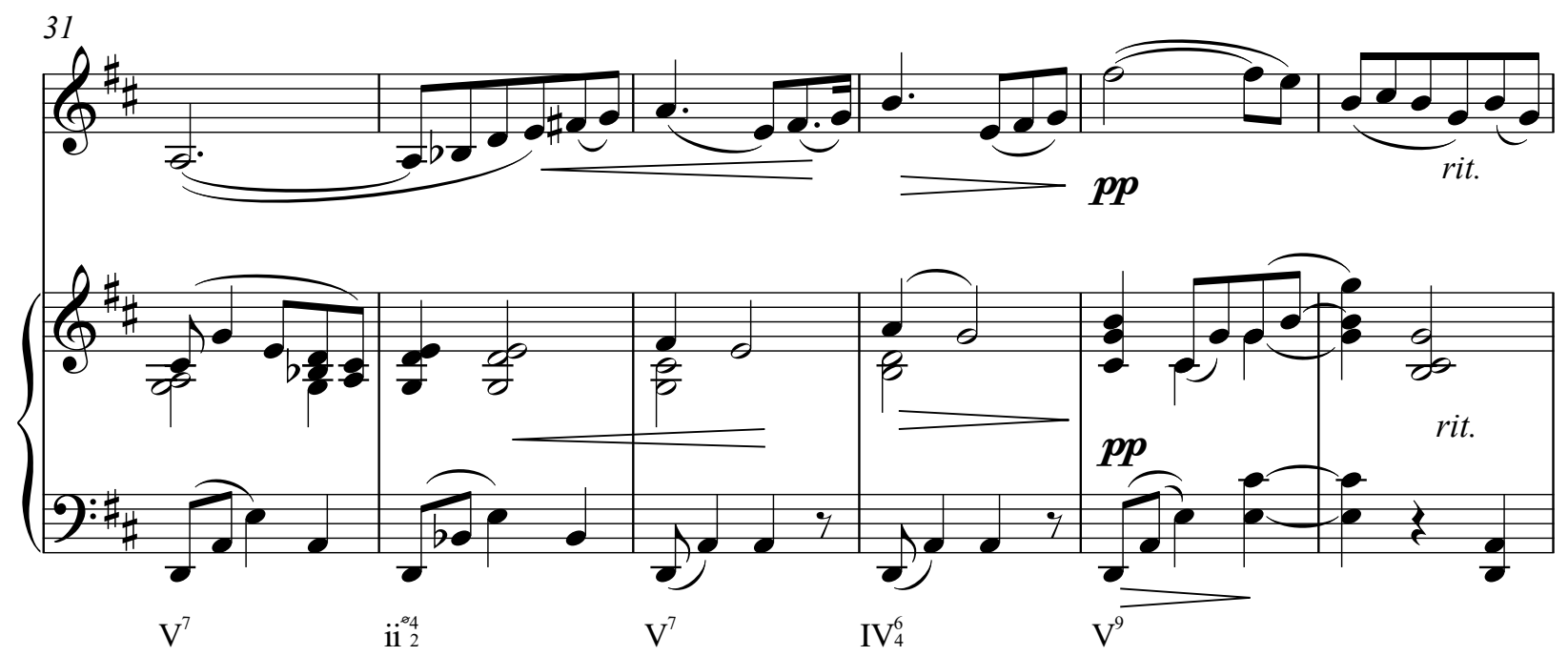

The harmonies in A' are initially a duplicate of A. Measures $42-45$ contain the first deviation, where Beach chose to write a clear cadential progression of vi-ii-IV-V-I (example 4.24). Melodically this is the equivalent to mm 10-13. The next deviation from the A section happens in $\mathrm{mm} .47-48$. These measures contain a tonicization of IV, while ultimately returning to D major (example 4.25).

Example 4.24: Berceuse, mm. 42-45

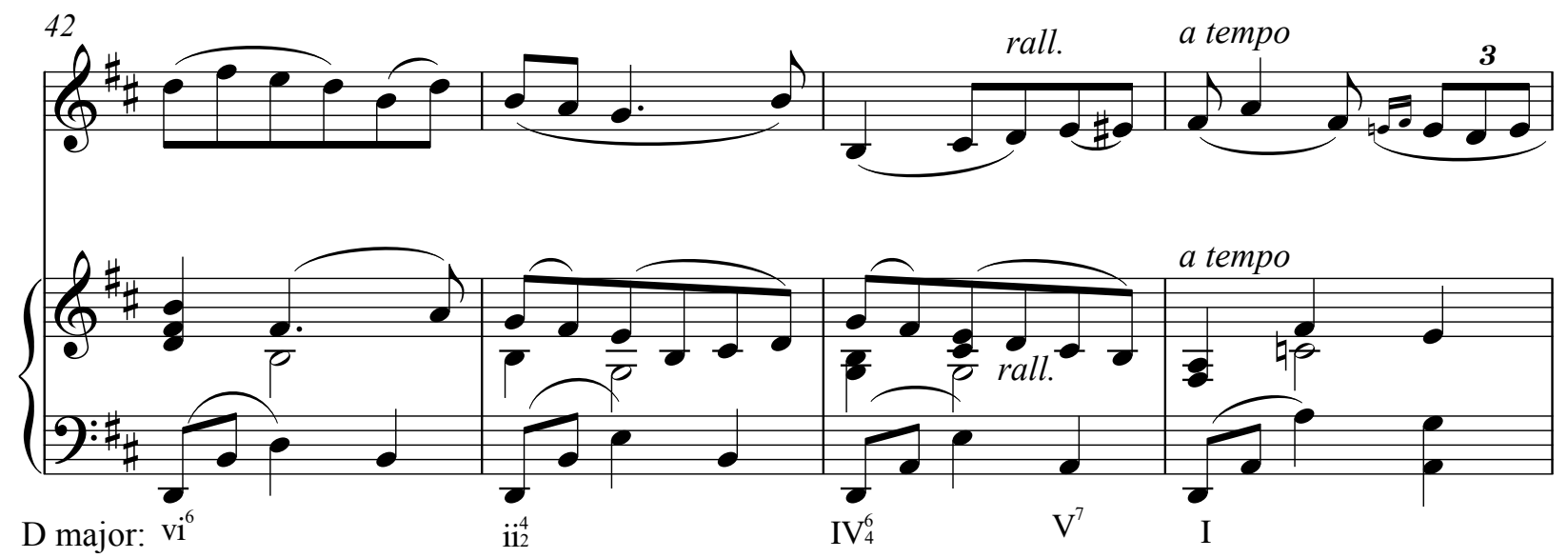


Example 4.25: Berceuse, mm. 47-53
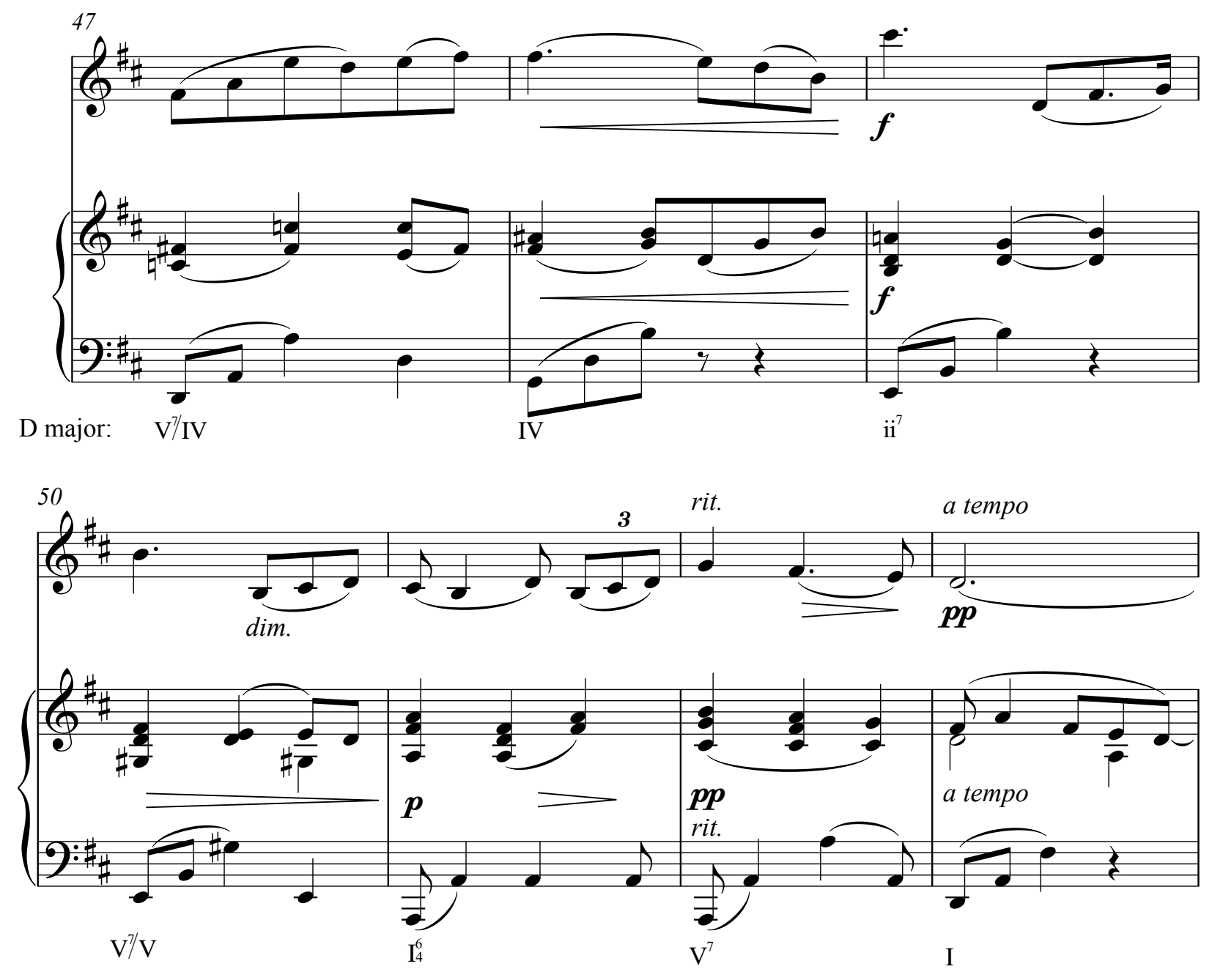

The coda returns to a simpler harmonic language, using primarily tonic and dominant harmonies. A tonic pedal is constant throughout the coda except in m. 59-60 where it briefly switches to a dominant pedal (example 4.18). Finally the piece concludes with a heavenly plagal cadence. 
Example 4.26: Berceuse, mm. 64-69

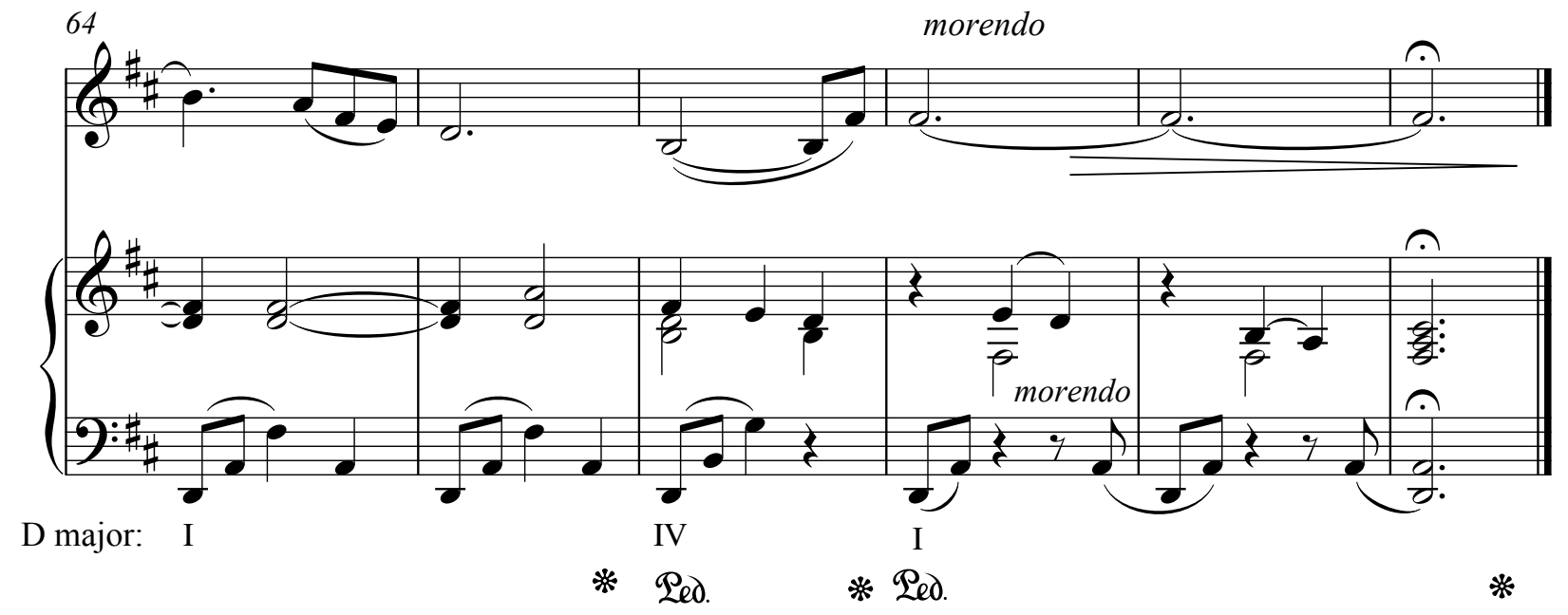

Given the soft, slow, and gentle nature of the ending, the baby is no doubt finally sleeping soundly. 


\section{Mazurka, Op. 40 No. 3}

The third piece in Beach's Opus 40 collection is the Mazurka. A mazurka is a Polish dance from the Mazovia region. As is commonly known, the mazurka in concert music was made famous by Chopin. The tempo of a mazurka should be on the slower side, yet maintain a lively character. Traditionally a mazurka was often accompanied by bagpipes. In concert music a pedal tone, usually on the tonic or dominant, serves to represent the bagpipes. Chopin's mazurkas were known for having a short call and response pattern one or two measures in length. One of the most well known characteristics of a mazurka is the emphasis on the weak beat of a triple meter. ${ }^{75}$ All of these elements can be found in Beach's Opus 40, No. 3.

The form of this mazurka is ternary. ${ }^{76}$ It begins with a four measure introduction and is followed by the A section from mm. 5-52. The middle section, B, is marked più mosso and contains a moto perpetuo line of eighth notes for the violin. The return of the A section (A') occurs in $\mathrm{m} .70$. Thus far, in the other pieces of this collection, all the forms have been very balanced. While the form is very clear in this piece, each section has its own unique length. The outer sections are a similar length, 48 and 41 measures respectively, while the middle section is 32 measures long, written as 16 measures with a repeat.

The introduction and first A section provide a good representation of many common characteristics found in a mazurka. In $\mathrm{m} .1$ the top voice of the piano has a one bar fragment which is echoed in $\mathrm{m} .2$ by the bottom voice of the piano. This is a good example of the short

\footnotetext{
75 Stephen. Downes, "Mazurka." Grove Music Online. Oxford Music Online. Oxford University Press, accessed May 5, 2015, http://www.oxfordmusiconline.com/subscriber/article/grove/music/18193.

76 Brown, Amy Beach and Her Chamber Music, 192.
} 
call and response pattern. Once the A section begins there is a tonic pedal throughout the first eight measure phrase. Frequently there are accents written on the second beat of a measure. All of these characteristics are shown in example 4.27.

Example 4.27: Mazurka, mm. 1-12

\section{MAZURKA.}
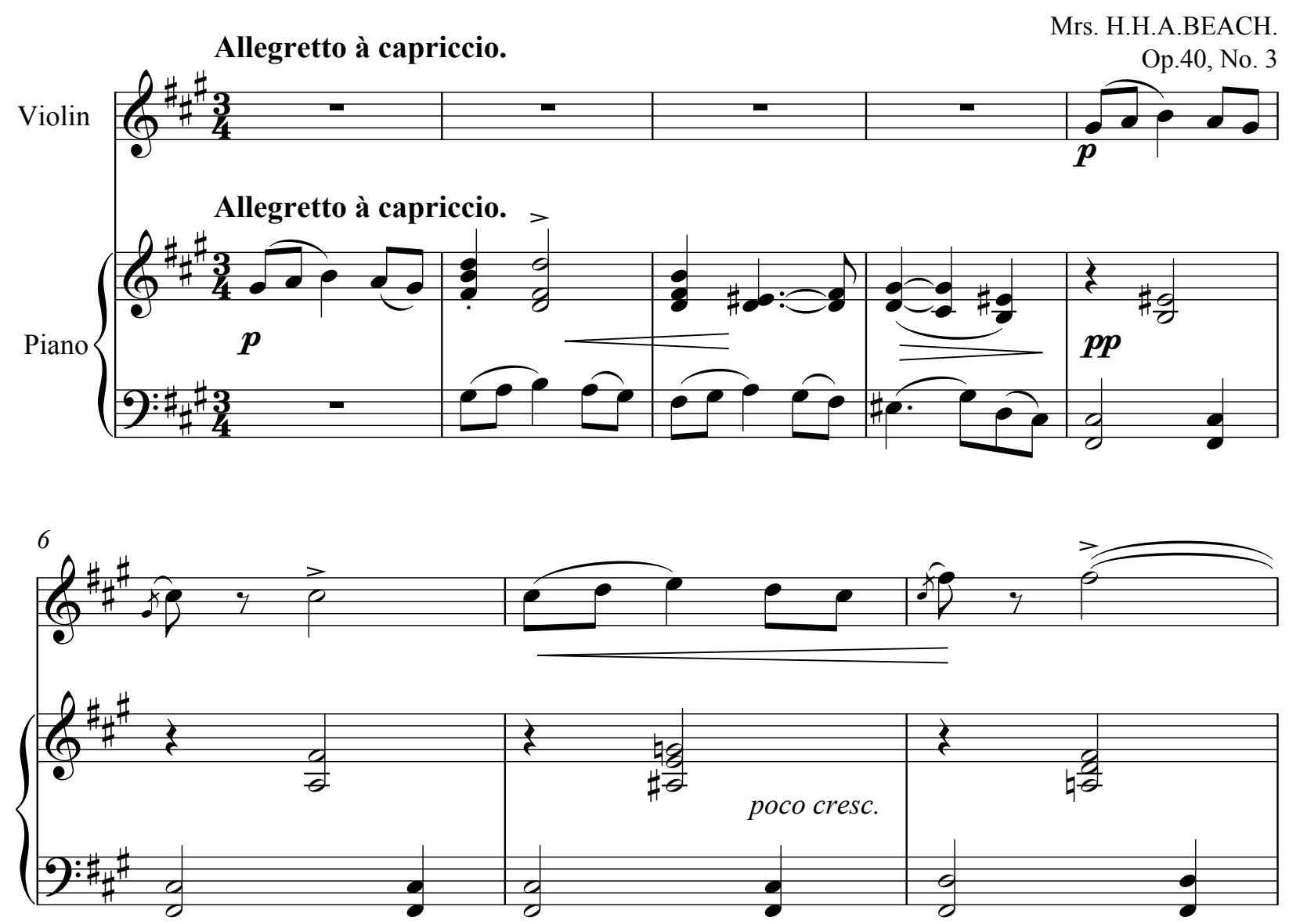
Example 4.27: Cont.

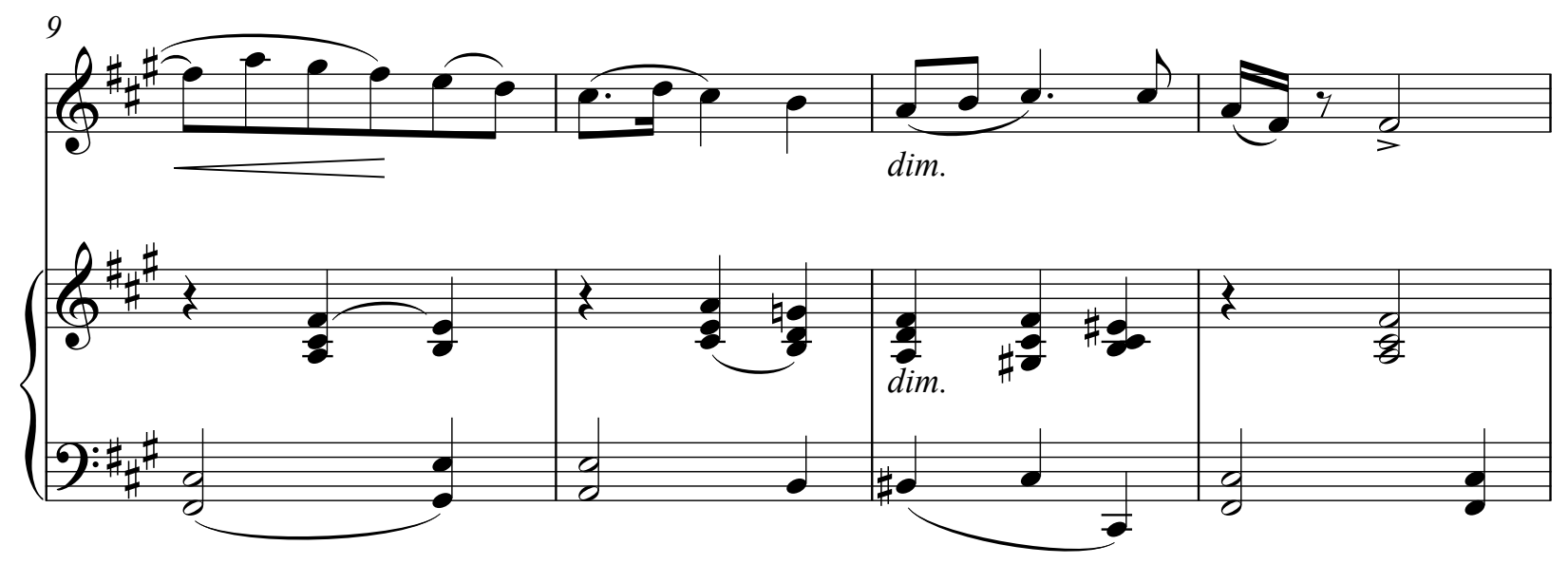

One of the most interesting aspects of this particular piece is how Beach organizes each of the major sections. Within the A section of the ternary form, she also has a smaller ternary form. Starting with the violin entrance in $\mathrm{m}$. 5, each group of eight measures can be labeled "a" through "f". Furthermore, they can be grouped into three sections, a/b, c/d, and e/f. The outer sections, $\mathrm{a} / \mathrm{b}$ and e/f are related, creating a smaller ternary within the larger ternary.

Within the first small section, a, the violin has the melody while the piano has an accompaniment pattern which emphasizes the second beat of each measure. At the beginning of the $\mathrm{b}$ section (m. 13), the piano has the melody at the same pitch level originally presented by both the violin and piano during their first entrances. The violin and piano entrances can be seen in example 4.27 and the beginning of the b section can be seen in example 4.28. Starting in $\mathrm{m} .17$ the violin regains the melodic material. In fact, $\mathrm{mm}$. 9-10 and $\mathrm{mm}$. 17-18 are very similar for the violin, just an octave higher. Measures 9-10 can be seen in example 4.27 whereas mm. 17-18 are shown in example 4.28. It is quite clear how $a$ and $b$ are melodically related and can be considered a unit. 
Example 4.28: Mazurka, mm. 13-18
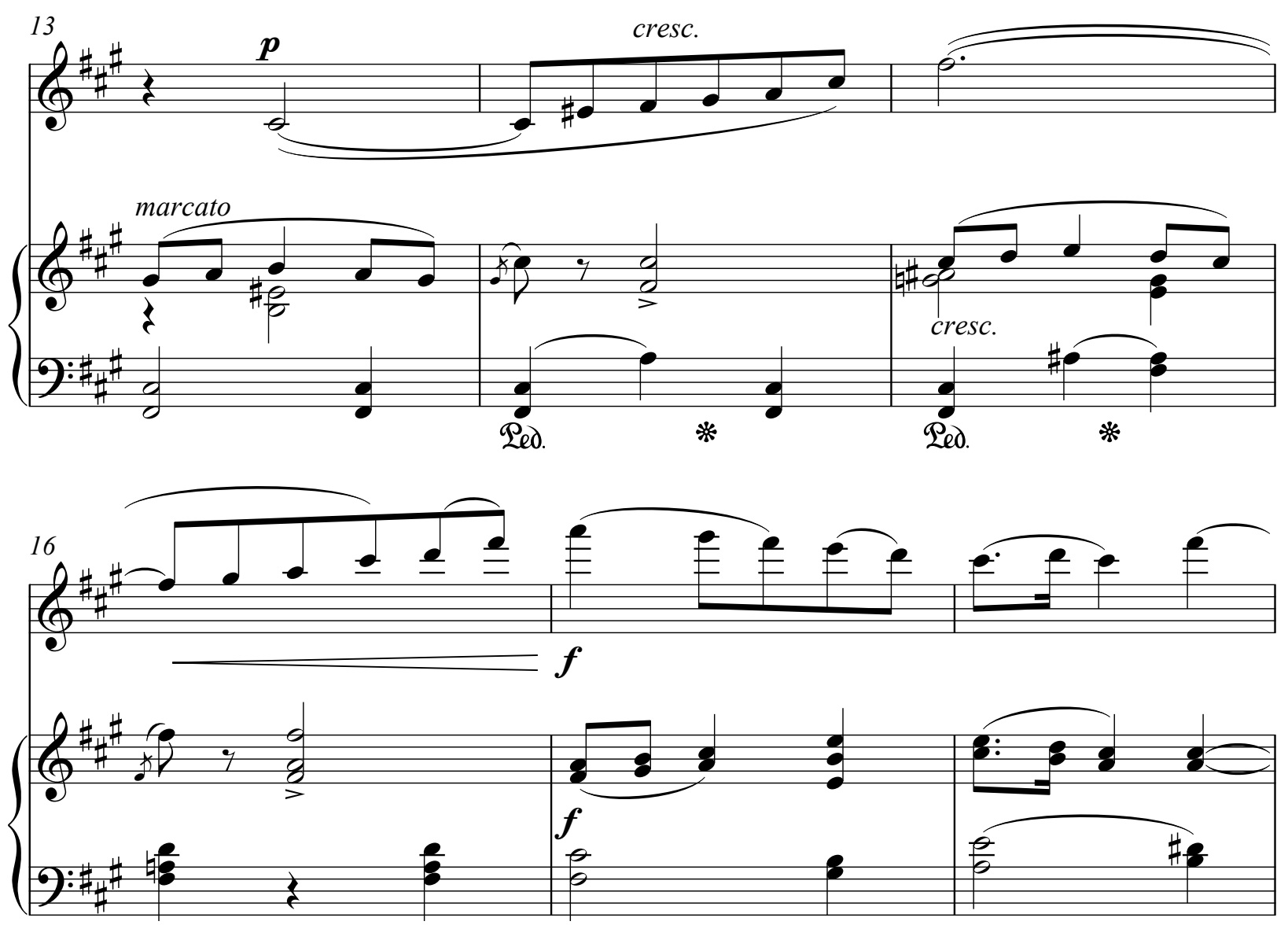

The next section, c, begins with a new melodic idea. The violin contains a sigh figure shown in mm. 21-23 and mm. 25-28 below.

Example 4.29: Mazurka, mm. 21-28

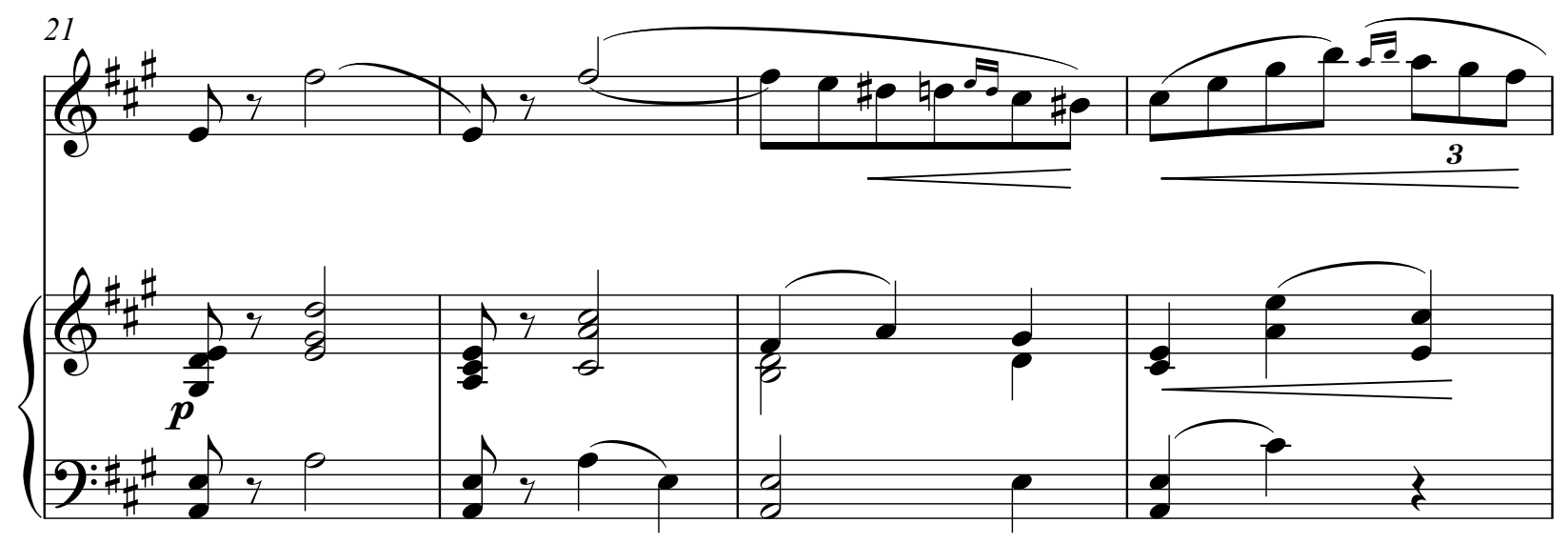


Example 4.29: Cont.

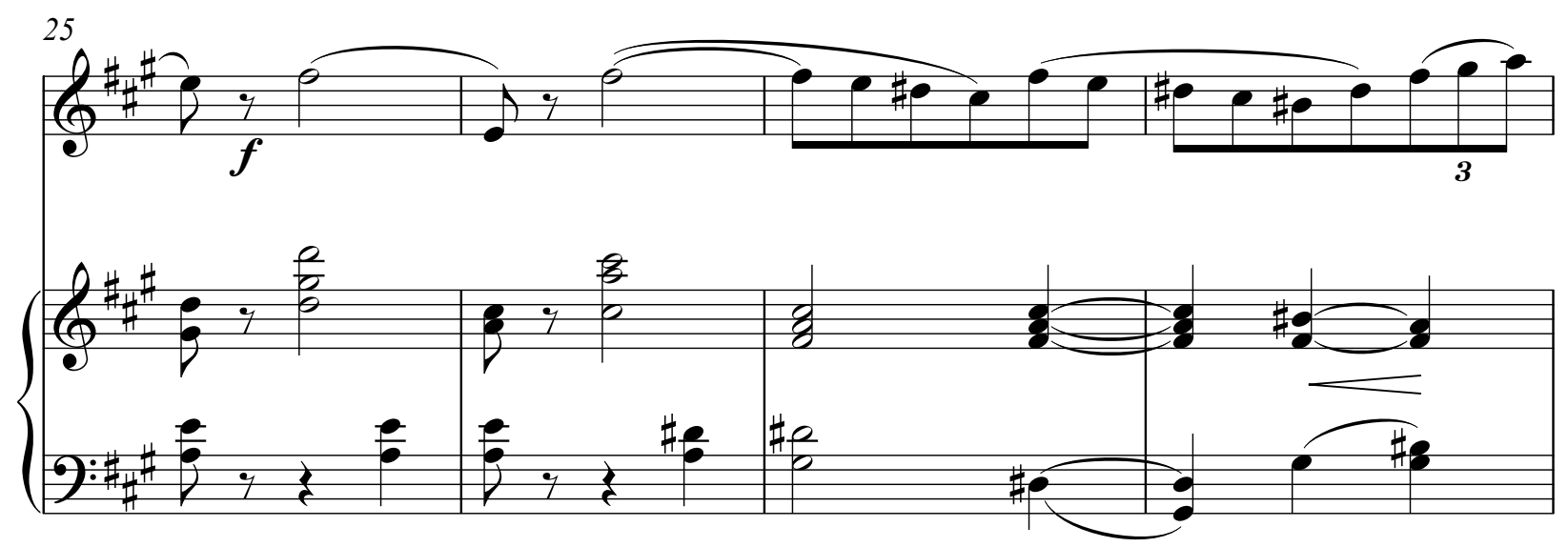

Similar to $\mathrm{a} / \mathrm{b}$, the $\mathrm{c}$ section contains multiple examples of Beach emphasizing the second beat. In mm. 21-22 and 25-26 (example 4.29) it is possible to imagine moving the bar lines so the second beat becomes the downbeat. Beach also writes a hemiola in mm. 27-28 (example 4.29) that results in the second beat of $m .28$ being emphasized.

Melodically the $\mathrm{d}$ section is separate from the $\mathrm{c}$ section. However, it is the harmonic implications and connections which allow these two smaller sections to be grouped together. A detailed discussion of this point will take place later. One of the unifying factors throughout the $\mathrm{d}$ section is the use of a $\mathrm{C} \#$ pedal tone. This pedal tone begins in $\mathrm{m}$. 29 and continues almost uninterrupted through $\mathrm{m} .39$, which is the third measure of the e section. Throughout $\mathrm{c}$ and $\mathrm{d}$ there is almost no hint of the opening melodic motive, except in the right hand piano line from mm. 29-30. 
Example 4.30: Mazurka, mm. 29-39
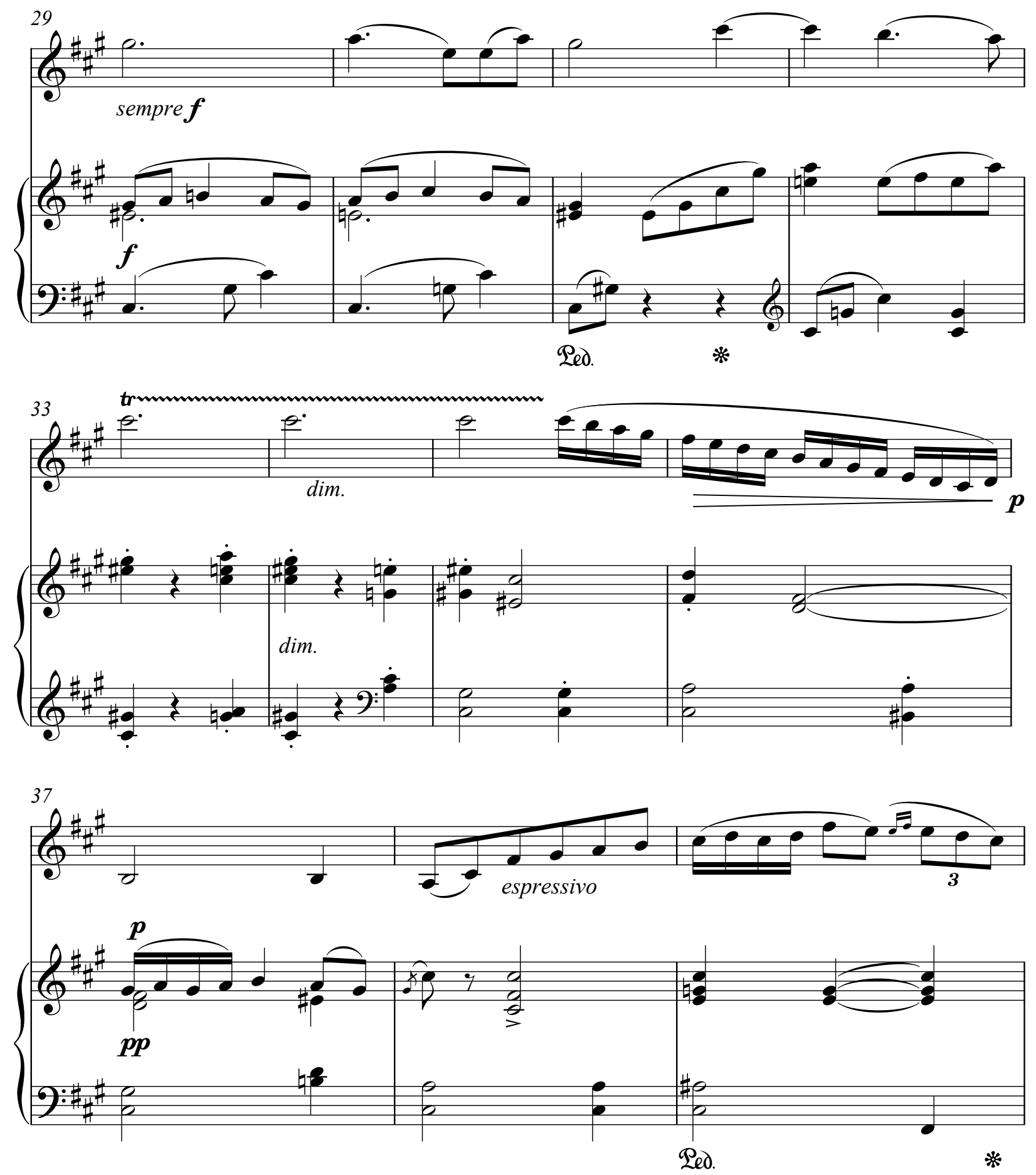
The e section begins with an ornamented version of the opening melodic motive (m. 37 in example 4.30). The ornamentation used in $\mathrm{m} .37$ sets a pattern for how the motive will be presented throughout e and $\mathrm{f}$. In example 4.30 it is easy to see the relationship between the top voice of the piano in $\mathrm{m} .37$ and the violin line in $\mathrm{m} .39$. The $\mathrm{f}$ section begins in $\mathrm{m} .45$ with an almost identical ornamentation.

Example 4.31: Mazurka, mm. 45-48

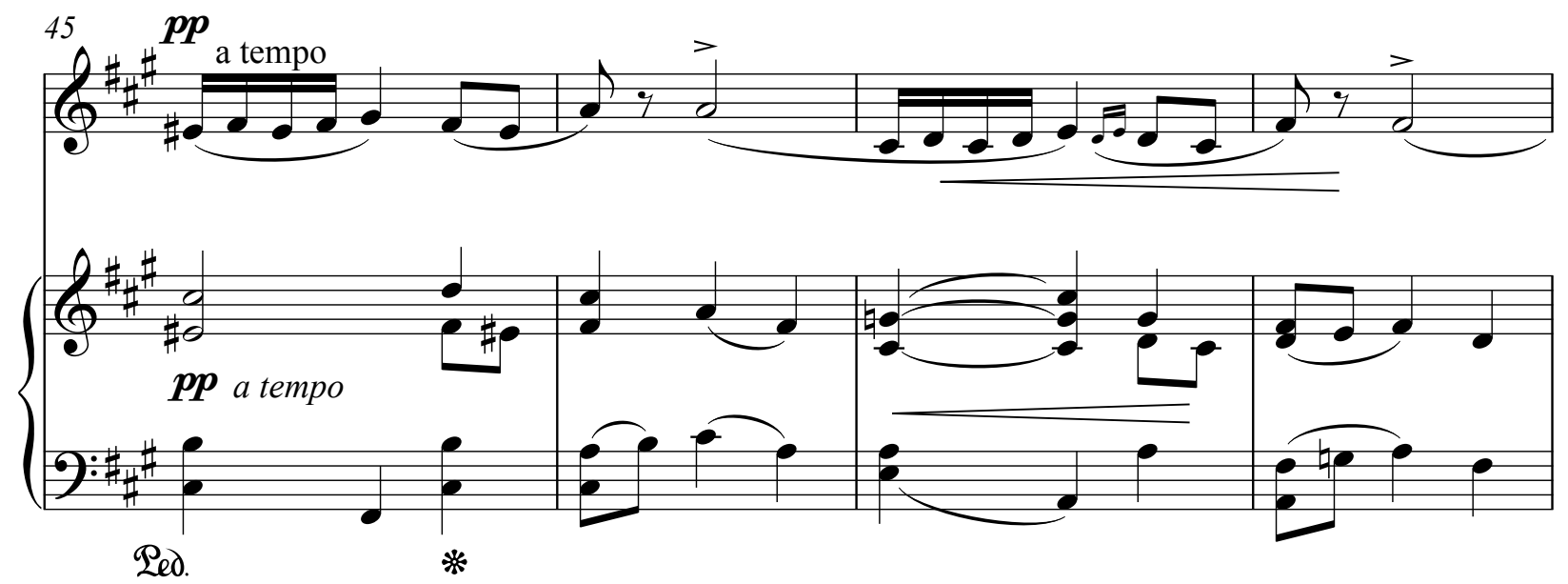

Since the $\mathrm{f}$ section serves as the closing phrase for $\mathrm{A}$, it appropriately includes melodic themes found in the a, c and d sections. The motive from the introduction/a section is clearly shown in example 4.31 above, while the motive from the c section can be found in $\mathrm{mm}$. 48-49 (example 4.32). Lastly, the f section closes on a figure that is very similar to the end of the $d$ section (m. 36 in example 4.30), only inverted. 
Example 4.32: Mazurka, mm. 48-52

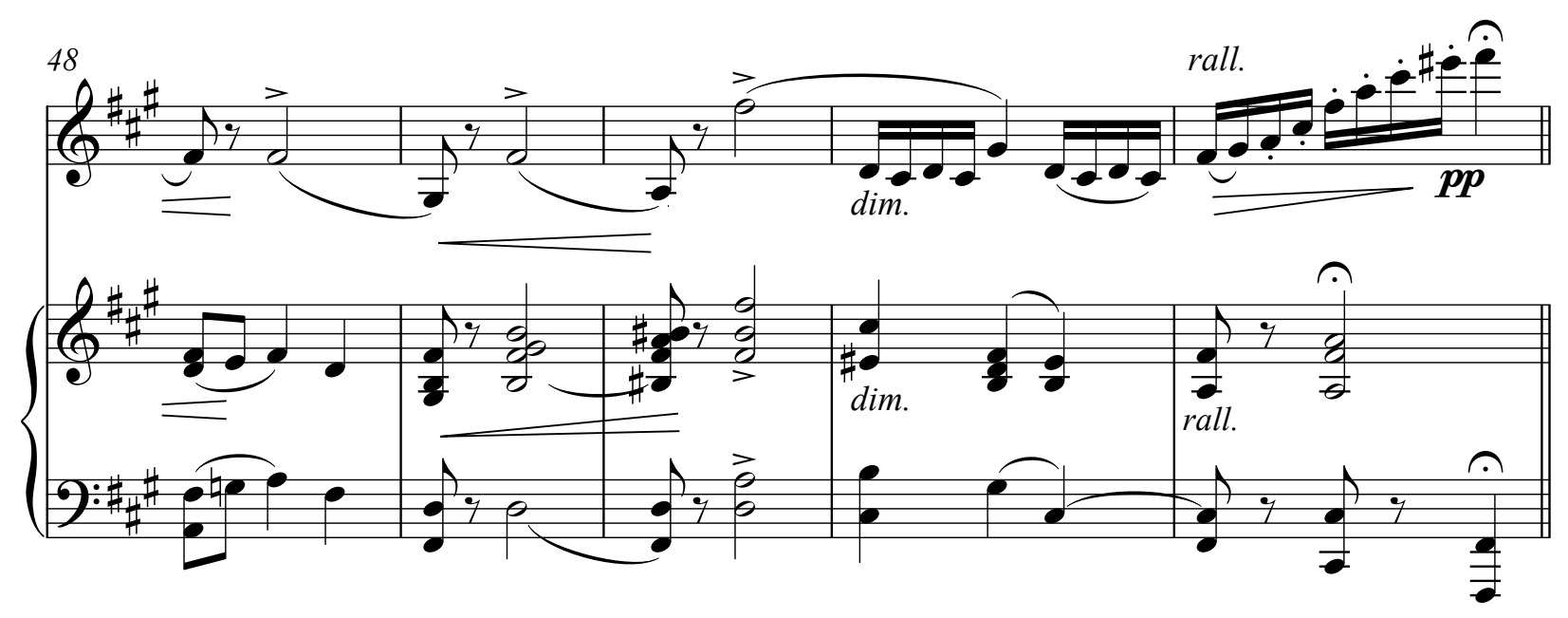

The B section consists of two eight measure phrases. In Amy Beach and Her Chamber

Music, Brown notes, "the piano is given a lilting waltz pattern of accompaniment."."77 Melodically this entire section forms a musical period. Grove Music Online defines a musical period as, "a musical statement...built of complementary members, each generally two to eight bars long and respectively called 'antecedent' and 'consequent'. Symmetry provides another defining element in period structure. Complementary figures and phrases establish a regular pattern of movement that allows the listener to anticipate the final point of arrival in a self-contained unit." 78 The antecedent phrase, from mm. 53-60, end on VI, a relatively weaker harmonic ending than the consequent phrase which concludes with a perfect authentic cadence in the first ending.

Melodically the two phrases are closely related. The first four measures of each phrase are the same in the violin line, except the consequent phrase is raised an octave.

\footnotetext{
77Brown, Amy Beach and Her Chamber Music, 193.

78Leonard G. Ratner, "Period," Grove Music Online. Oxford Music Online, Oxford University Press, accessed October 26, 2016. http://www.oxfordmusiconline.com/subscriber/article/grove/music/21337.
} 
Example 4.33: Mazurka, mm. 53-69

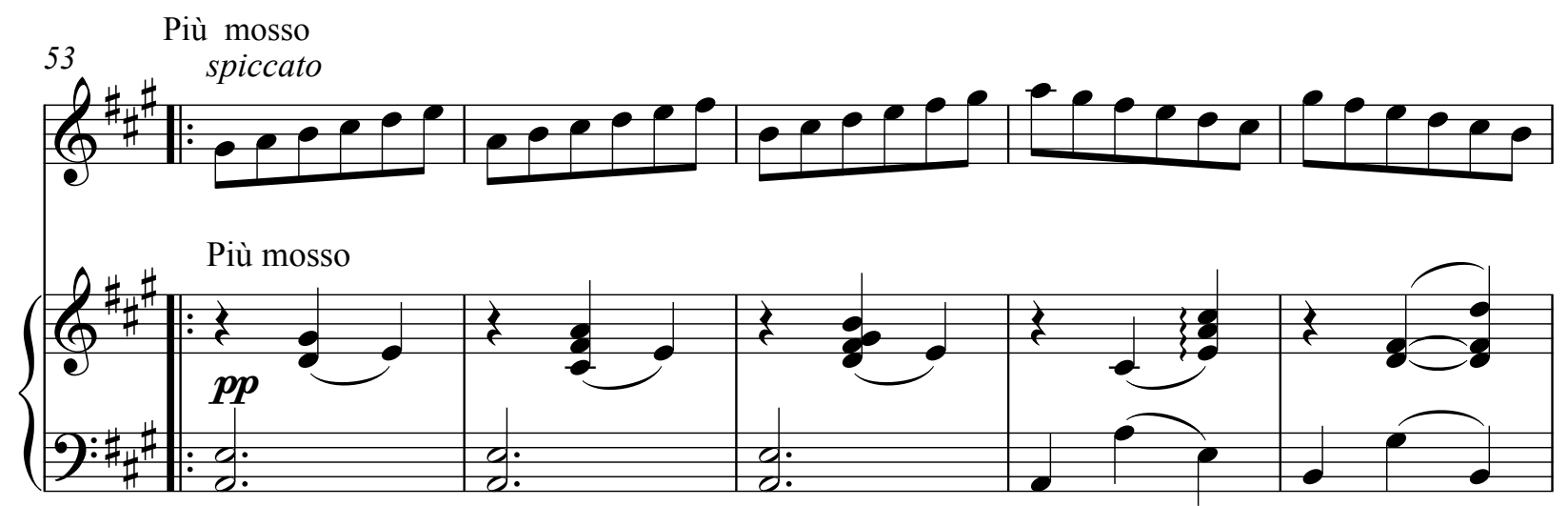

A major:

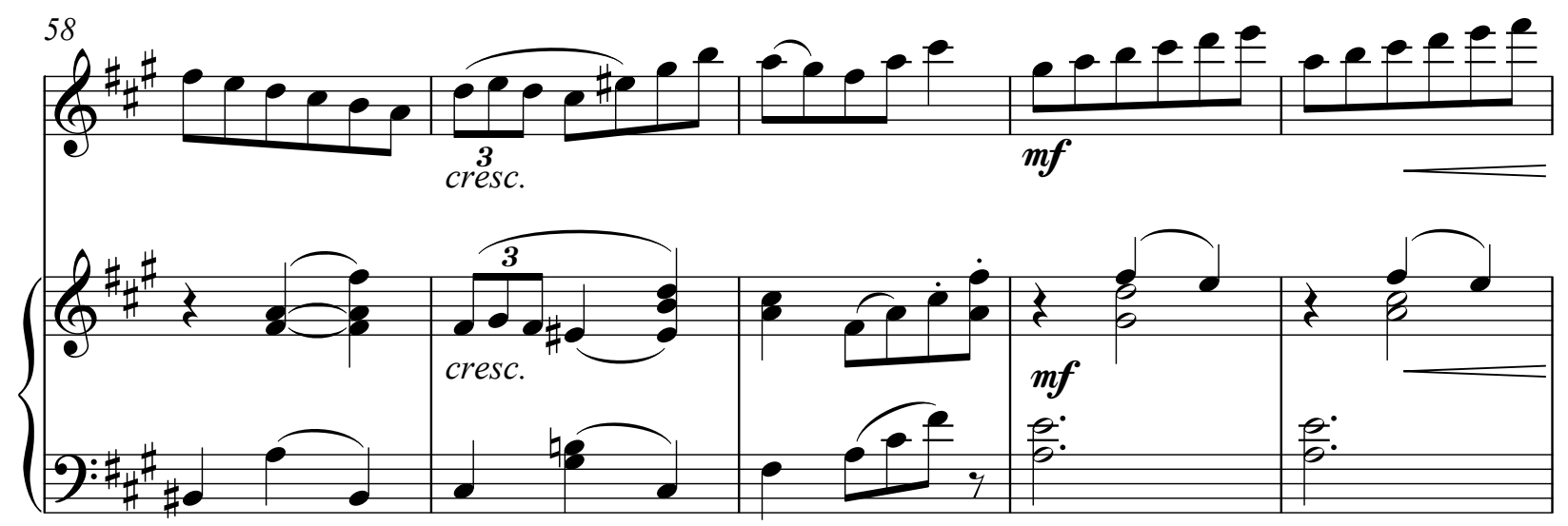

vi

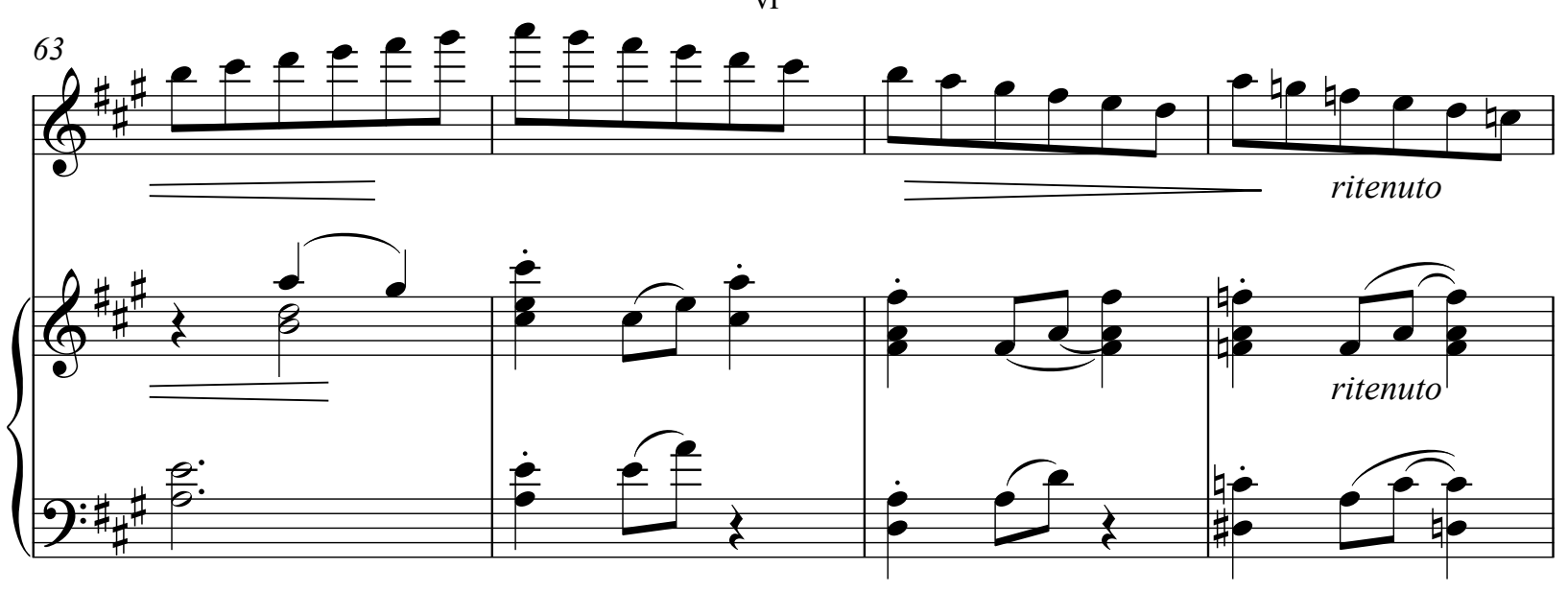


Example 4.33: Cont.

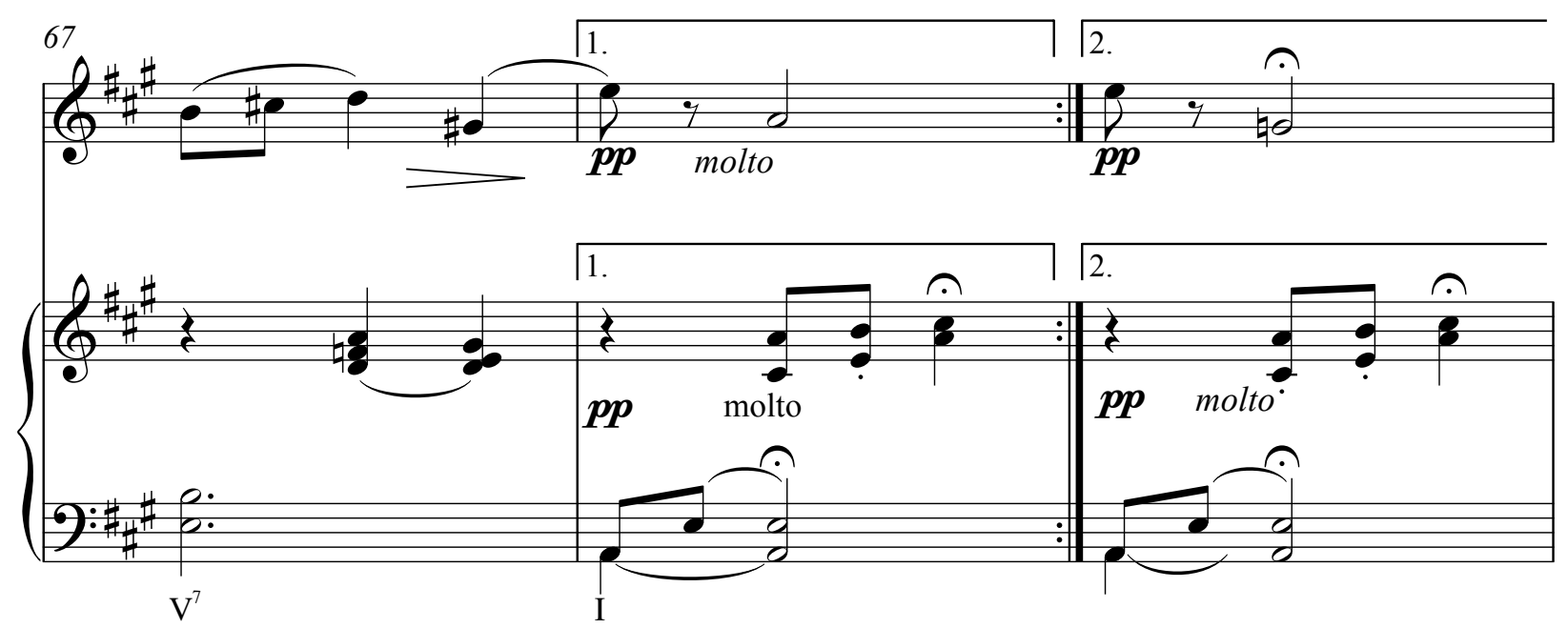

The final major section, A', can also be broken down into eight measure phrases, a'- e'.

When compared to the A section the f' section is missing, hence the overall shorter length of A'.

Melodically the first five measures of a' are almost exactly the same as a. In a, the violin had the melody from mm. 5-12. This time, the melodic line is passed from the violin to the piano after the first two measures. This can be seen by comparing example 4.27 with example 4.34 .

Example 4.34: Mazurka, mm. 70-74

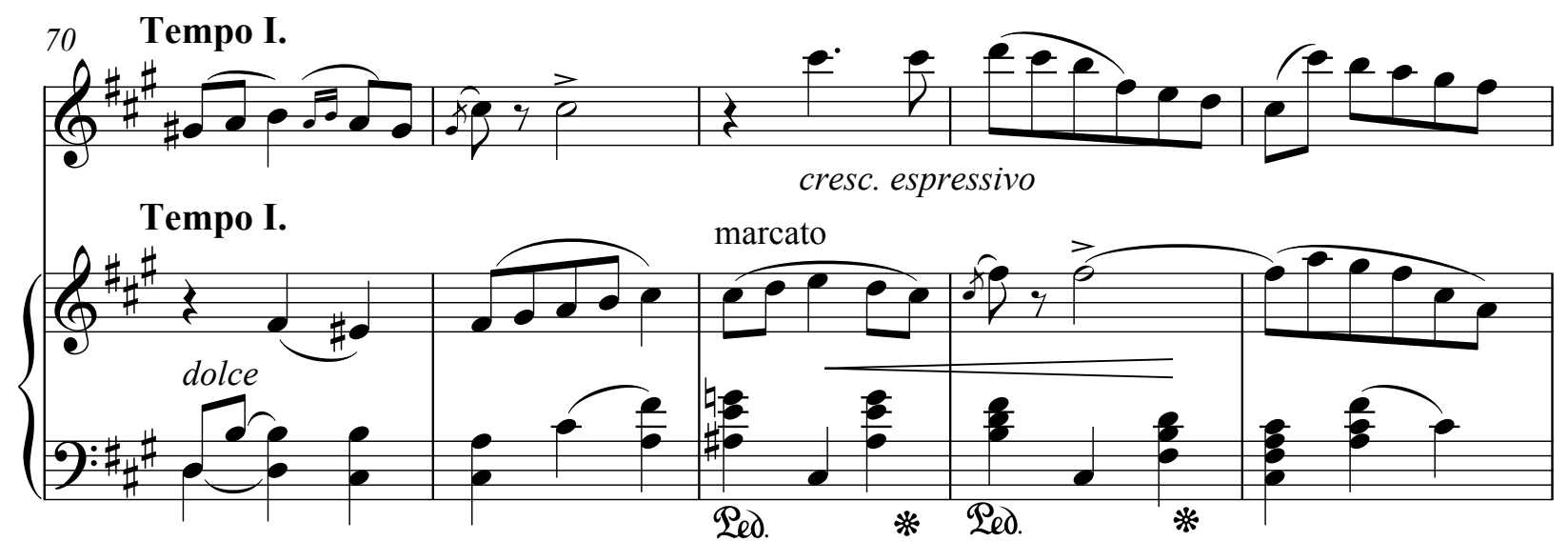


The next section, b', exploits the low range of the violin by presenting the melody starting on the lowest diatonic pitch (in $F \sharp$ minor) possible for the violin, G\#3. Beach also wrote for the violinist to stay on the $\mathrm{G}$ string for the first three measures. In fact these eight measures are the lowest eight consecutive measures for the violinist, never going higher than a B4.

Example 4.35: Mazurka, mm. 78-85
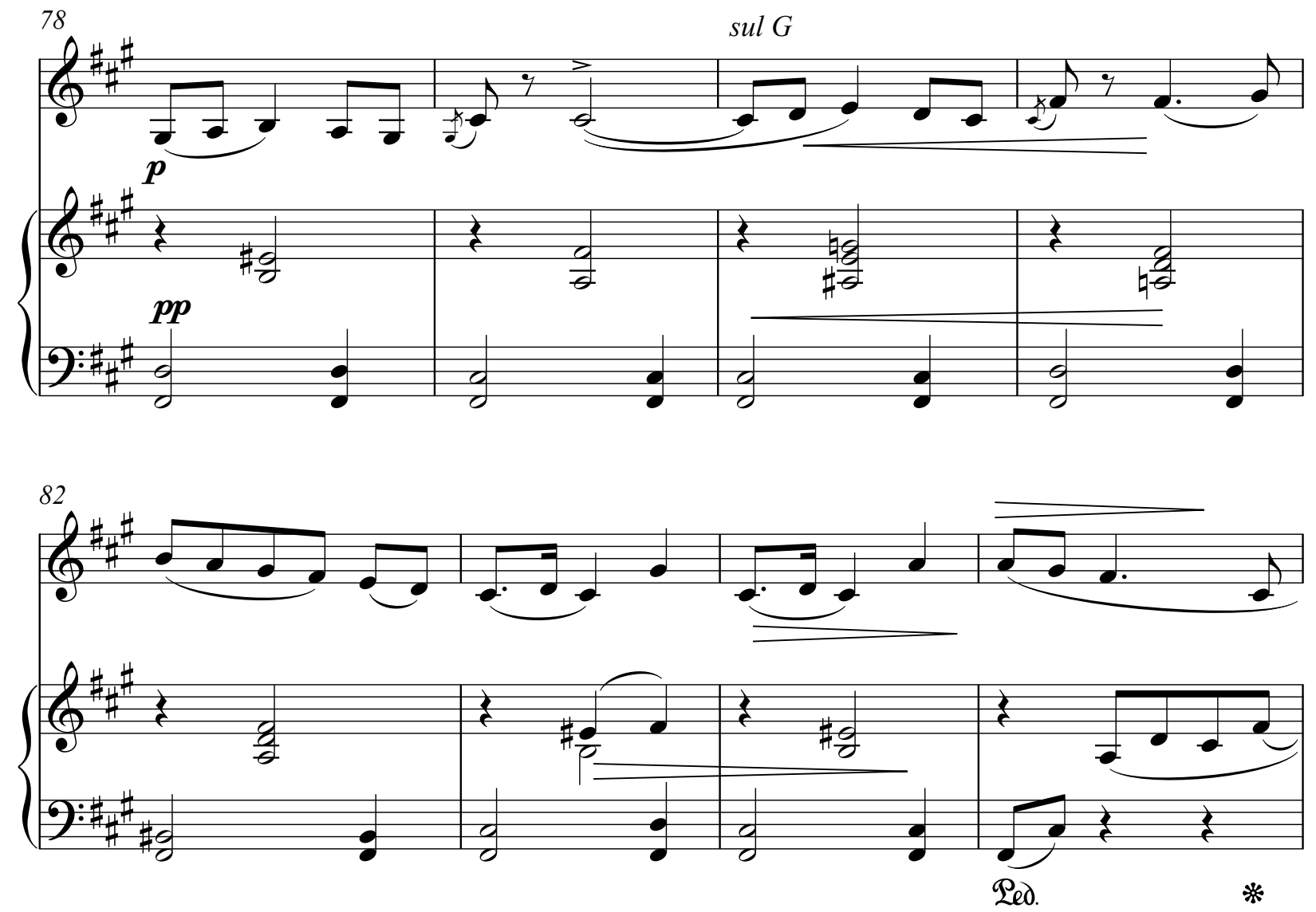

While the c' section is very similar to c, one notable change is in mm. 91-92 where these measures contain staccato chords in the piano part. Originally these type of chords were heard in the $\mathrm{d}$ section, not the $\mathrm{c}$ section. Consequently in the d' section there are no staccato chords, 
instead the piano lines stay long and connected. A unique feature, heard only in $\mathrm{d}$ and $\mathrm{d}$ ', is the use of trills. Originally in $\mathrm{d}$, the opening measure of the primary melodic phrase was used in a very small sequence in $\mathrm{mm}$. 29-30. This idea is expanded in the d' section when the piano begins by playing both measures of the melodic phrase twice. Then the top voice of the piano uses just the first measure sequentially, in mm. 98-100.

Example 4.36: Mazurka, mm. 94-100
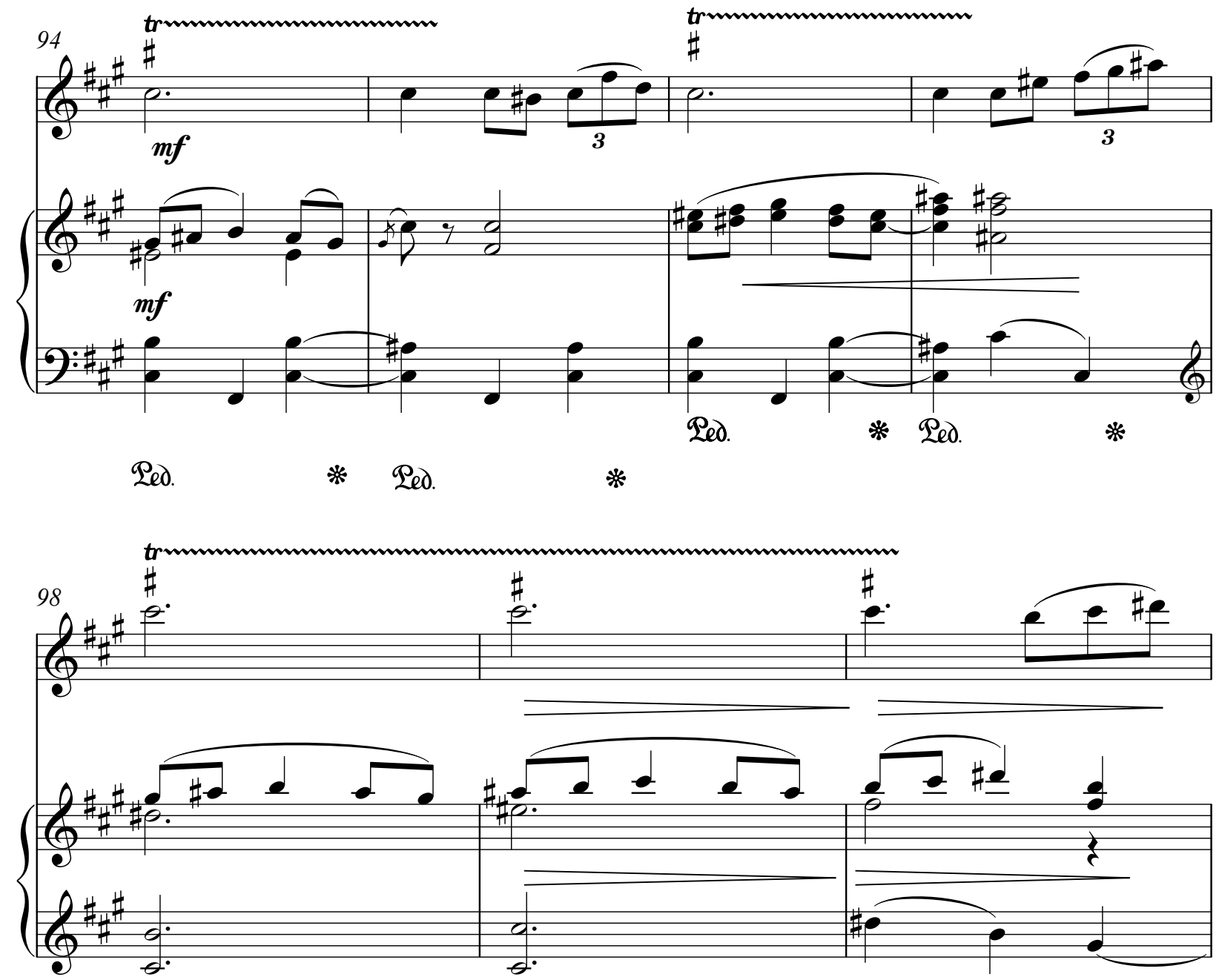
The final section of this piece, e', contains no sign of the two-bar melodic phrase that has been prevalent throughout. Melodically, the most striking feature is the high $A \sharp 6$ to begin this section. This is the single highest violin note in the entire opus. The largely descending stepwise motion over the next three measures creates an unraveling effect. Another effect unique in e' is the final five measures of the violin line, which are all pizzicato. This is the only time Beach chose to use pizzicato in her entire Opus 40, which creates a light and playful ending.

Each major section has a clearly defined tonality. The A section is in F\# minor, the B section is in A major, and the $A^{\prime}$ section returns to $F \#$ minor, until the end which finishes in $F \#$ major. This is the same strategy used in La Captive, which also ends in the parallel major. The introduction not only introduces the melody, but sets up a $\mathrm{ii}^{67}-\mathrm{V}^{7}-\mathrm{i}$ cadence to clearly define the opening key.

Example 4.37: Mazurka, mm. 1-5

\section{MAZURKA.}

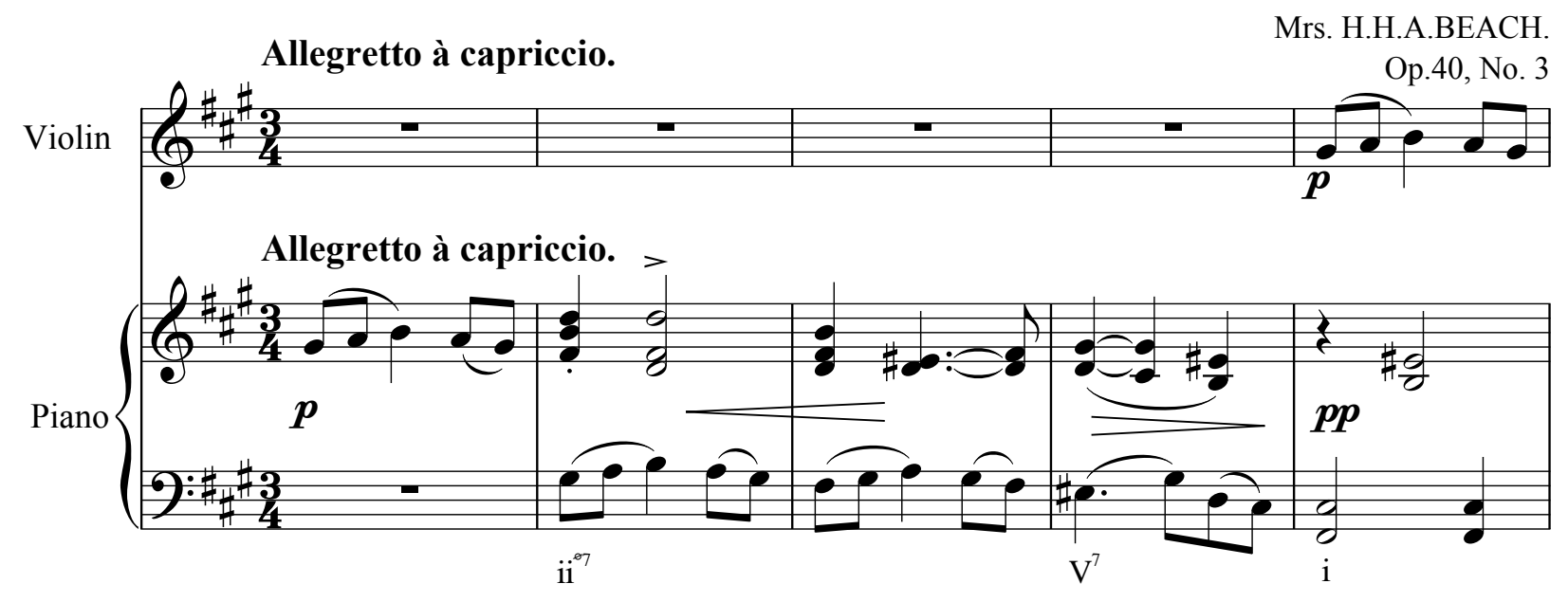


Beach foreshadows the move to A major through multiple V-I progressions during the opening a and $\mathrm{b}$ sections. Two particular instances occur in mm. 9-10 and 17-20.

Example 4.38: Mazurka, mm. 9-10

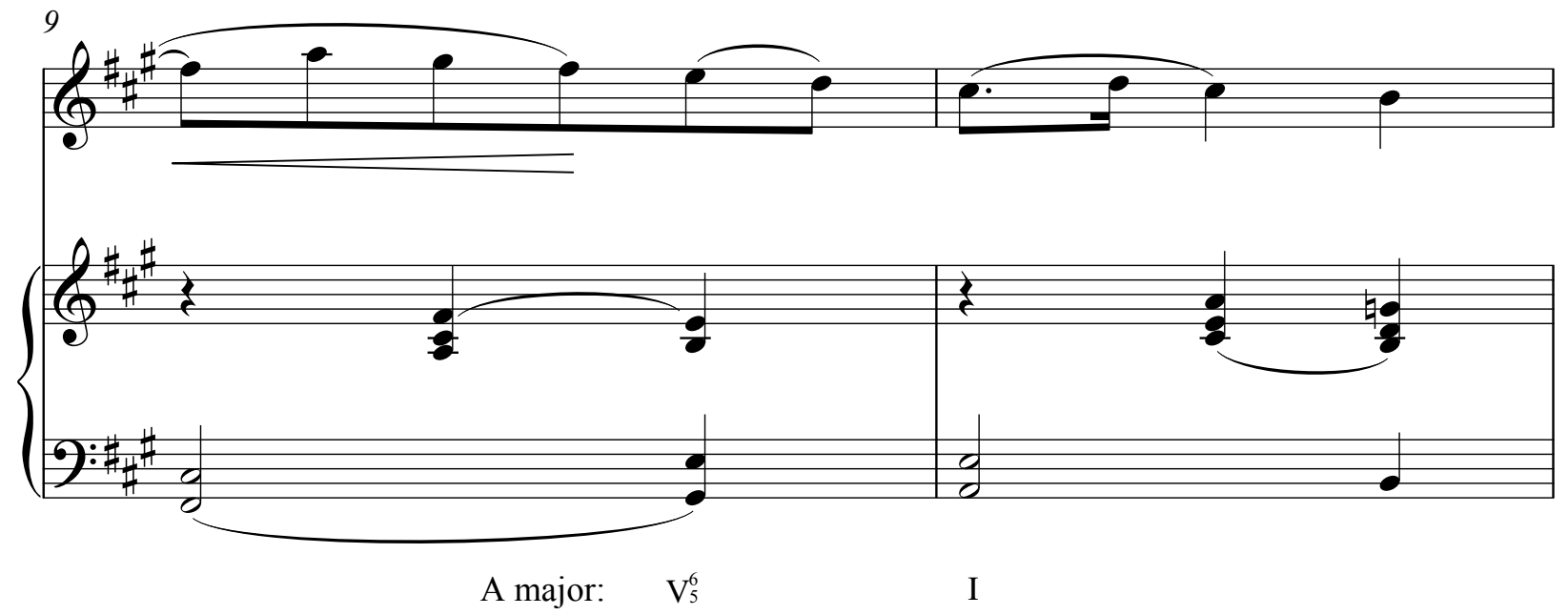

Example 4.39: Mazurka, mm. 17-20

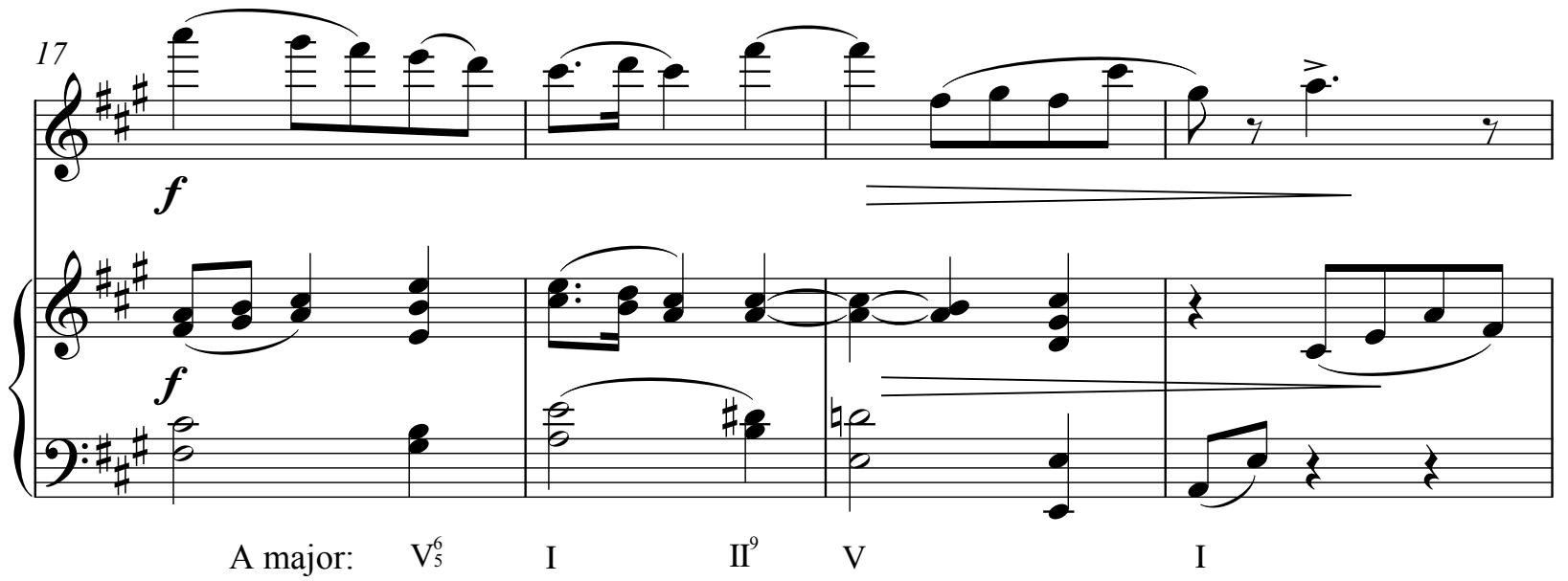


The latter of these two examples is a modulation to A major, which is the key for the $\mathrm{c}$ section. Throughout the first five measures of the c section, mm. $21-26$, there is a tonic pedal tone. In $\mathrm{m} .27$ the pedal tone moves to a $\mathrm{G} \#$, as part of a $\mathrm{G} \# 11$ harmony which is a preparation for the $\mathrm{C} \sharp$ major harmony that will be prominent in the $\mathrm{d}$ section. The $\mathrm{C} \sharp$ pedal tone, which begins in m. 29, continues throughout most measures until the end of the A section.

Example 4.40: Mazurka, mm. 25-29

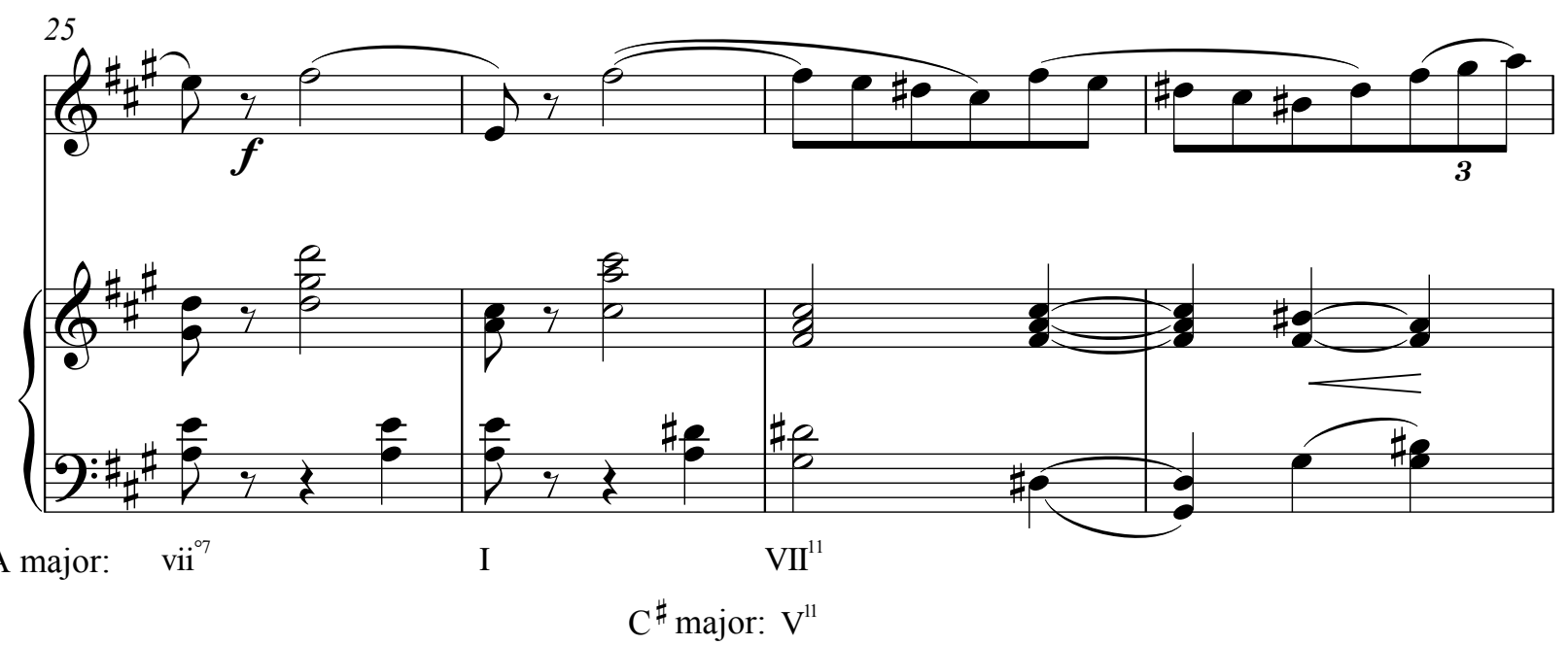

Through the next two sections, $d$ and e, all of the important harmonies have a mediant relationship. The first example is $\mathrm{mm}$. 29-32 (the $\mathrm{d}$ section) where the harmonies alternate in each measure between $C \sharp$ major and A major. Then in mm. 33 and 34 the alternation occurs every other beat (example 4.41). In this instance the A major is functioning as a coloristic addition rather than a functional chord. It is arrived at by stepwise voice movement rather than root motion, as there is an extended $\mathrm{C} \sharp$ pedal tone beginning in $\mathrm{mm}$. 29. The A major chord also references the key area of the previous section. In the e section the important harmonies are F\# 
minor and $\mathrm{D}$ major, again chords separated by a third. $\mathrm{F} \#$ minor harmonies appear in $\mathrm{mm} .38,41$, and 44 , while $\mathrm{D}$ major appears in $\mathrm{mm} .40$ and 43 . The $\mathrm{B} \#$ in the bass on the downbeat of $\mathrm{m} .43$ is a chromatic passing tone between B and C\#. These measures are shown in example 4.42.

Additionally, there is a tonic/dominant relationship between the first set of harmonies, $\mathrm{C} \#$ major and A major, and the second set, F\# minor and D major. Beach will tie these four chords together in the $\mathrm{f}$ section.

Example 4.41: Mazurka, mm. 29-34

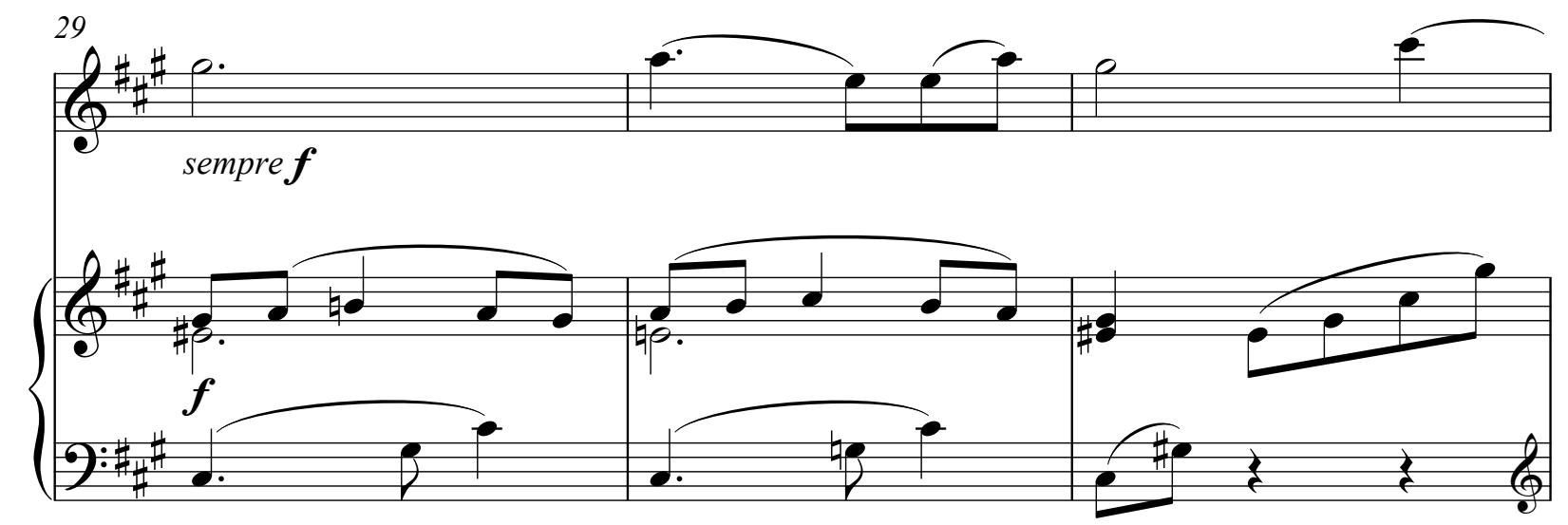

F\# minor: V -

*

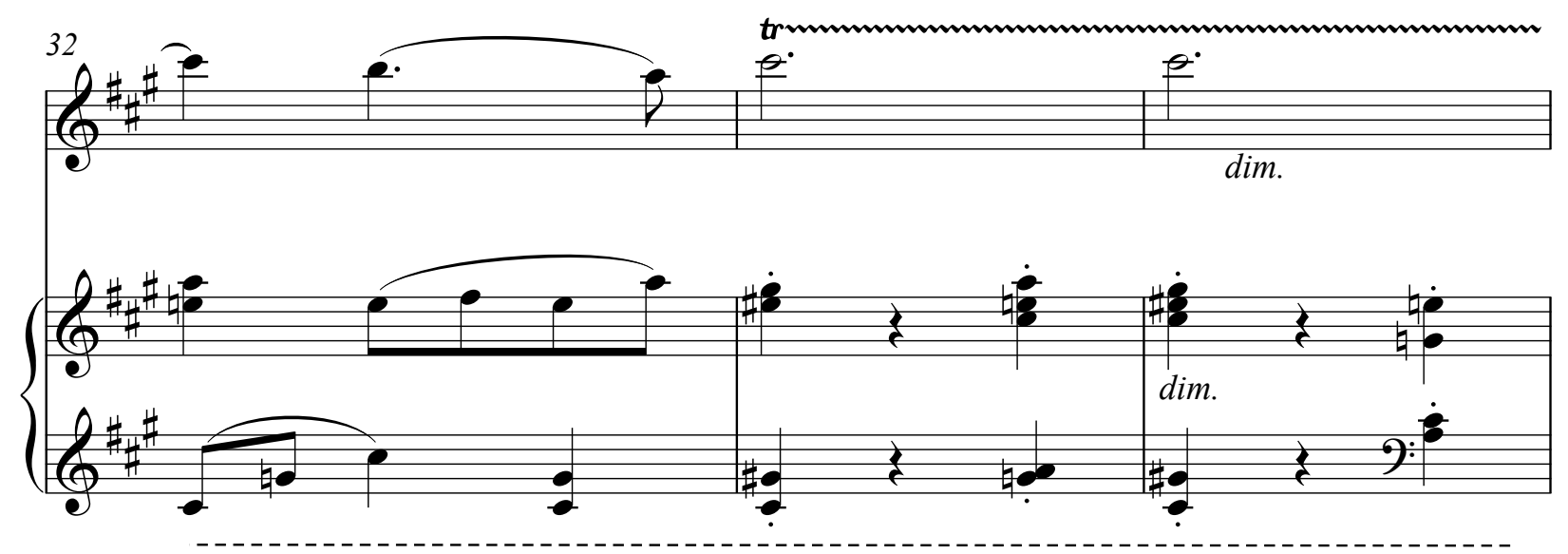


Example 4.42: Mazurka, mm. 38-44
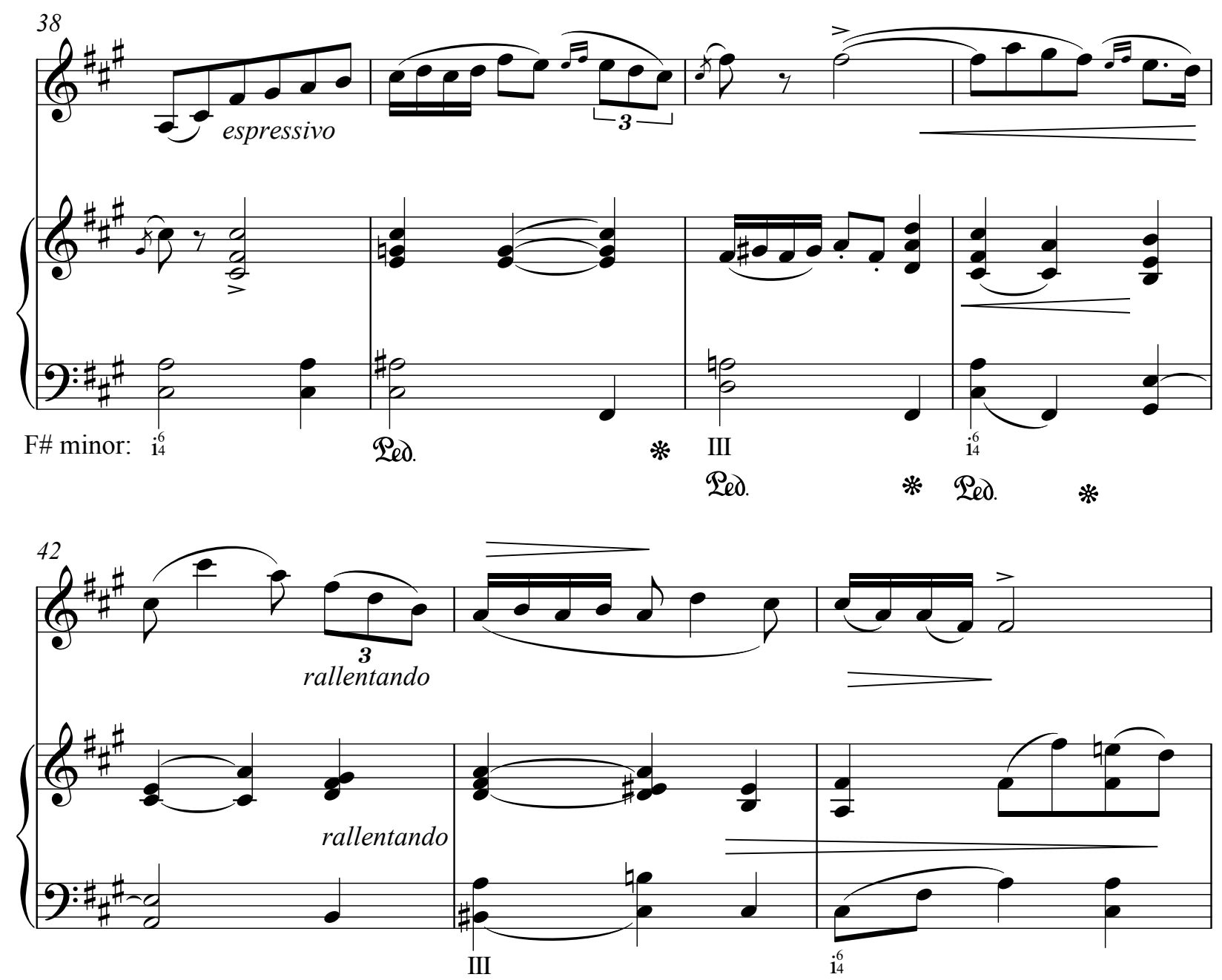

Harmonically, the f section serves to reinforce the important harmonies from $\mathrm{d}$ and e.

These four harmonies can all be found in the first four measures of $f$. This time, instead of being grouped as pairs of mediant relationships, they are presented as tonic/dominant relationships. 
Example 4.43: Mazurka, mm. 45-48

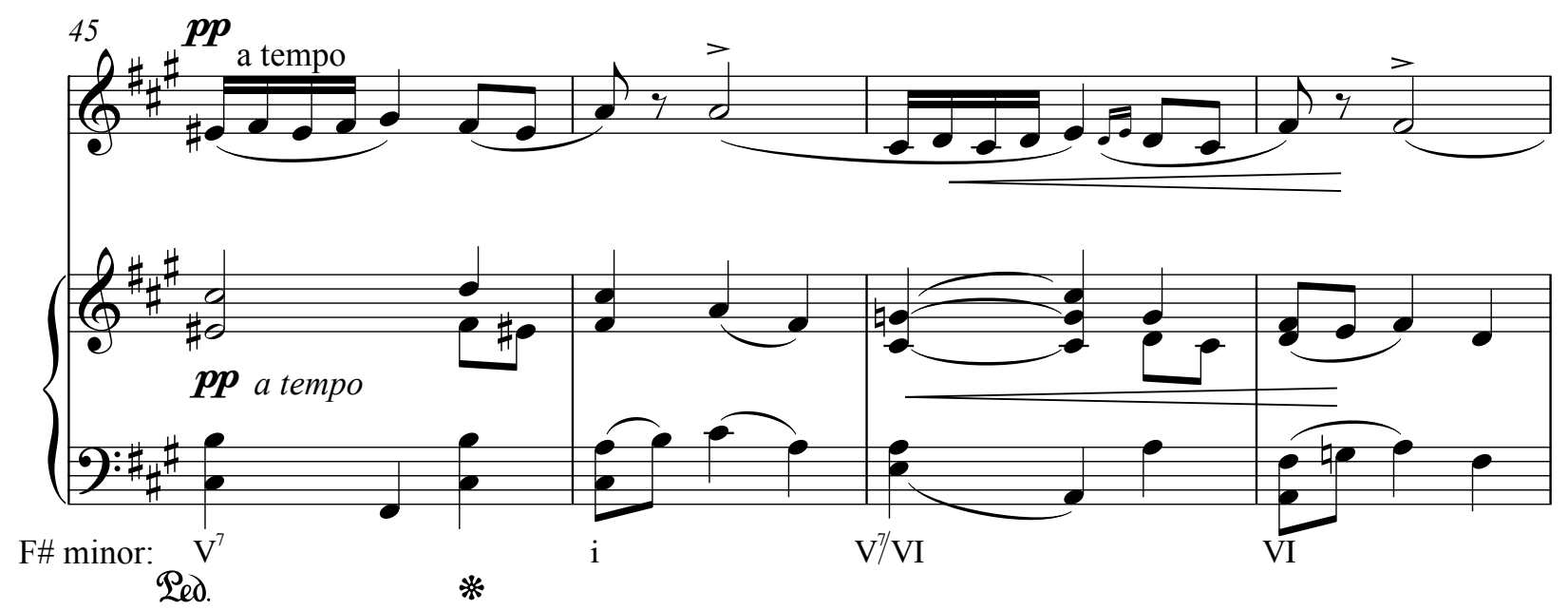

The B section, as previously noted, is in A major. Throughout the first eight measures Beach uses only three chords: I, vi, and $\mathrm{vii}^{67}$. There is only one instance of a vii ${ }^{\circ 7}$, in $\mathrm{m}$. 59 , as part of the deceptive cadence that ends the first phrase (example 4.44). The second group of eight measures is harmonically more diverse. From mm. 64-68 there is a I-IV-Gr ${ }^{+6}-V^{7}-\mathrm{I}$ (example 4.45). While this is considered a standard progression it certainly provides more harmonic variety than the first phrase. Another feature that appears in the B section is a tonic pedal tone, which occurs in the initial four bars of both the first and second phrases.

The first subsections, a' and b', in the final major section (A'), are harmonically very similar to $a$ and $b$. The most noticeable difference is the lack of progressions which tonicize A major, as seen in example 4.40 on page 106. Instead, the subdominant chord (B minor) and the tonic key (F\# minor) are prevalent. While $\mathrm{b}$ ' does include $\mathrm{F} \#$ major, it always appears as an extended chord, such as a seventh or ninth chord. An instance of this is shown in example 4.46. 
Example 4.44: Mazurka, mm. 59-60

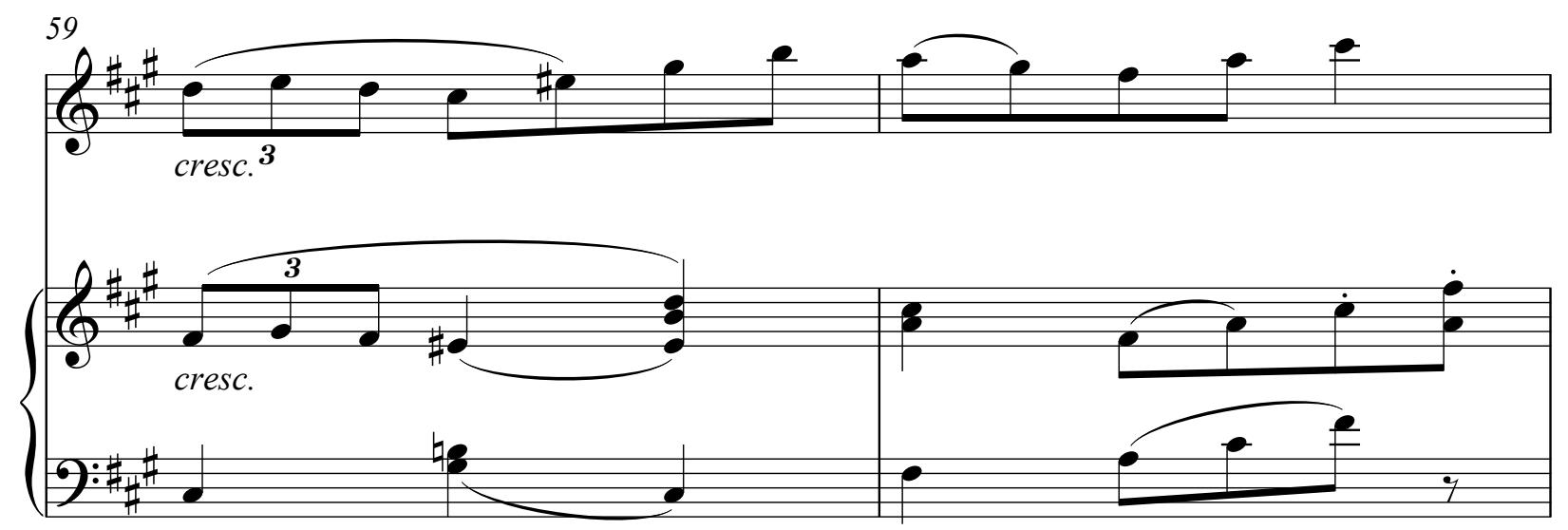

A major: vii $^{07}$

vi

Example 4.45: Mazurka, mm. 64-68

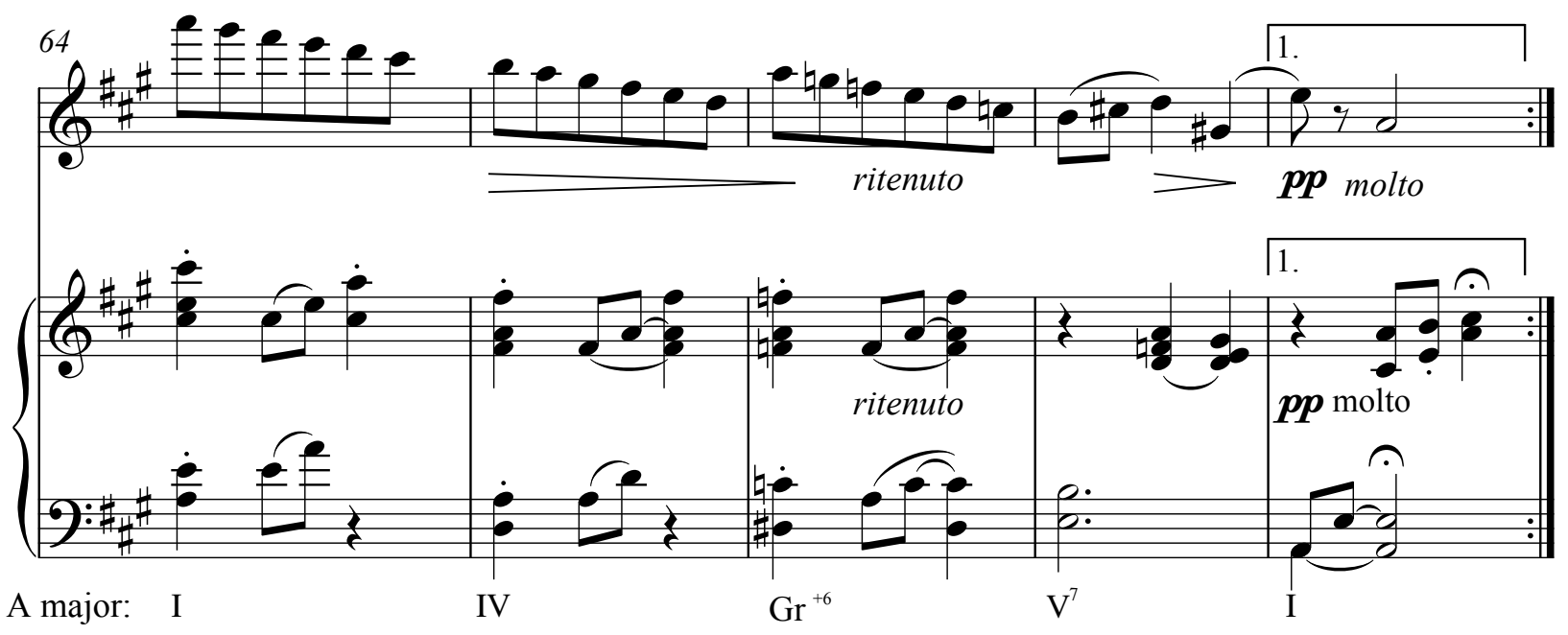


Example 4.46: Mazurka, m. 80

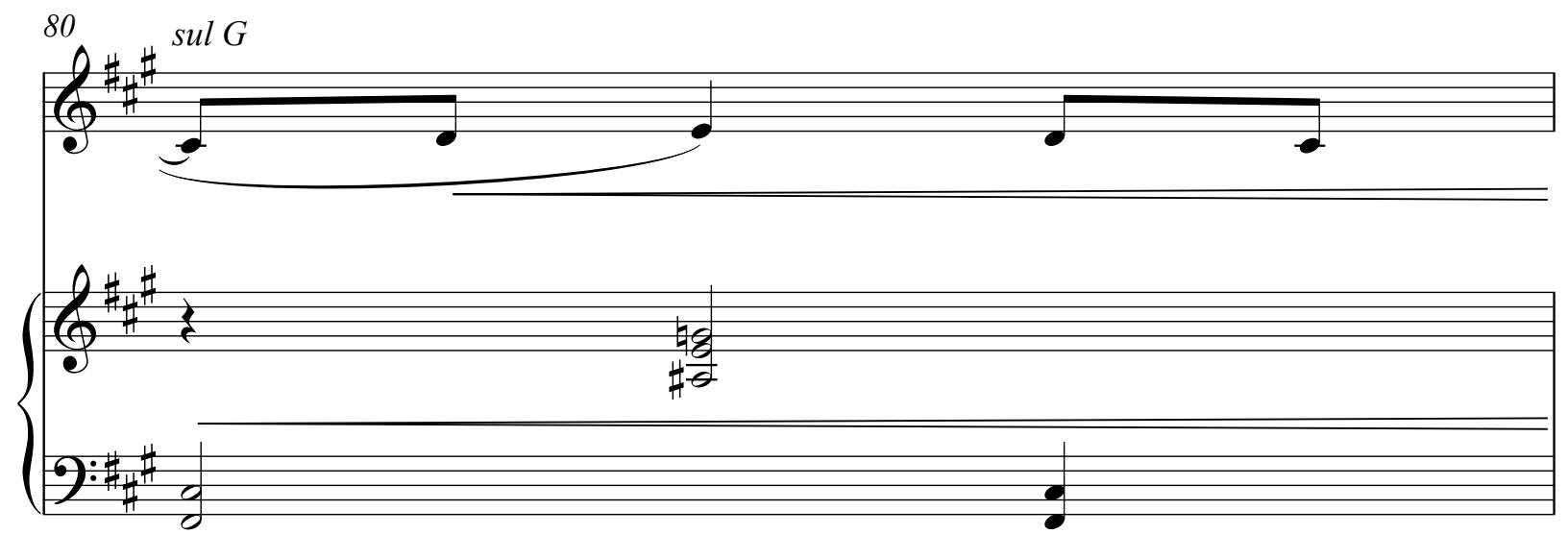

F\# minor: $\mathrm{I}^{9}$

Just as c departed from the key area of a and b, so does c', which begins with an extended tonicization of the Neapolitan (bII). Ultimately, c' moves to $\mathrm{V}^{7}$ of F\# Major on the last measure of the section (m. 93). The $\mathrm{V}^{7}$ in $\mathrm{m} .93$ is ultimately resolved to the tonic chord in $\mathrm{m} .95$ which is part of the d' section. Overall mm. 86-95 can be reduced to $\mathrm{V}^{7} / \mathrm{bII}-\mathrm{bII}-\mathrm{V}^{7}$-I (example 4.47). As previously noted, this piece ends in the parallel major. The final two sections, d' and e', emphasize $\mathrm{F} \#$ major by utilizing mostly $\mathrm{V}$ and I chords.

Example 4.47: Mazurka, mm. 86-95

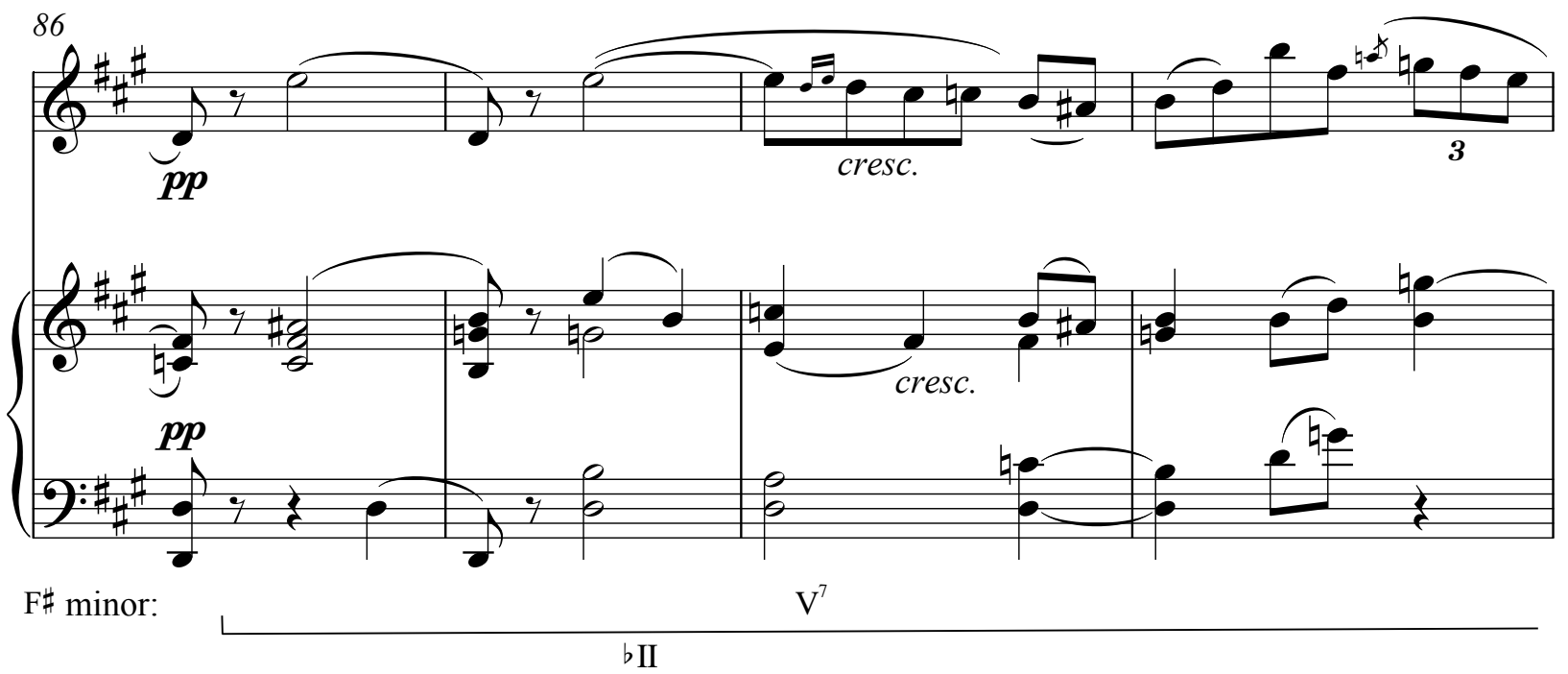


Example 4.47: Cont.
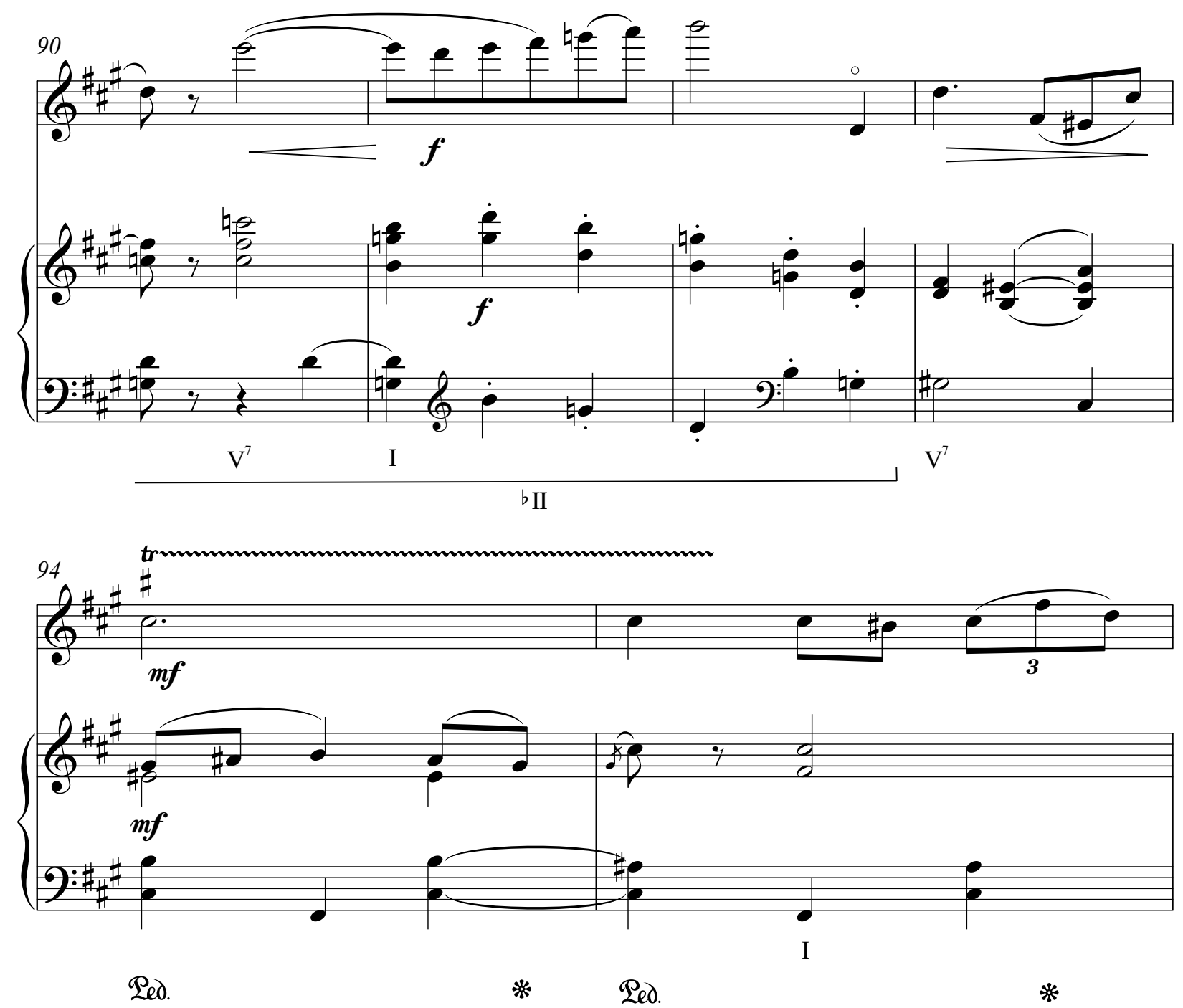

The most significant change for these transcriptions is the transposition down a perfect

fifth. The primary reasons were to preserve Beach's intervals, register relationships, and melodic intentions. La Captive could have remained in G minor without any necessary changes.

However, since the dark, rich quality of the $\mathrm{C}$ string is so alluring, the chance to play a luscious melodic piece all on the $\mathrm{C}$ string was irresistible. Other than the transposition to $\mathrm{C}$ minor, no other changes were made to La Captive. For the Berceuse, besides the transposition, there was 
also an extended section where the right hand of the piano was raised an octave. Although not necessary for any technical reasons, it helped the melody in the piano to be more easily heard. Specifically this occurred in mm. 38-52, during the A' section. For the most part, a violist could easily play the Berceuse in the original key except for a few important measures at the end; $\mathrm{m}$. 49, with the $C \sharp$ (example 4.25) and mm. 60-61 (example 4.18) with the climb to the F\#6. While those notes are certainly within the range of a viola, playing them as written would lend a more virtuosic feel to the piece than Beach intended. Another option would be to take those two sections down an octave; however, in m. 49 it would end up even lower than simply transposing down a fifth and change the tone of the section. Regarding mm. 60-61, there is a magical quality to saving the highest note for the very end, which would naturally be lost if taken down an octave. Like La Captive, the Mazurka needed no changes other than a transposition down a fifth. Of the three pieces in Amy Beach's Op. 40, it was most necessary to transpose the Mazurka. There are numerous sections which, if played in the original key, sit very high in the viola's register and would have potentially sounded quite awkward. If just those sections had been taken down an octave, the overall result would greatly modify the vast majority of the piece. Therefore, the obvious answer was the transposition down a fifth.

Unlike the Romance, scholars will never know exactly why Beach chose to write $L a$ Captive, Berceuse, and the Mazurka or why she chose to have them published together as Op. 40. Given the overall simplicity of these pieces, Dr. Brown's theory that they were written for a pedagogical purpose is certainly plausible. Regardless of her reason, since Beach did not write 
extensively for solo string instruments, performers and scholars are lucky to have this charming collection of pieces. 


\section{Analysis of Invocation, op. 55}

Amy Beach's Invocation was published in 1904 by Schmidt Publishers. According to the Oxford Dictionary, "invocation" is defined as "the action of invoking something or someone for assistance; an incantation used to invoke a deity or the supernatural; (in the Christian Church) a form of words such as 'In the name of the Father' introducing a prayer, sermon, etc..."79. Clearly the word has religious connotations, which makes sense given that Beach is in part known for composing dozens of sacred solo and ensemble vocal pieces. The instrumentation for the Invocation also lends credence to the belief that this piece was composed for the church. ${ }^{80}$ Originally Invocation was marked for violin, piano or organ, and cello obbligato. Beach's inclusion of an organ strongly suggests that this piece was intended for the church as most organs, if not at a college or university, are located within a church. The version for violin and piano is the most frequently performed in the present time; as such, it will be used for the ensuing analysis.

This piece is in strophic form. ${ }^{81}$ There is a four measure introduction which begins with solo piano. The violin enters in $\mathrm{m} .4$ with an introductory figure leading to $\mathrm{m}$. 5 , which is the start of the A section. This section lasts for 18 measures (mm. 5-22) and is followed by a piano interlude. A' lasts for 21 measures (mm. 28-48) and the piece is concluded by a nine measure

\footnotetext{
${ }^{79}$ English Oxford Living Dictionaries, s.v. “invocation,” accessed September 25, 2016, https:// en.oxforddictionaries.com/definition/invocation.

${ }^{80}$ Brown, Amy Beach and her Chamber Music, 197.

${ }^{81}$ Hung, “The Violin Sonata of Amy Beach," 22.
} 
coda (mm. 23-end). The division between A and A' is made clear by the entrance of the violin. At the end of A the violin drops out for the interlude and re-enters to start A'. The coda is clearly distinguished by the range of its melodic content. Each major section (A and A') begins with the same melodic material, just in different octaves. The coda also begins with the same melodic material, yet again in a different octave.

Each section of this piece is a phrase group. One of the most important structural elements of this piece is the asymmetrical phrases within each phrase group, which is clearly delineated by the use of authentic cadences. There is an authentic cadence at the very beginning of each phrase group, between the piano's introduction (or interlude) and the beginning of the group. The first phrase in each group cadences on tonic. Beach extends and develops the second phrase within each group through tonicizations and thematic development, meanwhile avoiding any authentic cadences. An authentic cadence signals the end of each phrase group. The harmonic analysis of these cadences will be shown later in the chapter.

As should be evident from the length of the sections listed above, Beach expands the melodic material in A' by adding new measures. There are multiple purposes for these additional measures. Measure 27, the first new measure in A', is added to transition the violin into the upper octave for A'. This is evident when comparing mm. 4-5 from the beginning with $\mathrm{mm}$. 26-28. 
Example 5.1: Invocation, mm. 4-5

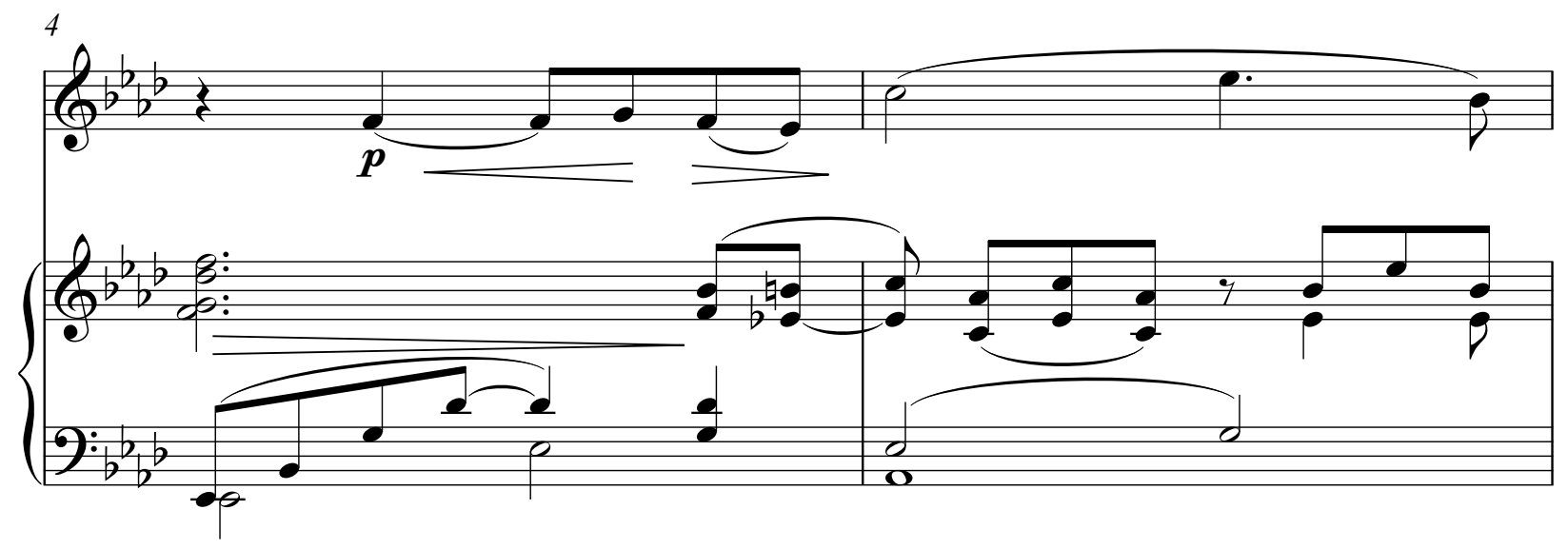

Example 5.2: Invocation, mm. 26-28

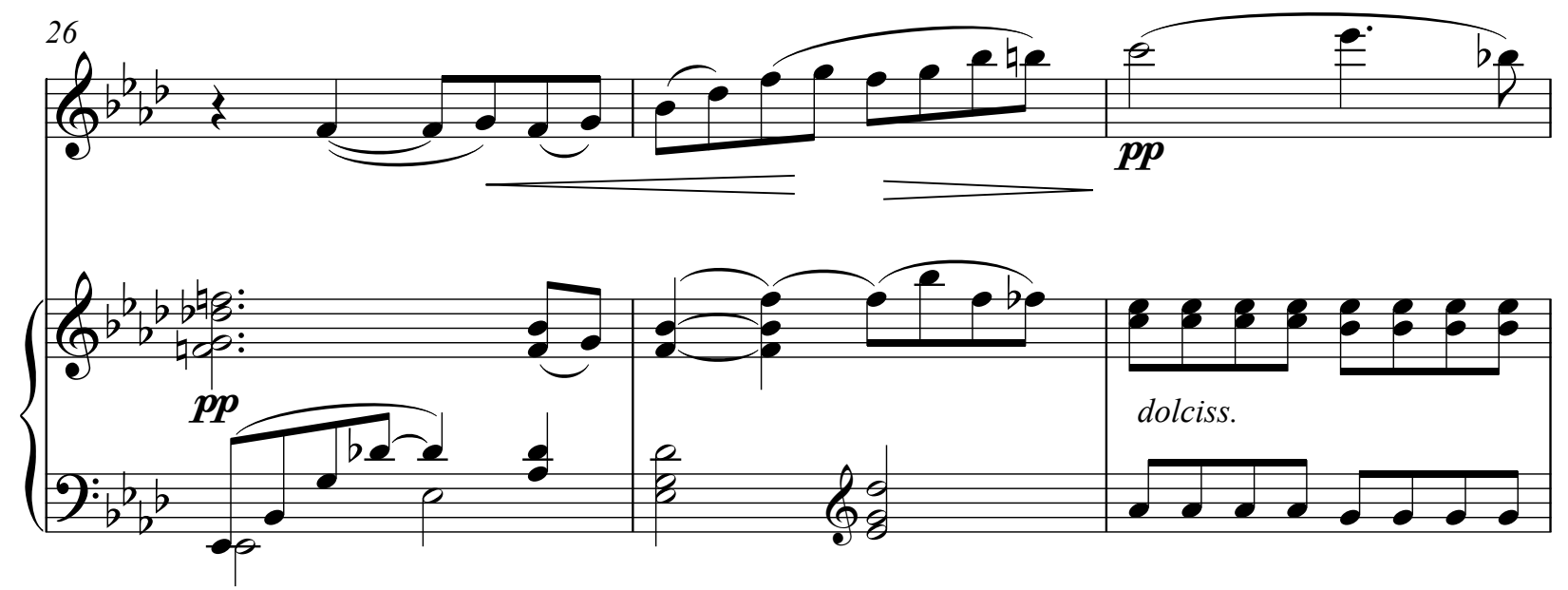

The rest of the additional measures in $A^{\prime}$ all occur at the end of the section, mm. 44-48. It is easy to see the measure-by-measure relationship between A and A' until m. 44 . Measure 43 is related to m. 20, then m. 44 drastically departs from m. 21 . 
Example 5.3: Invocation, mm. 20-21

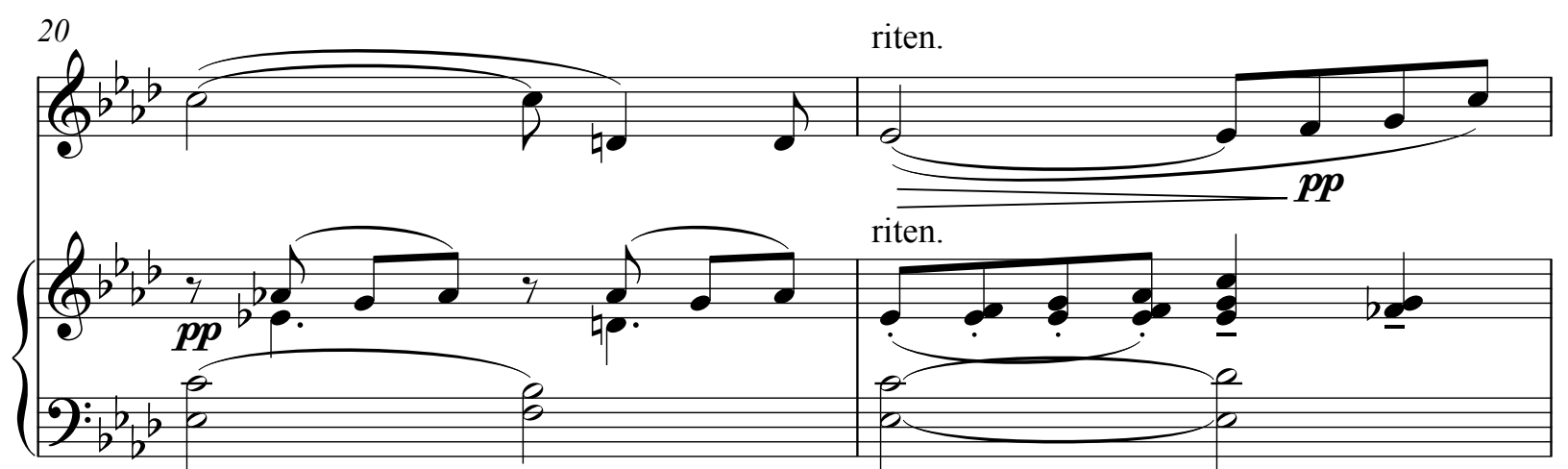

Example 5.4: Invocation, mm. 43-48

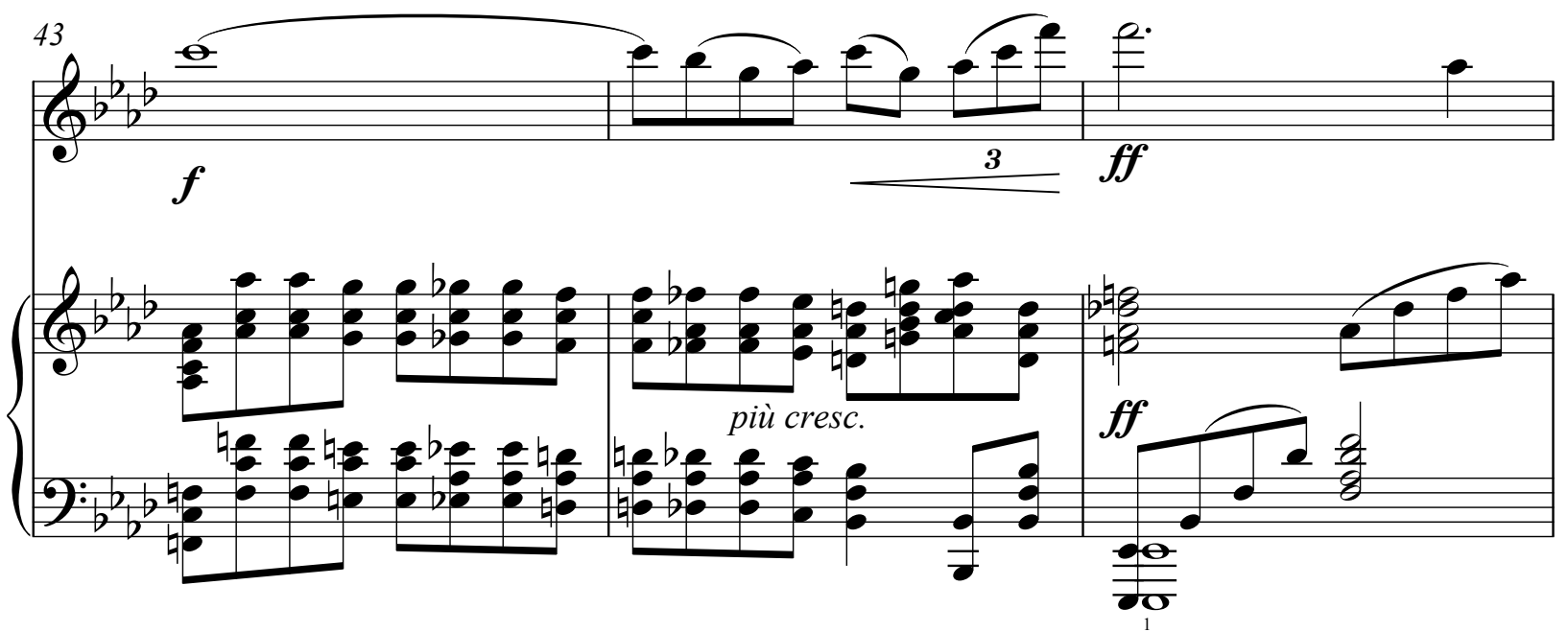

Ted. *

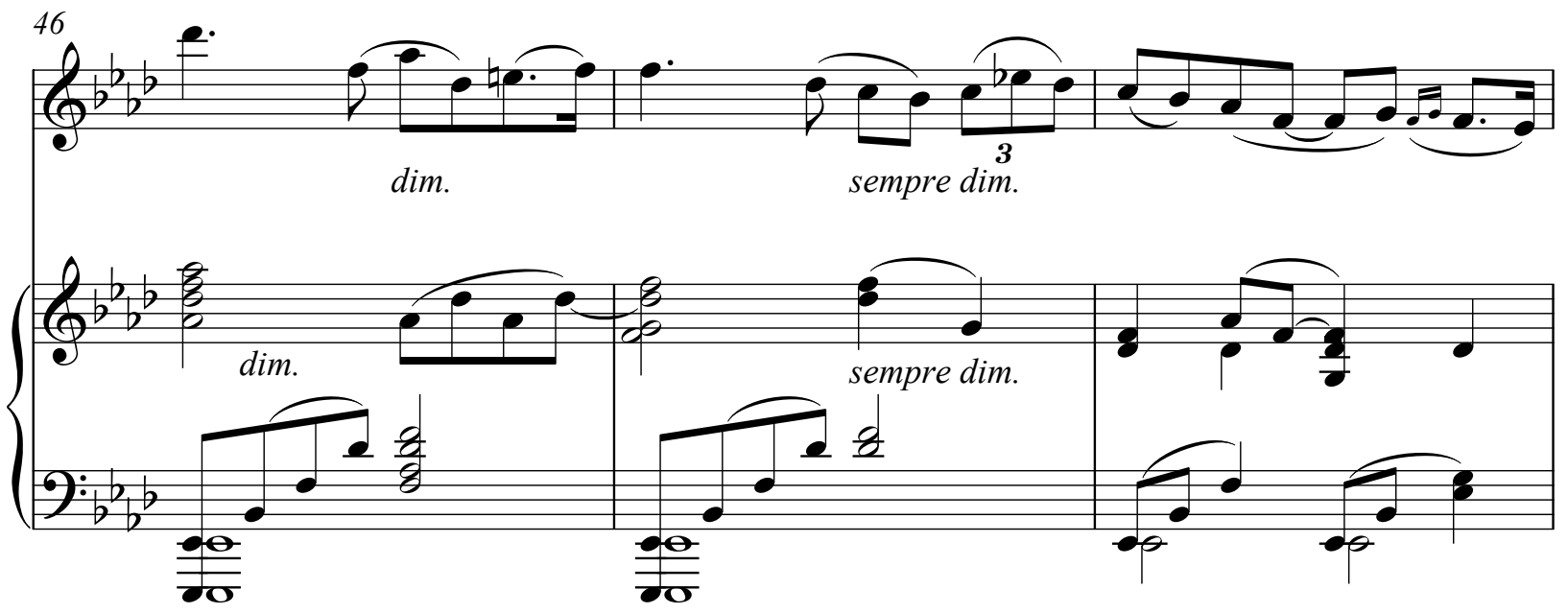


One reason for the additional measures at the end of the A' section is the climax, which occurs in m. 45. Beach saves the loudest dynamic of the piece, fortissimo, for this moment. Additionally, the violin is also playing one of its highest notes in this piece, an F6. After a sweeping climax, the next few measures serve to calm the music in preparation for the coda, with the violin line gradually descending in register, the texture thinning, and multiple diminuendos.

Melodic embellishments happen frequently throughout the A' section. One such instance occurs in $\mathrm{m} .35$, which corresponds to $\mathrm{m} .12$ in the A section. Measure 12 contains a whole note, whereas m. 35 is a clear embellishment. The following measures, m. 13 in A and m. 36 in A', are identical just in different octaves. More examples of melodic embellishment occur in mm. 30-32 and 41-42 when compared with mm. 7-9 and 18-19.

Example 5.5: Invocation, mm. 12-13

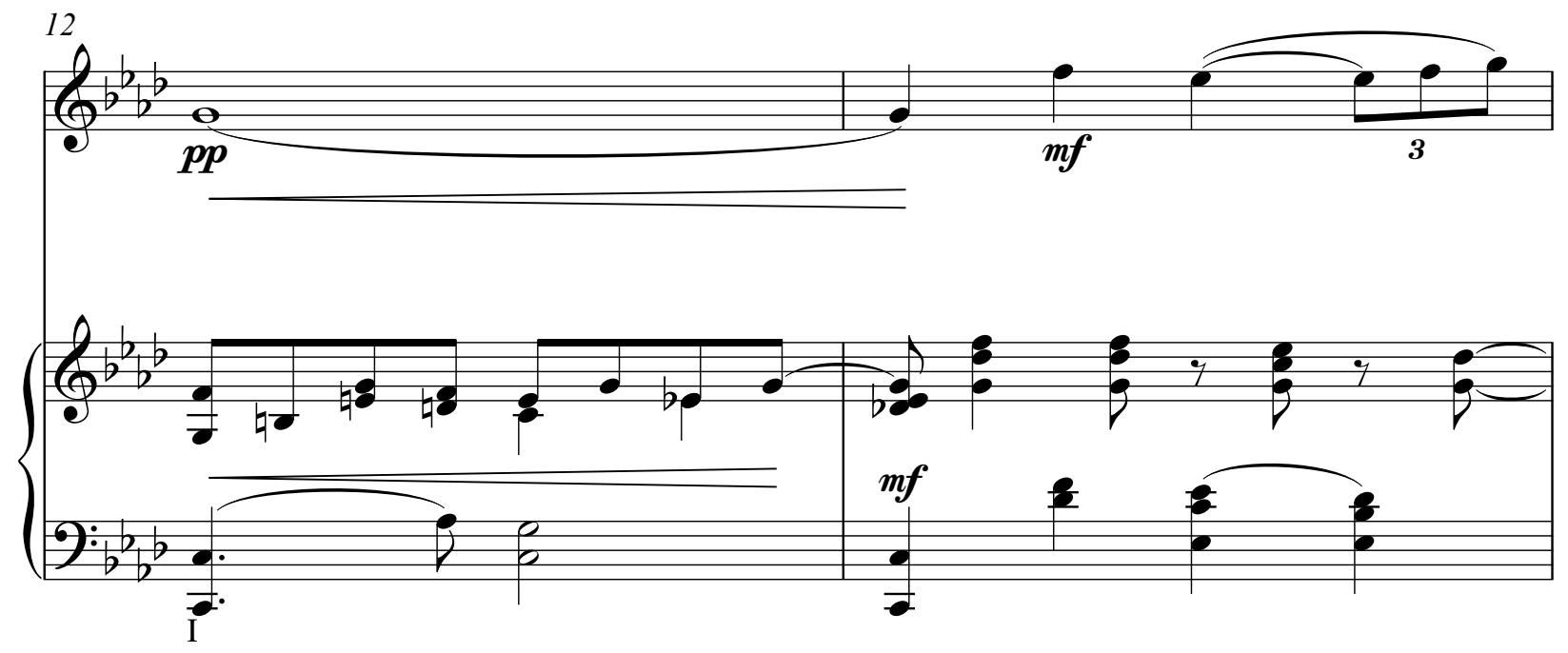


Example 5.6: Invocation, mm. 35-36

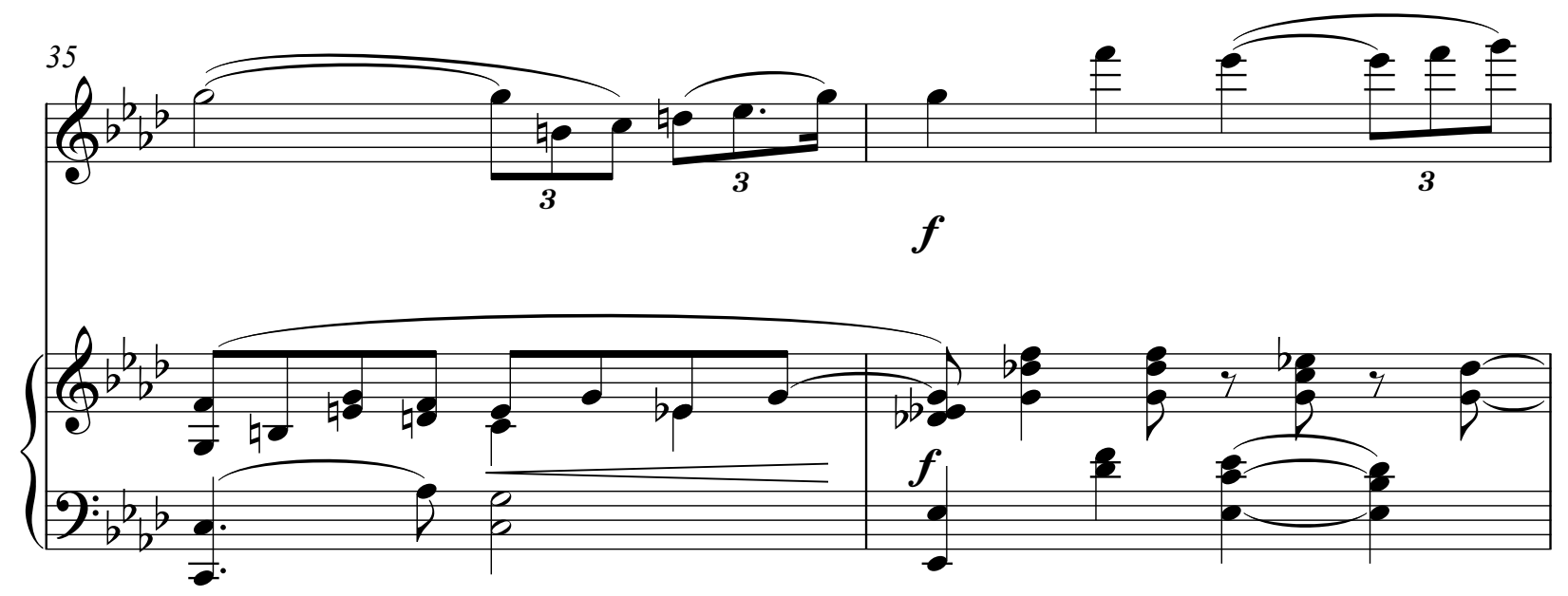

Example 5.7: Invocation, mm. 7-9

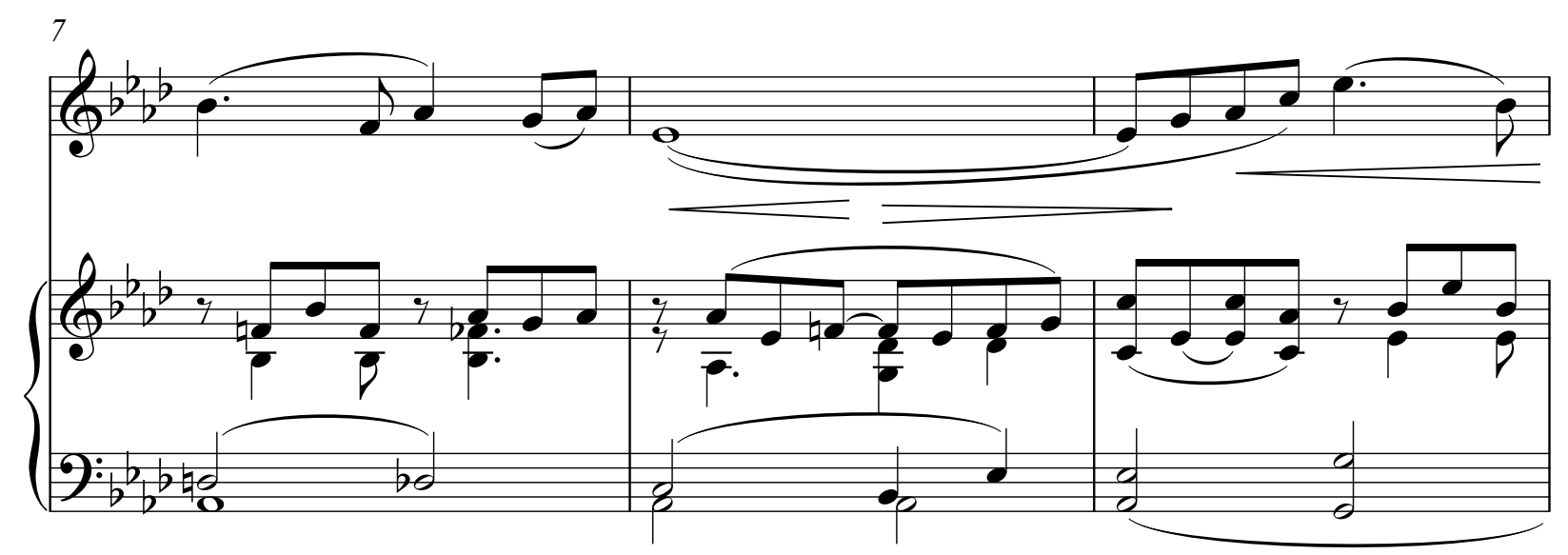

Example 5.8: Invocation, mm. 30-32

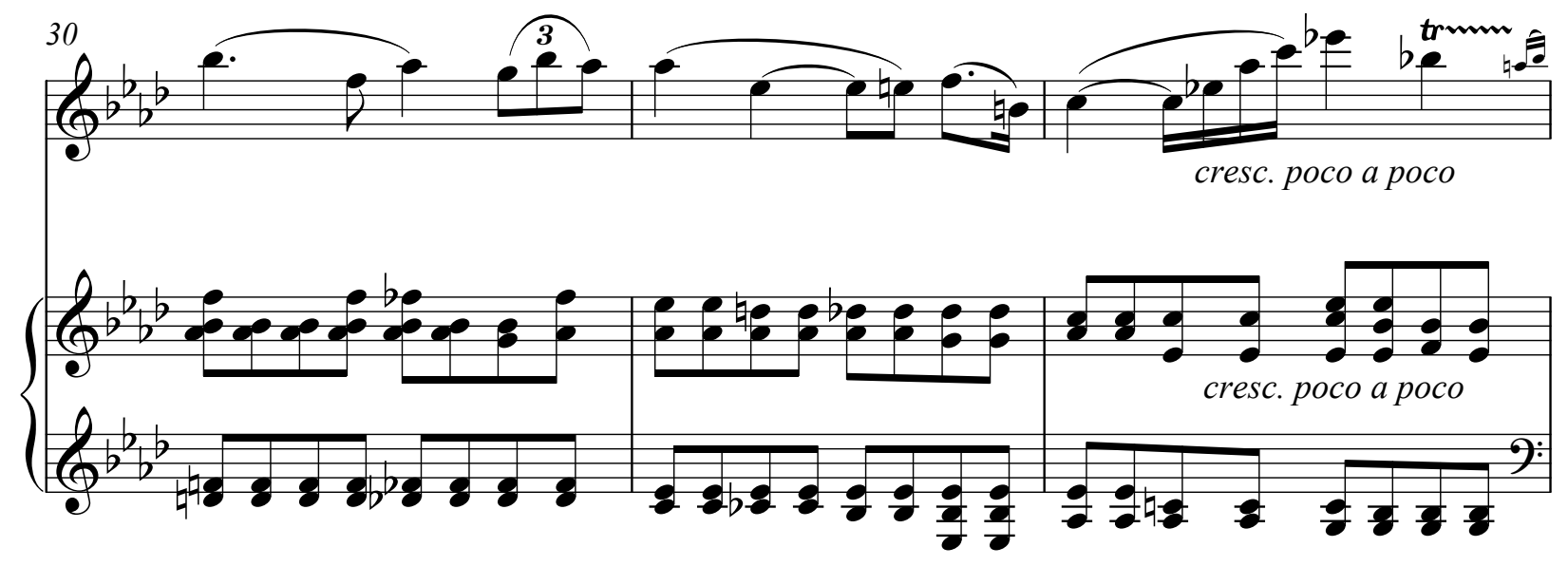


Example 5.9: Invocation, mm. 18-19

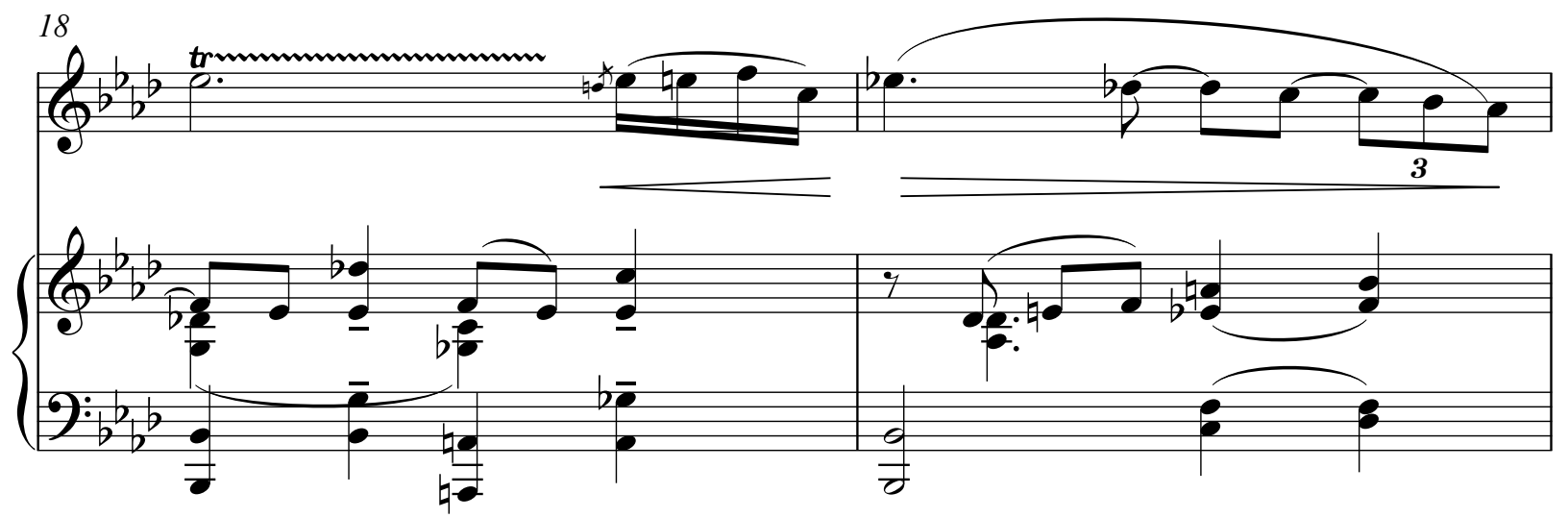

Example 5.10: Invocation, mm. 41-42

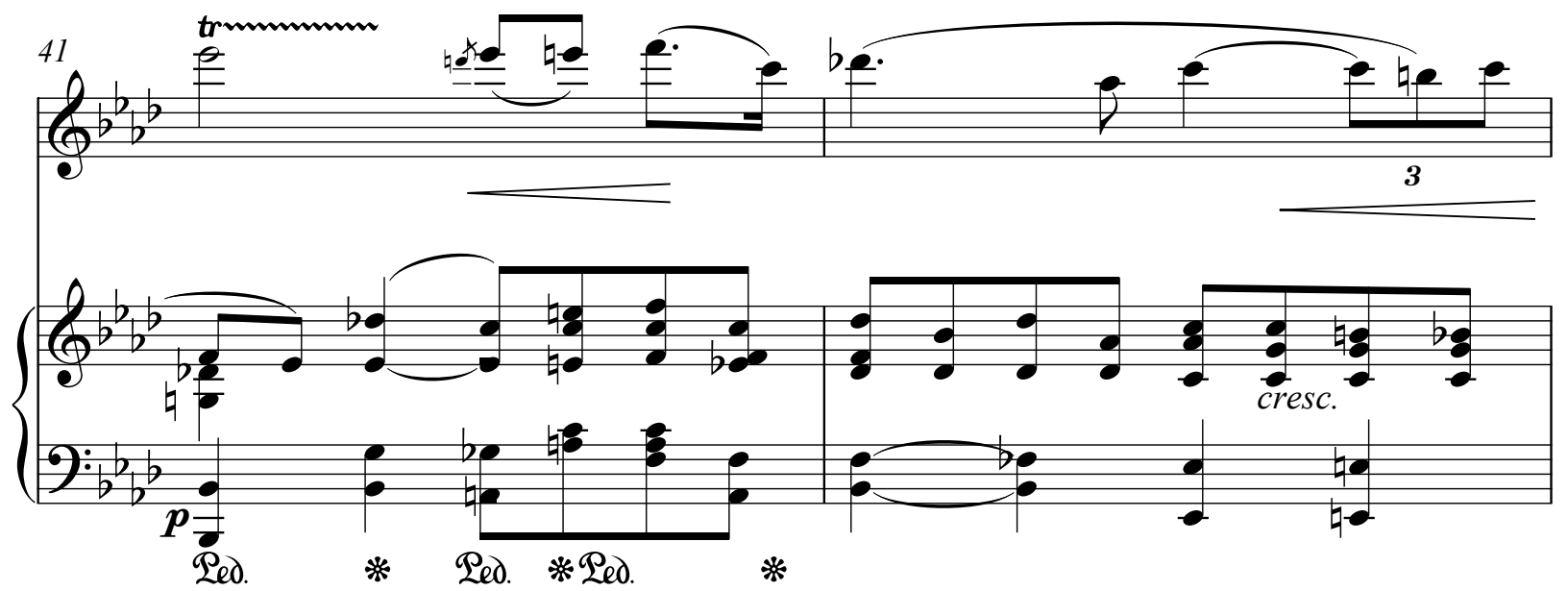

Although Beach changes the octave of the violin melody for each major section (A, A', and coda), the pickup measure remains in the same octave. The melody clearly starts in $\mathrm{mm}$. 5, 28 , and 49 in each respective section, but in each instance the violin precedes the melody with the same figure in the same octave. This figure can be seen in mm. 4, 26, and 48 shown in examples 5.11-5.13 below. Although it can easily be missed in $\mathrm{m}$. 48, a closer look reveals that the violin does indeed have the same figure. 
Example 5.11: Invocation, mm. 4-5

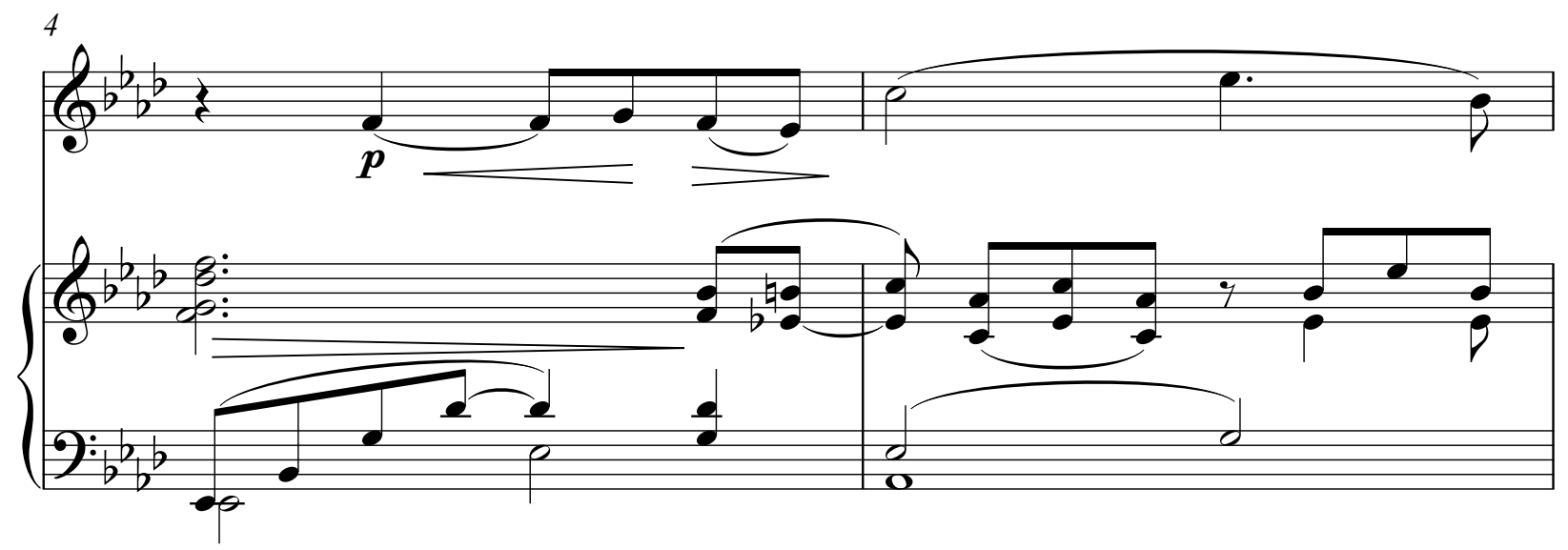

Example 5.12: Invocation, mm. 26-28

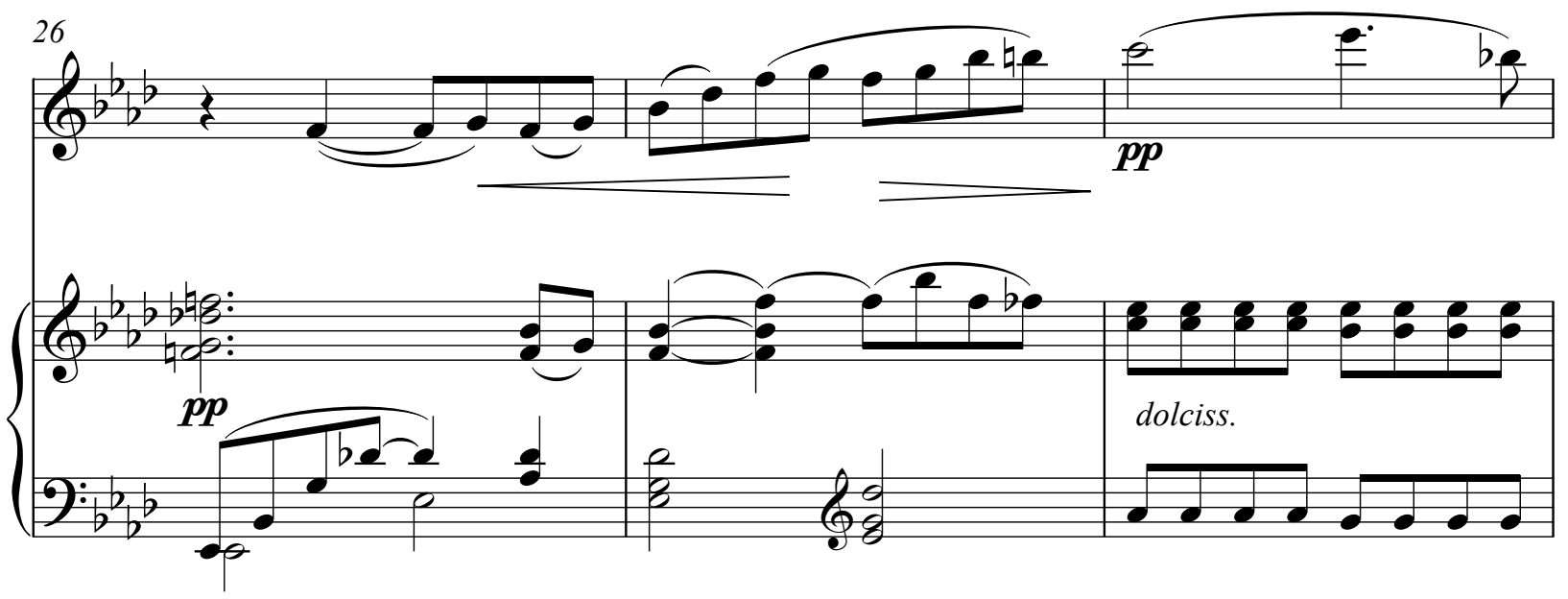

Example 5.13: Invocation, mm. 48-49

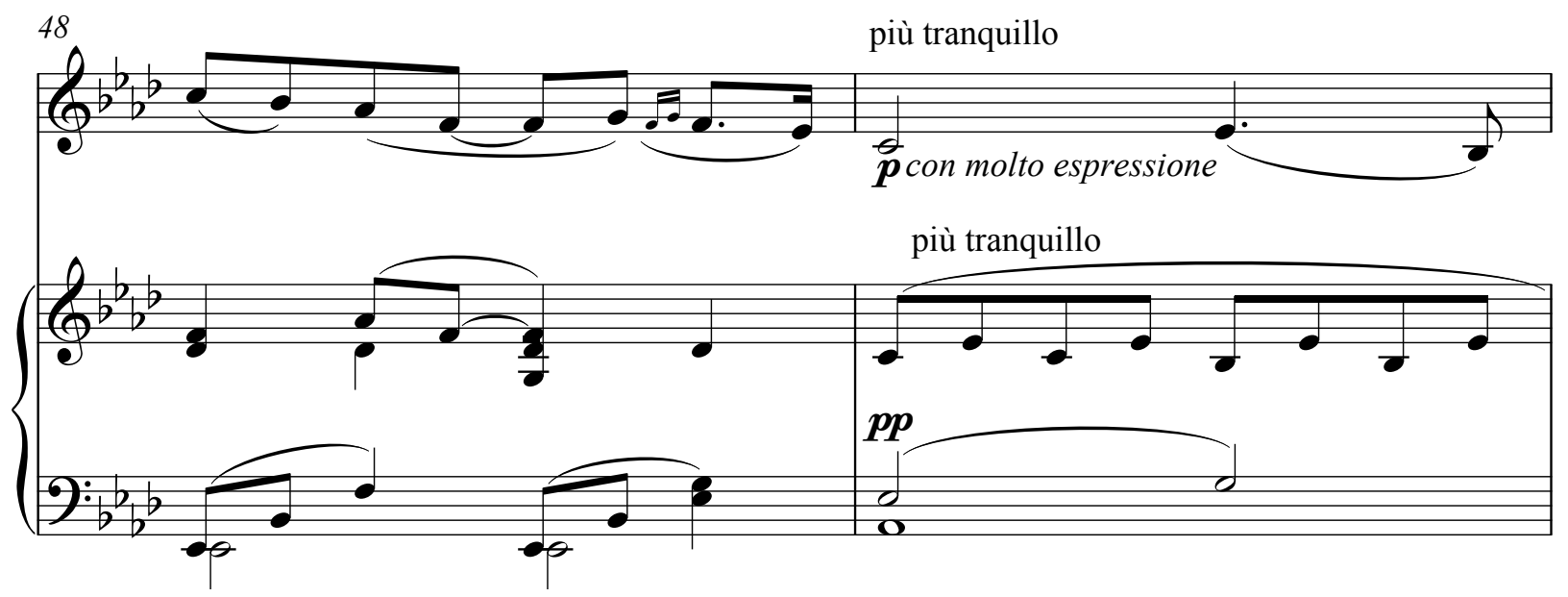


The first few bars of the coda are the same as A and A', then the violin breaks off and arpeggiates up to the final note. She uses this type of ascending arpeggiation at the end of both La Captive and the Mazurka.

Throughout the Invocation Beach uses a variety of textures in the piano. While the violin is always a flowing, melodic voice the piano changes accompaniment patterns. The introduction starts off with long, overlapping lines. Once the violin begins the main melody, the piano lines switch to longer notes in the left hand, which are filled out by eighth and quarter notes in the right hand (example 5.14). This continues through the first half of the A section. Starting in $\mathrm{m} .11$ the left hand becomes more active while the right hand alternates between off-beat eighth notes and longer, more melodic lines (example 5.15). The interlude has the same texture as the introduction. A' distinguishes itself by introducing a completely new texture: straight eighth notes (example 5.16). These continuous eighth note chords last for the first half of A', at which point the piano returns to a similar texture as $\mathrm{m}$. 11. The straight eighth note chords, now thicker in texture, return in mm. $43-44$ as a build up to the climax (example 5.4). The coda presents another new texture: flowing, steady, tranquil eighth notes in the right hand and longer note values in the left hand (example 5.17). In the final three measures both piano lines shift to a final, slower chordal texture (example 5.18). 
Example 5.14: Invocation, mm. 1-5

\section{Invocation}

Mrs. H. H. A. Beach, Op. 55
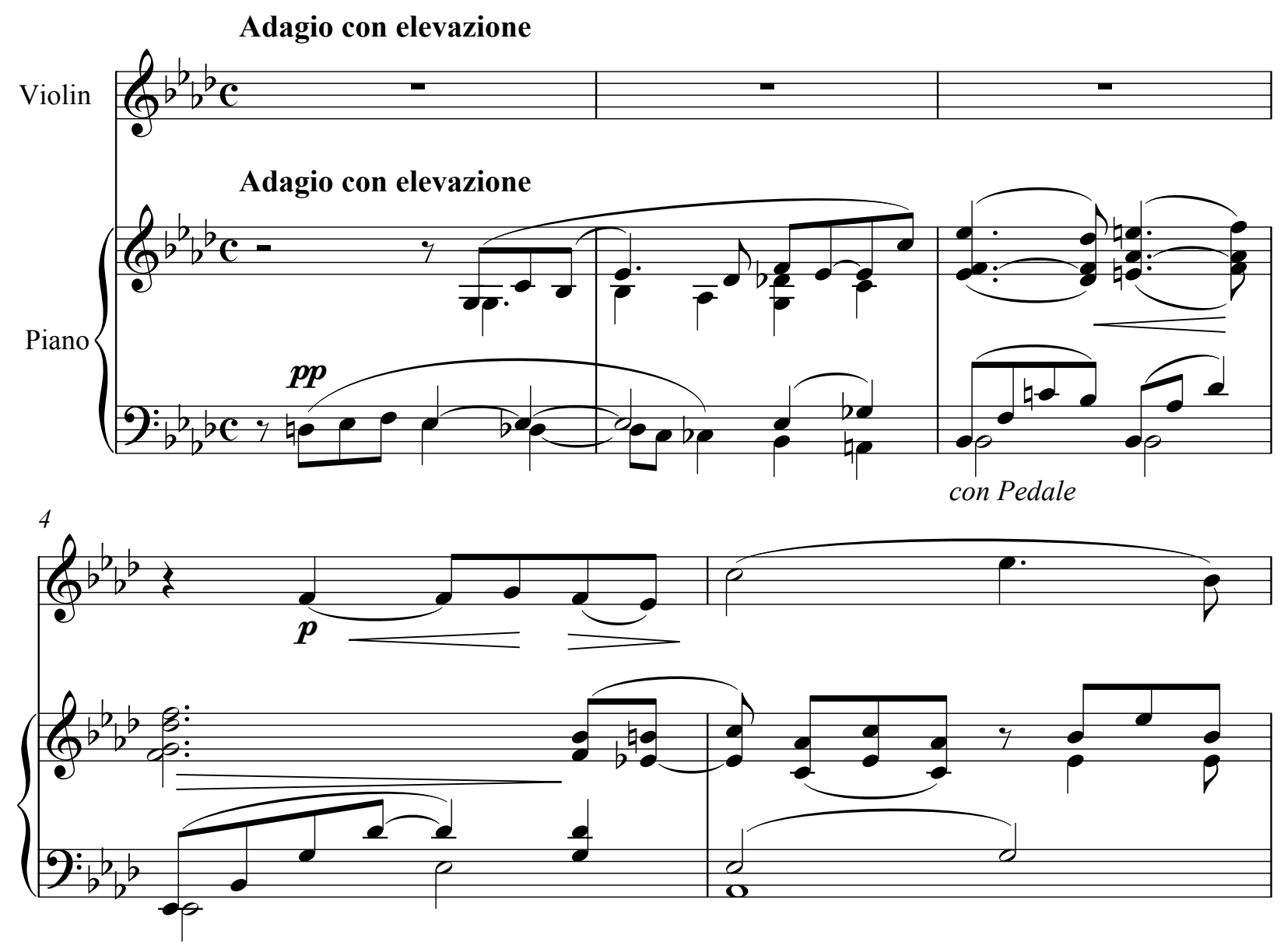
Example 5.15: Invocation, mm. 10-15
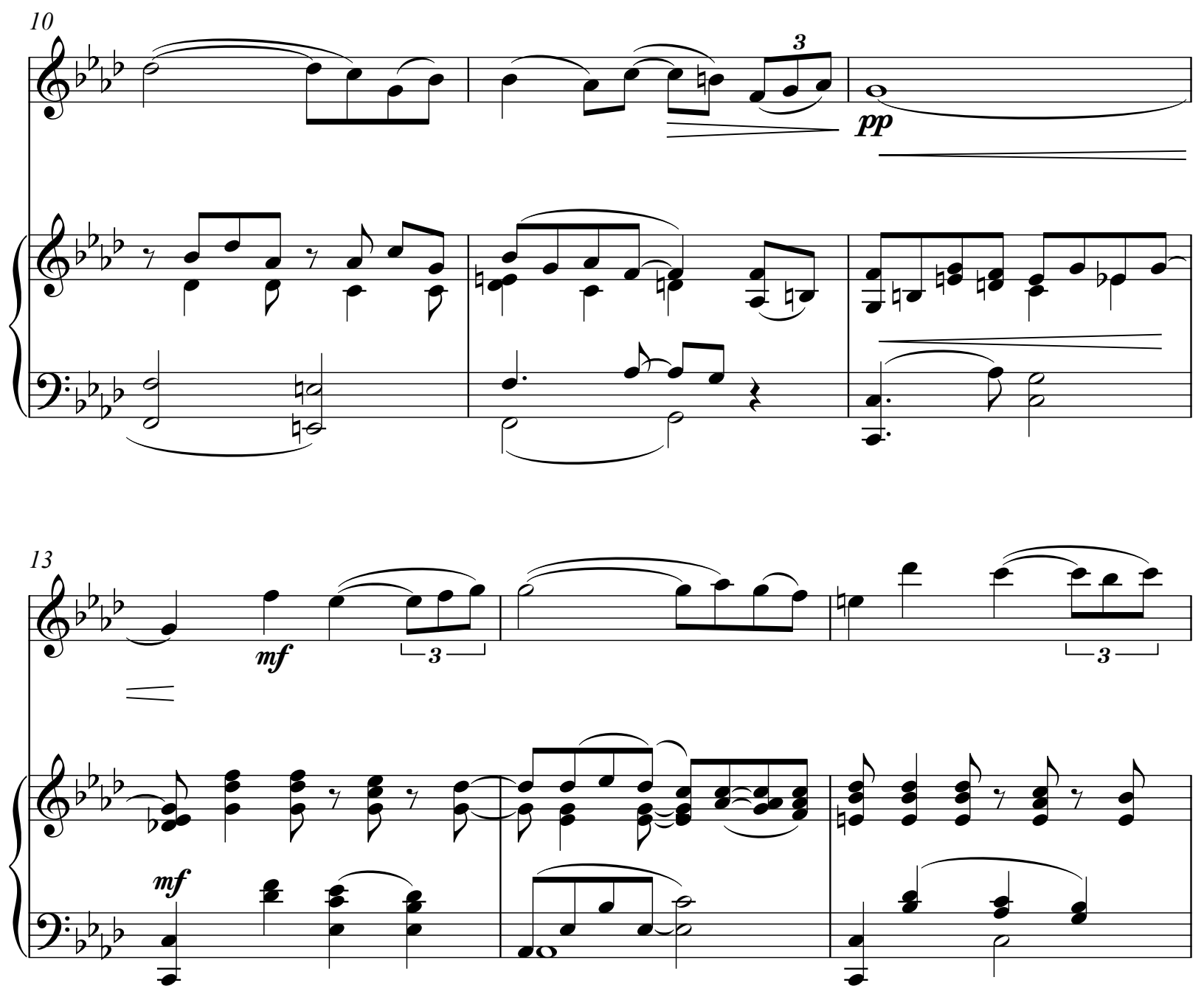

Example 5.16: Invocation, mm. 27-29

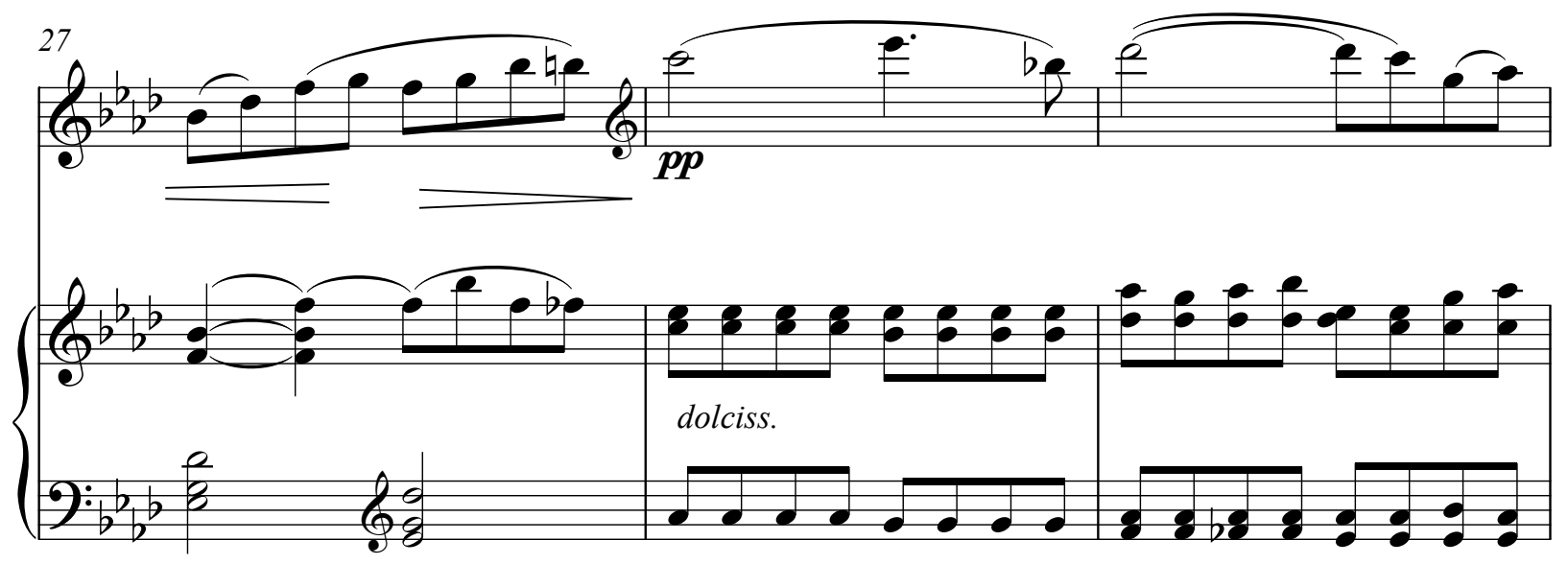


Example 5.17: Invocation, mm. 49-50

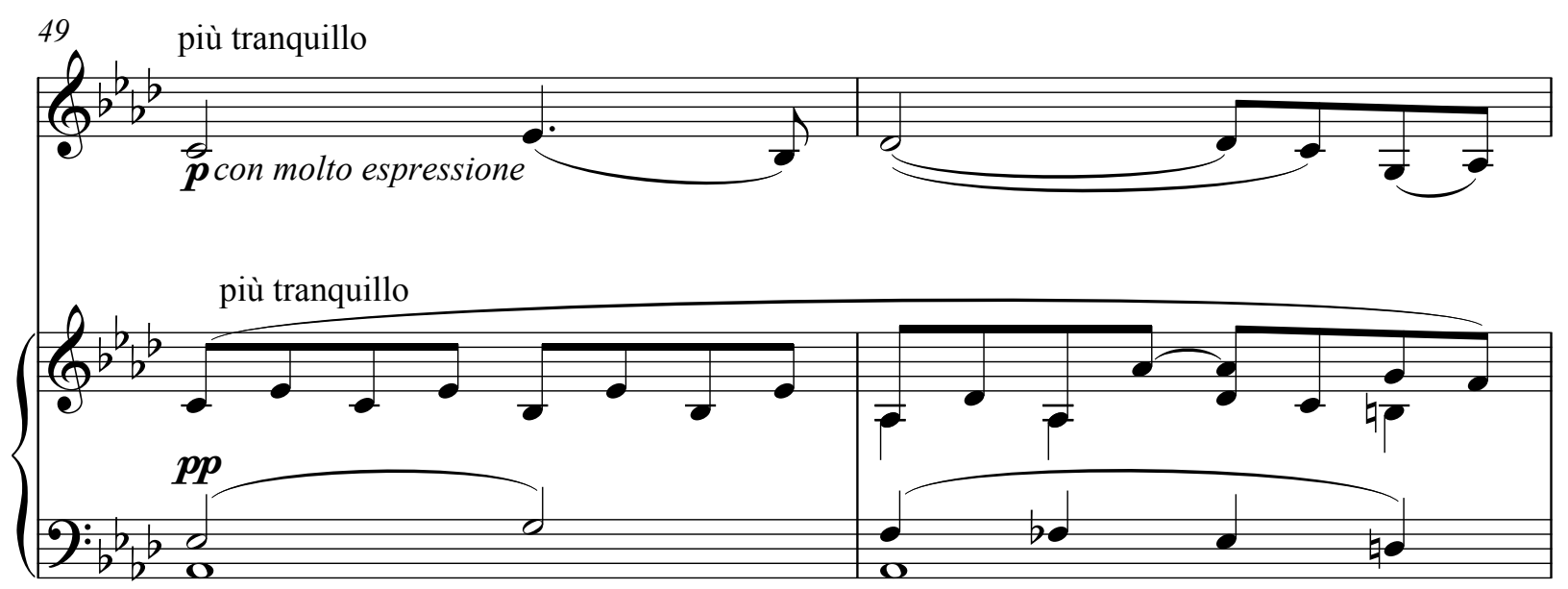

Example 5.18: Invocation, $\mathrm{mm} .55-57$

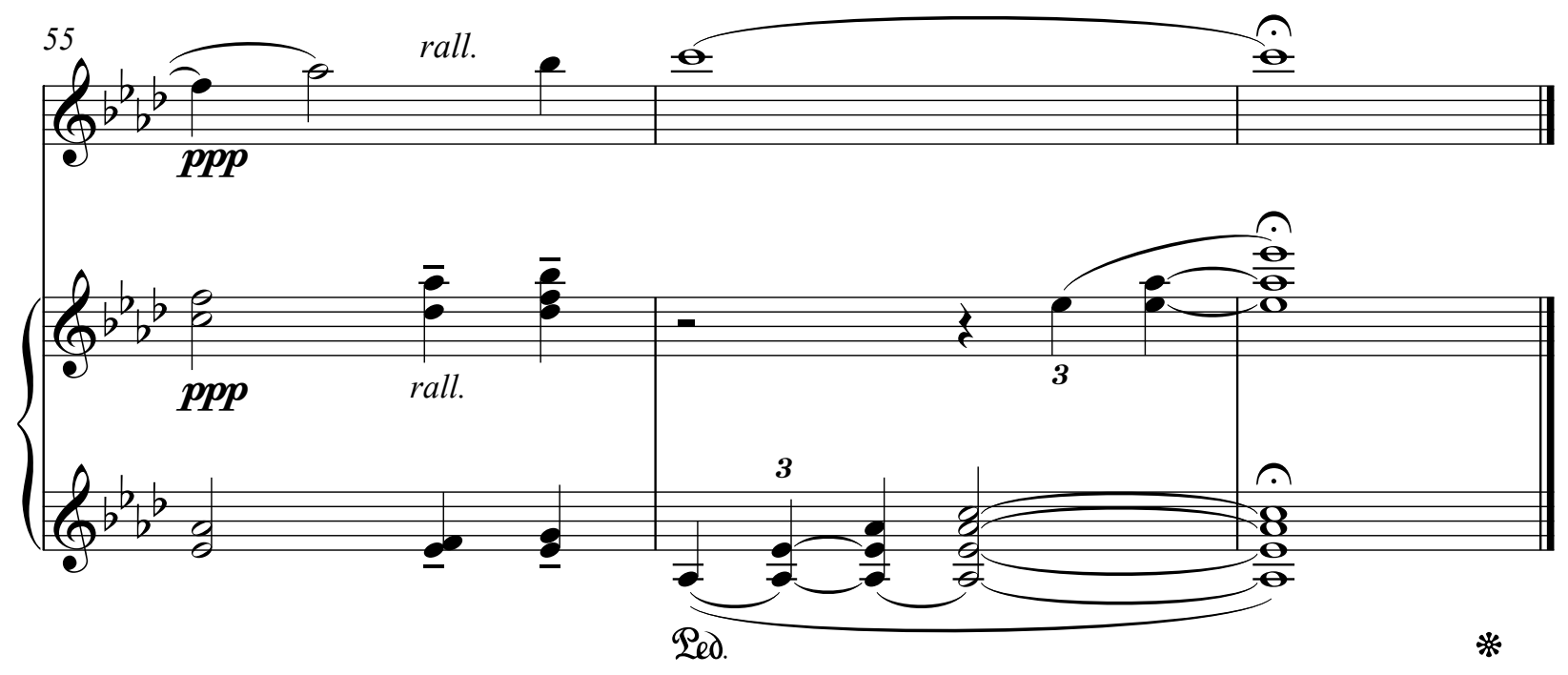

Similar to the beginning of the Romance, the Invocation starts with an emphasis on the dominant, which in this case is Eb major. The dominant preparation, which also includes a measure of supertonic harmony, lasts four measures before finally reaching the tonic chord in $\mathrm{m}$.

5. 
Example 5.19: Invocation, mm. 1-5

\section{Invocation}

Mrs. H. H. A. Beach, Op. 55

\section{Adagio con elevazione}
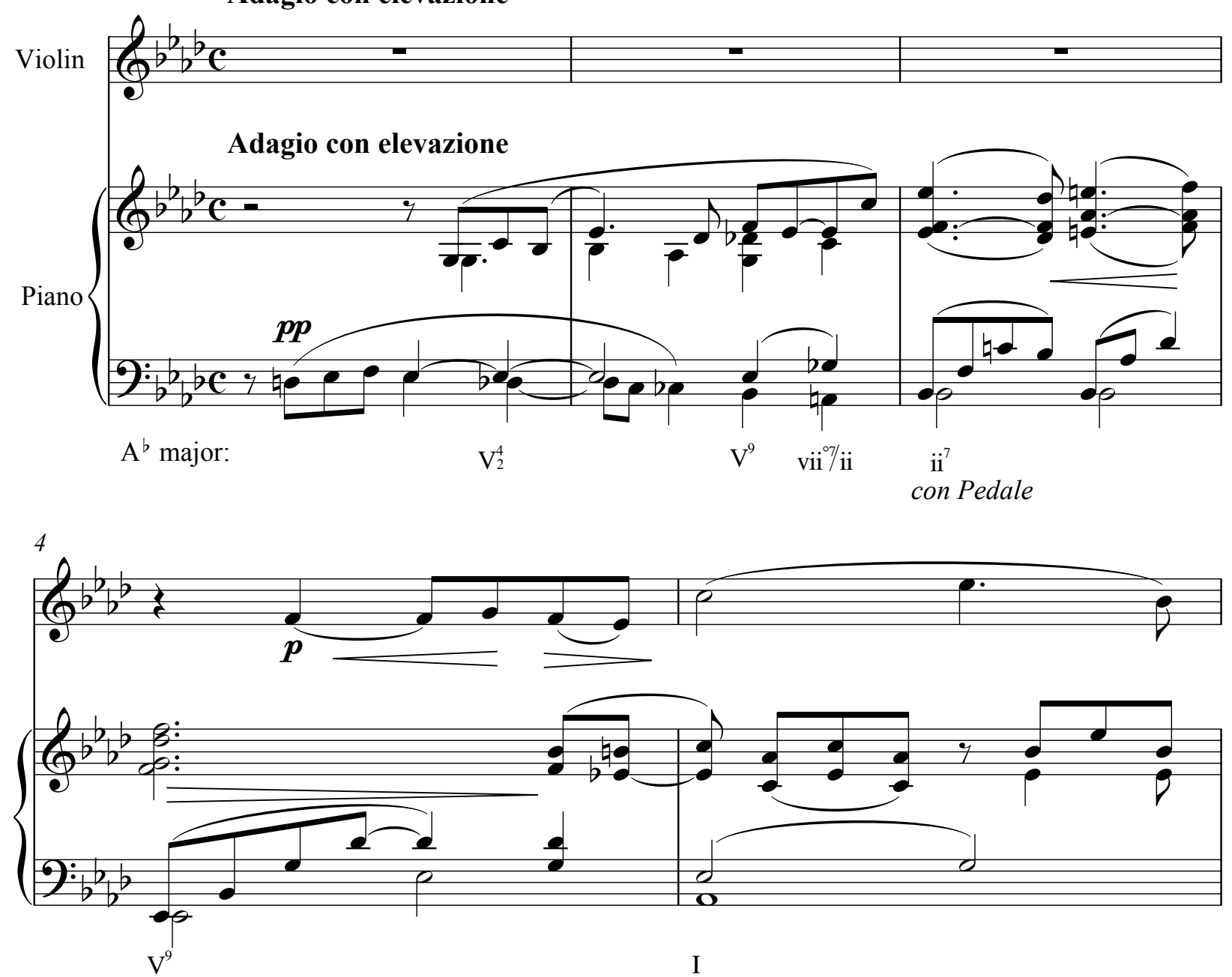

Beach employs an Ab pedal tone from mm. 5-9. Measure 8, the end of the first phrase, cadences in $\mathrm{Ab}$ major. Starting on the $\mathrm{G}$ in $\mathrm{m} .5$, the tenor voice has a descending, somewhat chromatic, scalar passage which switches to the bass voice in $\mathrm{m} .9$ and continues through the Eq in m. 10 . 
Example 5.20: Invocation, mm. 5-10
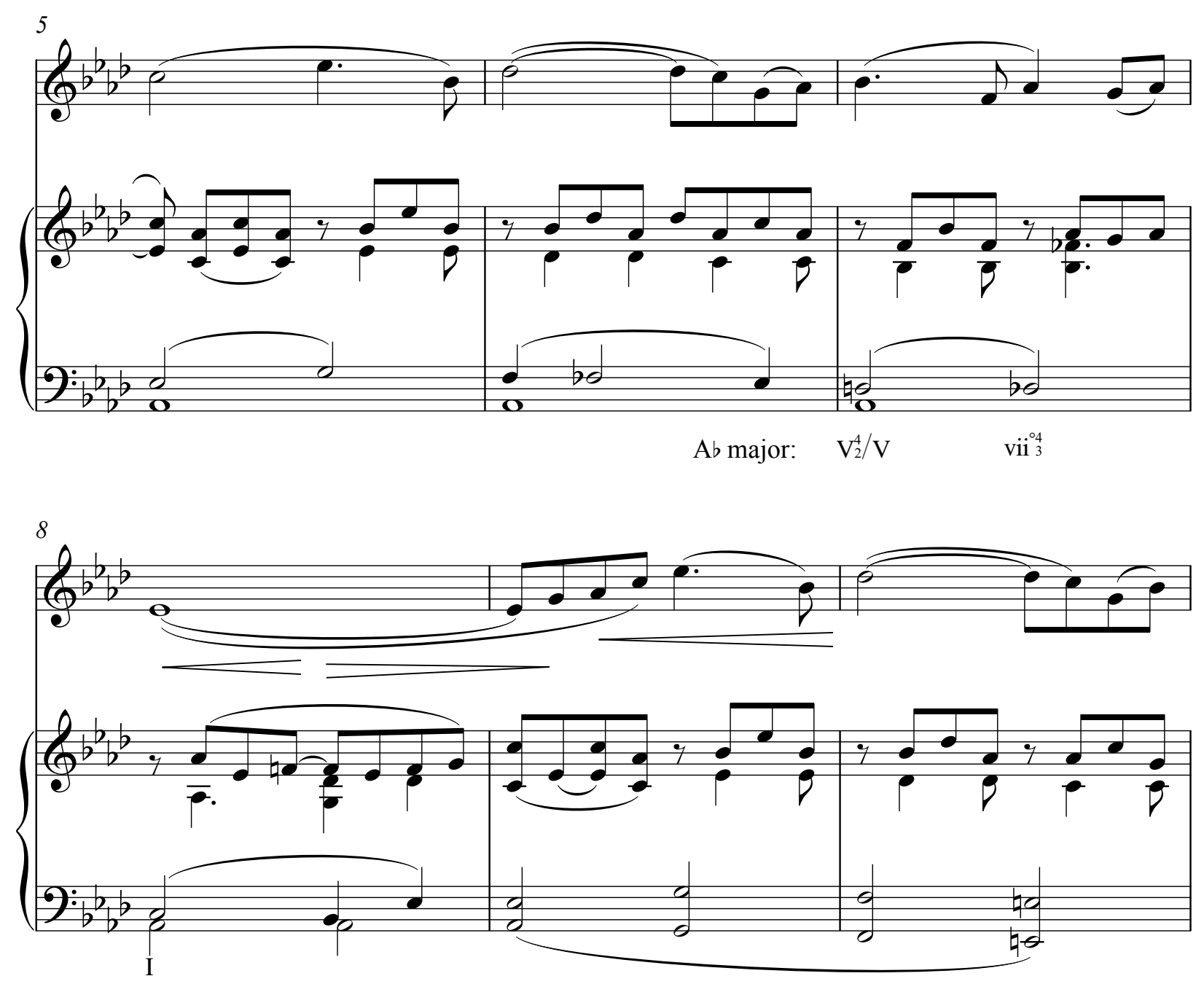

The second half of the A section stays in Ab major, yet avoids any authentic cadences.

Instead she uses a variety of progressions which are clearly in Ab major, meanwhile bypassing a strong dominant to tonic motion. One such example is in mm. 13-14. Here it appears as if she may be setting up a V-I with the $\mathrm{V}^{7}$ in $\mathrm{m} .13$, followed by the bass motion to $\mathrm{Ab}$ in $\mathrm{m} .14$. However, the rest of the voices do not follow the bass motion and instead remain on a $\mathrm{V}^{7}$. Usually when this occurs (having a dominant chord above tonic) the dominant chord eventually 
resolves to the expected tonic a few beats later. Instead, Beach chose to move to a very brief vi at the end of the measure before landing on a V/vi in $\mathrm{m}$. 15. A second spot is from $\mathrm{m}$. 16 , beat 3 to m. 18, beat 1 (example 5.21). In these measures is a brief tonicization of IV, followed by a $\mathrm{I}^{6}$ which moves to a $\mathrm{V}_{3}^{4}$. In mm. 18-19 Beach also incorporates a tonicization of the supertonic, very similar to what was seen in the introduction, in mm. 18-19 (example 5.21). Finally there is a standard $\mathrm{V}^{7}$-I in Ab major in mm. 21-22 (example 5.22).

Example 5.21: Invocation, mm. 13-19

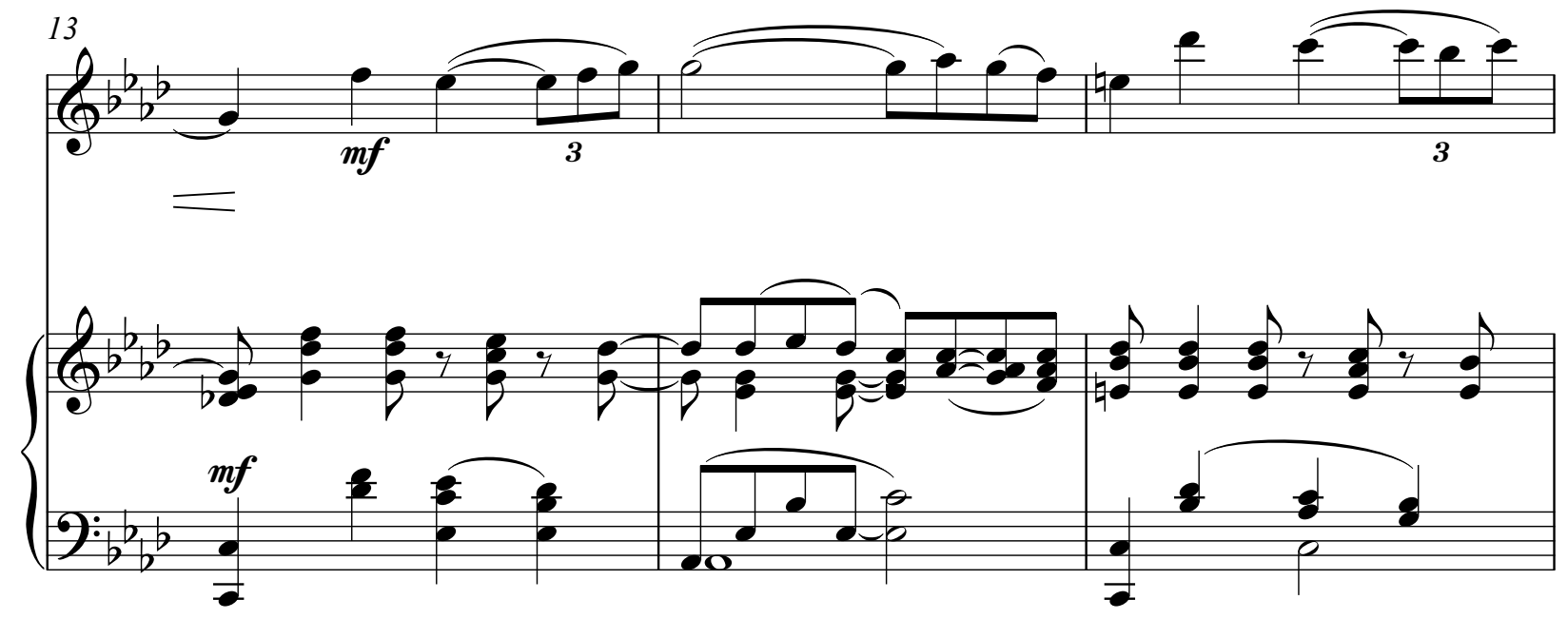
Ab major: $\mathrm{V}^{7}$
[vi] $\quad \mathrm{V} / \mathrm{vi}$

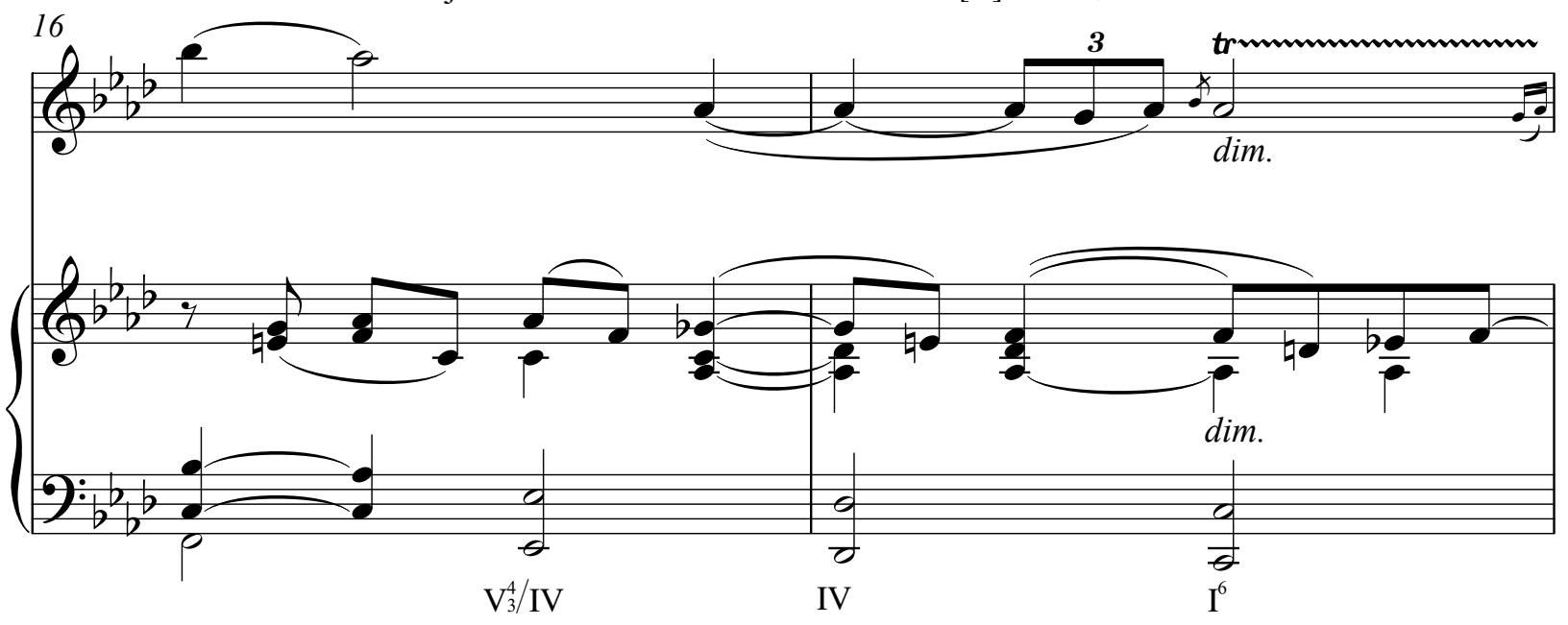


Example 5.21: Cont.

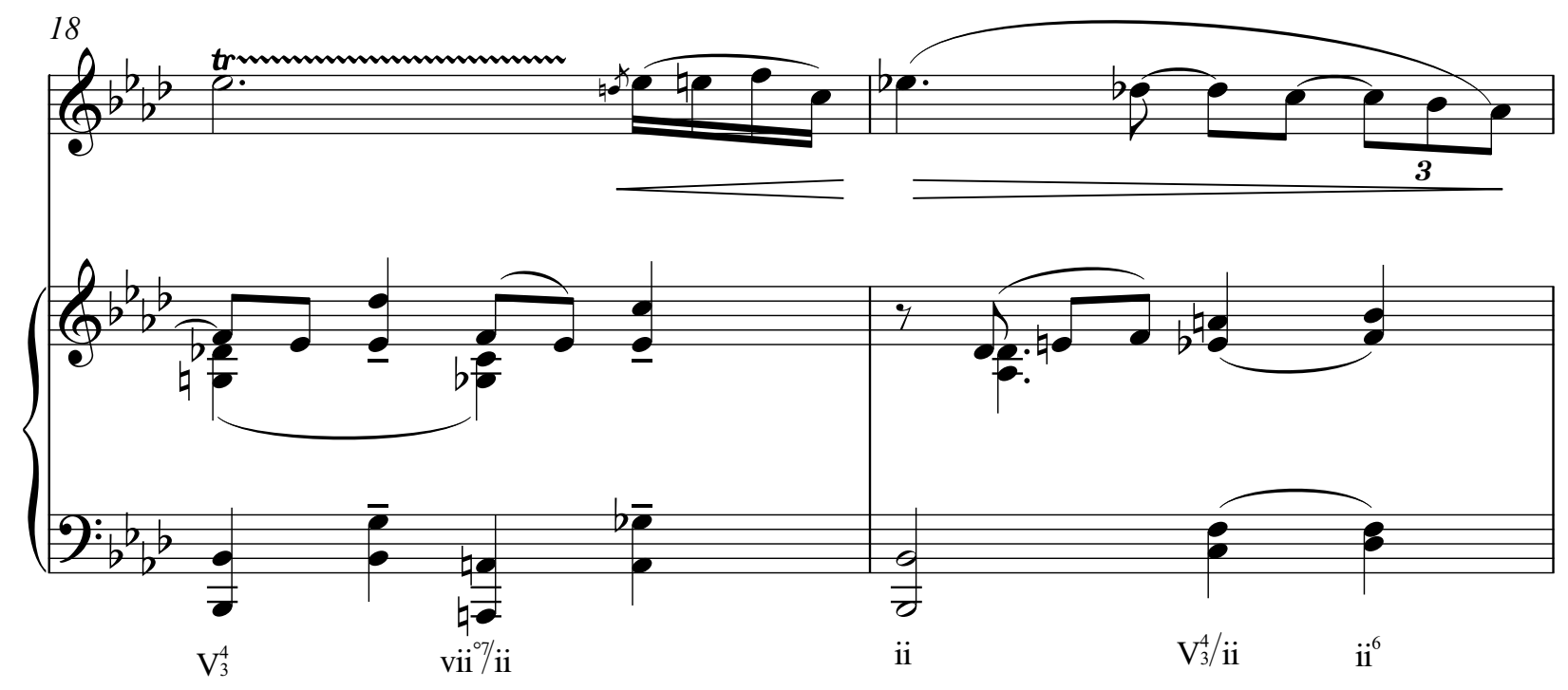

Example 5.22: Invocation, mm. 21-22

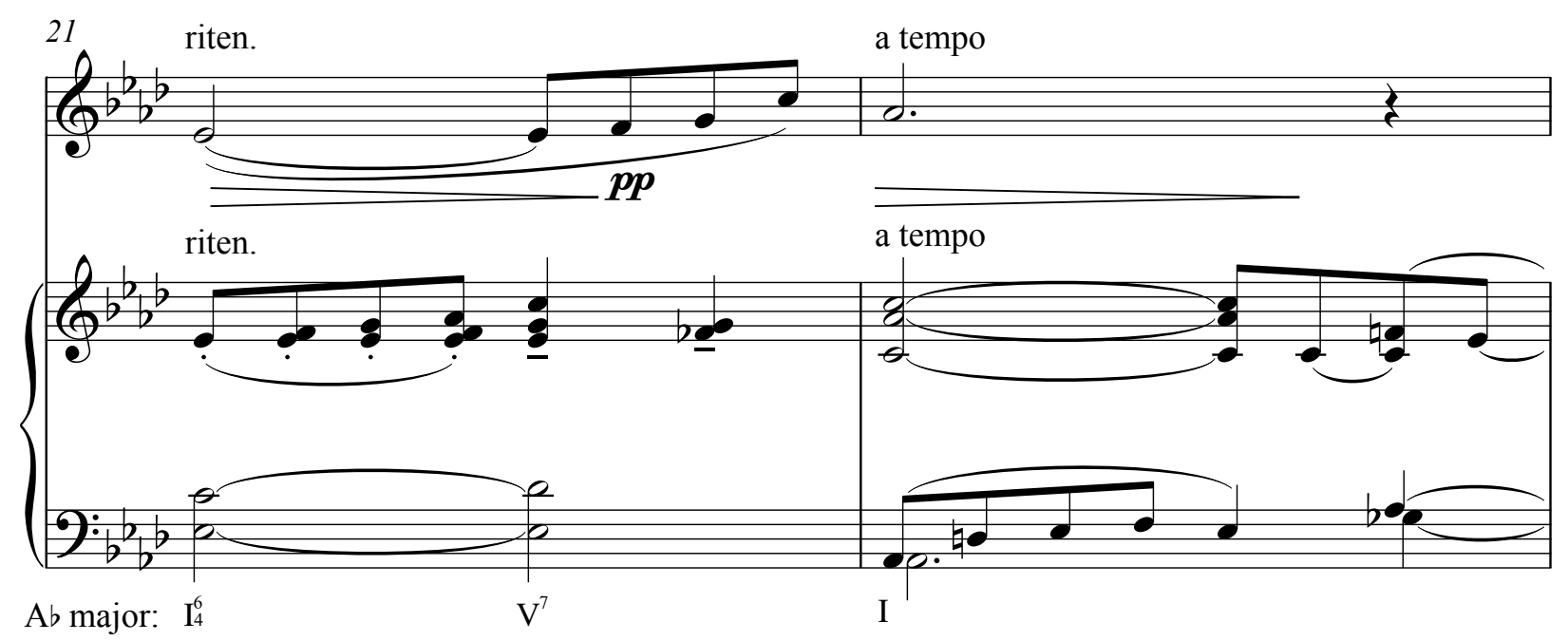

The interlude, in mm. 22-27, functions the same harmonically as the introduction. It emphasizes the dominant while preparing to return to tonic. This is accomplished in the interlude by a $\mathrm{vii}^{07} / \mathrm{V}-\mathrm{V}$ progression, as well as a $\mathrm{Gr}^{+6}-\mathrm{V}^{9}-\mathrm{I}$, which resolves on the first measure of A' (example 5.23). 
Example 5.23: Invocation, $\mathrm{mm} .22-28$
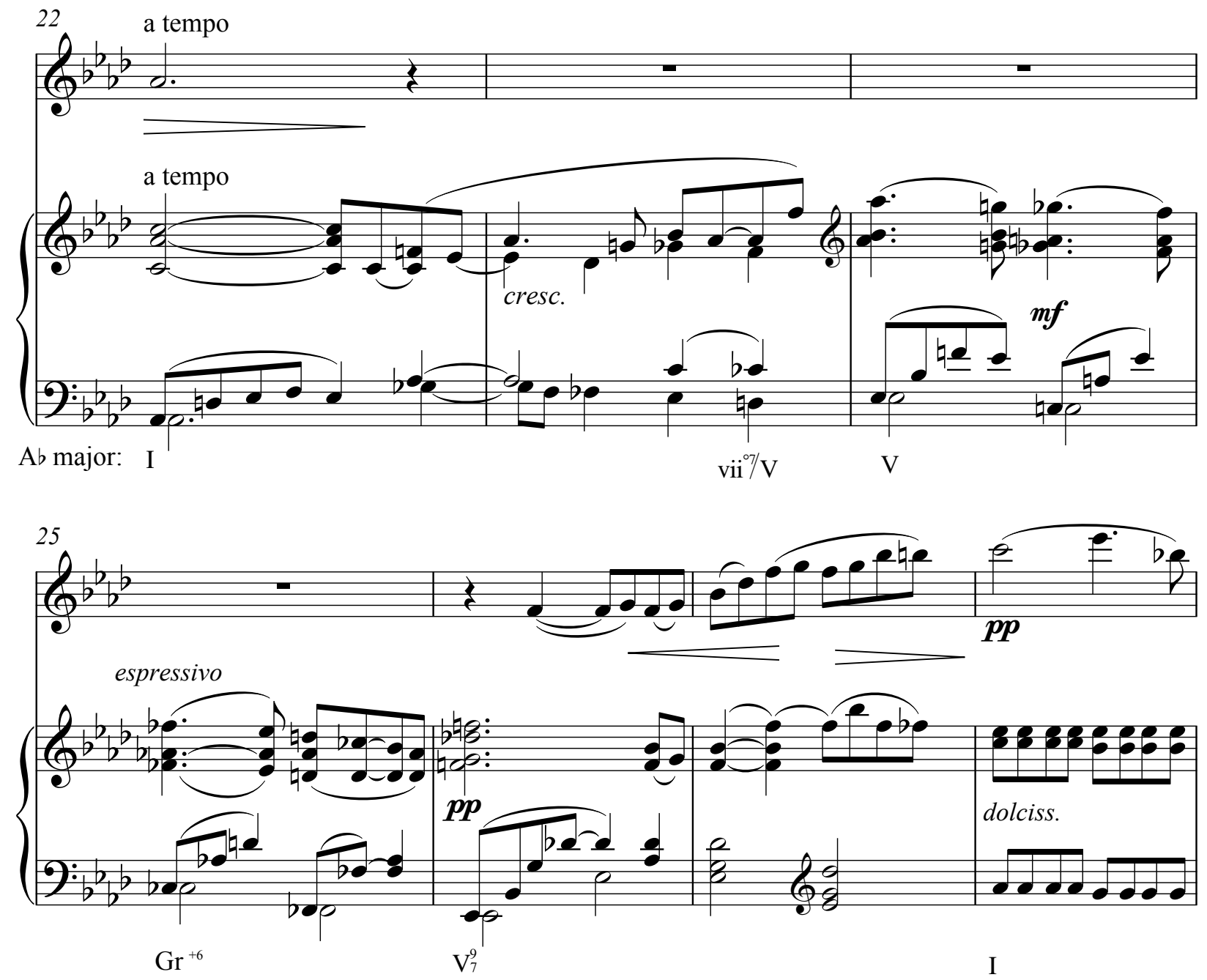

As the A' section is harmonically almost a duplicate of the A section, there is nothing further to add concerning mm. 28-43. A' breaks considerably from the A section in m. 43. Beach combines the straight eighth note texture initially seen in $\mathrm{m}$. 28 , with a chromatic descent in almost all of the voices. This builds to the climax in $\mathrm{m}$. 45 , which starts a dominant pedal that lasts until the coda. Above the dominant pedal is a $\mathrm{V}^{11}$. In the buildup to the climax, Beach includes some secondary dominants and predominants leading to the extended dominant harmony. The tonic harmony finally returns in $\mathrm{m} .49$, the start of the coda. 
Example 5.24: Invocation, mm. 43-49
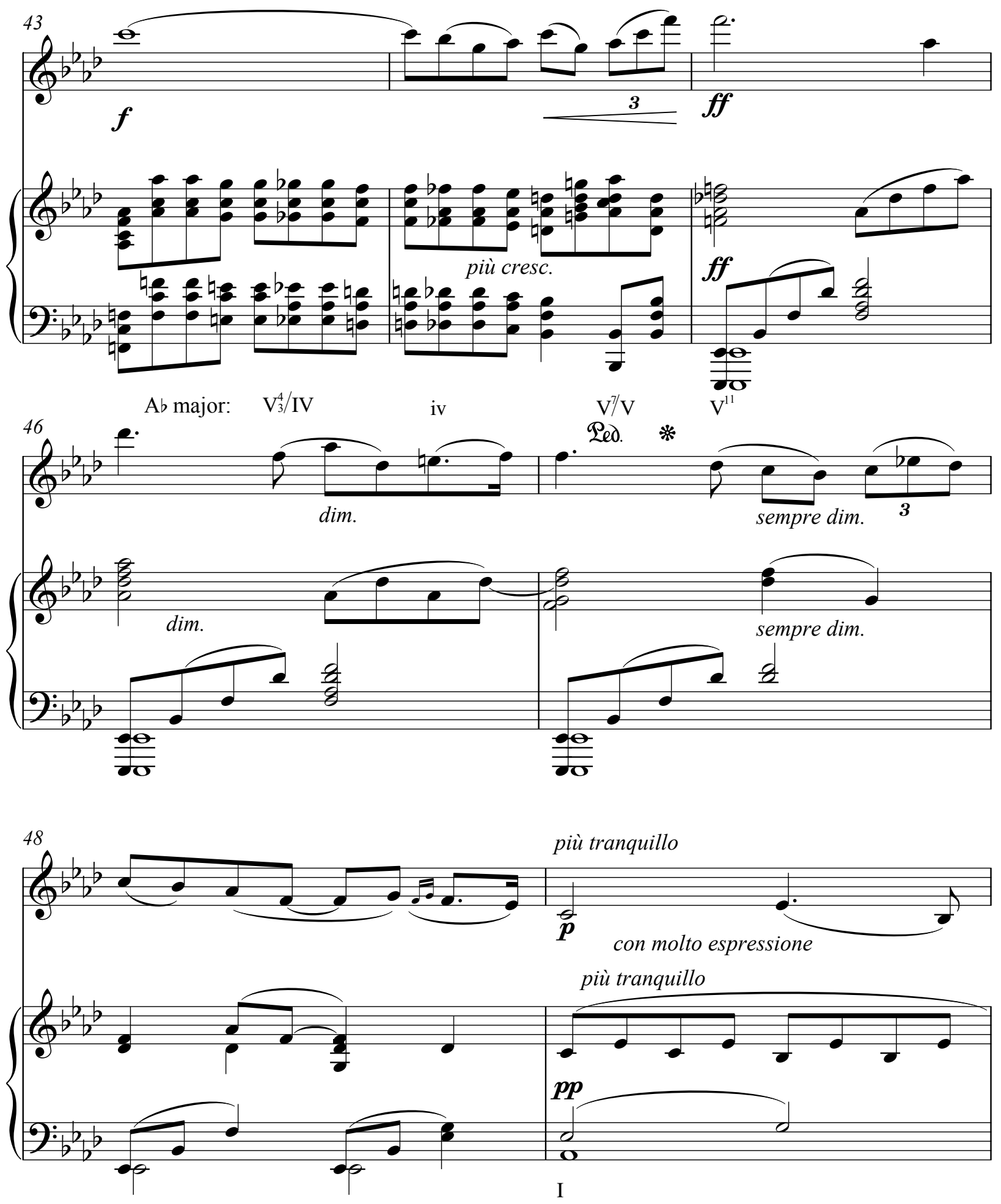
The coda combines many elements previously seen throughout A and A', including a descending tenor line (mm. 49-52), pedal tones, and an accompaniment of continuous eighth notes. These eighth notes contribute greatly to the tranquil character of this section, especially when considered with the più tranquillo marking. Harmonically, the coda is almost all tonic, ending with an authentic cadence.

Example 5.25: Invocation, mm. 49-52

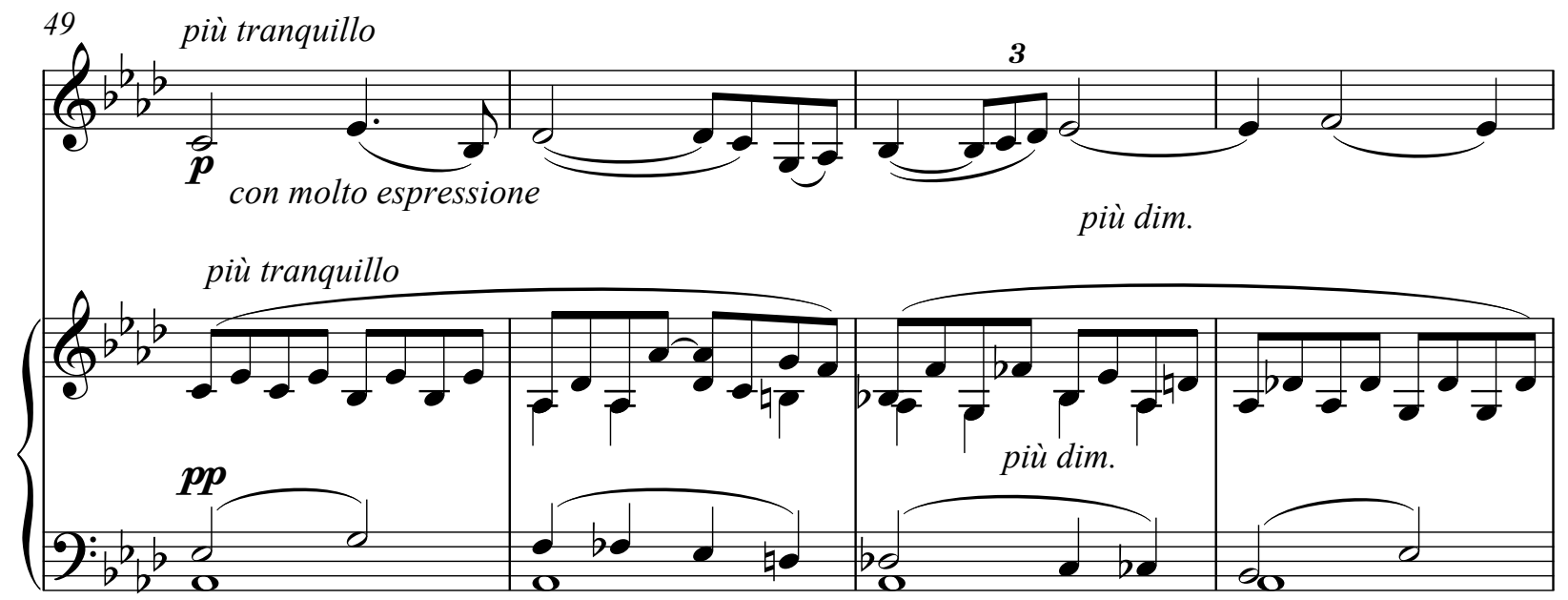

Example 5.26: Invocation, mm. 55-57

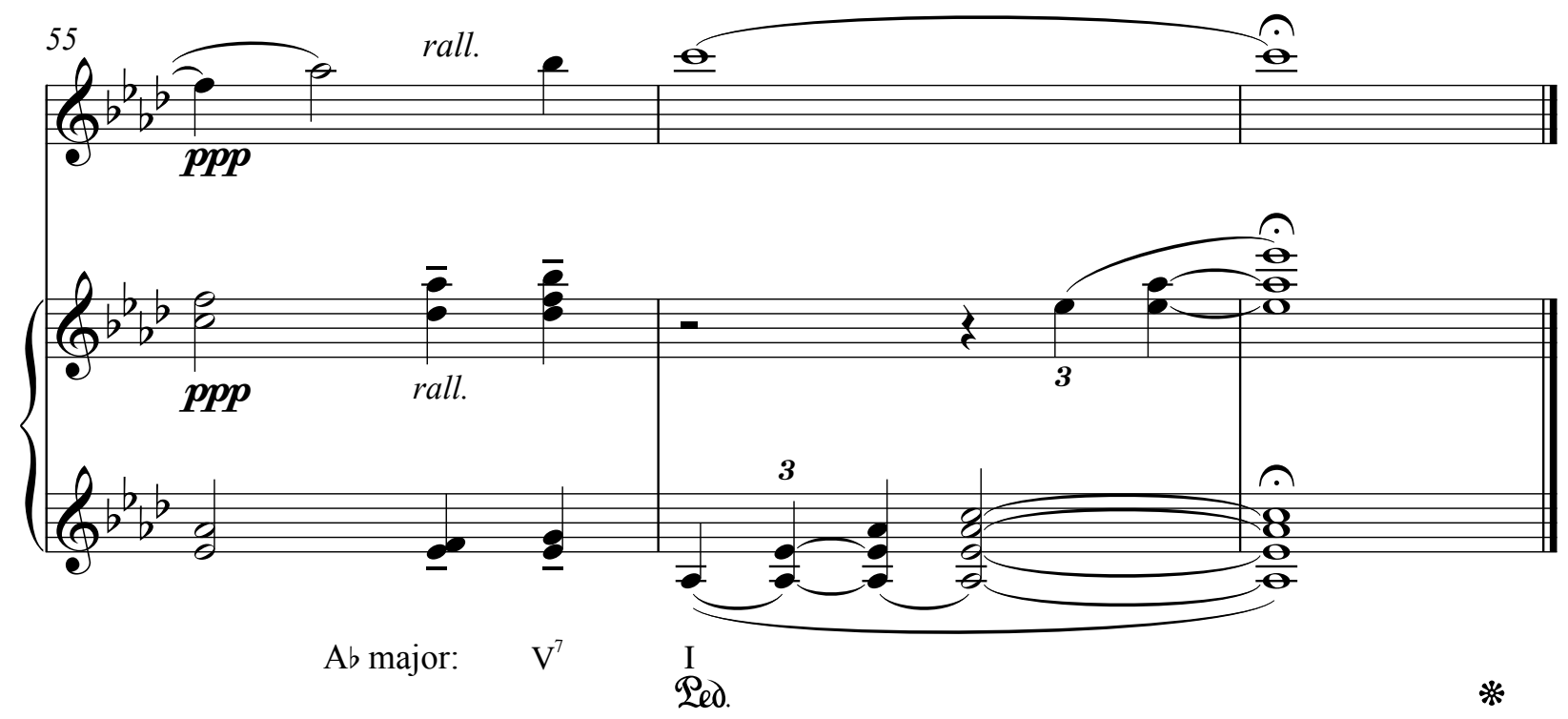


In order for the Invocation to keep the same range and feel of the piece for the viola, the transcription is lowered a perfect fifth. This changes the key from Ab Major to Db Major. While the viola could have played the majority of the piece in the original key it would sound more virtuosic and less simple. Beach also strategically places high notes at important points (such as the climax); however, if left in the original key, these notes would need to be transposed down an octave and therefore lose their intensity. The piano part is quite intricate so there were some changes necessary in order to keep lines clear. For example, the opening introduction is raised an octave in both staves for the first two measures. This was done to prevent the low chromatics from causing a muddier sound than originally intended. As has been pointed out throughout the analysis, the descending scalar lines in the left hand are very important. Therefore, it was advantageous to raise some of the lines an octave, so they would be more prominent in the texture. This occurred in mm. 5-8. To make this easier for the pianist the lines were also revoiced. The descending bass line was moved to the bottom of the right hand and the recurring quarter notes were moved to the top of the left hand. Example 5.20 shows the original and the transposed/re-voiced score is shown in example 5.27. 
Example 5.27: Invocation, mm. 5-8, viola transcription

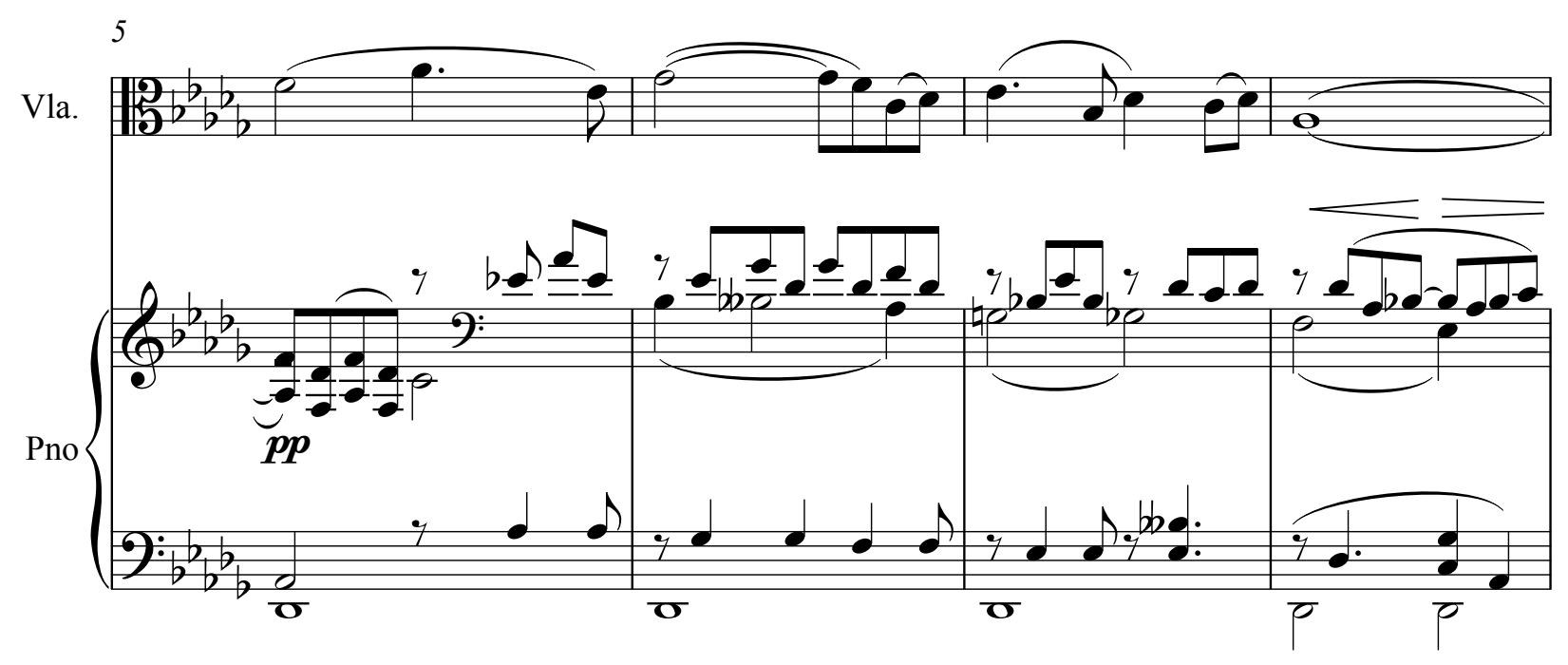

The $\mathrm{B} b b-\mathrm{Ab}$ in $\mathrm{m} .37$ was also raised an octave.

Example 5.28: Invocation, m. 37, viola transcription

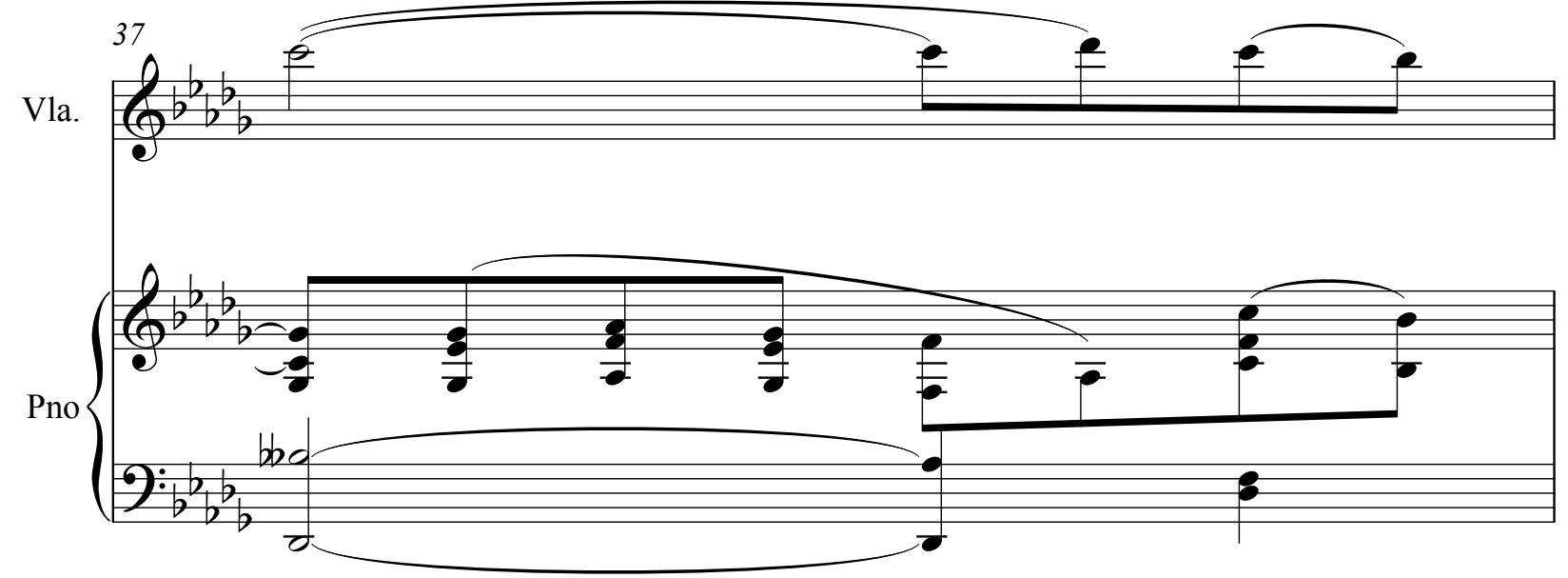

More adjustments were made in mm. 43-44 (example 5.29). In m. 43 on the downbeat, the F was taken out of the left hand to avoid a muddier sound than was originally intended. For the same reason, in $\mathrm{m} .44$, the $\mathrm{B} b$ was removed from the last eighth note in the left hand. 
Example 5.29: Invocation, mm. 43-44, viola transcription

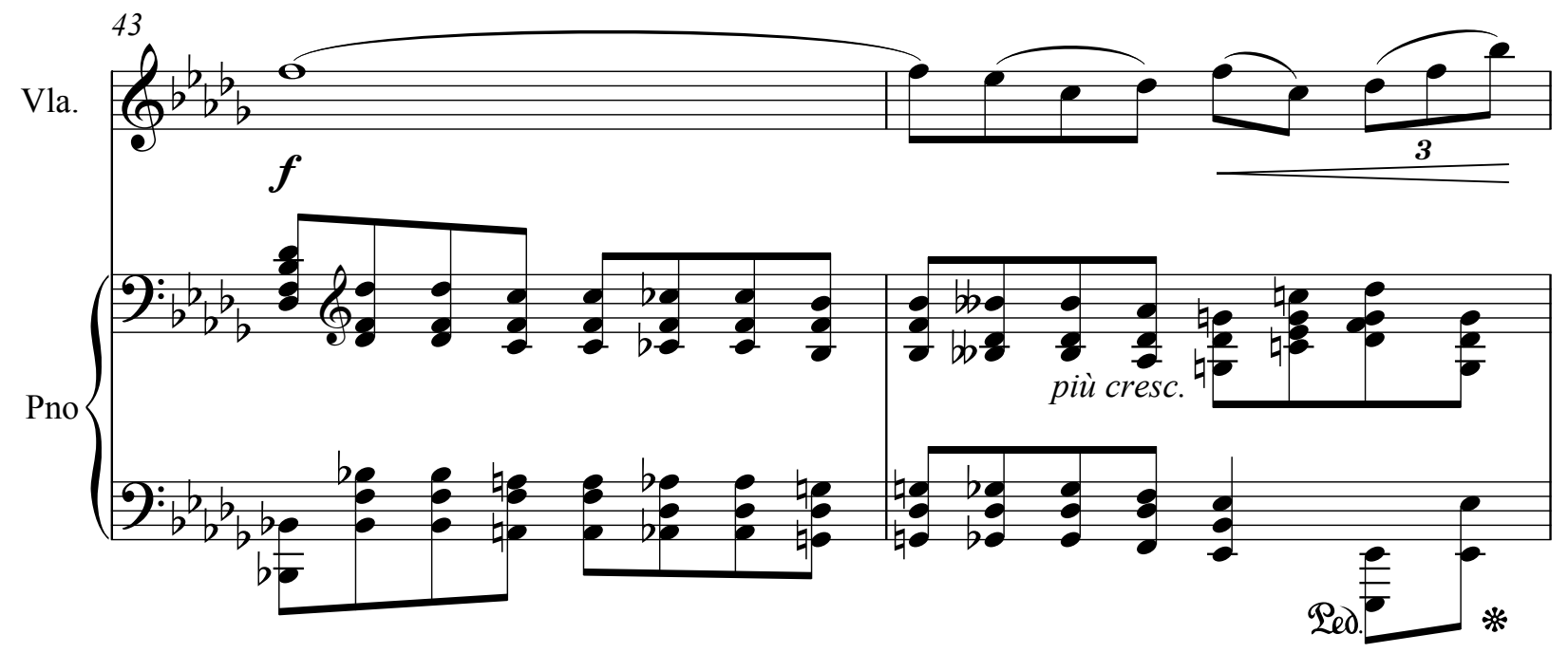

The simple, beautiful nature of this piece adapts very easily to the viola and despite the transposition, the original intent and feeling is maintained. 


\section{Chapter 6: Pedagogical and Performance Uses of the Viola Transcriptions}

Amy Beach's opuses 23, 40, and 55 help to fill the noticeable void within the viola repertoire of pieces written by American Women composers. They provide new performance options for both students and professionals. This Chapter will explore the difficulties encountered in each piece, as well as give suggested performance situations. Additionally, two difficulty levels will be assigned to each piece. One of the many problems with assigning difficulty is the subjective nature of any rating system. The two systems used will be the American String Teachers Association Certificate Advancement Program (ASTACAP), and Donald McInnes's Representative List of Viola Repertoire. Every rating system has its strengths and weaknesses, and these two are no exception. However, they are both well respected and trusted by many teachers, which makes them an ideal fit for this document.

ASTACAP has levels ranging from foundational through level ten, while Donald McInnes has just four levels. In some respects the goals of each list are opposites. While they both break down repertoire by difficulty level, ASTACAP is aimed at students ranging from those who have just begun playing through an advanced level, typical of a junior or senior undergraduate performance major. Meanwhile, all of the pieces on Donald McInnes' list are suitable for a professional concert setting. McInnes uses level one to denote the easiest pieces on his list and level four to designate the most difficult repertoire. The goal of his list is to guide advanced students and professional violists in their repertoire choices. An example of this difference in philosophy can be found in the rating of Infanta Marina for Viola and Piano by Vincent Persichetti. ASTACAP rates this at a level ten, the highest level possible, while McInnes 
gives this a level two rating. After much cross referencing there does not seem to be a suitable blanket conversion between the two lists; meaning it is not possible to say that levels one to three of ASTACAP cover the same repertoire as McInnes level one. ASTACAP level ten pieces range from levels two to four in the McInnes system. All of this is stated to make it clear that while the author diligently attempted to give each piece an appropriate rating, naturally arguments could be made to raise or lower each specific recommendation. The pieces below will be presented in publication order, as they were in Chapters 3-5.

The piece most clearly intended for professionals is the Romance. As noted in Chapter 3, this piece was written for one of the preeminent violinists at the time, Maud Powell. By this point in Maud Powell's career she had already played the Bruch G Minor concerto with both the Berlin Philharmonic and the New York Philharmonic. While Beach was writing the Romance, Powell was preparing to premiere the Dvořák Violin Concerto in the United States. According to Joseph Joachim, the Dvořák concerto was too hard for a woman to perform. ${ }^{82}$ However, after Dvořák heard Powell play the concerto, he said he "should write to Joachim at once that he [Dvořák] had found a woman who could play his concerto perfectly." "83

One of the biggest technical challenges of the Romance is the frequent leaps to high notes. Instead of the highest notes being approached by step-wise scalar motion, such as in the Mazurka or Berceuse, they are almost always approached by leap. The examples below show a

82“"Maud Powell Meets Dvořák," The Maud Powell Society for Music and Education Souvenir Autumn (2015): 3 .

${ }^{83}$ Ibid, 3. 
few such moments, although many more exist throughout the piece. It should be noted the examples below are from the viola transcription.

Example 6.1: Romance, m. 39, viola transcription

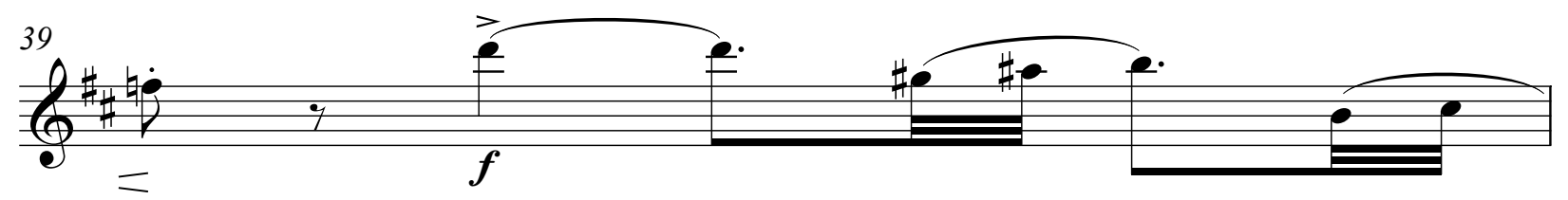

Example 6.2: Romance, mm. 46-47, viola transcription

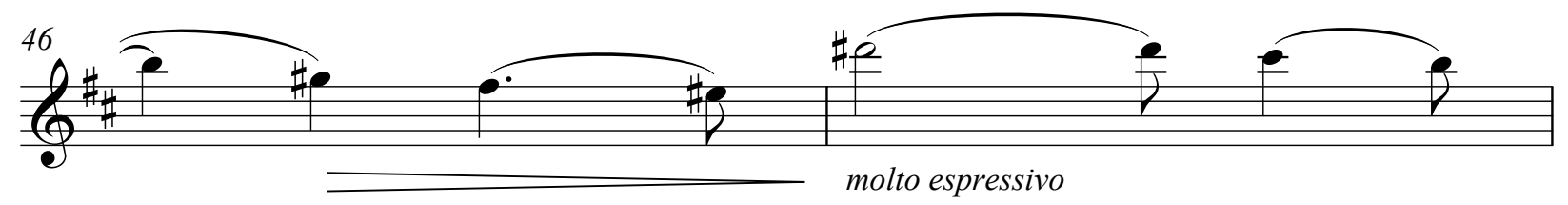

The range is another aspect which firmly cements the Romance's status as a difficult piece. When comparing the highest note in the Romance with the big three viola concertos (Walton, Bartók, and Hindemith's Der Schwanendreher), the highest note lands between that of Der Schwanendreher and Bartók. For comparisons sake, the concerto with the lowest high note is Hindemith's Der Schwanendreher which contains a D6. The Bartók concerto contains a G6 and the Walton concerto is the highest with an A6. The Romance, even transposed, contains an F6. Musically, this piece has many long, extended phrases which require a mature sense of phrasing and a fully developed vibrato. One aspect that makes it a little easier than many other works is the lack of double stops. In fact, throughout all of the opuses covered by this paper, 
there is not a single double stop written. The Mazurka does conclude with a few pizzicato chords, but those do not present the same level of challenge as extended double stop passages. Whether this was a conscious or unconscious choice by the composer will never be known; however, it is a characteristic that does contribute to making these pieces more accessible to students. Due to the issues of range and the exclusion of double stops, the Romance would fit into level ten for ASTACAP and level three for McInnes. This piece can be considered as challenging as either Schubert's Arpeggione Sonata or Brahms's F Minor Sonata, which are both considered to be level ten pieces for ASTACAP and level three pieces for McInnes. Both the Schubert and Brahms are devoid of extended double stop passage, like the Romance. Also the range of both sonatas is within a third of the Romance. The highest note in Arpeggione is an E6 and the Brahms is a $\mathrm{C} \sharp / \mathrm{D} b 6$. Similar to the Romance, both pieces also have long extended phrases requiring a mature vibrato, especially in each respective second movement. Additionally, in the ASTACAP goals for level ten it lists "fluent playing over the entire range of the instrument. ${ }^{" 84}$ Based on the above discussion, the Romance would help a student achieve those ASTACAP requirements.

La Captive, the first of the Op. 40 pieces, restricts the performer to only using the $\mathrm{C}$ string. Therefore it requires frequent shifting into higher positions, which are often underutilized by advancing players. Besides addressing any technical shifting issues the student may have, this piece can also be used to work on the sound production in those positions. Normally, when a less advanced player shifts high on the $\mathrm{C}$ string, the sound quality noticeably diminishes. A variety of

84Nancy Bargerstock et al., The American String Teachers Association Certificate Advancement Program Handbook (2014), 43. 
factors can cause this problem such as the contact point of the bow, the amount of weight used in the right arm, or the question of how much pressure to use in the left hand fingers. This piece provides a melodic opportunity to address those concerns. Since students tend to enjoy practicing their repertoire more than etudes, this piece can serve a double function. Additionally, as it is also well composed and beautifully written, it would be appropriate to program for a jury or recital. Naturally this piece could also be played by a professional, as they could use this opportunity to showcase their sound quality in a range not frequently demonstrated on the viola. The appropriate ASTACAP level for this piece would be level eight, and for McInnes would be level two. Comparable pieces would be Bruch's Romanza or the first and fourth movements of Schumann's Marchenbïlder, both of which are rated level eight in ASTACAP and level two in McInnes. The Bruch and specific movements of the Schumann have overall slower tempos and longer musical lines, like La Captive, which require at least a developing vibrato and maturing sense of phrasing. Although the Bruch and Schumann cover a larger range than La Captive, usually only shifts into fifth position are required for either piece, whereas in La Captive shifts into $8^{\text {th }}$ position are necessary. Additionally, this piece would help a student achieve some of the specific goals for ASTACAP level eight such as "confidence and accuracy in shifting" and "developing varied speeds and widths of vibrato." 85

The Berceuse tackles another technique which is not often addressed in private lessons: playing while muted. Using a mute is a common occurrence in either an orchestra or a chamber ensemble; however, there are not many solo pieces which require the user to perform muted. Two

85Bargerstock et al., ASTACAP Handbook, 41. 
prominent examples are the end of the third movement of Berlioz's Harold in Italy, as well as m. 160 -end of the $3^{\text {rd }}$ movement in Shostakovich's Viola Sonata. Currently there are a large variety of mutes available for violists, and the Berceuse offers a great opportunity to test out an assortment of options.

Mutes come in a mixture of shapes, sizes, and materials. It is possible to buy mutes made out of rubber, plastic, metal, or leather. Each mute has a unique shape. While some mutes can fit on one string, others need multiple strings. Some mutes are meant to sit next to the bridge, while others need to sit on the bridge. The Heifetz mute is an adjustable mute with a metal arm that can be slid up or down to vary the dampening effect. Luckily, since mutes are not expensive, it would be possible to buy multiple options for experimentation while working on the Berceuse.

One aspect of the Berceuse that makes it a perfect candidate to test a variety of mutes is the range covered on the viola. This piece goes down to $\mathrm{D} 3$, the lowest $\mathrm{D}$ on the viola, and all the way up to B5 which requires the player to be in at least fifth position. This means that the Berceuse covers the range represented by the muted section in both Harold in Italy and Shostakovich's Sonata. Of all the pieces analyzed in this paper this is the easiest and therefore should be considered a level six for ASTACAP and level 1 for McInnes. Pieces of a similar difficulty include Fauré's Après un rêve or Bach's Arioso (from Suzuki Vol. 6). Après un rêve, Arioso, and Berceuse all are to be played at a slower tempo. Excluding mm. $60-61$ of the Berceuse, the rest of the notes could be played in first position. The same is true for the Arioso, and all except one note in Après un rêve. For musical reasons a performer would shift multiple times during these pieces; however, they would mainly use first, second, third, and fourth 
positions. The goals for ASTACAP level six include "growing skills in shifting and playing in upper positions," "more fluid and even vibrato used in pieces," and "beauty of tone in sustained passages. ${ }^{" 86}$ If a violist achieved ASTACAP's goals for level six then their performance of the Berceuse would be successful.

The Mazurka, the final piece in Op. 40, offers the most technical challenges for the student performer. Since the pieces in Op. 40 were written separately, but published together, they could be performed as a set, or each piece could be extracted and played on its own, as is frequently the case. As discussed in Chapter 4, the mazurka as concert music was made famous by Chopin who composed at least 57 mazurkas between the years $1825-1849.87$ Since then many other composers and arrangers have been inspired to write their own mazurkas, and now even a violist has multiple options. Some were originally written for the viola, such as Hermann Ritter's Introduction and Mazurka or Hans Sitt's Gavotte and Mazurka, Op. 132. There are also those that have been transcribed for the viola such as numerous Chopin examples, or Mazurkas by Mikhail Glinka and Edward Elgar. Elgar's Mazurka was originally written for full orchestra but later transcribed by the composer for solo piano and violin with piano. It is now available as a solo viola piece from J.W. Pepper. Although Beach's Mazurka is the hardest piece in op. 40, it is technically less demanding than most of the mazurkas listed above. Therefore this piece would be a suitable introduction to the genre for a student violist. However, like the rest of Op. 40, it is

\footnotetext{
86Bargerstock et al., ASTACAP Handbook, 39.

87Kornel Michałowski and Jim Samson, "Chopin, Fryderyk Franciszek," Grove Music Online, Oxford Music Online, Oxford University Press, accessed January 13, 2017, http://www.oxfordmusiconline.com/ subscriber/article/grove/music/51099.
} 
composed well enough to also sound appropriate when played by a professional. The challenges encountered in Beach's Mazurka include long spiccato passages, large leaps in range, and the ability to capture the stylistic qualities of a mazurka.

As mentioned in Chapter 4 there are a number of stylistic features of which a performer needs to be aware when playing the dance known as the mazurka. First, while the music is based on a dance with a lively character, the tempo is supposed to be on the slower side. As the mazurka is in a triple meter, accents frequently occur on the weak beats, a feature that would need to be emphasized without disrupting the phrasing. Pedagogically there are a number of methods that a teacher could use to help their students learn more about mazurkas. For example, they could study the original dance movements and music. Although this particular mazurka was not intended to be used for dancing, an understanding and appreciation for the original intent of the style would benefit the performer. Also, it would be useful to study the mazurkas written for violin by the famous Polish violinist Henryk Wieniawski, to better understand how a native composer wrote specifically for a string instrument within the mazurka style.

An appropriate ASTACAP level for Beach's Mazurka would be a nine and for the McInnes list would be a two. It is of similar difficulty to the Stamitz Viola Concerto in D Major or various movements of J.S. Bach's Cello Suites, both of which are respectively rated as a nine and two. There are many reasons why the Mazurka can be considered as challenging as the Stamitz concerto. For example, within the first 17 measures of the viola's entrance in both pieces a D6 is reached. As a reminder, that is the same single highest pitch for the solo viola as found in Hindemith's Der Schwanendreher. Each work also has a number of fast scalar passage that 
quickly cross all four strings. Lastly, in the final movement of the Stamitz, the third variation is usually played off the string, which corresponds to the middle section of the Mazurka.

Concerning the Bach Cello Suites, the most obvious similarity is the stylistic considerations of playing concert music based upon traditional dance music. Just as learning about the origins of the mazurka would be helpful, so is learning the history of the various dance styles found throughout the suites. The range of the $6^{\text {th }}$ Suite can be compared to the Mazurka, especially if a violist plays the Suite in the original key of D major. The goals for level nine which the Mazurka meets are, "increased fluency and ease of shifting in high positions," "clean and even passagework and extended fast passages," and "heightened development of a sense of style and instrumental imagination." 88 There is much to be learned from studying Beach's Mazurka, including a variety of technical and stylistic techniques.

The final piece analyzed in this document, the Invocation, is a beautiful, lyrical piece. As discussed in Chapter 5 this piece was possibly written for a church service. The challenges found in the Invocation are very similar to La Captive. Although the performer is not limited to one string, the Invocation does contain many long, sustained musical lines which require shifting into higher positions on the A string. A mature or developing vibrato is needed to help with the phrasing of the long notes, while smooth shifting and good bow control of string crossings are necessary to keep the longer, more complicated lines flowing. The performer must be comfortable sustaining a soft dynamic, even in a high register, as only 13 measures of the piece are written either forte or fortissimo. This piece would deserve to be rated an eight for ASTACAP

88 Bargerstock et al., ASTACAP Handbook, 42. 
or a two for McInnes. Like La Captive, this piece would be a good match for the level eight goals of "confidence and accuracy in shifting" and "developing varied speeds and widths of vibrato." 89

The finished transcriptions of the above works will be available soon through Spartan Press Music. As detailed above, these five pieces can serve a variety of purposes for both the professional and student violist. Many important technical concepts are covered, including shifting into high positions, vibrato, spiccato, projection, and stylistic considerations. La Captive may be the only viola piece written entirely for the $\mathrm{C}$ string, the Berceuse may be the only piece for viola that is to be played entirely muted, and the Mazurka is a great introduction to the genre. The Invocation gives another option for violists looking to program a shorter lyrical work, and the Romance is a technically demanding piece that is sure to challenge any performer. This collection of pieces is a welcomed and much needed addition to the viola repertoire.

89 Bargerstock et al., ASTACAP Handbook, 41. 


\section{Chapter 7: Conclusion}

Amy Marcy Cheney Beach was a pioneer for women. She was a professional musician while also fulfilling the era's societal obligations for women. In one extraordinary lifetime she lived three separate lives. As a child and teenager Beach lived the life of a piano prodigy, breaking the mold by succeeding without formal European training. In 1885 she married Dr. Henry Beach, and for 25 years she was the wife to a well respected doctor. Although they never had children, possibly the biggest regret of her life, Beach was able to not only run a household and fulfill her social obligations, but to also compose and occasionally perform. It was during this period that she wrote some of her most famous works including the Gaelic Symphony, Piano Concerto in $\mathrm{C} \#$ minor, and her Mass. During her marriage Beach also composed all of the pieces discussed in this document. Following her husband's death in 1910, when Beach was 43 years old, she began yet another new chapter in her life. She traveled often to Europe, spent considerable time at the MacDowell Colony, expanded her seasonal living quarters to include New York City, and continued composing. Beach lived in a time when women were fighting to be considered equal to men. Her actions helped to advance the women's rights movements without ever becoming controversial. It is an honor to be able to help advance her legacy through the transcription and performance of Beach's music. It would be difficult for someone to study the life of Amy Beach and find serious fault with her life choices.

Violists, like women, have struggled long and hard to be thought of as soloistic equals to either of their closest string relatives, the violin or cello. Due to centuries of perceived inequality, the viola repertoire has significant gaps. This document and published transcriptions provide 
violists with more selections when seeking repertoire written by late $19^{\text {th }}$ - early $20^{\text {th }}$ century American women composers. With the addition of these five pieces to the repertoire, professionals, teachers, and students now have new programming options.

The detailed analytical work provided in this document will be of assistance to future scholars and performers. For scholars, these fives pieces are analyzed in as much harmonic, thematic, and melodic detail as possible. Beach was an entirely self-taught composer at a time when her only resources were scores and writings. Consequently her stylistic, harmonic, and melodic choices are fascinating. As noted in Chapter four there is a possibility that this paper may have discovered the first time, in classical music, that an augmented sixth chord served as a dominant substitution in a circle progression which ultimately resolved to $\mathrm{I}$, not $\mathrm{V}$ or $\mathrm{I}_{4}^{6}$. For performers, the goal is to provide an accessible analysis that would deepen their knowledge and understanding of both the composer and the construction of her pieces. As all examples are from the original violin scores, these analyses will be of use to future performers of either the original violin works or the viola transcriptions.

The author's transcriptions of these works will be available shortly through Spartan Music Press. It is the author's sincere hope that these pieces may become a beloved part of the viola repertoire. 


\section{Bibliography}

“50 Years Ago...Hurricane of '38 and Winds of War!” MacDowell Colony News 15 (1987-1988).

“Arthur P. Schmidt Collection.” (Library of Congress, Washington, D.C.) 1898-1944.

Bargerstock, Nancy, Nancy Allwein, Renata Bratt, Mira Frisch, Kelley Johnson, David Littrell. The ASTA Certificate Achievement Program Handbook. (2014).

Beach, Amy. Music For Violin/Viola and Piano. Klugherz-Timmons Duo. Centaur \#2312, 1997. CD.

Beach, Amy Marcy Cheney. Sonata: For Viola and Piano. Transcribed and Edited by Roger Hannay. New York: C.F. Peters, 1984.

Beach, Amy. "Why I Chose My Profession: The Autobiography of a Woman Composer." Interview by Edna Aiken. Mother's Magazine 11 (February 1914): 7-8.

Block, Adrienne Fried. Amy Beach: Passionate Victorian. New York: Oxford University Press, 1998.

Blood, Blanche. "Barcarolle for Viola and Piano." Edited by David M. Bynog. American Viola Society. http://www.americanviolasociety.org/PDFs/Resources/American-Viola-Project/ Blood-Barcarolle.pdf.

Broe, Carolyn Waters. "Viola Music by Women Composers." American String Teacher 57, no. 3 (2007): 68-71.

Brown, Jeanell Wise. Amy Beach and Her Chamber Music. New Jersey, U.S.A.: Scarecrow Press, 1994.

Cowen, Gertrude F. “Mrs. H. H. A. Beach, the Celebrated Composer.” Musical Courier 60 (8 June 1910): 14.

Downes, Stephen. "Mazurka." Grove Music Online. Oxford Music Online. Oxford University Press, accessed May 5, 2015. http://www.oxfordmusiconline.com/subscriber/article/ grove/music/18193.

English Oxford Living Dictionaries, s.v. "invocation." accessed September 25, 2016, https://en.oxforddictionaries.com/definition/invocation. 
Hamilton, Kenneth L. "Berceuse." Grove Music Online. Oxford Music Online. Oxford University Press, accessed April 7, 2015. http://www.oxfordmusiconline.com/subscriber/ article/grove/music/02749.

Herndon, Hillary. La Viola. Performed by Hillary Herndon and Wei-Chun Bernadette Lo. 2012. Newton, CT: MSR Music. CD.

Howe, Julia Ward. Women's Journal (February 13, 1982).

Hughes, Agnes Lockhart. "Mrs. H. H. A. Beach, America's Foremost Woman Composer." Boston Times (13 March 1915): S3.

Hughes, Edwin. "The Outlook for the Young American Composer: An Interview with the Distinguished American Composer, Mrs. H. H. A. Beach.” Etude 33 (January 1915): 13-14.

Hung, Yu-Hsien Judy. “The Violin Sonata of Amy Beach.” Doctoral dissertation, Louisiana State University, 2005.

Jenkins, Walter S. The Remarkable Mrs. Beach, American Composer. Edited by John H. Baron. Michigan, U.S.A.: Harmonie Park Press, 1994.

Kinscella, Hazel Gertrude. “ 'Play No Piece in Public When First Learned,' Says Mrs. Beach.” Musical America 28 (7 September 1918): 9-10.

Lawson, Dorothea. “Mrs. H. H. A. Beach.” The Colby Voice (October 1921): 8-10.

Lee, Hsiaopei. "The History of Viola Transcriptions and a Comprehensive Analysis of the Transcription for Viola and Piano of Beethoven's Violin Sonata Op. 30, no. 1." Doctoral thesis, University of Cincinnati, 2005.

"Maud Powell Meets Dvořák." The Maud Powell Society for Music and Education Souvenir Autumn (2015): 3.

Michałowski, Kornel and Jim Samson. "Chopin, Fryderyk Franciszek." Grove Music Online. Oxford Music Online. Oxford University Press, accessed January 13, 2017, http://www.oxfordmusiconline.com/subscriber/article/grove/music/51099.

“Mrs. Beach Appears in Own Works at White House.” Musical Leaders 68 (9 May 1936): 10.

“Mrs. Beach, Leading Composer Dies at 77." Musical America 65 (10 January 1945): 24. (Unsigned article, NYPL clipping file). 
“Mrs. Beach Will Devote Energies to War Work.” Musical America 27 (1918): 27.

“Our Mission.” The MacDowell Colony. Accessed September 23, 2015. http:// www.macdowellcolony.org/about-Mission.html.

Ratner, Leonard G. "Period." Grove Music Online. Oxford Music Online. Oxford University Press, accessed October 26, 2016. http://www.oxfordmusiconline.com/subscriber/article/ grove/music/21337.

Unnamed author. Attributed by Beach to C. L. Capen. Boston Home Journal, S2 (1896): 26.

“Viola Sonata, Op.22.” IMSLP. http://imslp.org/wiki/Viola_Sonata,_Op.22_(Bauer,_Marion).

Williams, Amédée Daryl. Lillian Fuchs: First Lady of the Viola. Lincoln, NE: iUniverse, 2004. 